\title{
ZOOTAXA
}

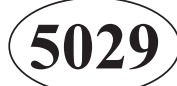

\section{Revision of the 'dragon-head' cusk eels of the genus Porogadus (Teleostei: Ophidiidae), with description of eight new species and one new genus}

WERNER W. SCHWARZHANS ${ }^{1 *} \&$ PETER R. MØLLER ${ }^{2,3}$

${ }^{I}$ Natural History Museum of Denmark, University of Copenhagen, Universitetsparken 15, DK-2100 Copenhagen, Denmark; and AhrensburgerWeg 103, D-22359 Hamburg, Germany. "=wwschwarz@aol.com; (1) http://orcid.org/0000-0003-4842-7989 ${ }^{2}$ Natural History Museum of Denmark, University of Copenhagen, Universitetsparken 15, DK-2100 Copenhagen, Denmark. !"PDRMoller@snm.ku.dk; • http://orcid.org/0000-0002-0177-0977

${ }^{3}$ Norwegian school of Fisheries, UiT Norwegian Arctic University, Tromsø, Norway ${ }^{*}$ Corresponding author

\section{E3}

Magnolia Press

Auckland, New Zealand 
WERNER W. SCHWARZHANS \& PETER R. MØLLER

Revision of the 'dragon-head' cusk eels of the genus Porogadus (Teleostei: Ophidiidae), with description of eight new species and one new genus

(Zootaxa 5029)

96 pp.; $30 \mathrm{~cm}$.

3 Sept. 2021

ISBN 978-1-77688-350-9 (paperback)

ISBN 978-1-77688-351-6 (Online edition)

\section{FIRST PUBLISHED IN 2021 BY}

Magnolia Press

P.O. Box 41-383

Auckland 1041

New Zealand

e-mail: magnolia@mapress.com

https://www.mapress.com/j/zt

(C) 2021 Magnolia Press

All rights reserved.

No part of this publication may be reproduced, stored, transmitted or disseminated, in any form, or by any means, without prior written permission from the publisher, to whom all requests to reproduce copyright material should be directed in writing.

This authorization does not extend to any other kind of copying, by any means, in any form, and for any purpose other than private research use.

ISSN 1175-5326 (Print edition)

ISSN 1175-5334 (Online edition) 


\title{
Table of Contents
}

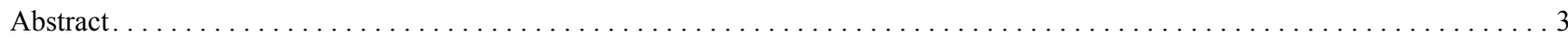

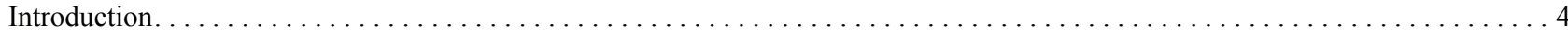

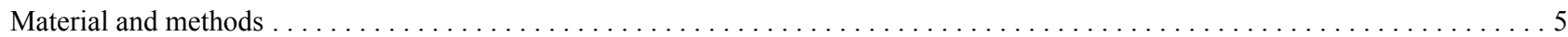

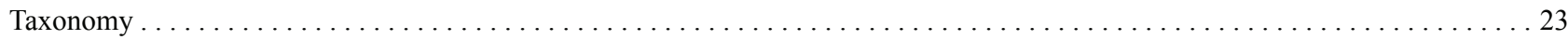

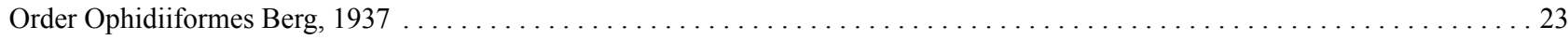

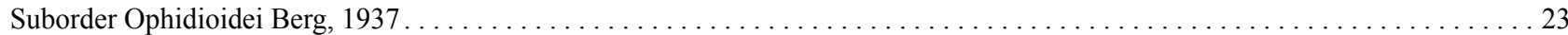

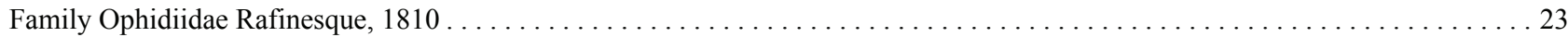

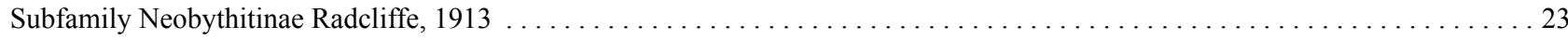

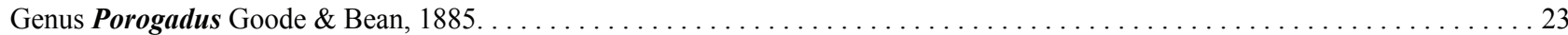

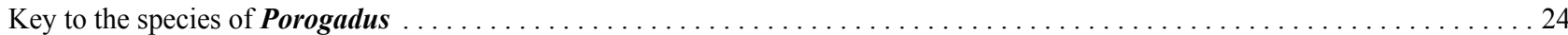

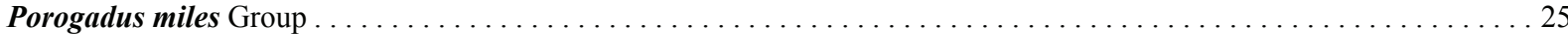

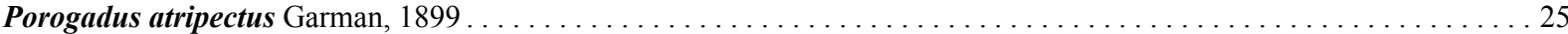

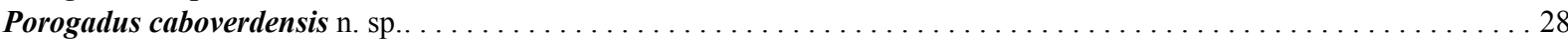

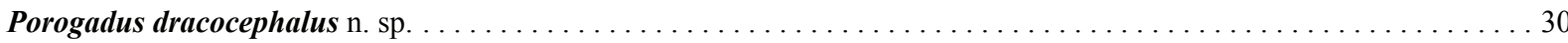

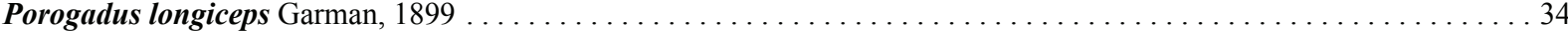

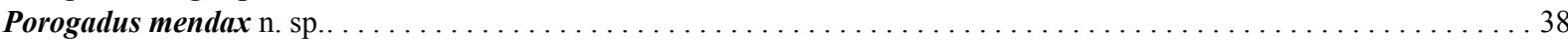

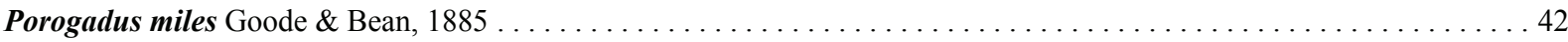

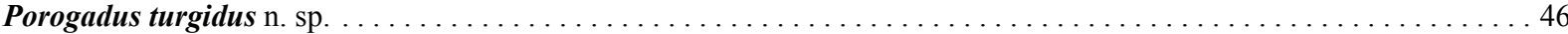

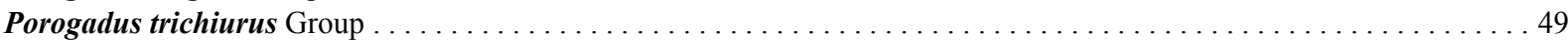

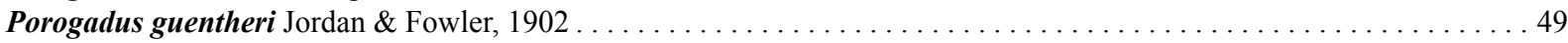

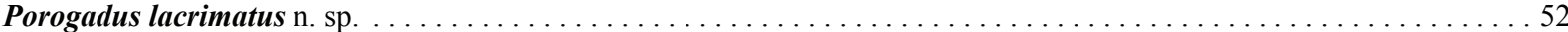

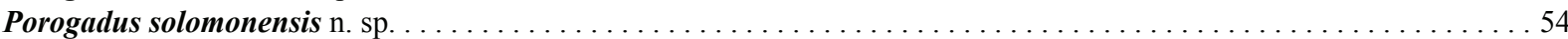

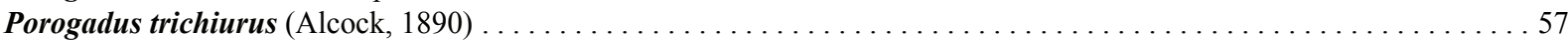

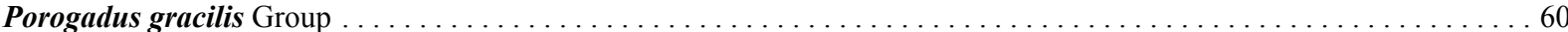

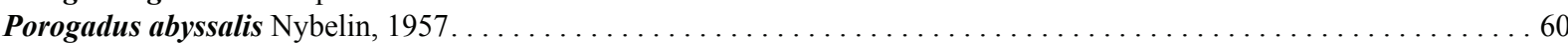

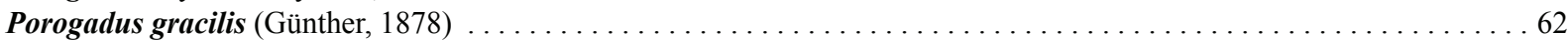

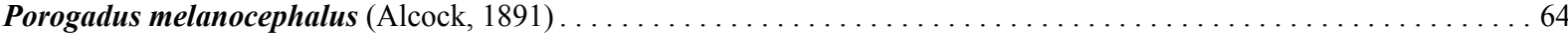

Porogadus catena Group . . . . . . . . . . . . . . . . . . . . . . . . . . . . . . . . . . . . . . . . . . . . . 67

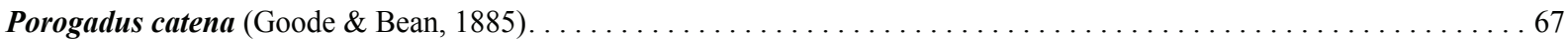

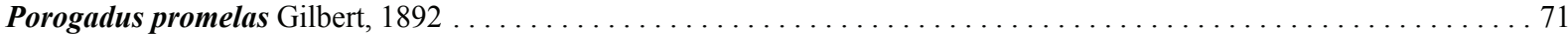

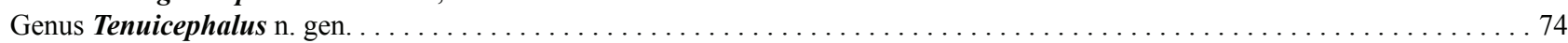

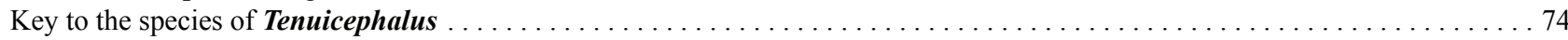

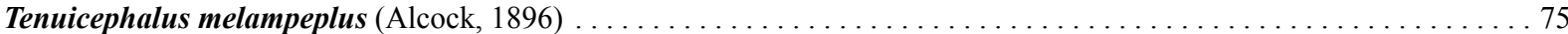

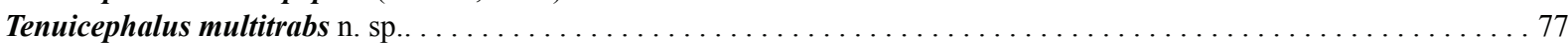

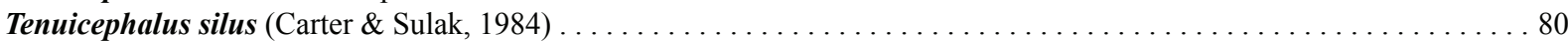

Tenuicephalus squamilabrus $n$.

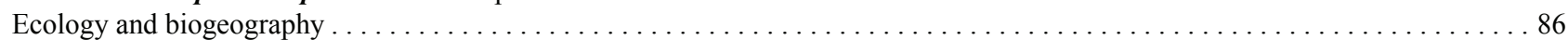

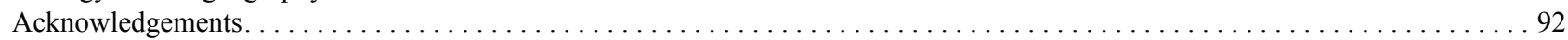

References. . . . . . . . . . . . . . . . . . . . . . . . . . 92

\begin{abstract}
The ophidiid genus Porogadus occurs between 800 and $5300 \mathrm{~m}$ in the tropical and subtropical world oceans. Fifteen nominal species have been described since 1878 and most of them until 1902. The genus has been highlighted as needing revision in recent compilations about ophidiiforms and here we present the first comprehensive review. Twelve of the previously described species are here accepted as valid with two being moved to the newly established genus Tenuicephalus n. gen. that encompasses fishes differing from those of Porogadus in the extremely weak ossification, the stout head, absence of head spines and absence of the "triple" lateral line system considered typical for Porogadus and a reduced dentition. In addition, eight new species are described: Porogadus caboverdensis, P. dracocephalus, P. lacrimatus, $P$. mendax, P. solomonensis, P. turgidus, Tenuicephalus multitrabs and T. squamilabrus.

The species of Porogadus show a distinctive depth segregation with the majority of species having a demersal bathyal life-style between 800 and $3500 \mathrm{~m}$ and other species being more or less exclusively restricted to abyssal depths below $3000 \mathrm{~m}$. The biogeographic distribution pattern of bathyal groups shows putative species pairs in the Atlantic versus the eastern Pacific and a clear separation of eastern Pacific from Indo-West Pacific species. The geographic effects and timing are being discussed that may have led to this speciation events. Generally, we found widely distributed species that are found far away from continental masses and others restrained to continental slopes and sometimes exhibiting regionalism. In abyssal depth, the Cabo Verde and Canary basins off NW-Africa have yielded three exclusive species, but it is uncertain at this stage whether this could represent a sampling bias with this area being extensively sampled by the
\end{abstract}


Discovery research vessel (BMNH) over the years from 1970-1998. Another instance of a potentially endemic abyssal species is that of Porogadus melanocephalus in the Bay of Bengal. The latter has been caught with 45 specimens in a single trawl, representing the highest number of Porogadus specimens collected in any trawl and indicating that these fishes may actually not be as rare as one might assume from the literature.

Key words: Porogadus, Tenuicephalus, Ophidiidae, abyssal, bathyal, new species

\section{Introduction}

The fishes of the genus Porogadus Goode \& Bean, 1885 live at great depth in the tropical and subtropical oceans of the world. They are caught below $800 \mathrm{~m}$ and down to $5300 \mathrm{~m}$ (Nielsen et al., 1999), i.e., below the oxygen minimum zones of the World Ocean. That makes them one of the most deeply living vertebrates in the oceans (see Gerringer 2019 for a compilation of teleosts at great depth). Many of the 15 nominal species have been described on the basis of very few or unique specimens. All but two Porogadus species had been described between 1878 and 1902 during the initial years of deep sea research facilitated by the then new deep water collection techniques. The species of that epoch were described by Alcock (1890, 1891, 1896), Garman (1899), Gilbert (1892), Goode \& Bean (1885), Günther (1878), Jordan \& Fowler (1902) and Vaillant (1888). Presumably, the authors of the new Porogadus species may have known those described by their colleagues only from their descriptions and documentations. The nominal genera Dermatorus Alcock, 1890, Celema Goode \& Bean, 1896 and Moebia Goode \& Bean, 1896 were synomized with Porogadus by Cohen \& Nielsen (1978). Cohen \& Nielsen (1978) remarked that the genus Porogadus was much in need for revision, a remark that was repeated by Nielsen et al. (1999). Nybelin (1957) had reviewed specimens that he could then investigate at the British Natural History Museum in London (BMNH) and the Musée Nationale d'Histoire Naturelle in Paris (MNHN). Carter \& Sulak (1984) reviewed the Porogadus species from the western North Atlantic.

Fishes of Porogadus are remarkable for the spectacularly large pores in the head channels of the pore system (hence the name Porogadus) and, in many species, the more or less intense head armature with many spines. Nybelin (1957) grouped the nominal species in three groups according to the intensity and abundance of spines on the head, but considered these groups for practical purposes only and explicitly noted that he did not consider them as natural subgenera. Nevertheless, this grouping was also reflected in Carter \& Sulak (1984) and Nielsen et al. (1999), and despite a few inconsistencies in Nybelin's original concept and the here presented review still represents a good basis for a first allocation of freshly collected Porogadus specimens. However, we also noted that certain species depart from the redefined diagnosis of the genus considerably in the lack of head spines, a very short snout, differences in dentition and a weak ossification of head bones that warrant separation in a distinct genus as described here - Tenuicephalus $\mathbf{n}$. gen.

Here, we present a comprehensive review of the fishes of the genus Porogadus based on material from many international collections (see Materials and Methods, and Acknowledgements) including type specimens from Alcock (as far as housed in BMNH), Carter \& Sulak, Garman, Goode \& Bean, Günther and Vaillant. We were able to study representative material from all nominal species. Porogadus melampeplus (Alcock, 1896) was studied from only two poorly preserved and newly collected specimens and a photograph of the unique holotype courtesy to scientists from the Zoological Survey of India in Calcutta (ZSI) (see Acknowledgements), which has never been documented before. As a result of this review we consider the following 10 species of Porogadus as valid: P. abyssalis Nybelin, 1957, P. atripectus Garman, 1899, P. catena (Goode \& Bean, 1885) (syn. P. subarmatus Vaillant, 1888), P. gracilis (Günther, 1878), P. guentheri Jordan \& Fowler, 1902, P. longiceps Garman, 1899, P. melanocephalus (Alcock, 1891), P. miles Goode \& Bean, 1885 (syn. P. nudus Vaillant, 1888), P. promelas Gilbert, 1892 (syn. P. breviceps Garman, 1899) and P. trichiurus (Alcock, 1890). The following species are described as new: P. caboverdensis $\mathbf{n}$. sp., . dracocephalus $\mathbf{n}$. sp., P. lacrimatus $\mathbf{n}$. sp., P. mendax $\mathbf{n}$. sp., P. solomonensis $\mathbf{n}$. $\mathbf{s p .}$ and $P$. turgidus $\mathbf{n}$. sp. The following species are placed in the new genus Tenuicephalus n. gen.: T. melampeplus (Alcock, 1896), T. multitrabs n. sp., T. silus (Carter \& Sulak, 1984) and T. squamilabrus n. sp.

Catches of Porogadus specimens are relatively rarely recorded in past literature and also relatively few specimens are usually found in museum collections. The distribution and abundance of deep water fishes is still poorly understood. For instance Porogadus melanocephalus hitherto was only known from the two syntypes of Alcock (1891), one kept at BMNH, the other at ZSI. Our review has resulted in the recognition of 48 further previously un- 
recognized specimens of that species, 45 of which came from a single trawl station during the Galathea II expedition in the Bay of Bengal in 1951. This observation may serve as an indication that Porogadus species could be more common in the deep ocean than previously assumed and that at least some species may occur in schools.

Carter (1984) investigated the stomach content of demersal deep-sea ophidiid fishes with the aim to better understand their feeding strategies and functional morphology. Three species of Porogadus (one now in Tenuicephalus n. gen.) were included in his study: Porogadus catena, P. miles and Tenuicephalus silus. Porogadus catena and T. silus were found to feed mainly on small-sized calanoid copepods and other small benthopelagic crustaceans. He further concluded that these species were more often feeding off the ground than other ophidiids studied. Few specimens studied of Porogadus miles were found to have mainly fed on gammaridean amphipods. Carter (1984) assumed that the extremely anteriorly depressed head and very attenuate body would indicate more of a bottom feeding habit and that these fishes were "not heavily reliant on large mobile prey". The preference of small crustaceans as food is indeed reflected by the presence of numerous minute villiform teeth on all tooth patches in all species of the two genera and the outward warping of the dentition of the lower jaw in many of them. Also the numerous long gill-rakers confirm the capability of retaining tiny food items such as copepods.

\section{Material and methods}

Nearly 300 specimens were studied belonging to species of Porogadus and Tenuicephalus n. gen., many of them denoted as Porogadus sp. in the various collections from which they were obtained. Porogadus (including the here newly established genus Tenuicephalus) were considered to be related to Bathyonus, Penopus and Alcockia by Cohen \& Nielsen (1978). Representative specimens of these genera were included in our study and the results largely confirm the view of Cohen \& Nielsen. The distribution maps are based on a combination of referenced published data, and specimens studied (see below).

Descriptions of the species are focused on the characters varying between the species. The characters common to all species within the two genera are summarized in brief in the respective species descriptions. Complete descriptions are only given for new species. Counts and measurements for the holotype are given first, followed in parentheses by those for paratypes. Gill rakers were counted on the 1st gill arch. Rudimentary, atrophied rakers occur in varying amounts, often alternating with the developed rakers and are occasionally of additional diagnostic value and are therefore discussed in the context.

Meristics are mainly done with the help of high resolution x-rays with the exception of counts of the pectoral fin rays and gill rakers. However, the species of Porogadus and Tenuicephalus n. gen. are known for their extremely attenuate tail, which negatively affects counting of vertebrae and fin rays close to the tip of the tail even when well preserved. We have therefore restricted all counts to the trunk section of the fishes in front of the first anal fin ray, and in vertebrae only the precaudal ones. Abbreviations used are D/V (first dorsal fin ray above vertebra), D/A (dorsal fin ray above first anal fin ray) and V/A (first anal fin below vertebra).

Most species of Porogadus and all species of Tenuicephalus have highly deciduous scales which are commonly lost during capture, albeit varying from one species to another. We found that squamation across the head is quite varying and may in fact represent diagnostically useful patterns, but unfortunately head scales are preserved only in exceptional cases and hence is rarely of practical use. The same is true for scale counts across the trunk. We found that counting of scale pockets is very ambiguous in the majority of cases and therefore have not used this as a diagnostic character. We show head scales and scale pockets in the absence of scales as dotted outlines on drawings indiscriminately, but only where positively identified. This can lead to apparent differences in drawings of specimens of a given species and is addressed in the descriptions.

Morphometric characters are given as percentage of standard length (SL) and head length (HL). However, morphometric measurements meet certain obstacles or complexities in these fishes. The thin caudal tip is often missing in specimens either because of damage during or after the catch or due to partial loss in vivo. As a result, measurements of SL are not always possible. Even where the tail is seemingly complete it is sometimes the result of a previous in vivo loss and subsequent rejuvenation, which may not be easily discernable in every case. This effect can lead to distortions of measurement values relating to the SL and such values need to be filtered from the data set. Likewise, measurements of HL can be influenced by soft head ossification in some species. The head length was measured from the tip of the snout, to the tip of the opercular flap or opercular spine, whichever was found to 
project further. When the opercle was damaged or incomplete then head length measurements were omitted. Head depth (HD) is measured at two locations: vertical at the position of the rear end of the occiput, which more or less corresponds to the maximal head depth, and along a vertical through the center of the eye. The maximium body height was measured at the insertion of the pelvic fin. Snout length was measured from the tip of the upper jaw to the anterior rim of the eyeball; the limits of the orbit were found to be too variable and/or too easily affected by preservation for reliable measurements in many cases. Specimens with mouths fixed open were not used for any measurements requiring relationships to $\mathrm{HL}$, and SL was estimated. The length of the pectoral or pelvic fins can only be measured in some more robust species and therefore is of limited practical use. Other external measurements and counts were made following Hubbs \& Lagler (1958). Measurements are given to the nearest $0.1 \mathrm{~mm}$ for $\mathrm{HL}$ and SL and percentages to the nearest 0.1 fractal.

Dentition is present on dentaries, premaxilla, vomer, palatines and basibranchials but missing on ectopterygoids. Since all teeth observed are very small, villiform and are not arranged in clearly defined rows, the counts reflect ranges rather than defined locations and should be considered as reflection of the width of the tooth bearing elements.

Porogadus and Tenuicephalus $\mathbf{n}$. gen. fishes are characterized by a greatly elaborated lateral line system on body and head, which however is preserved to varying degrees of clarity between the species, and a highly diverse pattern of spines on the head (Fig. 1). The head pore system is particularly well developed along the infraorbital and mandibular and preopercular stretches. The pores are numbered from anterior to posterior as infraorbital pores, postorbital pores, mandibular pores and preopercular pores. The skin covering the respective canal systems is thin and easily damaged during capture and therefore the actual size of the various pores in vivo is rarely adequately preserved and thus of limited diagnostic value. The head spines are usually very well preserved, when present and from anterior to posterior include lacrimal spines, an ethmoidal spine, a prefrontal spine, interorbital and supraorbital spines, 5th infraorbital spines, sphenotic, supratemporal and posttemporal spines, one or two opercular spines and spines along the inner and outer preopercular rims. Many species of both genera exhibit one to three large, leaf shaped sensory papillae on the opercle which are free and not covered by scales.

Otoliths were generally only extracted from the right side of a fish. The number of otoliths investigated per species varied greatly depending on preservation due to exposure to formalin and otherwise was kept to a maximum of about 10 specimens. Otolith morphometrics followed Schwarzhans (2010) and are given to the nearest $0.05 \mathrm{~mm}$. For morphometrics in respect to the sulcus, outlines of the colliculi within the sulcus have been used because they are more clearly defined in ophidiiform otoliths. The following abbreviations are used in the otolith descriptions: $\mathrm{OL}=$ otolith length; $\mathrm{OH}=$ otolith height; $\mathrm{OT}=$ otolith thickness; $\mathrm{OCL}=$ ostial colliculum length; $\mathrm{CCL}=$ caudal colliculum length; TCL $=$ total colliculum length as combine of OCL and CCL or in case of fused colliculi. Morphometric otolith characters are given as ratios: OL:OH, OL:OT, OCL:CCL, OL:TCL.

As stated above, many specimens of Porogadus and even more so of Tenuicephalus $\mathbf{n}$. gen. are not well preserved because of the often delicate nature and fragility of the body and particularly the diagnostically important head. Otoliths, which present another useful diagnostic character, were found to be absent/dissolved in several specimens due to lengthy exposure to formalin. Unfortunately, this resulted in several specimens not being adequately identifiable. Such poorly identifiable specimens are either listed as "tentatively assigned specimens" in the descriptive part or were excluded. It was not possible to investigate all specimens attributable to Porogadus from all institutional collections, even though we attempted to achieve a representation of the diversity and geographic distribution as good as possible. Certain specimens described/mentioned in previous studies of authors were not available for review. These are included in our listings as separate entries and only where felt to be reasonably identifiable in the sense of this review.

Institutional abbreviations follow Fricke \& Eschmeyer (2013).

\section{Character analysis}

1. Head morphology (Figs. 1-3). The heads of the fishes of the genera Porogadus and Tenuicephalus n. gen. exhibit a great wealth of diverse morphological features, which offer multiple characters for diagnostic differentiation of the many species, but which are also easily adversely affected by preservation. In the genus Tenuicephalus particularly, skull ossification is so weak, the skin is so thin and the scales are so easily shed that only under rare circumstances is a head well enough preserved to study its morphological features with reasonable detail. The following morphological features of the head are found to be particularly useful. 

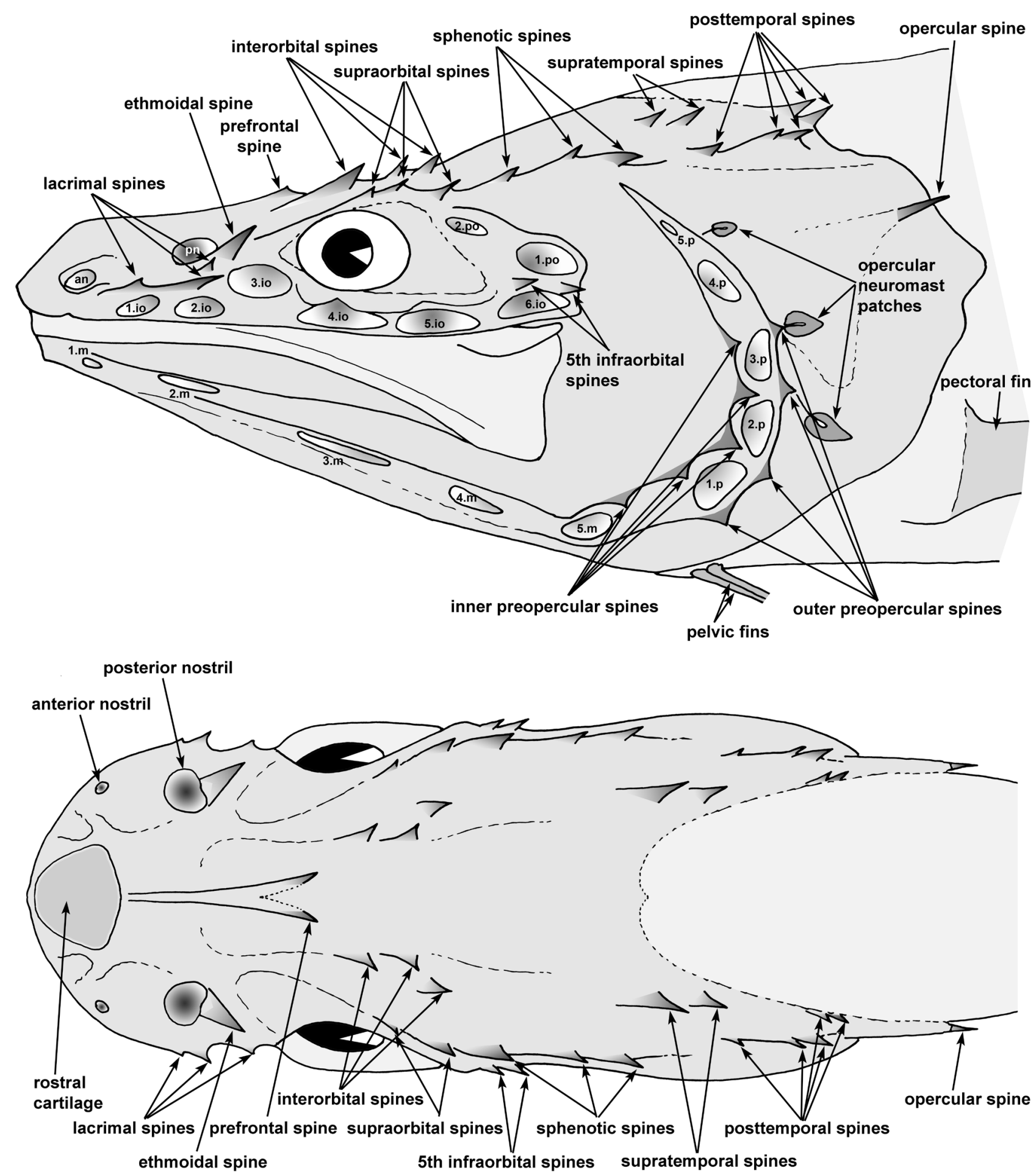

FIGURE 1. Schematic drawing depicting occurrences and terminology of head spines and head pore systems in Porogadus (P. miles) in lateral view (upper figure) and dorsal view (lower figure). Abbreviations used for head pore systems are: an $=$ anterior nostril; $\mathrm{pn}=$ posterior nostril; io $=$ infraorbital pores; $\mathrm{po}=$ postorbital pores; $\mathrm{m}=$ mandibular pores; $\mathrm{p}=$ preopercular pores.

Goode \& Bean (1885) apparently named Porogadus after the many large mucous pores on the head. These pores are positioned along the very wide mucous infra-/postorbital and mandibular-preopercular canal systems (Fig. 1). The infra-/postorbital canal leads from near the tip of the snout below the eye and bends upwards behind the eye. It contains $2-3$ long and narrow anterior pores below a much elongated lachrymal bony ridge, 2-3 individual pore openings in a large chamber just in front of the eye, 3 mostly large posterior pores below the eye and 2-3 pores along the upward bend behind the eye. The mandibular-preopercular canal begins near the tip of the chin leading along the 
lower jaw and curves upwards along the rear margin of the preopercle. It usually carries a small pore at the chin, 4 long and narrow pores along the lower jaw behind the chin and 3-5 mostly large pores along the preopercular canal. Finally the supraorbital canal leads from a small pore at the tip of the snout upwards above the eye to the rear end of the head above the preopercle and opercle, usually branching off inwards towards its termination. The number of pores on the occiput is very variable reaching up to 6 pairs or being entirely absent. However, pores on the occiput particularly are easily induced artificially during preservation or handling of specimens since the skin cover over the large mucous pots is very thin and easily punctured. It is often not clear whether these are really pores or only artifacts. It is therefore recommendable to judge the presence and number of pores on the occiput only from symmetrical occurrences on well preserved specimens. Often, the thin skin covering the infraorbital and preopercular cavernous systems too is damaged or completely removed during capture so that the in vivo size is rarely recognizable and therefore not used here. The rear infraorbital and preopercular pores are usually the largest and often the space in between is so narrow that it is easily torn apart, in which case the mucous canal is exposed to the outside in its entirety. Where discernable, the number and location of the pores along these systems appear rather stable throughout both genera and are also similarly found in the putatively related genera Bathyonus and Alcockia. In Alcockia specifically the skin cover of the canals is thicker and more robust and the specimen from ZMUC P77677 shows a perfectly preserved canal and pore system (Fig. 2) showing that the pores are indeed mostly small while the underlying canals are very wide.

Another feature of particular importance and well preserved in most specimens is the presence of a rather diverse number and expression of spines on the head in the genus Porogadus (Fig. 1), while the genus Tenuicephalus is mostly avoid of spines or shows only very few. The most prominent is often a backward curved spine on the ethmoidal just behind the, often large, posterior nostril and a broad rostral cartilage. Spines occur further on the lachrymal (up to 3, sometimes fused to a ridge-like feature), the fifth infraorbital (up to 4), at the rear tip of a y-shaped ridge on the prefrontal, above the eye on the interorbital (up to 4), on the supraorbital (up to 3), along the sphenotic (up to 4), on the supratemporal (up to 3 ) and the posttemporal (up to 4) and on two rows along the preopercle, the inner in front of the preopercular pore canal, the outer along the preopercular margin (both up to 5). The opercular spine varies from flat, skin covered to long, sharp and free, at times extending beyond the opercular margin. The lower opercular flap below the opercular spine varies in extend, and in some species shows many distinct radial ridges whereas it is smooth in other species. The many head spines observed in Porogadus represent a derived character. The supposed related genera Bathyonus and Penopus show no such spines, and Alcockia only an ethmoidal and two sphenotic spines (Fig. 2). The polarity of this character within Porogadus and Tenuicephalus, however, remains elusive. It is not clear whether the few spines observed in several Porogadus species and the near complete absence in Tenuicephalus represents a plesiomorphic character or a secondary atrophy. Diminishing of the intensity of head spines with ontogenetic growth has been described by Garman (1899) for Porogadus longiceps. However, the specimens in questions differ in so many additional aspects that we consider the small specimens only as tentatively assigned at this stage (see descriptive part). Nybelin (1957) attempted to group the various species according to the intensity and strength of the spines on the head, a practical approach which was also followed by Carter \& Sulak (1984) and Nielsen et al. (1999). However, we do not fully agree with the placement of all species in that scheme. For instance P. melanocephalus was listed as having strong head spines while it really has few and weak ones. Or P. longiceps that is listed as having very weak head spines while actually it has some strong ones, which however are short and poorly visible. We have therefore formulated a new scheme for species groups within Porogadus based on the combination of abundance and strength of spines, and the head morphology in lateral view, i.e., stout versus slender and long head shapes (see below).

A rarely described feature is the presence of sensory papillae or neuromast patches at various places on the head. Several nerve cords can be seen below the head skin in thin skinned deep sea ophidiids, the two most prominent ones leading from the brain capsule curving behind and below the eye and leading along the anterior margin of the preopercle curving into the upper margin of the mandible (with extensions onto the opercle along its course). These nerve cords are often seen to branch along their course, particularly at the mandible, leading to small circular papillae extruding from the skin and showing a nerve termination spot at its centre. In Porogadus (and Tenuicephalus), however they are much enlarged to patches, in large magnification often showing intense branching of the veins within these patches (Fig. 3). The largest and most characteristic ones are located along the inner margin of the opercle and subopercle (mostly 2 or 3, rarely 1 or sometimes absent in Tenuicephalus). They are leaf-shaped, of the size of a scale, and in the presence of scales on the opercle they remain free. Smaller sensory papillae may occur 

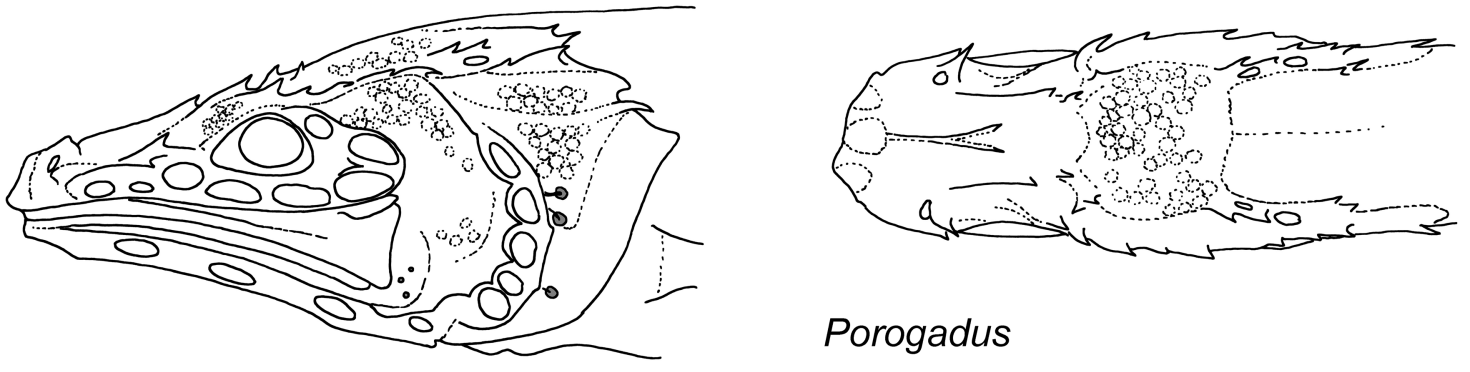

\section{Porogadus}
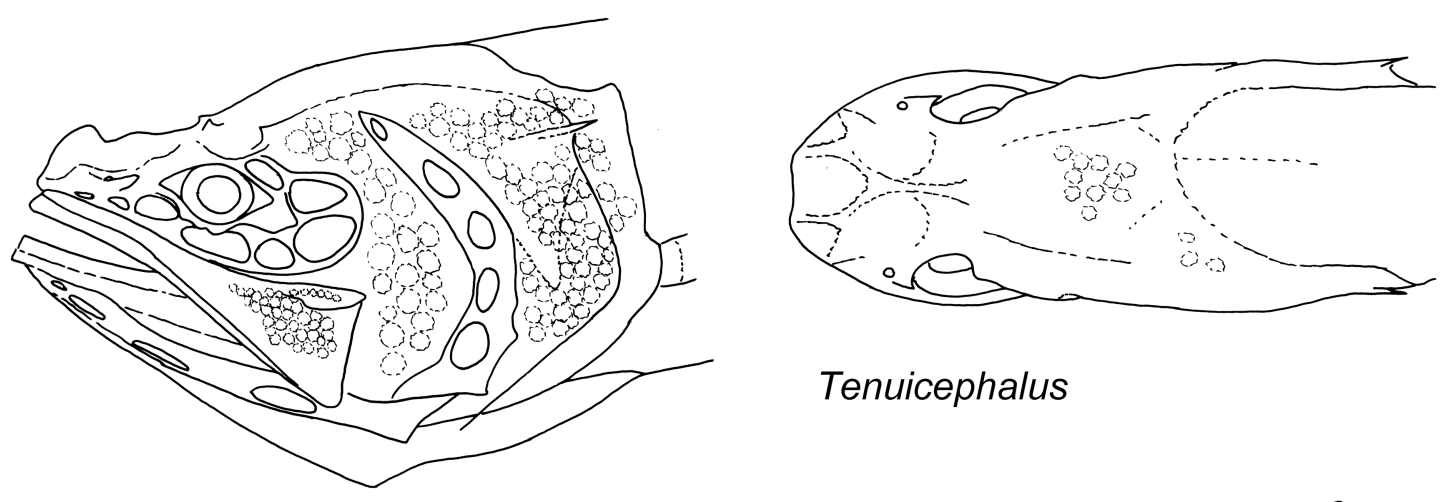

\section{Tenuicephalus}
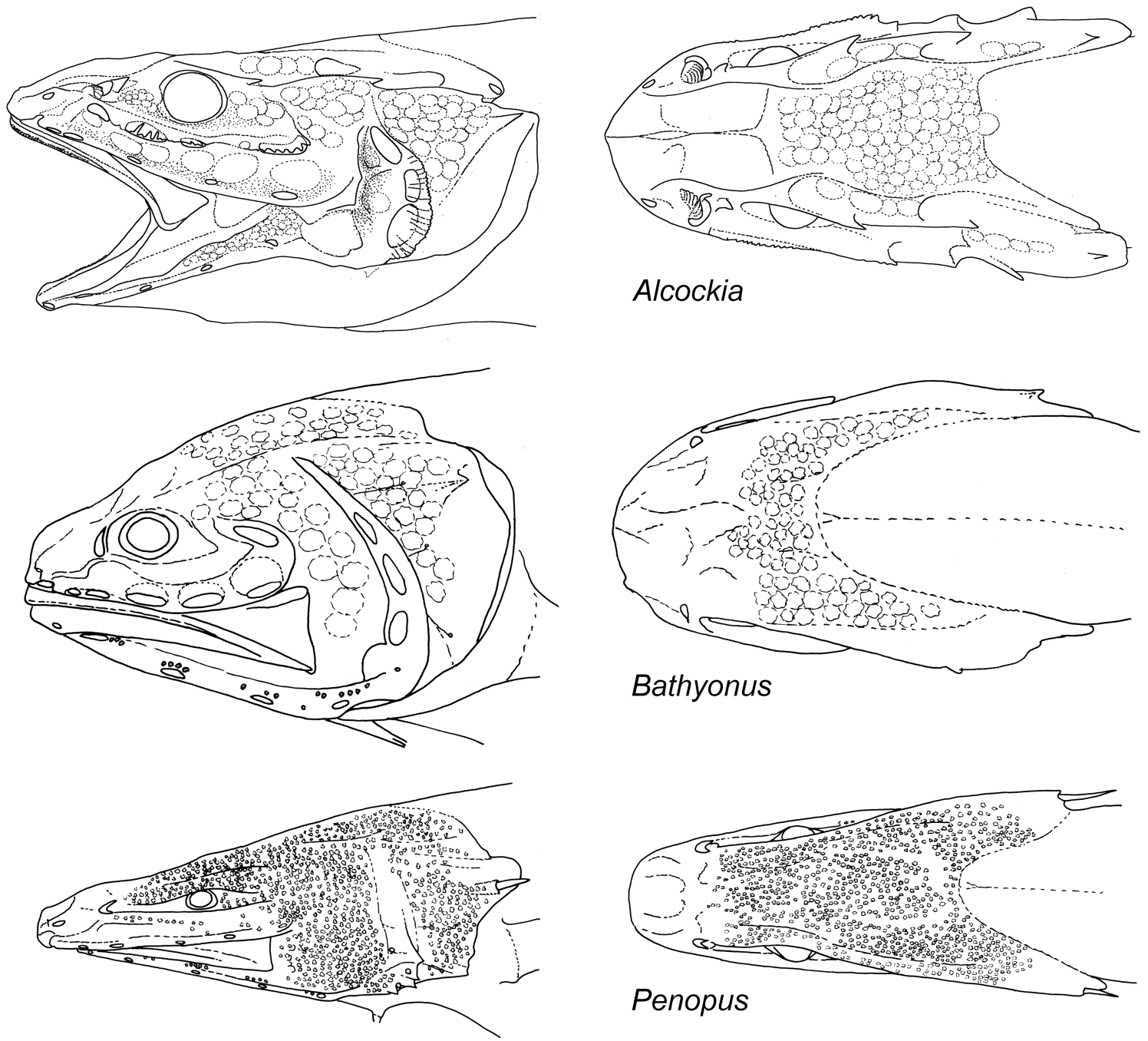

FIGURE 2. Panel of comparative head drawings: from top to bottom: Porogadus (P. miles), Tenuicephalus (T. squamilabrus $\mathbf{n}$. sp.) and selected putative related genera; Alcockia (A. rostrata), Bathyonus (B. laticeps) and Penopus (P. microphthalmus). 
on the skin behind the maxilla. Further sensory papillae or patches appear to be hidden within the infraorbital and mandibular mucous canals and are rarely preserved or visible. The large neuromast patches on the opercle appear to be a derived character of Porogadus, while the presence of only one such papilla on the opercle or the complete absence in Tenuicephalus could represent a secondary reduction.

Another diverse feature is the head squamation, but it has to be stressed that this feature is often incomplete or destroyed due to the thin skin covering the head and the deciduous nature of the scales which are easily shed, and scale pockets are variably preserved too. These characteristics should therefore be used with particular care when applied for diagnostic differentiation. Many species of the genus Porogadus depict head squamation across much of their heads including the occiput, cheeks and opercle, often with a high degree of continuity but also at times with a more patchy distribution pattern, and sometimes across a part of the maxilla. Some species of the genus Porogadus exhibit mostly smaller scales around the orbit in front of the eye, behind, and in a few instances also below. Scales on the maxilla, which are particularly rarely preserved, also tend to be rather small compared to other scales on the head. In Tenuicephalus, one species shows minute scales on the rear part of the maxilla and on the supramaxilla.

Head proportions are expressed in the ratio HL:HD ranging from 1.3 to over 2.0 and in percentage of SL (14$18 \%$ ). They represent one of the most obvious characters for grouping of Porogadus species in combination with presence and intensity of head spines (see below).

2. Lateral line and scales (Fig. 3). Nielsen et al. (1999) noted as a diagnostic character of Porogadus that the "lateral line is represented by 3 rows of circular organs variously developed from one species to another and by a row of easily shed modified scales." However, Carter \& Sulak (1984) noted for the description of Porogadus silus (now Tenuicephalus silus) that "three lateral line rows are not evident." We concur with their observation and found no lateral line rows evident in any of the Tenuicephalus species, while they seem to be generally present in the species of Porogadus, where they represent a derived character, but are usually only well visible in species of the Porogadus miles group. The lateral lines are characterized by the large sized modified scales that are indented posteriorly to leave space for the extruding often differently colored neuromast patches, and are often recognizable even in the event of lacking scales by the larger scale pockets or the neuromast coloration (Fig. 3).

The upper lateral line row is the shortest. It starts above the opercular flap and consists of particular large and narrowly spaced modified scales (Fig. 3). It is located over the joint of the upper and lower epaxial muscles. The lateral line follows a distinct nerve cord located directly under the skin and terminates with it in most instances. Occasionally, it continues upwards in an angle to the tip of the dorsal fin following a second nerve cord that starts below the opercle, runs above the vertebral column, and abruptly changes path upwards passing by the termination of the upper nerve cord and leading further upwards in a more slanted angle. Lateral line pores are much more widely spaced when following upwards along the second nerve cord. The number of neuromasts / pores along the upper lateral line row range from 7 to 13 along the horizontal stretch, and can reach up to 22 when continuing upwards along the slanted line.

The central lateral line row is located above the vertebral column and between the muscles obliquus superioris and obliquus inferioris (Fig. 3). It follows the above mentioned nerve cord in the same position and is usually well recognizable to the point where the nerve cord switches upwards. The central lateral line row continues along the same joint between the obliquus superioris and inferioris muscles for a long distance, but becomes increasingly indistinct until it finally fades. The modified scales associated with the central lateral line row are much smaller and less indented than those of the upper lateral line row and diminish towards posterior and become less distinctive along with the fading of the row (Fig. 3). Neither length nor neuromasts/pores can be counted reliably and therefore we do not use the central lateral line row as a distinctive character for diagnostic purposes.

The lower lateral line row starts just below the lower margin of the pectoral fin base. The first 2 to 3 pores are on a downward slanted line until the lower lateral line row reaches the lower margin of the obliquus inferioris, which it follows until the beginning of the anal fin after which it follows the suture of the obliquus inferioris with the inclinator analis. Anteriorly, the lower lateral line row is associated with large scales with a strong posterior indention for the extruding neuromasts, and the pores are narrowly placed. Basically every scale is large and modified along the anterior reaches of the lower lateral line row and carries a pore for a neuromast (Fig. 3). At some point along the row the modified scales begin to become smaller (Fig. 3) and the distance between each pore / neuromast increases. The lower lateral line row continues behind the beginning of the anal fin for a long stretch but fades and its termination is not clearly defined. Nevertheless, the pores / neuromasts of the lower lateral line row are often well visible up to 
the beginning of the anal fin and can be counted. The changes in spacing of the pores along this interval provides a useful character for species recognition. The lower lateral line row does not seem to be associated with a shallow nerve cord below the skin.

Body scales are not counted due to their deciduous nature that renders such counts as not practicable for diagnostic purposes. The location below the pectoral peduncle is the best place to find preserved body scales. The scales are cycloid (Fig. 3) with radial furrows towards the anterior half and very fine concentric rings. Extraction and measurements from various species of the genus Porogadus showed sizes ranging from about 1.5 to $3.5 \mathrm{~mm}$ but appear to be related to the size of the fish from which they were taken, i.e., range from 0.65 to $1.0 \mathrm{in} \%$ of SL in most instances. However, the size of scales on the head varies depending on the position, with those on the snout, maxilla, and frontals being smaller than elsewhere (see above). Porogadus promelas is notable for the scales on the cheeks being somewhat larger than those on the opercle.

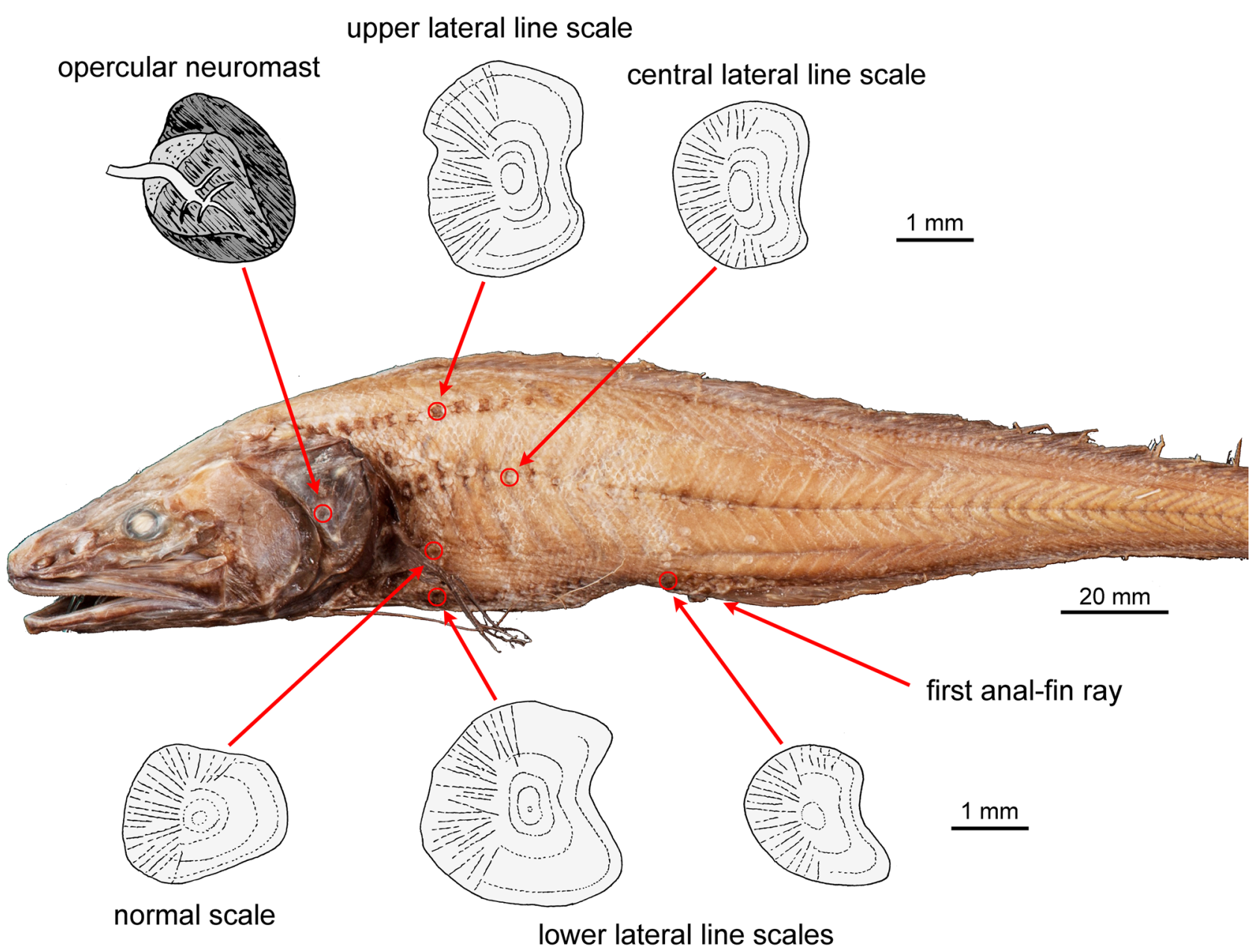

FIGURE 3. Lateral line system in Porogadus. Photograph of fish and drawings of opercular neuromast is from P. longiceps, drawings of scales are from $P$. dracocephalus $\mathbf{n}$. sp.

3. Meristics (Fig. 4). Most meristics vary within very narrow ranges. The most useful meristics are the following. The number of precaudal vertebrae range from 14 to 19 and exhibit limited consistency in respect to neck vertebrae (with ribs but without parapophyses), breast vertebrae (with both ribs and parapophyses) and loin vertebrae (without ribs and with parapophyses). However, in Porogadus there are always 1 or 2 loin vertebrae, while in Tenuicephalus n. gen. the number of loin vertebrae is 1 or 2 in T. silus, but ranges from 2 to 5 in the other species. The number of precaudal vertebrae seems to be connected with the position of the first dorsal fin ray. Low numbers in both are typical for species of the genus Tenuicephalus $\mathbf{n}$. gen. and are considered a derived pattern. The number of pectoral fin rays ranges from 15 to 23 . The position of the first dorsal fin ray is above vertebra 3 to 7 , and the first anal fin ray is under dorsal fin ray 21 to 30 . The number of long gill rakers on the first gill arch, which are located along the lower branch only, ranges from 11 to 21 and appears to be relatively stable with ontogeny and of good diagnostic value on the species level. Porogadus guentheri is notable for bladed developed gill rakers. Flat plates and short rakers 
occur on the upper branch and at the beginning of the lower branch of the first gill arch before the commencement of developed long gill rakers in all species and may occur also alternating with developed gill rakers for a certain interval. However, Porogadus trichiurus is notable for the lack of intermittent plates and the species of the genus Tenuicephalus $\mathbf{n}$. gen. have only very indistinct, atrophied intermittent plates.

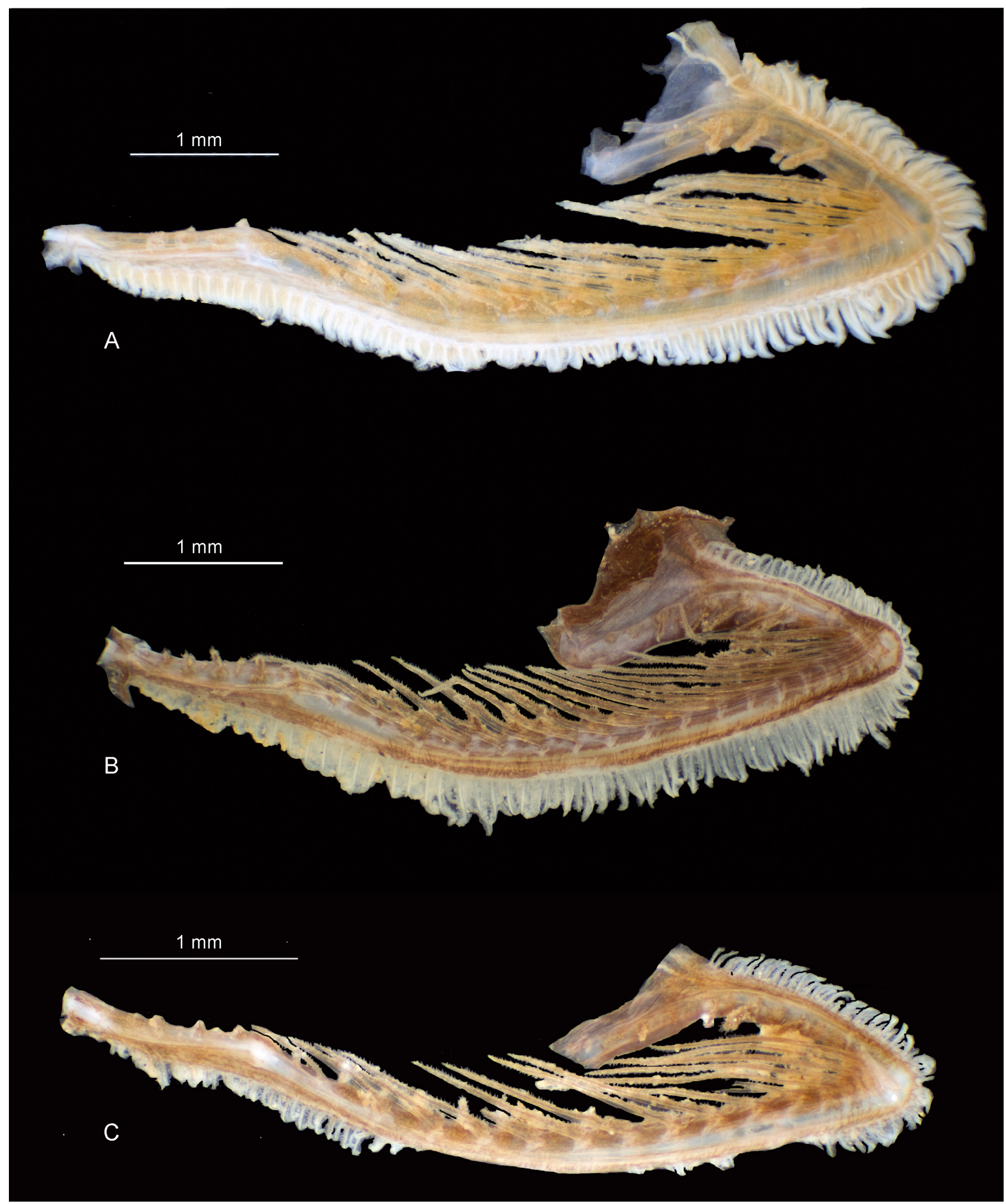

FIGURE 4. Examples of first gill arches. 4A, Porogadus miles ZMUC P2397157, 259 mm SL. 4B, Tenuicephalus multitrabs n. sp. CAS 83066, 156 mm SL. 3C, P. solomonensis ZMUC P771578, 173+ mm SL. 
4. Morphometrics. Adult fishes of the genus Porogadus average between 200 and $400 \mathrm{~mm}$ SL, but within the Porogadus miles group can reach well above $500 \mathrm{~mm}$ SL for instance in P. miles and P. longiceps. Specimens of Tenuicephalus n. gen. are considerably smaller mostly between 130 and $200 \mathrm{~mm}$ SL. The unique holotype of $T$. melampeplus is calculated at about $220 \mathrm{~mm}$ SL measured from the photograph provided by ZSI. Morphometric measurements have not shown to be very effective for species diagnoses. Standard measures relating to predorsal (mostly 15-20\% SL), prepectoral (14-19\% SL) and preanal (26-33\% SL) lengths are all within very narrow ranges and only in few instances have shown to be of differential diagnostic value. Eye diameter is generally between 1 and $2 \%$ SL, snout length mostly between 4.5 and $6.0 \%$ SL and upper jaw length between 8 and $11 \%$ SL and very variable. Reliable measurements of fin lengths (pectoral and pelvic fins) are too rare to be of practical use, and body depth and width measurements show too high degrees of variability and measuring uncertainty. This leaves the relative head length and depth as the only widely attributable and distinctive characters of use in this group of fishes (see above to head morphology).
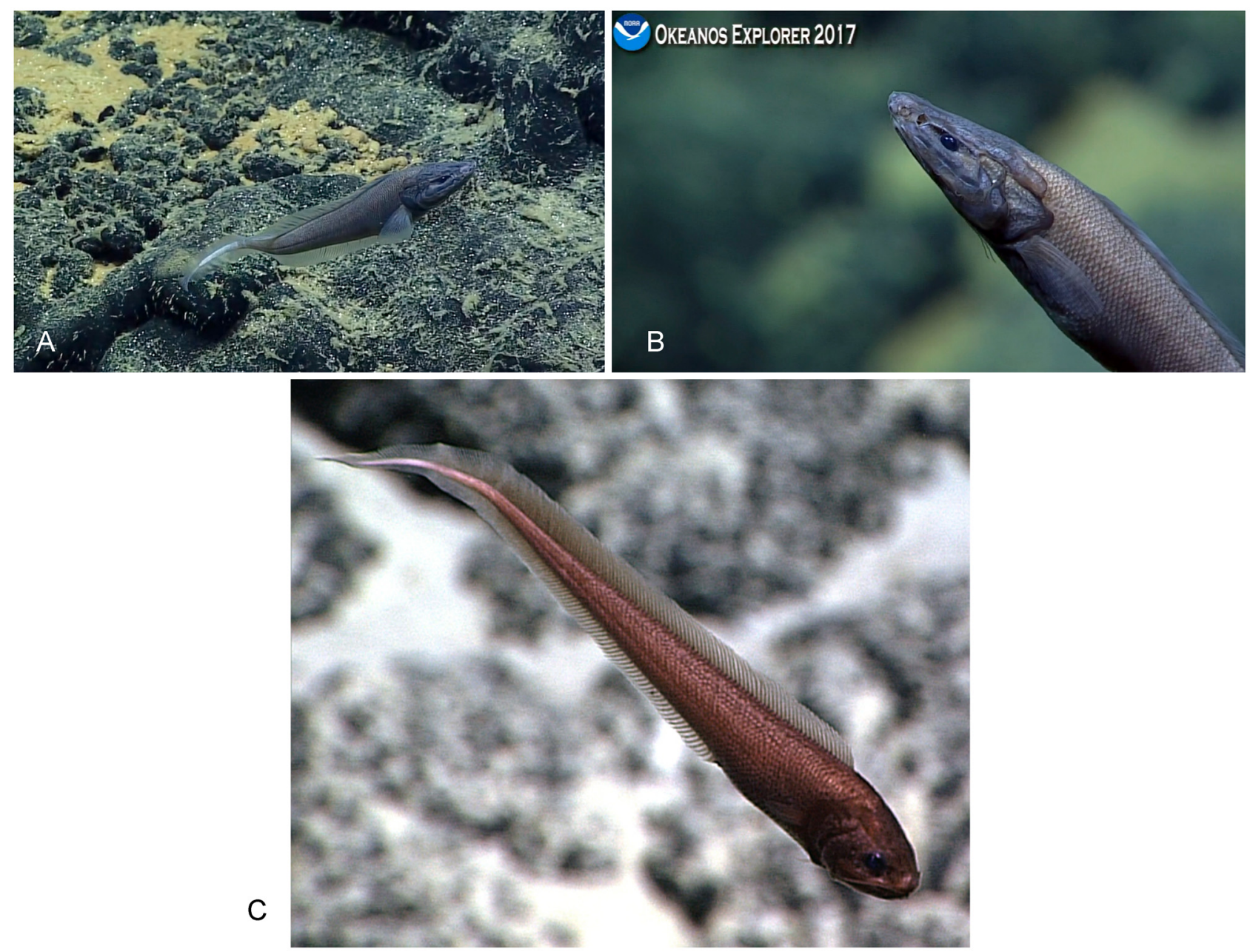

FIGURE 5. Live figures from ROV dives. 5A-B, putative long-nosed Porogadus specimen; photo taken on 23.03 .2017 during Okeanos EX 1703, dive 17 at 4'22’31'’S, 172 ${ }^{\circ} 59^{\prime} 52^{\prime \prime} \mathrm{W}$ at $5856.8 \mathrm{~m}$. 5C, putative short-nosed Tenuicephalus specimen; photo taken on 20.09.2015 during Okeanos EX 1504, leg 4, dive 7 at $15^{\circ} 12^{\prime} \mathrm{N}, 168^{\circ} 03^{\prime} \mathrm{W}$, maximal depth of dive $1950.7 \mathrm{~m}$. Photographs courtesy of the NOAA Office of Ocean Exploration and Research.

5. Dentition of vomer, palatines and basibranchials. Porogadus and Tenuicephalus $\mathbf{n}$. gen. have uniform very small villiform teeth on dentary, premaxilla, vomer, palatines and basibranchial tooth patches. The vomer is vshaped, diverse in size and width and intensity of dentition. Porogadus species have 1 to 5 rows of teeth on the vomer, except for $P$. guentheri that has only few teeth anteriorly. Tenuicephalus species have no or very few teeth on the vomer, and this is subject to intraspecific variability. Dentation on the palatines range from only 1 or 2 rows on very narrow palatines as found in Tenuicephalus to 3 to 6 or more rows on wide palatines found in Porogadus. Width of vomer and palatines and number of teeth rows is somewhat variable in the species of Porogadus but nevertheless constitutes useful diagnostic characters. We interpret low dentition patterns as a derived character. Both 
genera usually show a single, variably long and wide basibranchial tooth patch. The narrowest basibranchial tooth patches with a single or two rows of teeth is found in Tenuicephalus, and T. silus is the only species in this study to occasionally have no basibranchial tooth patch altogether. It is not uncommon in certain species of Porogadus to show a small lateral tooth patch in addition to the elongate central basibranchial tooth patch, and in rare instances a pair of small lateral patches. These appear to represent an unusual degree of variability of this character, which in other genera like Holcomycteronus or Dicrolene appears to be an important and reliable character (Nielsen et al., 1999). Only Porogadus solomonensis n. sp. appears to have consistently a long central basibranchial tooth patch flanked by a pair of small lateral tooth patches.

6. Coloration (Fig. 5). Little is known about the life coloration of Porogadus and Tenuicephalus species. Few life photoshots exist of putative Porogadus specimens from the Okeanos Explorer (Bell et al. 2016, Raineault et al. 2018) that seem to represent each a long-snouted (Fig. 5 A-B) and a short-snouted (Fig. 5 C) species, which show uniform dark grey or brownish colors. The long-snouted specimen was photographed during Okeanos Excursion

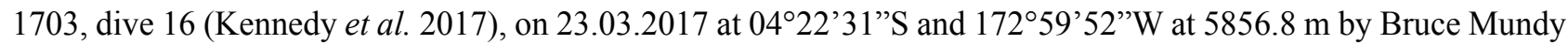
and therewith would represent the deepest observation of a Porogadus (see also: Ocean Networks Canada, SeaTube Pro 2017). It is also slightly off the studied records of Porogadus but within the geographic reach of $P$. aff. miles (see below). The short-snouted specimens was photographed during Okeanos Excursion 1504, leg 4, dive 7 (Kennedy et al. 2019), on 20.09 .2015 at about $15^{\circ} 12^{\prime} \mathrm{N}$ and $168^{\circ} 03^{\prime} \mathrm{W}$ at a maximum depth of $1950 \mathrm{~m}$. This record would be off the currently observed distribution of both Porogadus and Tenuicephalus. When preserved, the body color ranges from light brown to almost black. There appears to be some consistency in most species of the Porogadus miles, $P$. gracilis and $P$. catena groups to exhibit a light to medium brown uniform head and body color, whereas several species of the Porogadus trichiurus group and P. melanocephalus of the P. gracilis group show a black head and a paler body color. Tenuicephalus specimens tend to show a uniformly black body color except for T. melampeplus which appears to be paler judging from the photograph provided by ZSI.

7. Otoliths (Fig. 6). Otoliths represent an important additional character for taxonomic studies. Otoliths are available from all species of Porogadus and Tenuicephalus n. gen. except Tenuicephalus silus. The first and most obvious character for a characterization is the presence of two separated colliculi in the sulcus of the otolith or of a single, fused colliculum extending across the entire sulcus. In Porogadus guentheri that usually has a single fused colliculum, specimens occur where a faint distinction into ostial and caudal colliculi can be recognized. Conversely, Porogadus longiceps contains specimens where the otolith shows clearly distinct ostial and caudal colliculi and specimens where the colliculi are fused, but this species is currently insufficiently defined. Generally, the presence of a single, fused colliculum is considered a derived character, which however has occurred in many parallel lineages within the Ophidiiformes (Schwarzhans, 1981) indicating a functional morphological background for this development. Separated colliculi are known from Porogadus miles, P. nudus, P. longiceps and P. turgidus $\mathbf{n}$. sp. A very large specimen of $P$. longiceps has fused colliculi, but also a small, tentatively assigned specimen (see above). Useful otolith morphometrics are the ratio OL:OH, ranging from 0.9 to 2.2, the ratio OH:OT ranging from about 2.0 to 4.0 and the ratio OL:TCL ranging from 1.6 to 3.2. It should be noted though that the relative size of otoliths in comparison to the head length may not always be a reliable character. Wilson (1985) has shown depth related changes in otoliths sizes in six species of macrourids. Wilson also noted size differences in otoliths of the same species and same standard length from different ocean basins. In ophidiiforms, size differences of otoliths from specimens of Glyptophidium argenteum Alcock, 1889 have been observed by Nielsen \& Machida (1988) and in this case apparently relate to geographic differences. However, it has also been observed that deep living fishes, which generally live at or below the Calcite compensation depth (CCD) tend to have only small otoliths with a simplified morphology (Schwarzhans, 2010: p. 87). This may also be the case for several of the species in Porogadus like in P. abyssalis and P. gracilis, but in other instances distinctive differences of relative otolith sizes are interpreted here as genuine distinctive characters, e.g., Tenuicephalus multitrabs $\mathbf{n}$. sp. and T. squamilabrus $\mathbf{n}$. sp. The otolith outline and the shape of the sulcus offer relatively few additional characters of use in the genera Porogadus and Tenuicephalus except for Porogadus miles exhibiting a distinct predorsal lobe which is considered to represent a plesiomorphic character in this context. We also note that the otoliths of many of the species of the genus Porogadus exhibit a stronger degree of variability than usually observed in ophidiiform otoliths.

Meristics, morphometrics and key characters of dentition, coloration, head spine development, head squamation and otolith morphology and morphometrics are summarized on Tables 1 to 7. 


\section{mesial view}

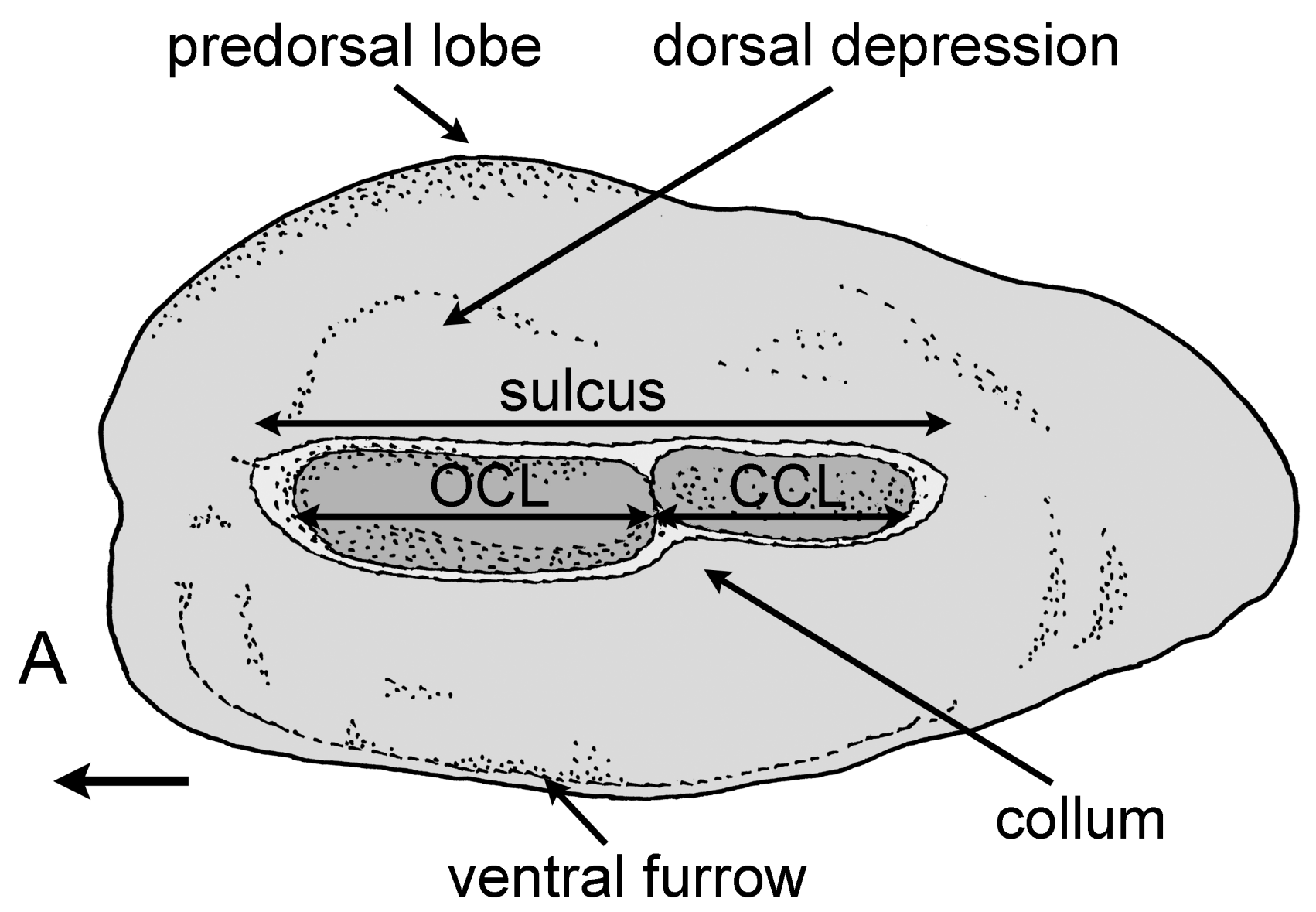

\section{ventral view}

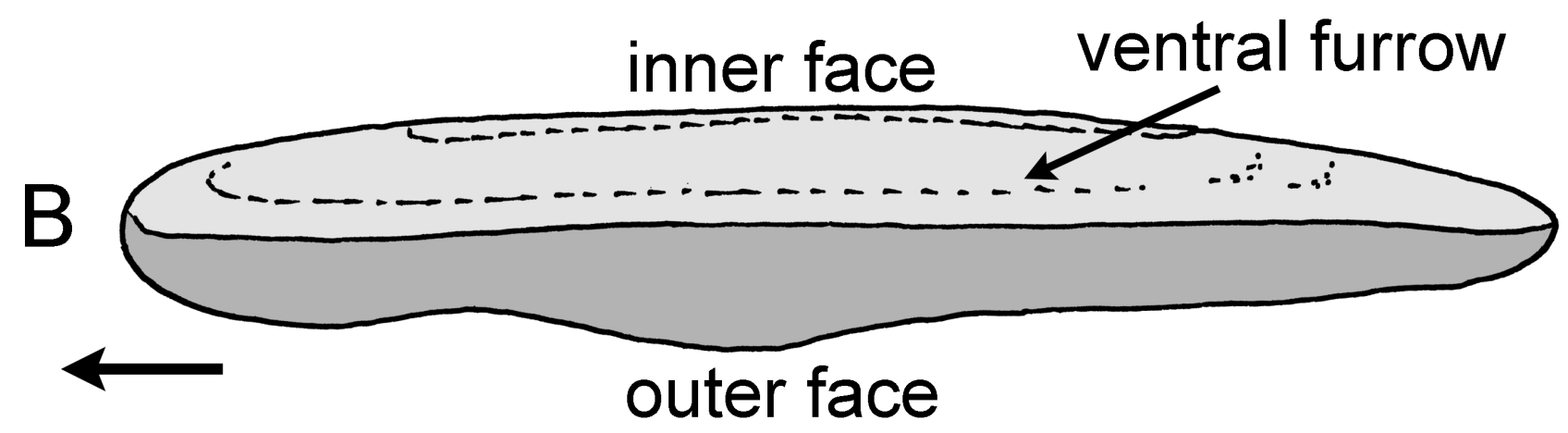

FIGURE 6. Schematic otolith drawings depicting morphological terminology (example from Porogadus miles); upper figure right otolith from inner face, lower figure ventral vie of right otolith. Abbreviations used: $\mathrm{OCL}=$ ostial colliculum length, $\mathrm{CCL}$ = caudal colliculum length. 


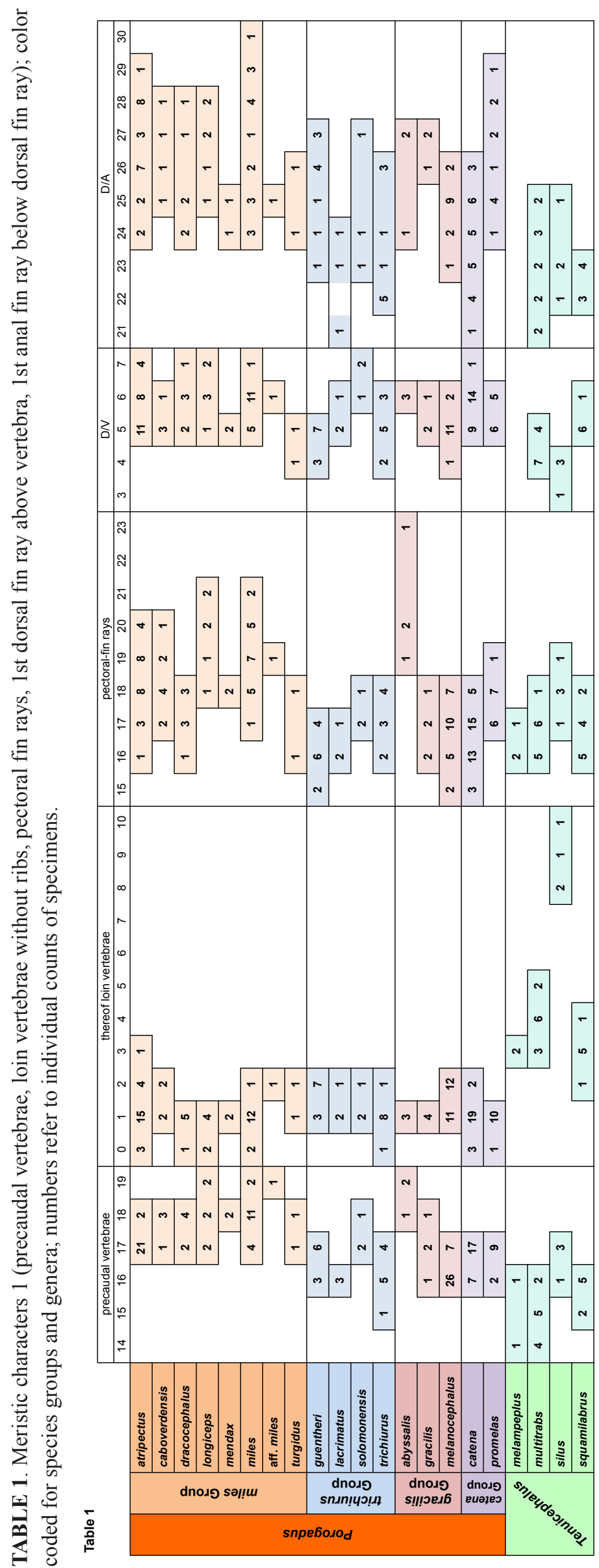




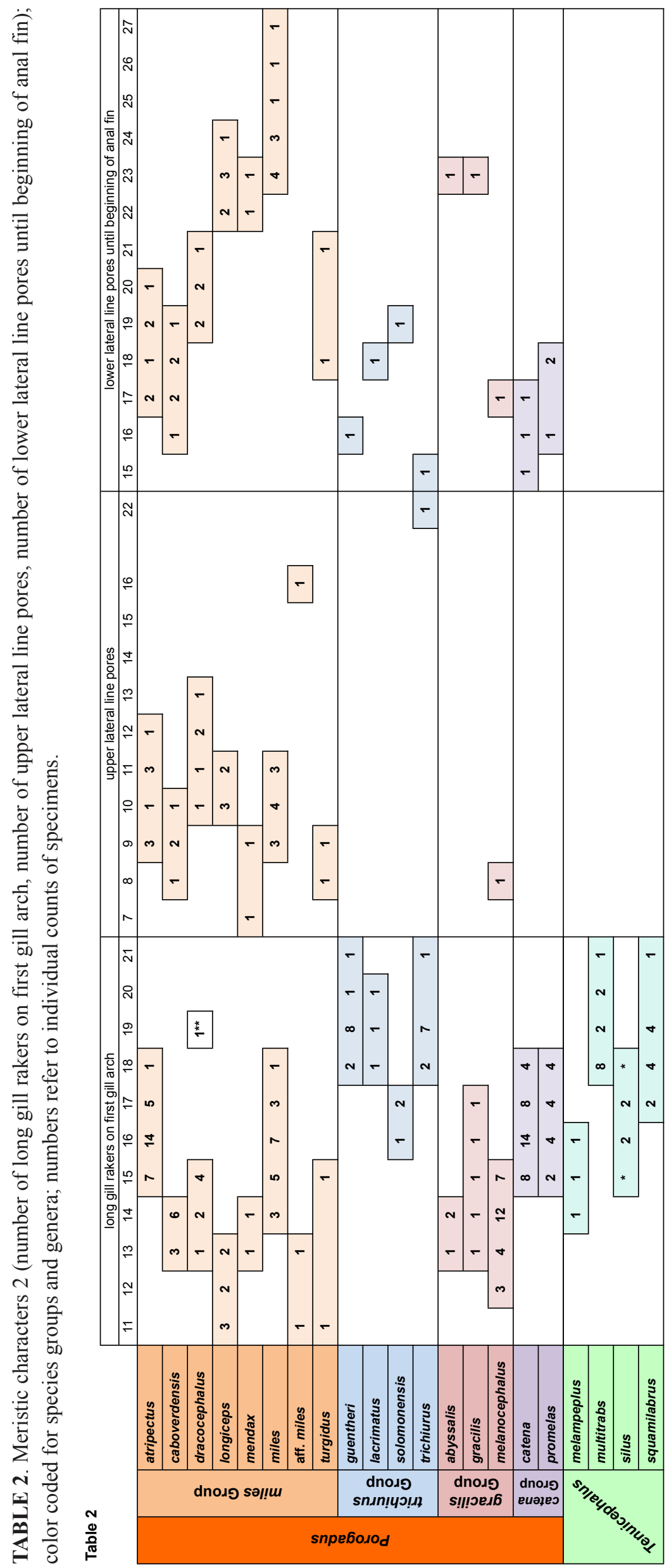

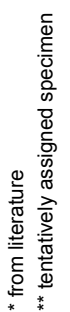




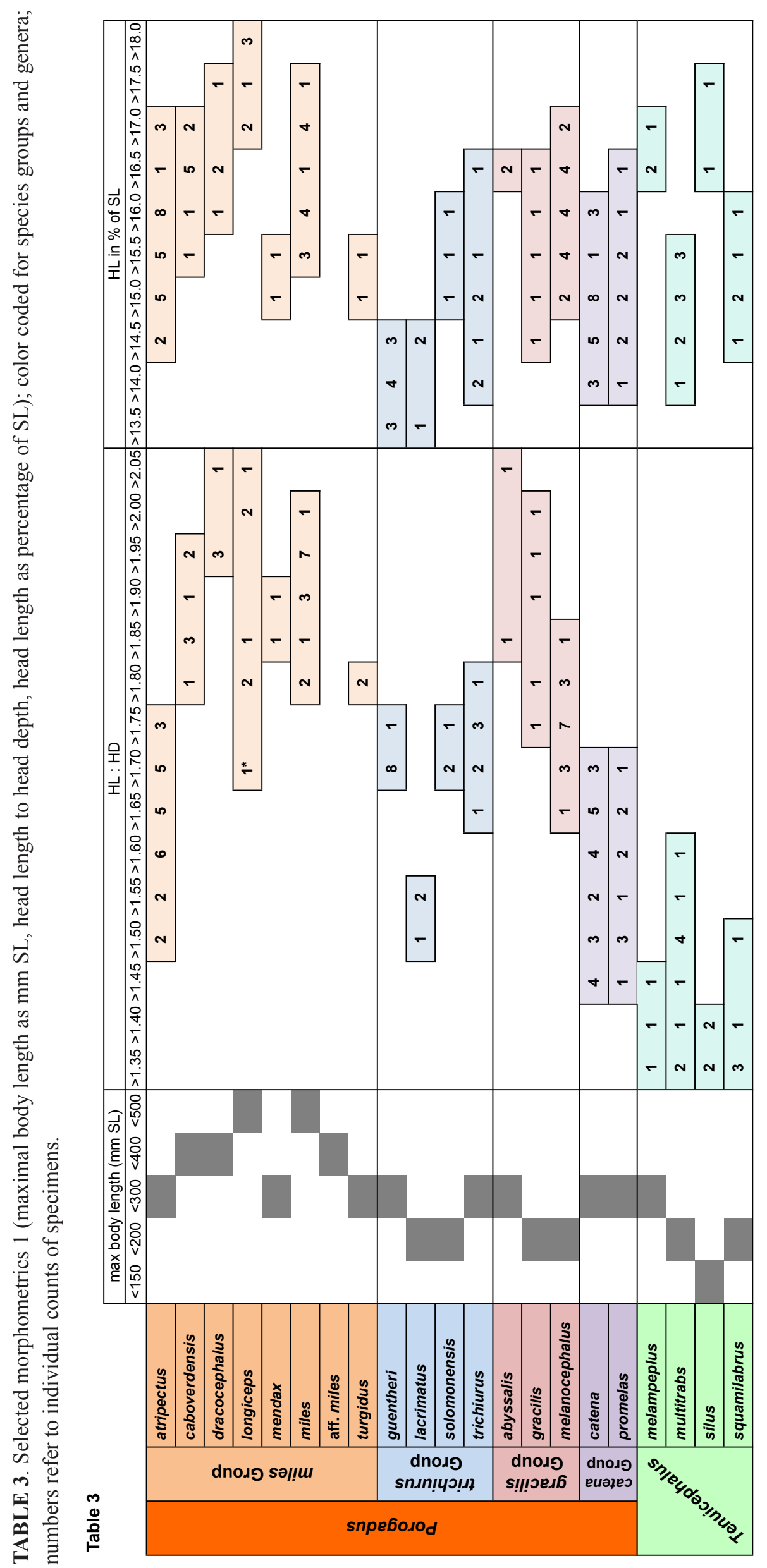




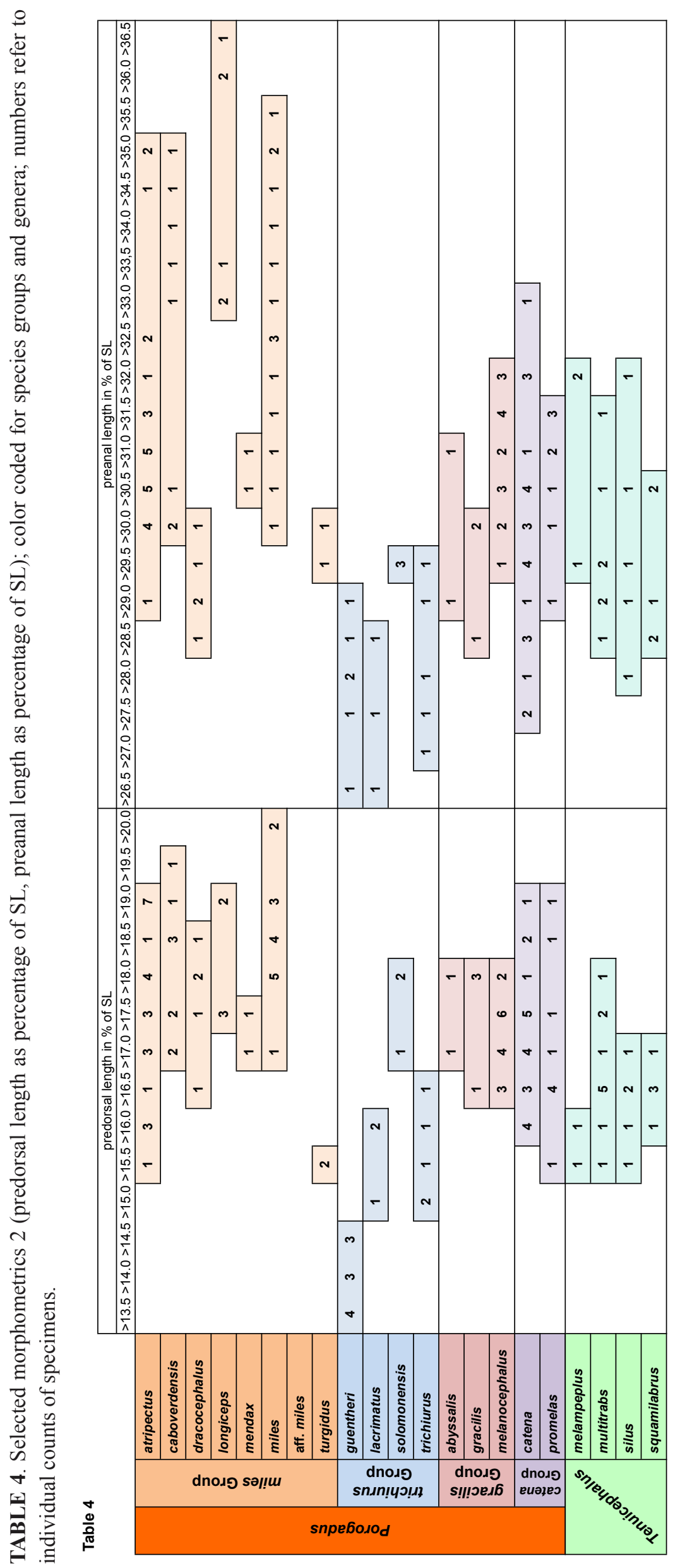




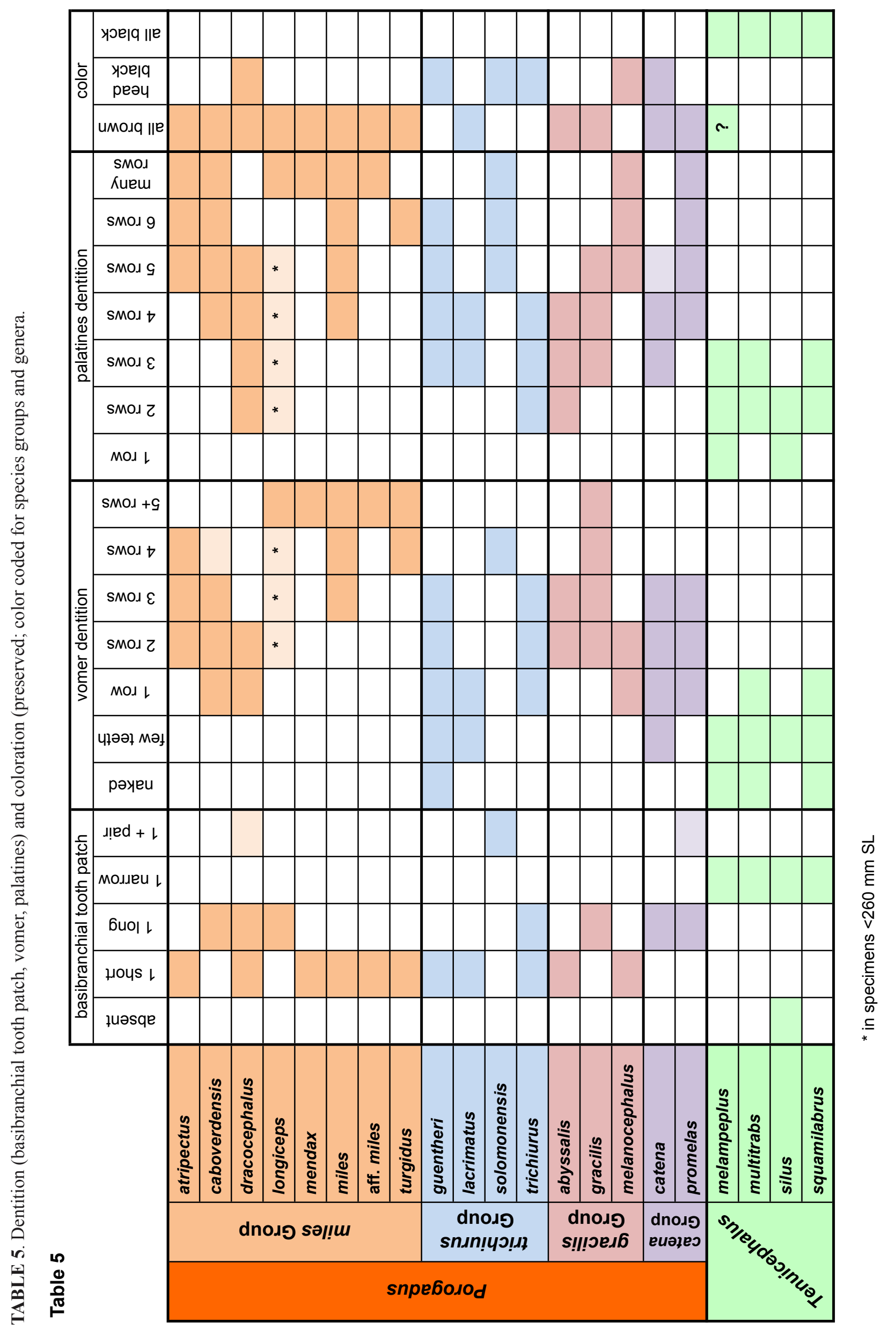




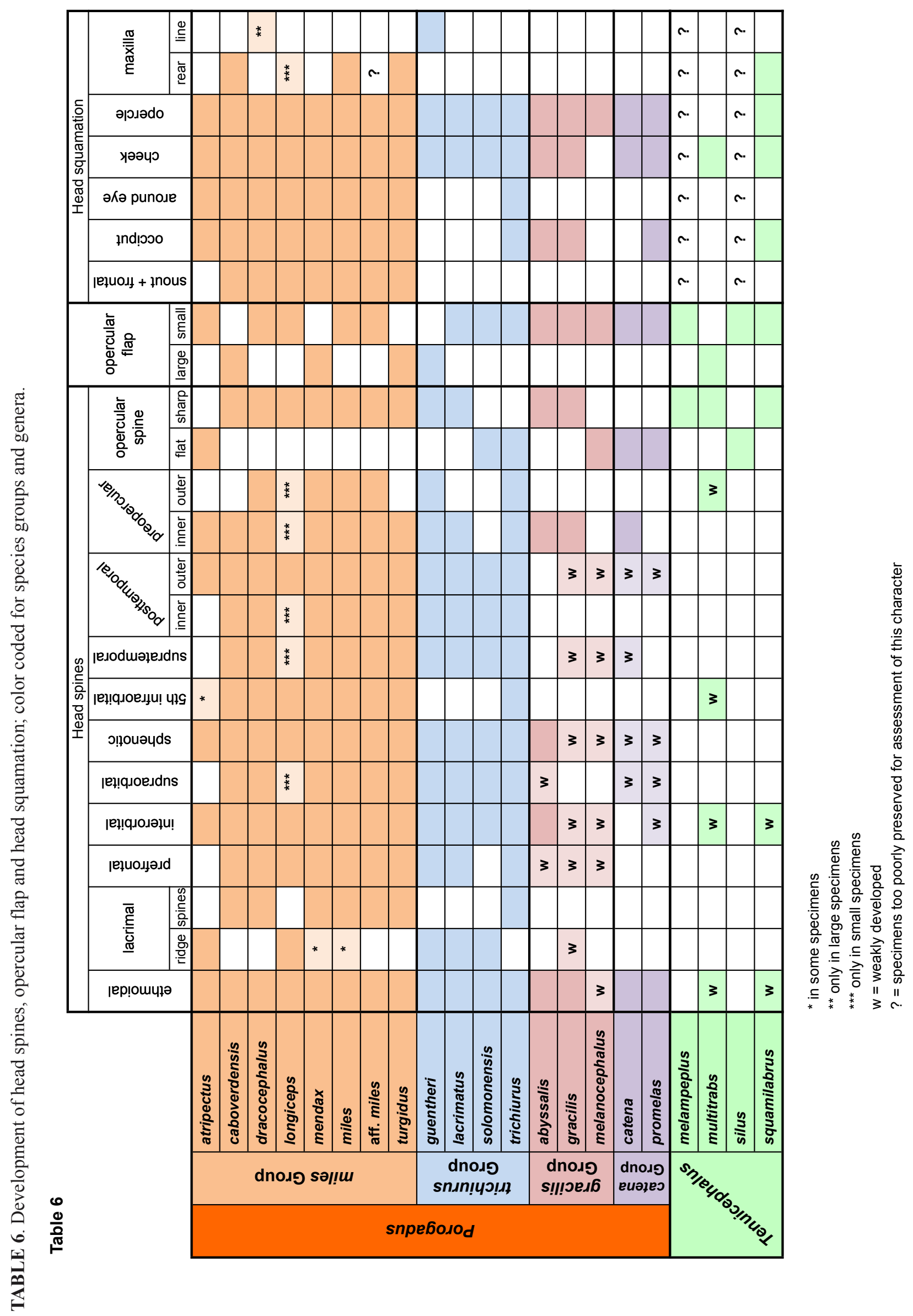




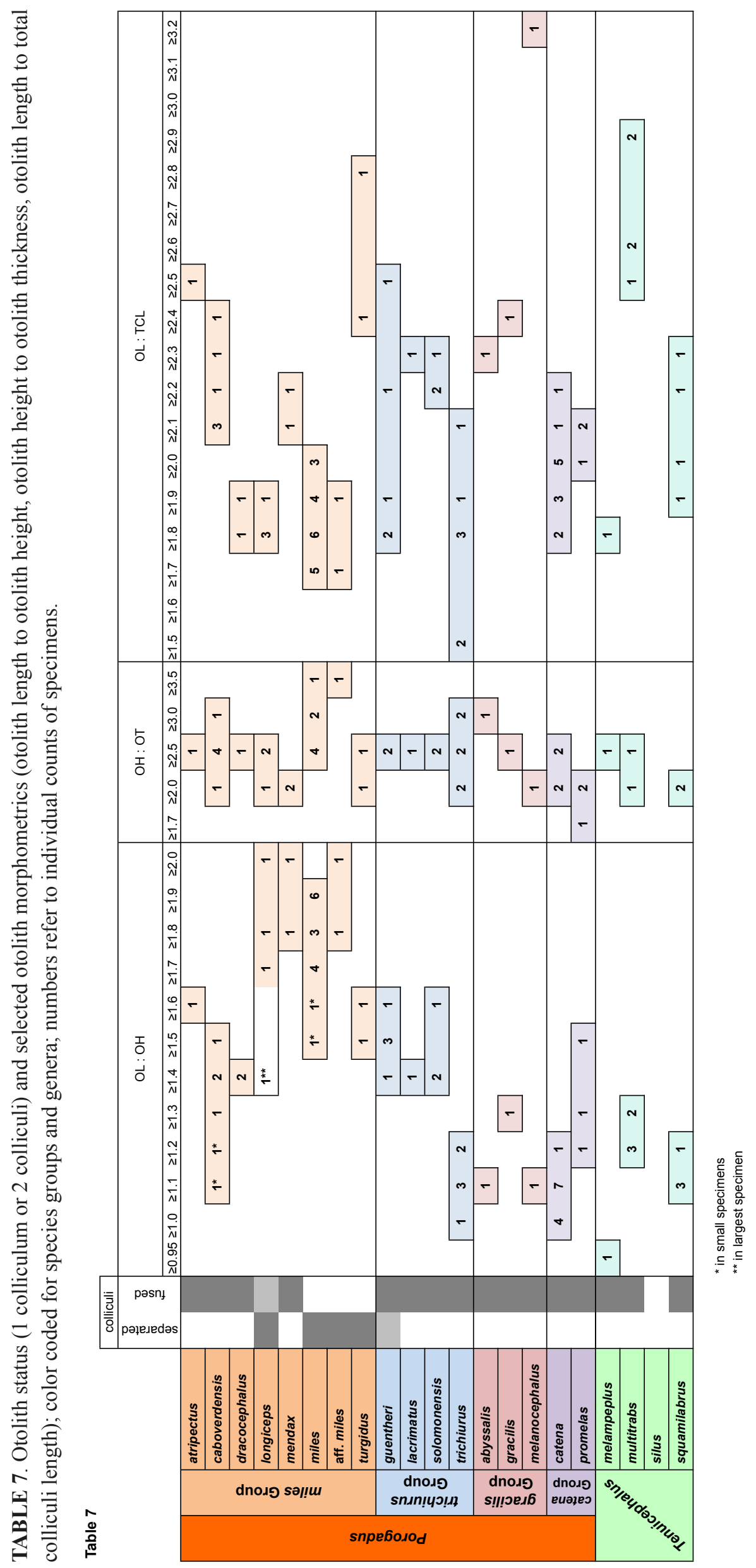




\title{
Taxonomy
}

\section{Order Ophidiiformes Berg, 1937}

\author{
Suborder Ophidioidei Berg, 1937
}

Family Ophidiidae Rafinesque, 1810

Subfamily Neobythitinae Radcliffe, 1913

\section{Genus Porogadus Goode \& Bean, 1885}

Porogadus Goode \& Bean, 1885: 602, type species by monotypy Porogadus miles Goode \& Bean, 1885. Dermatorus Alcock, 1890: 298, type species by monotypy Dermatorus trichiurus Alcock, 1890. Celema Goode \& Bean, 1896: 329, type species by subsequent designation Porogadus nudus Vaillant, 1888. Moebia Goode \& Bean, 1896: 331, type species by monotypy Bathynectes gracilis Günther, 1878. Porogadus: Cohen \& Nielsen, 1978; Nielsen, Cohen, Markle \& Robins, 1999.

Diagnosis (adopted and altered from Nielsen et al., 1999). A genus of the subfamily Neobythitinae characterized by the following combination of characters: Body long and slender; depth at anus more than 10 times in standard length, prominent mucous cavities and large pores along the infraorbital and mandibular-preopercular canal systems; spines on head variably developed but at least containing ethmoidal spine; upper jaw ends well behind eye; 1 median basibranchial tooth patch, rarely 1 pair of small lateral basibranchial tooth patches in addition; lateral line represented by 3 rows of circular organs variously developed from one species to another and by a row of easily shed modified scales; developed gill rakers 11 to 21 ; pectoral-fin rays 15 to 23; precaudal vertebrae 16 to 19 ; ratio HL:HD 1.5 to 2.1; vomer with 1 to 7 rows small villiform teeth (except $P$. guentheri with only few teeth); palatine with 2 to more than 6 rows small villiform teeth.

Similarity. Porogadus shares with Alcockia Goode \& Bean, 1896, Bathyonus Goode \& Bean, 1885, Penopus Goode \& Bean, 1896 and Tenuicephalus n. gen. described in the following the slender body and mucous cavities on the head. These genera were considered to be interrelated by Cohen \& Nielsen (1978) with whom we agree. Alcockia further shares with Porogadus the presence of sharp spines on the head, but differs in the presence of 2 median basibranchial tooth patches (vs 1, occasionally flanked by a small pair of tooth patches), 7 developed rakers on the first gill arch (vs 11 to 21), and the upper jaw terminating beyond eye (vs well behind eye). Alcockia is further characterized by a doubled infraorbital canal system below the eye, underlain by a bony ridge towards the upper jaw, a much widened and serrated preopercle and specialized scales on certain positions of the head (Fig. 2). Bathyonus differs from Porogadus in the large head (HL about $1 / 2$ preanal length and c. $20 \%$ of SL vs $14-18.5 \%$ of SL), absence of prominent spines on head and lower rays of pectoral fin free. Bathyonus is further characterized by a broad head with numerous small sensory papillae along the mandible and three small papillae on the opercle (Fig. 2). Penopus shares with Porogadus also the lateral line system and the upper jaw terminating far beyond the eye but differs in the anteriorly very depressed head with the snout long and projecting over mouth, the absence of head spines except for a strong opercular spine and 4 to 5 spines at the lower angle of the preopercle, the very small non-imbricate scales on the head (Fig. 2) and the 8 to 10 developed gill rakers on the first gill arch (vs 11 to 21). For differentiation from the new genus Tenuicephalus see below.

Species. We consider 10 of the previously described 15 species as valid for Porogadus and describe 6 new species in the following: Porogadus abyssalis Nybelin, 1957 from the deep Atlantic Ocean, P. atripectus Garman, 1899 from the East Pacific, P. caboverdensis n. sp. from the East Atlantic, P. catena (Goode \& Bean, 1885) from the Atlantic, P. dracocephalus n. sp. from the Indo-West Pacific, P. gracilis (Günther, 1878) from the Indo-West Pacific, P. guentheri Jordan \& Fowler, 1902 from the North-West Pacific off Japan, P. lacrimatus n. sp. from the West Pacific, P. longiceps Garman, 1899 from the East Pacific, P. melanocephalus Alcock, 1891 from the Indian Ocean, chiefly the Gulf of Bengal, $P$. mendax n. sp. from the East Atlantic, $P$. miles Goode \& Bean, 1885 worldwide under tropical to temperate seas except the East Pacific, P. promelas Gilbert, 1892 from the East Pacific, P. solomonensis n. sp. from the West Pacific, P. trichiurus (Alcock, 1890) from the Indo-West Pacific and P. turgidus n. sp. from the East Atlantic. 
Species Groups. The head proportion in combination with shape of the snout and the presence and intensity of spines on the head represent the best means to visually identify species groups. We recognize 4 species groups within Porogadus, but follow Nybelin (1957) in not assigning formal subgeneric ranking to them at this stage. Even though nominal generic names are available for three of the four species groups, we believe that a more extensive phylogenetic analysis is required before further taxonomic division can be justified. The four species groups are as follows.

1. Porogadus miles Group. The species of the Porogadus miles group are characterized by the combination of a long head with a slender snout and abundant and strong head armature. It comprises the largest group and includes $P$. atripectus, $P$. caboverdensis $\mathbf{n}$. sp., $P$. dracocephalus n. sp., $P$. longiceps, $P$. mendax $\mathbf{n}$. sp. $P$. miles and $P$. turgidus n. sp. However, the two species $P$. atripectus and $P$. turgidus n. sp. are intermediate in many characters with the following group in respect to the head proportions but have the slender snout of the Porogadus miles Group.

2. Porogadus trichiurus Group. Specimens of the Porogadus trichiurus group have a short head with intense head armature and a broad snout. It comprises the second largest group with four species: P. guentheri, P. lacrimatus n. sp., P. solomonensis $\mathbf{n}$. sp. and P. trichiurus.

3. Porogadus gracilis Group. This species group is characterized by a slender head and snout with weak spines and comprises the species P. abyssalis, P. gracilis and P. melanocephalus.

4. Porogadus catena Group. This group contains only two species with a short head and snout and weak spines: P. catena and P. promelas.

\title{
Key to the species of Porogadus
}

\author{
(see also tables 1 to 7 )
}

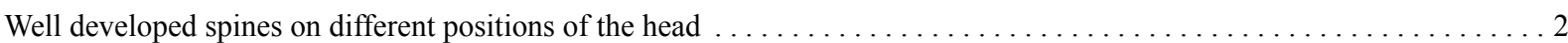
No or weak spines on the head except for ethmoidal and occasionally infraorbital spines $\ldots \ldots \ldots \ldots \ldots \ldots \ldots$

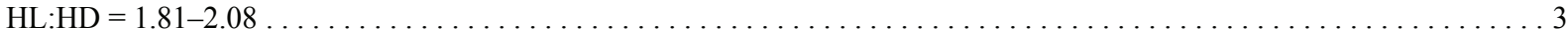

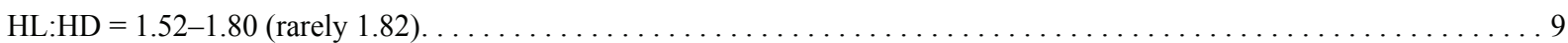

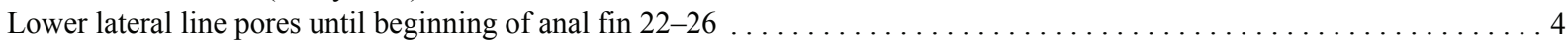

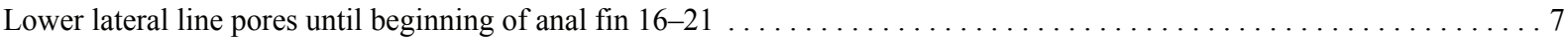

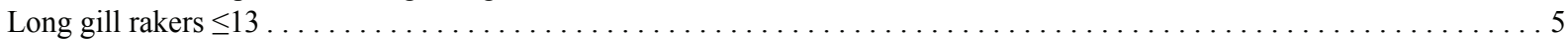

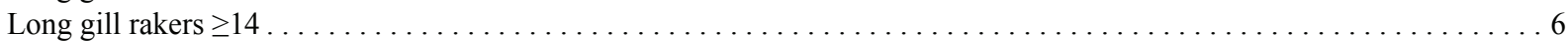
Predorsal $>19 \%$ of SL; small opercular flap; sulcus of otolith with divided colliculi $\ldots \ldots \ldots \ldots \ldots$ Porogadus longiceps Predorsal $17-18 \%$ of SL; large opercular flap with radial ridges; sulcus of otolith with undivided colliculi . .

Porogadus mendax n. sp. Maxilla with scales on rear portion; sulcus of otolith with divided colliculi; otolith length to total colliculi length $<2.0 \ldots \ldots$

Porogadus miles Maxilla without scales; sulcus of otolith with undivided colliculum; otolith length to total colliculum length $>2.1 \ldots \ldots \ldots$.

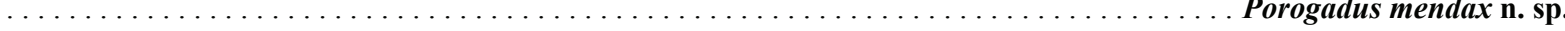
Vomer narrow, with $1-3$ rarely 4 rows of teeth; sulcus of otolith with undivided colliculum. $\ldots \ldots \ldots \ldots \ldots$ Vomer wide, with 4-5 rows of teeth; sulcus of otolith with divided colliculum . . . . . . . Porogadus turgidus n. sp. Palatines narrow, with 2-5 rows of teeth; maxilla with no or single line of scales along upper rim; otolith length to total colliculi length $<2.0 \ldots \ldots \ldots \ldots \ldots \ldots \ldots \ldots \ldots \ldots \ldots \ldots \ldots \ldots \ldots \ldots \ldots \ldots \ldots \ldots \ldots \ldots \ldots \ldots \ldots$ Porogadus dracocephalus $\mathbf{n} . \mathbf{s p}$. Palatines wide, with $4-9$ rows of teeth; maxilla with scales on rear portion; otolith length to total colliculi length $>2.1 \ldots \ldots$ Vomer with $2-5$ rows of teeth (rarely 1 row in $P$. trichiurus); opercular spine flap like $\ldots \ldots \ldots \ldots \ldots \ldots \ldots \ldots \ldots$

$10 \quad \mathrm{HL}: \mathrm{HD}=1.52-1.60$; predorsal $=15.4-16.3$; gill rakers not bladed $\ldots \ldots \ldots \ldots \ldots \ldots \ldots$ Porogadus lacrimatus $\mathbf{n} . \mathbf{s p}$. $\mathrm{HL}: \mathrm{HD}=1.71-1.80 ;$ predorsal $=13.7-14.7$; gill rakers bladed $\ldots \ldots \ldots \ldots \ldots \ldots \ldots \ldots \ldots$ Porogadus guentheri

11 Developed gill rakers $18-21$, with no or very few intermittent plates; palatines with $2-4$ rows of teeth; OL:OH $=1.1-1.3 \ldots$

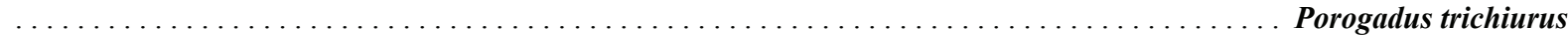
Developed gill rakers 15-17 (rarely 18), with many and regularly occurring plates in between; palatines with 5 or more rows of

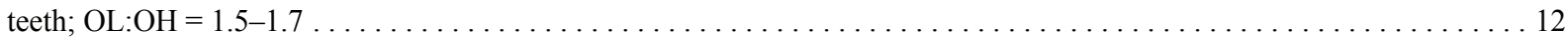

12 Spines along inner rim of preopercle; small scales around eye; median basibranchial without lateral pair (single rarely

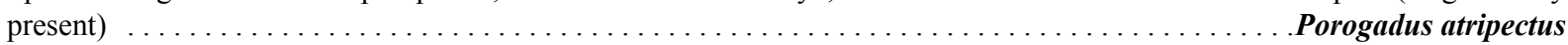
No spines along inner rim of preopercle; no scales around eye; median basibranchial and paired basibranchial $\ldots . . . \ldots$.

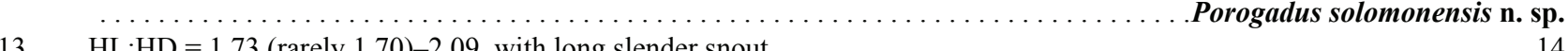

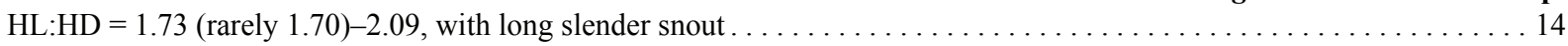




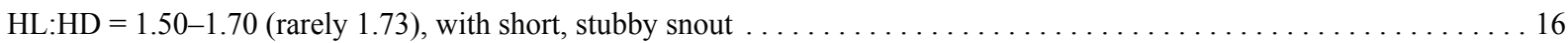

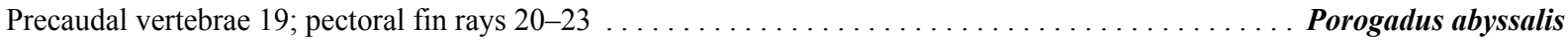

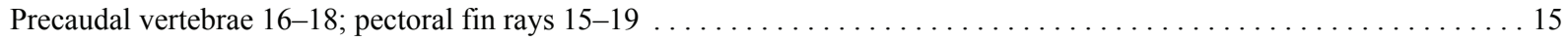

15 Head black; palatine with 5-7 rows of teeth; otolith length to total colliculum length $=3.3 \ldots$ Porogadus melanocephalus Head brown like body; palatine with $3-5$ rows of teeth; otolith length to total colliculum length $=2.5 \ldots$. Porogadus gracilis Supratemporal and postemporal spines weak; scales on cheeks and opercle equally large; $\mathrm{OH}: \mathrm{OT}=1.1-1.2$; dorsal rim of oto-

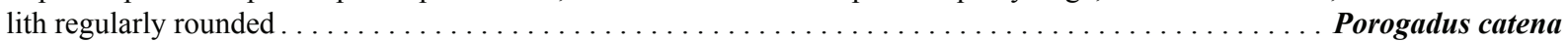
No supratemporal and postemporal spines; scales on cheeks larger than scales on opercle $\mathrm{OH}: \mathrm{OT}=1.25-1.5$; dorsal rim of otolith anteriorly expanded. $\ldots \ldots \ldots \ldots \ldots \ldots \ldots \ldots \ldots \ldots \ldots \ldots \ldots \ldots \ldots \ldots \ldots \ldots \ldots \ldots \ldots$ Porogadus promelas

\section{Porogadus miles Group}

\section{Porogadus atripectus Garman, 1899}

Figs. 7-8, 44, 49, Tab. 1-7

Porogadus atripectus Garman, 1899: 154, pl. 37, fig. 3; Nielsen et al. 1999: 86; Castellanos-Galindo et al. $2006: 198$.

Material examined (30 specimens): MCZ 28657 (lectotype), $253 \mathrm{~mm}$ SL, off Pacific Panama, $05^{\circ} 30^{\prime} \mathrm{N} 86^{\circ} 45^{\prime} \mathrm{W}$, $1951 \mathrm{~m}, \mathrm{R} / \mathrm{V}$ Albatross, large beam trawl, 27 February 1891; MCZ 28656 (paralectotype), Gulf of Panama, $07^{\circ} 05^{\prime} 30^{\prime} \mathrm{N} 79^{\circ} 40^{\prime} \mathrm{W}, 2322 \mathrm{~m}, \mathrm{R} / \mathrm{V}$ Albatross, large beam trawl, 10 March 1891; MCZ 28658 (paralectotype), $193 \mathrm{~mm} \mathrm{SL}$, off Mexico, $16^{\circ} 34^{\prime} \mathrm{N} 100^{\circ} 03^{\prime} \mathrm{W}, 1229 \mathrm{~m}, \mathrm{R} / \mathrm{V}$ Albatross, small beam trawl, 11 April 1891; LACM 36550-5 (3 specimens), 233-258 mm SL, off California, R/V Velero IV, IKMT Isaacs-Kidd Midwater Trawl, 26

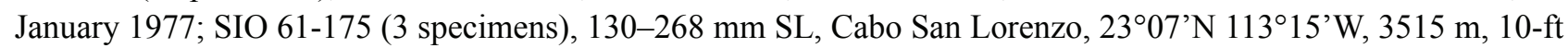
beam trawl, RV Spencer F Baird, collected by Mr. Parker, 3 May 1961; SIO 68-82 (5 specimens), 110-225 mm SL, Guaymas Basin, $27^{\circ} 12^{\prime} \mathrm{N} 111^{\circ} 25^{\prime} \mathrm{W}, 1875 \mathrm{~m}, \mathrm{R} / \mathrm{V}$ Thomas Washington, sta. MV 68-I-49, 41-ft ballon trawl, collected by Carl L. Hubbs \& party, 15-16 January 1968 ; SIO 70-248 (2 specimens), 198-216 mm SL, Guaymas Basin, $27^{\circ} 16^{\prime} \mathrm{N} 111^{\circ} 25^{\prime} \mathrm{W}, 1880 \mathrm{~m}$, Operation Blind Spot, 25 -ft otter trawl, collected by R. McConnaughey, 14 Jun 1970; SIO 70-249 (2 specimens), 185+ and $227 \mathrm{~mm}$ SL, Guaymas Basin, $27^{\circ} 17^{\prime} \mathrm{N} 111^{\circ} 26^{\prime} \mathrm{W}, 1875 \mathrm{~m}$, Operation Blind Spot, 25-ft otter trawl, collected by R. McConnaughey, 15 Jun 1970; SIO 81-148 (2 specimens), $260 \mathrm{~mm}$ SL, Panama Basin, $5^{\circ} 10.5^{\circ} \mathrm{N} 81^{\circ} 40.8^{\circ} \mathrm{W}, 3900-4000 \mathrm{~m}$, R/V Melville, 40-ft otter trawl, collected by R. Wilson, 3 October 1931; SIO 89-108 (1 specimen), 225 mm SL, San Clemente Basin, 32³6’N 118¹0’W, 1500-1940 m, R/V Robert Gordon Sproul, collected by R. Kaufman, 12 September 1989; USNM 405735 (9 specimens), 169-277 mm

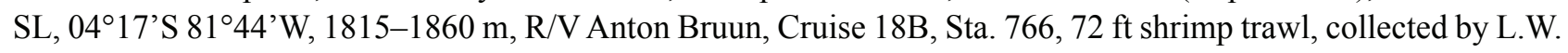
Knapp, 9 September 1966.

Diagnosis. Precaudal vertebrae 17-18; long gill rakers on first gill arch 15-18; HL:HD 1.6-1.8 (rarely 1.521.6); head spines strong on ethmoidal, sphenotic, outer posttemporal, inner preopercular rim, weak on lacrimal, prefrontal, interorbital, 5th infraorbital, absent on supraorbital, supratemporal, and outer preopercular rim; opercular spine flat, weak; lower lateral line pores until beginning of anal fin 17-20; vomer with broad dentition patch (2-4 rows); palatines with broad dentition patch (5-7 rows); otolith with single colliculum and step at collum; OL:OH $=$ $1.45-1.65$.

Description. Meristics: precaudal vertebrae $18(17-18), 0(0-2)$ last vertebrae without ribs; pectoral-fin rays 20 (16-20); D/V = 5 (5-7); D/A = 28 (24-29); V/A = 19 (18-20); long gill rakers on lower gill arch 16 (15-18). Gill rakers in a paralectotype (MCZ 28658) on lower first gill arch with seven plate-shaped rakers, followed by a series of 17 long rakers. The lower 13 of those intercepted by single plate shaped rakers. Upper gill arch with a series of three five plate shaped rakers intercepted by three slightly longer rakers.

Morphometrics: in \% of SL: HL 15.8 (14.7-17.6); maximal HD 9.2 (8.8-10.6); HD through center of eye 5.8 (5.6-7.3); bony interorbital width 3.9 (3.0-4.1); snout length 5.3 (4.7-5.7); upper jaw length 9.4 (8.6-10.9); predorsal 17.2 (15.5-19.1); preanal 31.2 (30.3-35.4); prepelvic 13.4 (11.3-14.5); prepectoral 15.6 (15.0-17.6); pectoral length 7.4 (7.4-10.4). Relations: HL:HD = 1.71 (1.61-1.80, rarely down to 1.52); HL to snout length 2.96 (2.78-3.25); preanal to predorsal 1.82 (1.65-2.01); predorsal to prepectoral $1.10(1.03-1.16)$.

Slender fish with long tapering tail and moderately pointed snout. Maximal size of fishes investigated $277 \mathrm{~mm}$ SL. Head moderately long and slender, with straight or slightly concave dorsal profile, with mostly weak spines as follows: 1 strong spine on ethmoidal, 2-3 strong spines along sphenotic, 1-2 strong spines on outer posttemporal, 
3-4 spines along inner preopercular rim, narrow ridge on lacrimal, 1 weak spine on prefrontal, 2 weak spines on interorbital, no or 1 spine on 5th infraorbital, no spines on supraorbital, supratemporal, and along outer preopercular rim. Opercle with flat, weak, poorly extruding spine. Eye small located in strongly asymmetric orbit. Maxilla extending far beyond eye, strongly widened posteriorly and with distinct supramaxilla. Infra-/postorbital and mandibular-preopercular pores wide, pores on occiput in front of nape. Head squamation on opercle, cheeks and occiput, small scales surrounding eye, no scales on snout and maxilla (Garman 1899 shows scales on maxilla). Opercle with two distinct large neuromasts behind preopercular edge; opercular flap small, with or without radial ridges, completely covered with scales. All three lateral line rows well visible. Upper lateral line row with 9-12 pores; lower lateral line row with 17-20 pores until beginning of anal fin; central lateral line row long, lower and central lateral line rows fading behind beginning of anal fin.
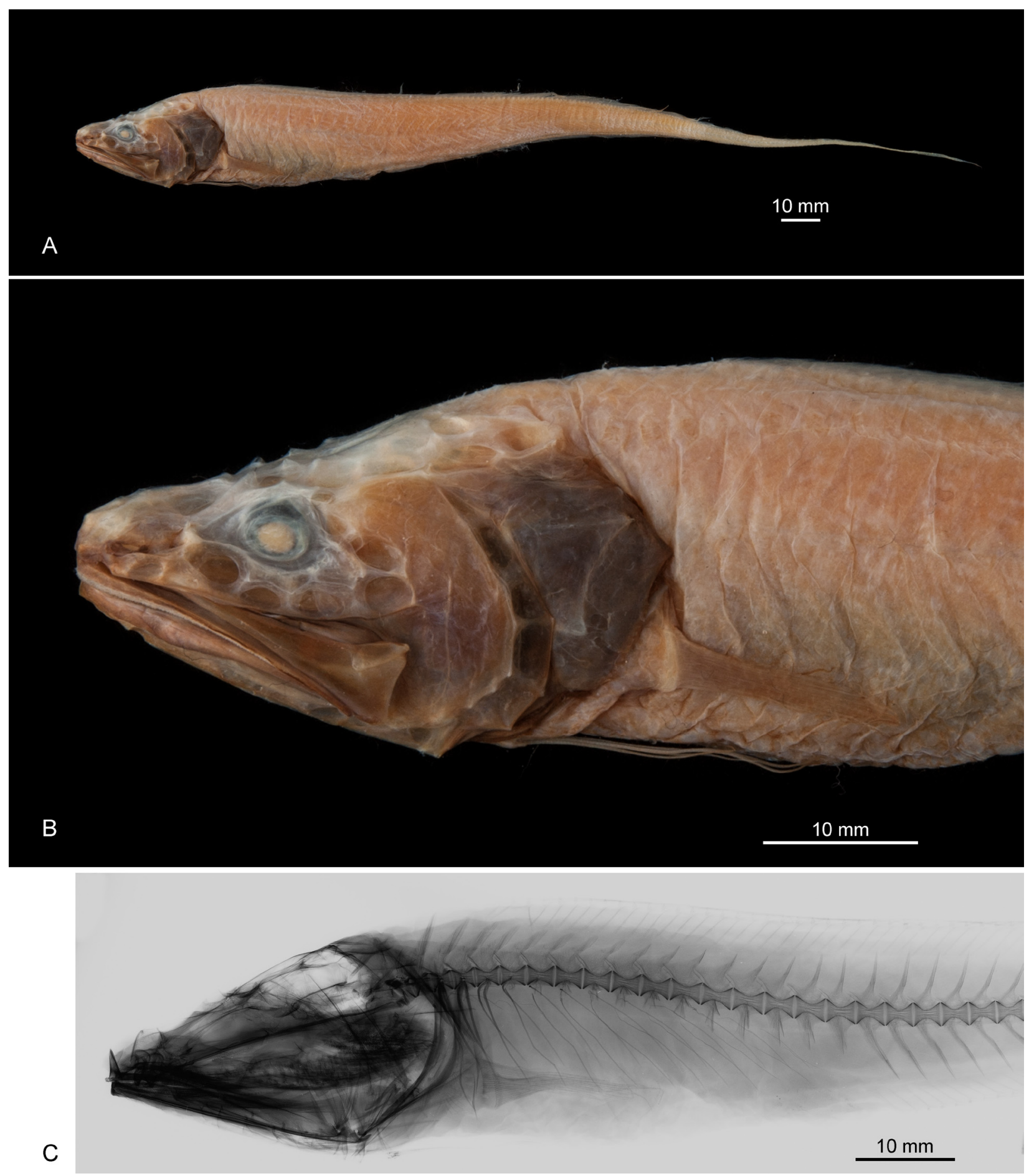

FIGURE 7. Porogadus atripectus Garman, 1899; LACM 36550-5, off California; 7A-B, 258 mm SL; 7C, 233 mm SL. 


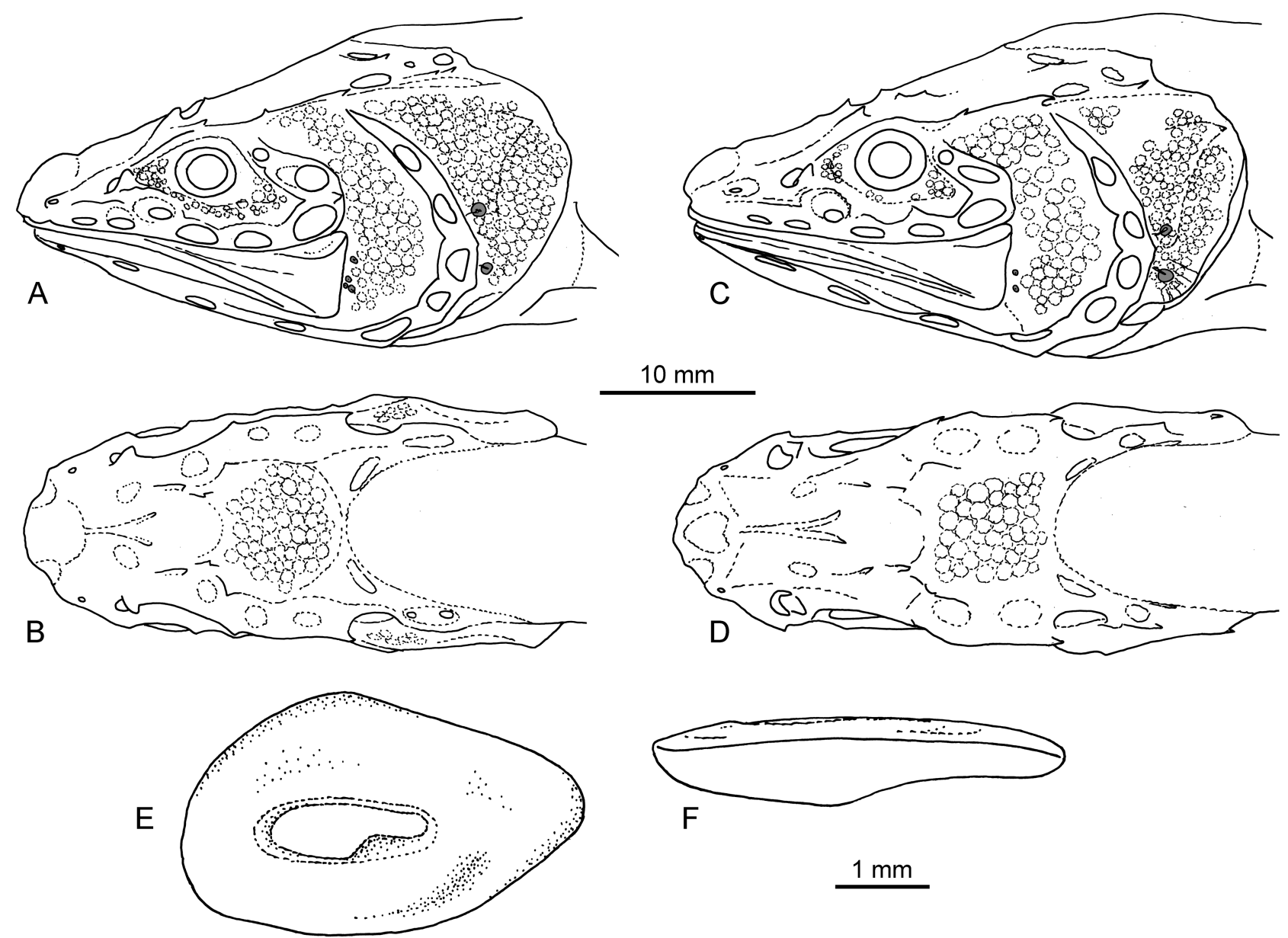

FIGURE 8. Porogadus atripectus Garman, 1899; 8A-B, SIO 89-108, $225 \mathrm{~mm} \mathrm{SL}, 32^{\circ} 36^{\prime} \mathrm{N}, 118^{\circ} 10^{\prime} \mathrm{W}, 1500-1940 \mathrm{~m}$, head drawings; 8C-D, USNM 405735, 236 mm SL, 04²17'S, 814' 'W, 1815-1860 m, head drawings; 8E-F, MCZ 28657, lectotype, $253 \mathrm{~mm} \mathrm{SL}, 05^{\circ} 30^{\prime} \mathrm{N}, 86^{\circ} 45^{\prime} \mathrm{W}, 1951 \mathrm{~m}$, otolith (E inner face, F ventral view).

Dentition. All teeth tiny and cone-shaped. Vomer with a v-shaped dentition patch with 2-4 rows of teeth anteriorly; palatines with a long and moderately wide dentition patch with 5-7 rows. Premaxilla tooth patches not fused anteriorly; ca. four teeth rows anteriorly and 1-2 rows posteriorly. Dentary tooth patches not fused anteriorly; ca. four teeth rows anteriorly and one row posteriorly. Median basibranchial tooth patch short to moderately long and wide, rarely with single tiny lateral patch.

Otolith morphology $(\mathrm{n}=2)$. Size up to $4.4 \mathrm{~mm}$ in length; $\mathrm{OL}: \mathrm{OH}=1.45-1.65$; OH:OT c. 2.5 . Thin, oval, moderately elongate otolith, anteriorly rounded, posteriorly slightly tapering. Dorsal rim with obtuse angle in front of middle; ventral rim shallow, regularly curving. All rims smooth. Inner face nearly flat, smooth, with short, centrally positioned sulcus; $\mathrm{OL}: \mathrm{TCL}=2.4$. Sulcus with shallow, undivided colliculum showing step in shape along ventral margin at collum.

Coloration. Live coloration not known. Color of preserved specimens light to medium brown; pectoral fin slightly darker; head darker than body, particularly opercle.

Discussion. Porogadus atripectus differs from all other species of the Porogadus miles Group in the less slender head (HL:HD $\leq 1.8$ vs $>1.8$ ), and the flat and weak opercular spine. Also, the head spines are generally less and weaker in many cases than in other species of the Porogadus miles Group. Because of the less slender head shape, P. atripectus resembles fishes of the Porogadus trichiurus Group but differs from them in the lower number of long gill rakers (15-17, rarely 18 vs $18-21$, except $16-17$ in P. solomonensis $\mathbf{n . s p}$.), the longer preanal (30.3-35.4 vs 26.7-30.0), and the presence of scales on frontal, occiput and around eye (vs no scales on frontal, occiput and around eye, except on occiput in P. trichiurus). Because its relatively weak head spines $P$. atripectus also resembles the species of the Porogadus gracilis Group but differs in the presence of spines along the inner margin of the preopercle (vs absent), the scales around the eye (vs absent), and the larger and more elongate otolith (OL:OH = 
$1.45-1.65$ vs $1.15-1.25)$. It thus appears that $P$. atripectus stands somewhat isolated from the other members of the Porogadus miles Group and morphologically somewhat intermittent to the Porogadus trichiurus and Porogadus gracilis groups.

Distribution. Porogadus atripectus is endemic to the East Pacific off the shores of America from $32^{\circ} \mathrm{N}$ to at least $04^{\circ} \mathrm{S}$ (Fig. 44). It has been caught mostly between 1800 and $4000 \mathrm{~m}$, rarely up to $1200 \mathrm{~m}$ on the lower reaches or the base of the continental slopes. There does not appear to be a relationship of fish sizes with depth of occurrence. Porogadus atripectus does not appear to venture away from the slope for more than about $500 \mathrm{~km}$ (Fig. 50).

\section{Porogadus caboverdensis n. sp.}

Figs. 9-10, 44, 49, Tab. 1-7

Material examined (10 specimens): Holotype BMNH 1991.7.9.826, $330 \mathrm{~mm}$ SL, $22^{\circ} 08^{\prime} \mathrm{N} 21^{\circ} 48^{\prime} \mathrm{W}$ (Cape Verde Basin), 4527-4630 m, R.R.S. Discovery Cruise, collected by N. Merrett, 02 September 1990; paratypes BMNH 1995.11.22.1-3 (3 specimens), 160-262 mm SL, 2055'N 31¹1'W (Cape Verde Basin), 4500-4610 m, R.R.S. Discovery Cruise semi-balloon otter trawl, collected by N. Merrett, 16 October 1993; BMNH 1995.11.22.12-14, 122-290 mm SL, 20 53'N 31 ${ }^{\circ} 13^{\prime} \mathrm{W}$ (Cape Verde Basin), 4480-4565 m, R.R.S. Discovery Cruise semi-balloon otter trawl, collected by N. Merrett, 4 October 1993; BMNH 1995.10.31.9, $274 \mathrm{~mm} \mathrm{SL}, 20^{\circ} 53^{\prime} \mathrm{N} 31^{\circ} 13^{\prime} \mathrm{W}$ (Cape Verde Basin), 4000+ m (no depth recorded), R.R.S. Discovery Cruise semi-balloon otter trawl, collected by N. Merrett, 1 October 1993; BMNH 1998.8.9.9525-9526, 100+ and $225 \mathrm{~mm} \mathrm{SL}, 20^{\circ} 08^{\prime} \mathrm{N} 24^{\circ} 49^{\prime} \mathrm{W}$ (Cape Verde Plateau), 4500-4600 m, R.R.S. Discovery Cruise semi-balloon otter trawl, collected by N. Merrett, 24 September 1990.

Diagnosis. Precaudal vertebrae 17-18; long gill rakers on first gill arch 13-14; HL:HD 1.8-2.0; all head spines strong, present on ethmoidal, lacrimal, prefrontal, interorbital, supraorbital, sphenotic, 5th infraorbital, supratemporal, inner and outer posttemporal, inner preopercular rim, absent along outer preopercular rim; opercular spine sharp, strong, extruding; lower lateral line pores until beginning of anal fin 16-18; vomer with narrow dentition patch (1-3, rarely 4 rows of teeth); palatines with broad dentition patch (4-9 rows of teeth); otolith with single, uniform colliculum; $\mathrm{OL}: \mathrm{OH}=1.3-1.5(1.05-1.2$ in specimens $<200 \mathrm{~mm} \mathrm{SL})$; OL:TCL $=2.1-2.45$.

Description. Meristics: precaudal vertebrae 18 (17-18), 1 (1-2) last vertebrae without ribs; pectoral-fin rays 19 (17-20); D/V = 6 (5-6); D/A = 28 (25-28); V/A = 20 (18-20); long gill rakers 13 (13-14). Gill rakers on lower first gill arch with five plate-shaped rakers, followed by a series of 13 long rakers in holotype (13-14). The lower seven of those intercepted by single plate shaped rakers. Upper gill arch with a series of five plate shaped rakers intercepted by three slightly longer rakers.

Morphometrics: in \% of SL: HL 15.7 (15.7-17.5); maximal HD 8.2 (8.2-9.3); HD through center of eye 5.5 (5.0-6.0); bony interorbital width 3.2 (3.0-3.5); snout length 5.6 (5.6-6.2); upper jaw length (9.5-10.7); predorsal 17.0 (17.0-19.8); preanal 30.0 (30.0-35.3); prepelvic 12.8 (12.8-14.7); prepectoral 15.7 (14.5-17.7); pectoral length 8.8 (8.8-11.8). Relations: HL:HD = $1.90(1.79-1.98)$; HL to snout length 2.78 (2.74-2.96); preanal to predorsal 1.76 (1.61-1.80); predorsal to prepectoral 1.08 (1.06-1.12).

Slender fish with long tapering tail and long, pointed snout. Maximal size of fishes investigated $330 \mathrm{~mm}$ SL. Head long and slender, with straight or slightly convex dorsal profile, with strong spines as follows: ethmoidal (1), lacrimal (ridge with up to 4 spines), prefrontal (1), interorbital (2), supraorbital (1-2), sphenotic (3-4), 5th infraorbital (2-4), supratemporal (1), inner and outer posttemporal (4-5), inner preopercular rim (5, the upper 3 being the most prominent); no spines along outer preopercular rim. Opercle with sharp, strong, extruding spine. Eye moderately small located in strongly asymmetric orbit. Maxilla extending far beyond eye, strongly widened posteriorly and with distinct supramaxilla. Infra-/postorbital and mandibular-preopercular pores wide, several pores on occiput along inner edges of temporal and sphenotic spines. Head squamation on opercle, cheeks and occiput, rear portion of maxilla and in front of eyes and extending partly on snout. Opercle with three distinct large neuromasts behind preopercular edge; opercular flap large, with radial ridges along lower margin, rear part of opercle may be without scales. All three lateral line rows well visible. Upper lateral line row with 8-10 pores; lower lateral line row with 16-19 pores until beginning of anal fin; central lateral line row long, lower and central lateral line rows fading behind beginning of anal fin.

Dentition. All teeth tiny and cone-shaped. Vomer with a V-shaped dentition patch with 1-3 (rarely 4) rows of teeth anteriorly; palatines with a long and moderately wide dentition patch with 4-9 rows. Premaxilla tooth patches 
not fused anteriorly; ca. seven teeth rows anteriorly and 2-3 rows posteriorly. Dentary tooth patches not fused anteriorly; ca. five teeth rows anteriorly and 1-2 rows posteriorly. Median basibranchial tooth patch long and wide.

Otolith morphology $(n=7)$. Size up to $3.65 \mathrm{~mm}$ in length (holotype); $\mathrm{OL}: \mathrm{OH}=1.05-1.5$, increasing with size $(1.05-1.2$ in specimens $<200 \mathrm{~mm}$ SL, $1.3-1.5$ in specimens $>200 \mathrm{~mm} \mathrm{SL})$; OH:OT $=2.4-3.6$. Thin, oval, moderately elongate otolith, anteriorly rounded, posteriorly slightly pointed or rounded. Dorsal rim with obtuse predorsal angle; ventral rim regularly curving. All rims smooth. Inner face nearly flat, smooth, with short, centrally positioned sulcus; OL:TCL $=2.1-2.45$. Sulcus with shallow, undivided, rather uniform colliculum showing ventral indentation towards posterior tip marking ostial-caudal joint. Dorsal field with broad, indistinct depression; ventral field with broad, half moon shaped ventral furrow. Outer face smooth, with moderate central umbo.
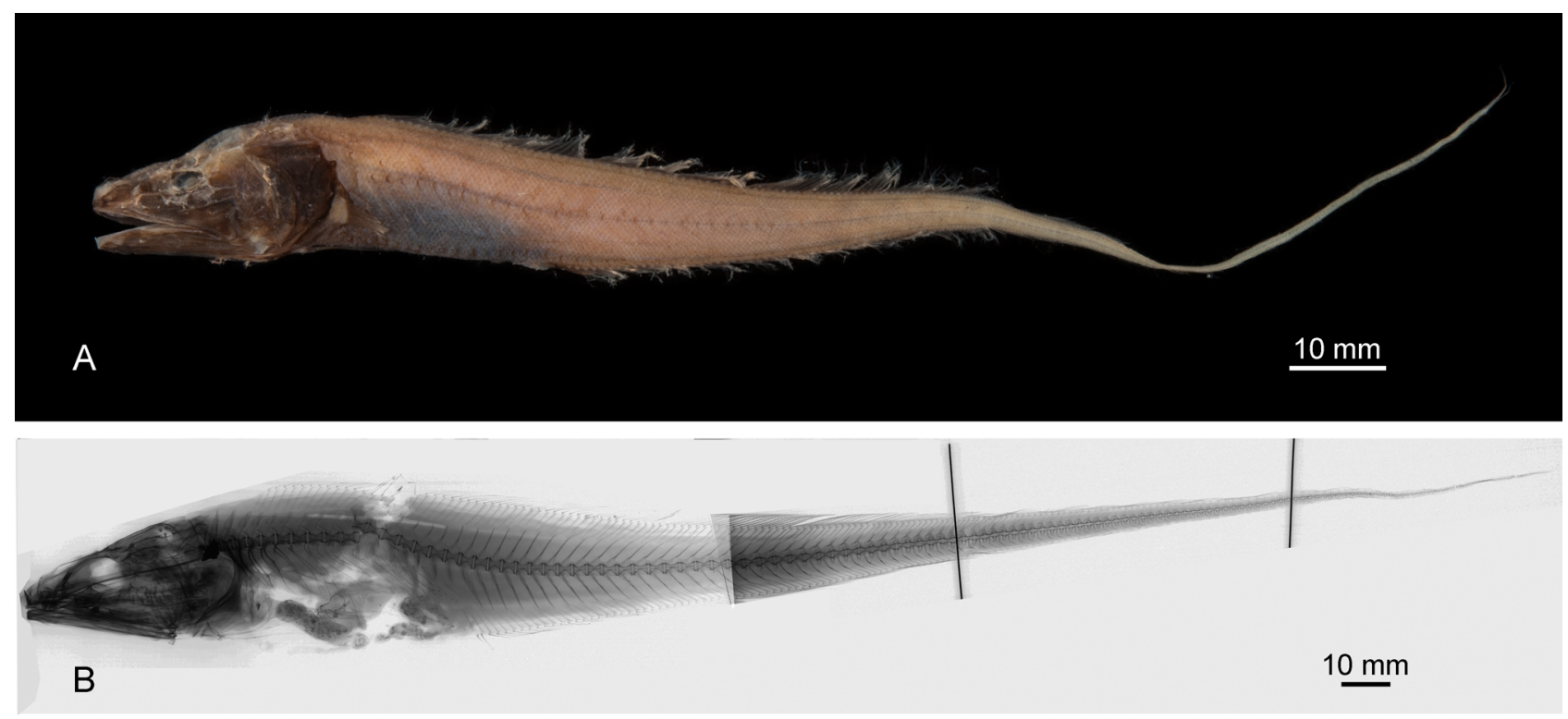

B

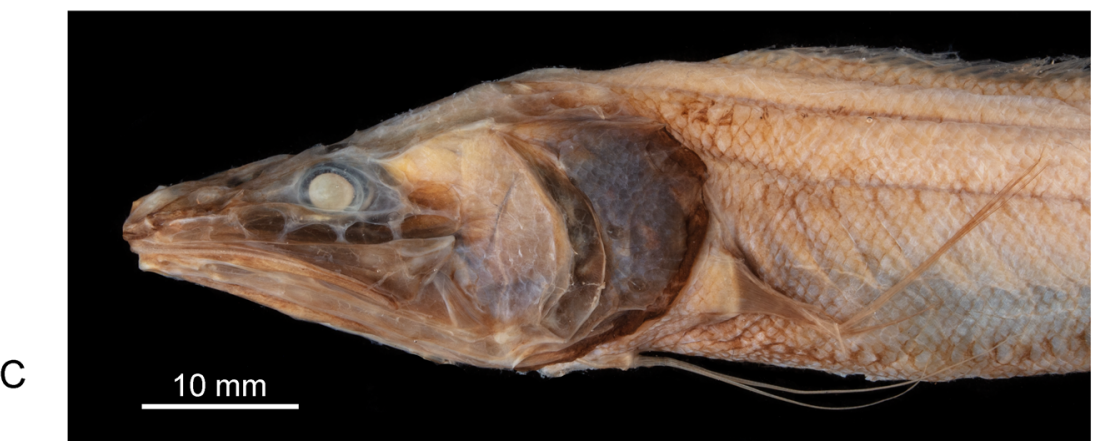

FIGURE 9. Porogadus caboverdensis n. sp.; 9A, BMNH 1995.11.22.1, paratype, 160 mm SL 2055' N, 31 ${ }^{\circ} 11^{\prime} \mathrm{W}, 4500-4610$

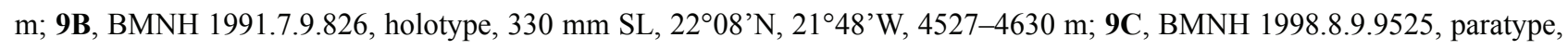
$225 \mathrm{~mm} \mathrm{SL}, 20^{\circ} 08^{\prime} \mathrm{N}, 24^{\circ} 49^{\prime} \mathrm{W}, 4500-4600 \mathrm{~m}$.

Coloration. Live coloration not known. Color of preserved specimens medium brown; head and belly darker than body, particularly opercle.

Discussion. Porogadus caboverdensis is a typical member of the Porogadus miles Group and resembles $P$. miles, P. longiceps, $P$. mendax n. sp., $P$. dracocephalus n. sp., and $P$. turgidus $\mathbf{n}$. sp. in the long and slender head (HL:HD >1.75) and the many and intense spines on the head. It differs from P. miles, P. longiceps and P. mendax in the lower number of lower lateral line pores until the beginning of the anal fin (16-19 vs 21-26), the narrow dentition on the vomer (1-3 rows, rarely 4 vs 3-7 rows, rarely 2$)$ and the compressed otolith (OL:OH $=1.05-1.5$ vs 1.7-2.0, rarely 1.6). Porogadus caboverdensis differ from $P$. turgidus in the narrow vomer (1-3, rarely 4 rows of teeth vs 4-7 rows) and in the single, uniform colliculum in the sulcus (vs separated colliculi). From $P$. dracocephalus it differs in the wide palatines with 4-9 rows of teeth (vs 2-5 rows), the mostly higher preanal ratio (30.0-35.3 vs $28.6-30.6 \%$ of SL) and the higher ratio OL:TCL of $>2.1$ (vs $<2.0)$.

Distribution. Porogadus caboverdensis is a deep-water species that has only been caught below $4480 \mathrm{~m}$ in the Cape Verde Basin off northwestern Africa, where it occurs together with two other deep-water species, i.e., $P$. 
mendax and P. turgidus.

Etymology. Named after the deep water Cape Verde Basin (Cabo Verde in local Portuguese language), from where this species so far is exclusively recorded.
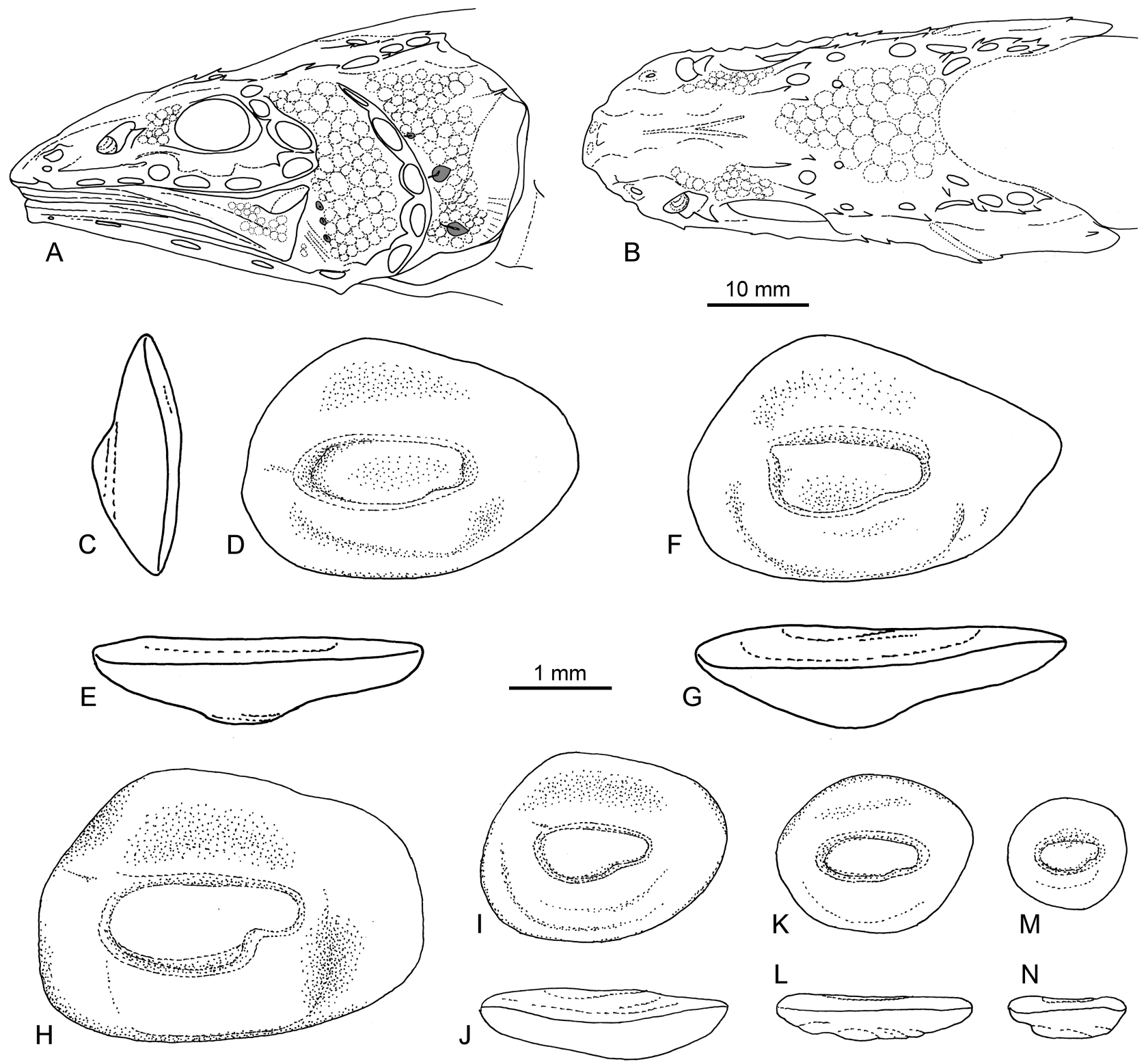

FIGURE 10. Porogadus caboverdensis n. sp.; 10A-B, BMNH 1991.7.9.826, holotype, $330 \mathrm{~mm} \mathrm{SL}, 22^{\circ} 08^{\prime} \mathrm{N}, 2^{\circ} 48^{\prime} \mathrm{W}$, 4527-4630 m, head drawings; 10C-E, BMNH 1995.11.22.3, paratype, $258 \mathrm{~mm} \mathrm{SL}, 20^{\circ} 55^{\prime} \mathrm{N}, 31^{\circ} 11^{\prime} \mathrm{W}, 4500-4610 \mathrm{~m}$, otolith (C anterior view, D inner face, E ventral view); 10F-G, BMNH 1991.7.9-826, holotype, $330 \mathrm{~mm} \mathrm{SL}, 22^{\circ} 08^{\prime} \mathrm{N}, 21^{\circ} 48^{\prime} \mathrm{W}$, 4527-4630 m, otolith (F inner face, G ventral view); 10H, BMNH 1995.11.22.12, $290 \mathrm{~mm}$ SL, 20 ${ }^{\circ} 53^{\prime} \mathrm{N}, 31^{\circ} 13^{\prime} \mathrm{W}, 4480-4565$

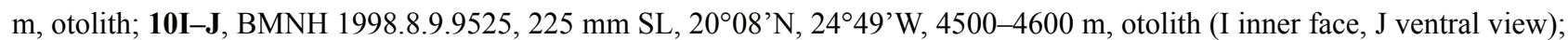
10K-L, BMNH 1995.11.22.13, 165 mm SL, 20 ${ }^{\circ} 53^{\prime} \mathrm{N}, 31^{\circ} 13^{\prime} \mathrm{W}, 4480-4565 \mathrm{~m}$, otolith (K inner face, L ventral view); 10M-N, BMNH 1995.11.22.14, $122 \mathrm{~mm} \mathrm{SL}, 20^{\circ} 53^{\prime} \mathrm{N}, 31^{\circ} 13^{\prime} \mathrm{W}, 4480-4565 \mathrm{~m}$, otolith (M inner face, $\mathrm{N}$ ventral view).

\section{Porogadus dracocephalus n. sp.}

Figs. 3, 11-12, 44, 49, Tab. 1-7

Porogadus trichiurus (not Alcock, 1890): Norman 1939: 77.

?Porogadus miles (not Goode \& Bean, 1885): Machida \& Amaoka 1990: 66, fig. 3. 
Material examined (8 specimens): Holotype: MNHN 2002-3875, $144 \mathrm{~mm}$ SL, 0900'S 159 49' E, 1169-1203 m, Solomon 1 expedition, Sta. cpl1754, 26 September 2001; paratypes: BMNH 1939.5.24.1453, $131 \mathrm{~mm}$ SL, John Murray Expedition station 1933-34, sta. 26, Gulf of Aden, $12^{\circ} 29^{\prime} \mathrm{N} 50^{\circ} 51^{\prime} \mathrm{E}, 2312 \mathrm{~m}, 11$ October 1933; BMNH

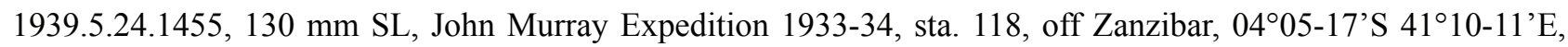

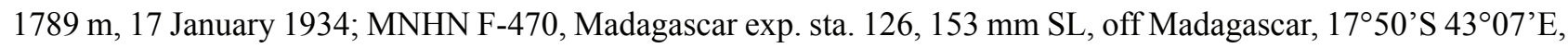
1475-1530 m, collected by Dr. A. Crosnier, 16 January 1975; MNHN 2021-0161 (ex MNHN 2002-3875), 122+ mm SL,same data as for Holotype; NSMT-P 63890, 133 mm SL, Okinawa Trough, 25⒉ $5^{\prime} \mathrm{N} 124^{\circ} 57^{`} \mathrm{E}, 2133 \mathrm{~m}, 3$ m ORE Beam Trawl, 25 April 2002; NSMT-P 98894, 320 mm SL, collected by S. Kojima, 4 m ORE Beam Trawl, North slope of Ryukyu Trench, 24 $4^{\circ} 1^{\prime} \mathrm{N} 127^{\circ} 25^{\prime} \mathrm{E}, 4466-4634 \mathrm{~m}, 18$ May 2005; tentatively assigned specimen: BMNH 1939.5.24.1454, 177 mm SL, John Murray Expedition 1933-34, sta. 62, Arabian Sea, 2253-56’N 6456’E, 1893 m, 18 November 1933.

Diagnosis. Precaudal vertebrae 17-18; long gill rakers on first gill arch 13-15; HL:HD 1.97-2.08; distance of pelvic base to beginning of anal fin 0.72-0.98 times head length; all head spines strong, present on ethmoidal, lacrimal, prefrontal, interorbital, supraorbital, sphenotic, 5th infraorbital, supratemporal, inner and outer posttemporal, inner and outer preopercular rims; opercular spine sharp, strong, extruding; maxilla without scales or a single line of scales along upper margin; lower lateral line pores until beginning of anal fin 19-21; vomer with narrow dentition patch (1-2 rows of teeth); palatines with narrow dentition patch ( $2-5$ rows of teeth); otolith with single, uniform colliculum; $\mathrm{OL}: \mathrm{OH}=1.4-1.5 ; \mathrm{OL}: \mathrm{TCL}=1.9-2.0$.

Description. Meristics: precaudal vertebrae $18(17-18), 1(0-1)$ last vertebrae without ribs; pectoral-fin rays 18 (16-18); $\mathrm{D} / \mathrm{V}=5$ (5-7); $\mathrm{D} / \mathrm{A}=24$ (24-28); $\mathrm{V} / \mathrm{A}=18$ (17-20); long gill rakers on first lower gill arch 13 (13-15, 19 in tentatively assigned specimen). Gill rakers in holotype on lower first gill arch with seven plate-shaped rakers, followed by a series of 13 long rakers. The lower five of those intercepted by single plate shaped rakers. Upper gill arch with a plate shaped rakers followed by three short rakers intercepted by plate shaped rakers and then additional two plate shaped rakers.

Morphometrics: in \% of SL: HL 16.5 (16.5-17.6); maximal HD 8.3 (8.1-8.9); HD through center of eye 5.7 (5.2-5.7); bony interorbital width 4.3 (3.4-4.3); snout length 5.5 (5.5-5.9); upper jaw length 9.5 (9.5-10.1); predorsal 16.5 (16.5-18.2); preanal 28.6 (28.6-30.6); prepelvic 13.1 (13.1-14.9); prepectoral 17.2 (16.1-17.8); pectoral length $(9.0-10.1)$. Relations: HL:HD $=1.97(1.97-2.08)$; HL to snout length 3.01 (2.87-3.02); preanal to predorsal 1.73 (1.60-1.76); predorsal to prepectoral $0.96(0.96-1.08)$.

Slender fish with long tapering tail and long, pointed snout. Maximal size of fishes investigated $320 \mathrm{~mm}$ SL. Head long and very slender, with flat dorsal profile, with strong spines as follows: ethmoidal (1), lacrimal (1-3 spines, increasing with fish size), prefrontal (1), interorbital (3), supraorbital (2-3), sphenotic (3-4), 5th infraorbital (1-3), supratemporal (2), inner and outer posttemporal (4-5), inner preopercular rim (3-4), outer preopercular rim (1-4, variable in strength). Opercle with sharp, strong, extruding spine. Eye small located in strongly asymmetric orbit. Maxilla extending far beyond eye, strongly widened posteriorly and with distinct supramaxilla. Infra-/postorbital and mandibular-preopercular pores wide, no or up to 2 pores on occiput along inner edges of temporal spines. Head squamation on opercle, cheeks, occiput, frontal, snout, and in front of eyes, maxilla without scales or, in the largest specimen (Fig. 12A) with single, short row of scales along upper margin of maxilla in front of supramaxilla. The largest specimen (NSMT 98894) is remarkable for a complete preservation of body scales, which were used for Fig. 3. Opercle with two to three distinct large neuromasts behind preopercular edge; opercular flap small, with few radial ridges along lower margin in largest specimen. All three lateral line rows well visible. Upper lateral line row with 10-13 pores; lower lateral line row with 18-21 pores until beginning of anal fin; central lateral line row long, lower and central lateral line rows fading behind beginning of anal fin.

Dentition. All teeth tiny and cone-shaped. Vomer with a v-shaped dentition patch with 1-2 rows of teeth anteriorly; palatines with a long and narrow patch with 2-5 rows of teeth in the middle part. Premaxilla tooth patches not fused anteriorly; ca. 4 teeth rows anteriorly and 1-2 rows posteriorly. Dentary tooth patches not fused anteriorly; ca. 3 teeth rows anteriorly and 1-2 rows posteriorly. Median basibranchial tooth patch short, moderately wide, in one case with pair of tiny lateral tooth patches.

Otolith morphology $(\mathrm{n}=2$ ). Size up to $4.35 \mathrm{~mm}$ in length (NSMT 98894); OL:OH =1.4-1.5; OH:OT c.2.6. Thin, oval, moderately elongate otolith, anteriorly and posteriorly rounded. Dorsal and ventral rims regularly curving. All rims smooth. Inner face nearly flat, smooth, with short, centrally positioned sulcus; OL:TCL = 1.9-2.0. Sulcus with shallow, undivided, uniform, oval colliculum. Dorsal field with broad, indistinct depression; ventral 
field with faint ventral furrow. Outer face smooth, with weak central umbo.

Coloration. Live coloration not known. Color of preserved specimens medium to reddish brown; head slightly darker than body, opercle distinctly darker.
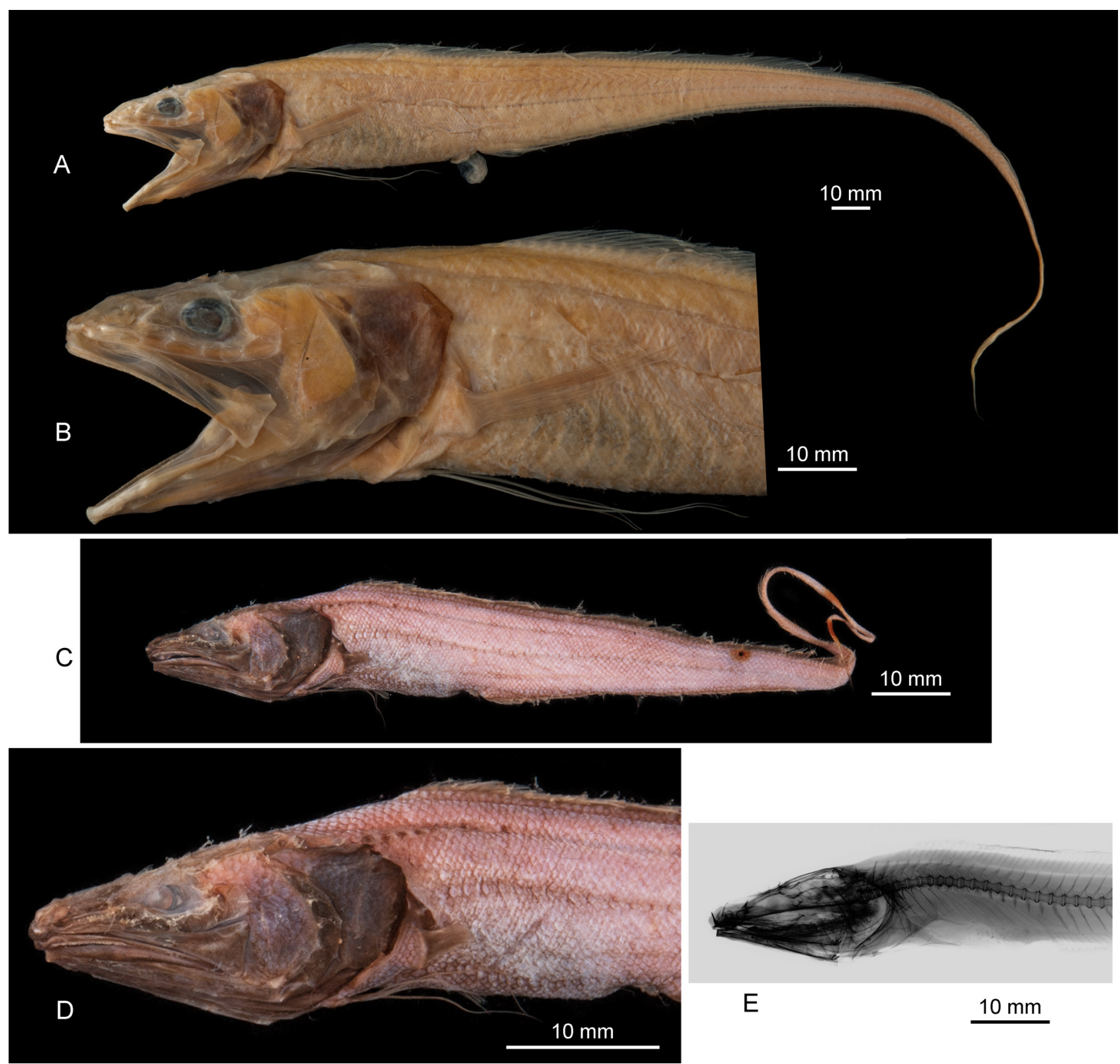

$\mathrm{E}$

$10 \mathrm{~mm}$

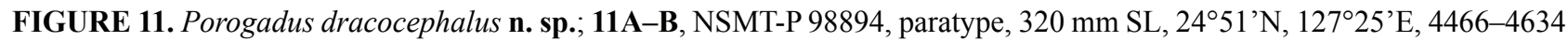
m; 11C-E, MNHN 2002-3875, holotype, 144 mm SL, 0900’S 15949’E, 1169-1203 m.

Discussion. Porogadus dracocephalus is similar to P. miles with which it may geographically overlap off Japan and elsewhere in the western Pacific. A single specimen from the John Murray Expedition from the Arabian Sea (BMNH 1939.5.24.1454) is only tentatively placed in P. dracocephalus because of its unusually high number of long rakers on the first gill arch (19 vs 13-15), which nevertheless could be just within the expected range of variability. In all other characters, this specimen resembles the type-series well. A single large specimen from the Ryukyu Trench of southern Japan (NSMT-P 98894) differs from the other type specimens in the larger size (320 $\mathrm{mm}$ SL vs 130-170 $\mathrm{mm} \mathrm{SL}$ ) and the complete preservation of body squamation. It thus represents a rare instance where head and body squamation can be studied in full extend. Unfortunately, it has an open mouth which prohibits certain measurements, e.g., head length and predorsal and preanal lengths. However, the spines on the head, the restricted squamation on the maxilla, the number of lower lateral line pores, vomer and palatine dentition and last but not least the otolith morphology confirms the attribution to $P$. dracocephalus. In this respect it needs to be noted 
that not all specimens of P. miles recorded from off Japan by Machida \& Amaoka (1990) were available for review, in particular not the southernmost specimen from the Ryukyu back arch basin (ZUMT 54316) and the unusual deep catch of ZUMT 54315. The very detailed head drawing of ZUMT 54316 shows complete squamation on cheeks, opercle and top of head, but no scales on the maxilla, which would be consistent with $P$. dracocephalus but not $P$. miles. It is therefore possible that Machida \& Amaoka (1990) also contain records of $P$. dracocephalus which were then regarded as representatives of $P$. miles.

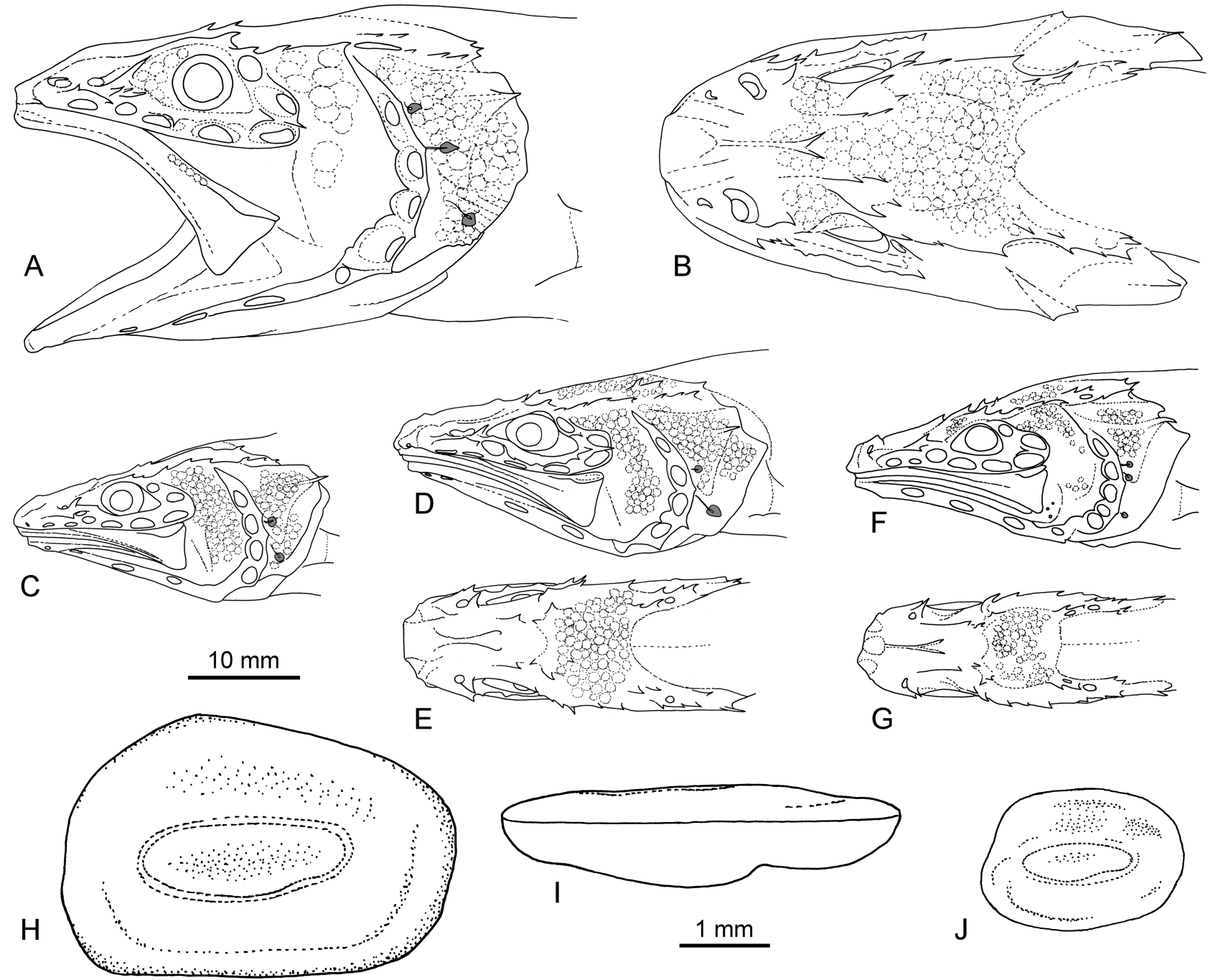

FIGURE 12. Porogadus dracocephalus n. sp.; 12A-B, NSMT-P 98894, paratype, $320 \mathrm{~mm}$ SL, 245' 'N, $127^{\circ} 25^{\prime} \mathrm{E}$, 4466$4634 \mathrm{~m}$, head drawing; 12C, BMNH 1939.5.24.1453, paratype, $131 \mathrm{~mm} \mathrm{SL}, 12^{\circ} 29^{\prime} \mathrm{N}, 50^{\circ} 51^{\prime} \mathrm{E}, 2312 \mathrm{~m}$, head drawing; 12D-E, MNHN 2002-3875, holotype, 144 mm SL, 0900'S 15949'E, 1169-1203 m, head drawing; 12F-G, NSMT-P 63890, paratype,

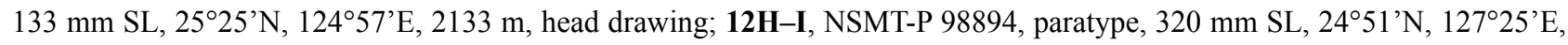
4466-4634 m, otolith (H inner face, I ventral view); 12J, BMNH 1939.5.24.1453, paratype, $131 \mathrm{~mm} \mathrm{SL}, 1^{\circ} 29^{\prime} \mathrm{N}, 50^{\circ} 51^{\prime} \mathrm{E}$, $2312 \mathrm{~m}$, otolith (inner face).

Porogadus dracocephalus differs from all other species of Porogadus in the distance from the pelvic fin base to the beginning of the anal fin being shorter than the head length (ratio 0.72-0.98) whereas it is of equal or considerable larger length in all other species (ratio 0.98-1.31). However, this is often a difficult character to reliably measure, particularly in fishes with open mouth. The external differences of $P$. dracocephalus to $P$. miles are all subtle or overlapping, e.g., number of lower lateral pores until beginning of anal fin 18-21 (vs 23-26), pectoral-fin rays $16-18$ (vs 18-21), preanal $28.6-30.6 \%$ of SL (vs 30.0-36.0), vomer with 1-2 rows of teeth (vs 2-5 rows), and palatines with $2-5$ rows of teeth (vs $>5$ rows). The most reliable and secure character for distinction therefore is the otolith, when preserved, which in $P$. dracocephalus is relatively compressed (OL:OH $=1.4-1.5)$ and bears a short, undivided colliculum while in $P$. miles it is more elongate $(\mathrm{OL}: \mathrm{OH}=1.55-1.9)$ and always shows two, clearly 
separated ostial and caudal colliculi. Porogadus dracocephalus differs from P. longiceps and P. mendax n. sp. in the lower number of lower lateral pores until the beginning of the anal fin of 18-21 (vs 22-24), the preanal length (28.6-30.6 \% of SL vs 30.6-37.0\%), the narrow vomer with 1-2 rows of teeth (vs wide with 3-9 rows, rarely 2 rows in specimens of $P$. longiceps $<150 \mathrm{~mm} \mathrm{SL}$ ), the narrow palatines (2-5 rows of teeth vs 5-11 rows, except 2-5 in specimens of $P$. longiceps $<260 \mathrm{~mm} \mathrm{SL}$ ). From $P$. longiceps it differs additionally in the otolith showing a uniform colliculum (vs two separate colliculi or at least a v-shaped indentation at the collum). Porogadus dracocephalus differs from P. trugidus in the dentition of the vomer (narrow with 1-2 rows of teeth vs wide with 4-5 rows) and the palatines (2-5 rows of teeth vs 5-6 rows), the more intense spines along the inner and outer rims of the preopercle, the reduced squamation on the maxilla (no scales or a single short row along the upper margin of the maxilla in front of the supramaxilla vs rear part of the maxilla with many scales represented as scale pockets in the specimens studied), and the sulcus of the otolith with a single, undivided colliculum (vs two distinctly separated ostial and caudal colliculi). For distinction from $P$. caboverdensis see above.

Distribution. Porogadus dracocephalus is widely distributed in the Indian Ocean from the Arabian Sea to the Mozambique Channel, but further south is replaced by P. miles. There are no records (yet) from the eastern Indian Ocean. Several records from off southern Japan (Ryukyu Chain) and off the Solomon Islands result in an apparent disjunctive distribution pattern. Porogadus dracocephalus may potentially overlap in geographic distribution with $P$. miles along the outer reaches of its distribution, particularly in the western Pacific. Most specimens studied of $P$. dracocephalus of sizes from 130-170 mm SL are from relatively shallow depths from about 1200 to $2300 \mathrm{~m}$. The only confirmed large specimen (320 mm SL; NSMT-P 98894) was caught significantly deeper at 4466-4634 m. This depth is deeper than any of the confirmed occurrences of $P$. miles and could indicate that $P$. dracocephalus is migrating into great depth when growing older.

Etymology. Name composed of draconis $($ Latin $)=$ dragon and cephalus $($ Latin $)=$ head, referring to the dragonhead shape of the heads of this species.

\section{Porogadus longiceps Garman, 1899}

Figs. 3, 13-14, 44, 49, Tab. 1-7

Porogadus longiceps Garman, 1899: 153, pl. F, fig. 2, pl. 76, fig. 1; Nielsen et al. 1999: 86; Castellanos-Galindo et al. 2006:199.

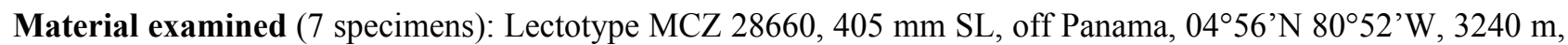
R/V Albatross, large beam trawl, 6 March 1891; paralectotypes: MCZ 28661, $258 \mathrm{~mm} \mathrm{SL}$, off Panama, $07^{\circ} 15^{\prime} \mathrm{N}$ 79³6’ W, $1865 \mathrm{~m}, \mathrm{R} / \mathrm{V}$ Albatross, large beam trawl, 10 March 1891; MCZ 28662, $130 \mathrm{~mm} \mathrm{SL}, 05^{\circ} 36^{\prime} \mathrm{N} 86^{\circ} 56^{\prime} \mathrm{W}$, 245 m, R/V Albatross, 28 February 1891; non-types: SIO 89-30, 476 mm SL, R/V Thomas Washington, sta. 69, dredge, collected by Mr. R. Comer, 10²0’N 10339’W, 2644 m, 29 February 1988; SIO 72-108-61, 410 mm SL, R/V Thomas Washington, $00^{\circ} 48^{\prime} \mathrm{N} 86^{\circ} 09^{\prime} \mathrm{W}$, caught at surface with dipnet, collected by Mr. M. Elston \& party, 26 June 1972; CAS (SU) 68833, 198 mm SL, 60 miles south of Isla del Coco, $04^{\circ} 50^{\prime} \mathrm{N} 87^{\circ} 00^{\prime} \mathrm{W}$, collected by William Beebe and John Tee-Van, no depth information, 30 May 1925; tentatively assigned specimen (syntype): MCZ 28659, 465 mm SL, off Panama, 06²1'N 8041’W, 3279 m, large beam trawl, 7 March 1891.

Diagnosis. Precaudal vertebrae 17-19; long gill rakers on lower first gill arch 11-13; pectoral-fin rays 19-22; HL:HD 1.81-2.08; head spines strong in small specimens, short and poorly extruding in large specimens, present on ethmoidal, lacrimal, prefrontal (weak), interorbital (weak), supraorbital (weak in large specimens), sphenotic, 5th infraorbital, supratemporal (absent in large specimens), inner and outer posttemporal (absent in large specimens), inner and outer preopercular rims (absent in large specimens); opercular spine sharp, strong, extruding; maxilla with no or few scales at rear; lower lateral line pores until beginning of anal fin 22-24; vomer with broad dentition patch (3-9 rows of teeth); palatines with broad dentition patch (2-11 rows of teeth); otolith with separate ostial and caudal colliculi indicated by ventral incision; $\mathrm{OL}: \mathrm{OH}=1.75-2.1 ; \mathrm{OL}: \mathrm{TCL}=1.8-1.9$.

Description. Meristics: precaudal vertebrae 19 (17-19), 1 (0-1) last vertebrae without ribs; pectoral-fin rays 20 (19-22, 17-18 in tentatively assigned specimen); $\mathrm{D} / \mathrm{V}=6$ (5-7); $\mathrm{D} / \mathrm{A}=28$ (25-28); $\mathrm{V} / \mathrm{A}=20$ (19-21); long gill rakers on lower gill arch 11 (11-13). Gill rakers in lectotype on lower first gill arch with eight plate-shaped rakers, followed by a series of 11 long rakers. The lower seven of those intercepted by single plate shaped rakers. Upper gill raker with a series of three plate shaped and three slightly longer rakers intercepted.

Morphometrics: in \% of SL: HL 17.5 (16.9-18.5); maximal HD 10.0 (8.1-10.1); HD through center of eye 
6.7 (5.3-6.7); bony interorbital width 3.7 (3.3-3.9); snout length 5.8 (5.2-6.9); upper jaw length 10.1 (9.8-11.0); predorsal 19.4 (17.7-19.4); preanal 33.5 (33.0-37.0); prepelvic 15.0 (14.2-16.3); prepectoral 19.0 (17.3-20.2); pectoral length 10.1 (9.7-11.4). Relations: $\mathrm{HL}: \mathrm{HD}=1.81(1.81-2.08,1.72$ in tentatively assigned specimen); HL to snout length 3.12 (2.93-3.52); preanal to predorsal 1.73 (1.73-2.01); predorsal to prepectoral 1.02 (0.97-1.11).

Slender fish with long tapering tail and long, pointed snout. Maximal size of fishes investigated $476 \mathrm{~mm}$ SL. Head long and slender, with flat dorsal profile, with strong spines in small specimens ( $<200 \mathrm{~mm} \mathrm{SL})$ and decreasing in length and strength or absent in large specimens (>400 mm SL) as follows: ethmoidal (1), lacrimal (ridge with 1 spine), prefrontal (1 weak), interorbital (2-3, weak in large specimens), supraorbital (2, absent in large specimens), sphenotic (2-3), 5th infraorbital (2), supratemporal (2, absent in large specimens), inner and outer posttemporal (3-5, 1 in large specimens), inner preopercular rim (3, none in large specimens), outer preopercular rim (3-4, absent in large specimens). Opercle with sharp, strong, extruding spine. Eye small located in strongly asymmetric orbit. Maxilla extending far beyond eye, strongly widened posteriorly and with distinct supramaxilla. Infra-/postorbital and mandibular-preopercular pores wide, 1 or 2 pores on occiput along inner edges of temporal spines. Head squamation on opercle, cheeks, occiput, frontal, snout (in small specimens), small scales in around eyes, maxilla without scales in large specimens, with small scales on rear part in small specimens. Opercle with one to three distinct large neuromasts behind preopercular edge; opercular flap very small, fully covered by scales, without radial ridges. All three lateral line rows well visible. The lectotype (MCZ 28660) is particularly remarkable for a good exposure of the lateral line pores, which is used for Fig. 3. Upper lateral line row with 10-11 pores (Garman 1899 figures many more pores); lower lateral line row with 22-24 pores until beginning of anal fin (22 in figure of Garman 1899); central lateral line row long, lower and central lateral line rows fading behind beginning of anal fin.

Dentition. All teeth tiny and cone-shaped or flattened. Vomer with a broad dentition patch with 5-9 rows of teeth anteriorly in specimens $>400 \mathrm{~mm} \mathrm{SL}$ and 3-4 rows in specimens $<250 \mathrm{~mm}$ SL; palatines with broad dentition patch with 7-11 rows of teeth throughout in specimens $>400 \mathrm{~mm}$ SL and 2-5 rows in specimens $<260 \mathrm{~mm}$ SL. Premaxilla tooth patches not fused anteriorly; up to 14 teeth rows anteriorly and 4-5 rows posteriorly. Dentary tooth patches not fused anteriorly; up to 10 teeth rows anteriorly and 3-4 rows posteriorly. Median basibranchial tooth patch long and wide.

Otolith morphology $(n=4)$. Size up to $7.2 \mathrm{~mm}$ in length (lectotype); OL:OH $=1.75-2.1(1.45$ in tentatively assigned specimen; Fig. 14H); OH:OT c.2.6. Thin, elongate otolith, anteriorly rounded, posteriorly slightly expanded. Dorsal with broadly rounded predorsal lobe, ventral rims regularly curving. All rims smooth. Inner face slightly convex, smooth, with moderately long, centrally positioned sulcus; $\mathrm{OL}: \mathrm{TCL}=1.8-1.9$. Sulcus with shallow, poorly divided colliculi (fused in tentatively assigned specimen; Fig. 14H), but separation into ostium and cauda always marked by indentation of ventral margin. Dorsal and ventral fields rather smooth. Outer face smooth, with weak central umbo.

Coloration. Live coloration not known. Color of preserved specimens medium to reddish brown; head slightly darker than body, opercle distinctly darker.

Variability and ontogeny. A large syntype (MCZ 28659) is only tentatively placed in P. longiceps because it somewhat differs from the other specimens in the shorter head expressed in a lower HL:HD ratio of 1.72 (vs 1.81-2.08), the lower number of pectoral-fin rays (17-18 vs 19-22), and the compressed, rather thick otolith (OL: $\mathrm{OH}=1.45$ vs $1.75-2.1$ ) with fused colliculi and no predorsal lobe (Fig. 14H-J). MCZ 28659 is a large specimen and it is possible that all the observed differences may still fall within the variability of $P$. longiceps but this would considerably stretch the diagnosis. It is also possible that some of the differences represent pathological deformations, for instance in the otolith morphology. In any case and before further specimens have become available for study we consider MCZ 28659 as tentatively assigned only.

Porogadus longiceps is also known for a distinctive and large degree of late ontogenetic changes. Garman (1899) noted that small specimens had much more intense spines on the head than large ones even to the extent that some spines totally disappear in large specimens. We confirm Garman's observation (see above description of spines) and further observe that the otolith of small specimen of $258 \mathrm{~mm}$ SL (MCZ 28661; not figured) is considerably more elongate than those of the larger specimens (MCZ 28660 and SIO 89-30; Figs. 14E-G) (OL:OH 2.1 vs 1.75-1.85). Other aspects affected in late ontogeny are the rows of teeth on vomer, palatines and premaxilla. Specimens larger than $400 \mathrm{~mm}$ SL have 5-9 rows of teeth on the vomer, 7-11 rows on the palatines and 11-14 rows on the premaxilla, while specimens smaller than $260 \mathrm{~mm}$ SL show 2-4 rows of teeth on the vomer, 2-5 rows on the palatines and 4-8 rows on the premaxilla. The number of teeth on the dentary ranges from 3 to 10 rows of teeth 

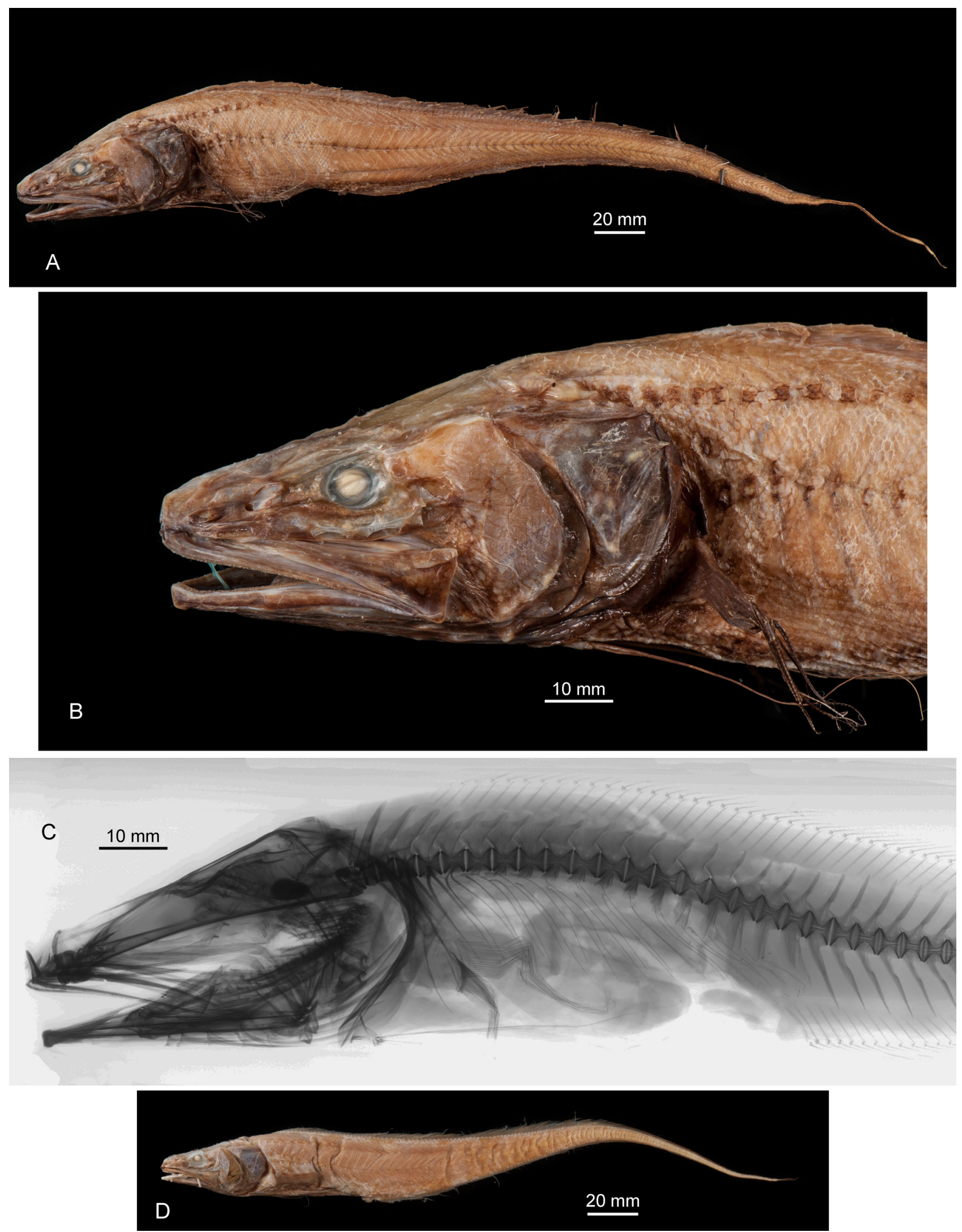

FIGURE 13. Porogadus longiceps Garman, 1899; 13A-C, MCZ 28660, lectotype, $405 \mathrm{~mm} \mathrm{SL}, 04^{\circ} 56^{\prime} \mathrm{N}, 80^{\circ} 52^{\prime} \mathrm{W}, 3240 \mathrm{~m}$; 13D, MCZ 28661, paralectotype, $258 \mathrm{~mm} \mathrm{SL}, 07^{\circ} 15^{\prime} \mathrm{N}, 79^{\circ} 36^{\prime} \mathrm{W}, 1865 \mathrm{~m}$. 


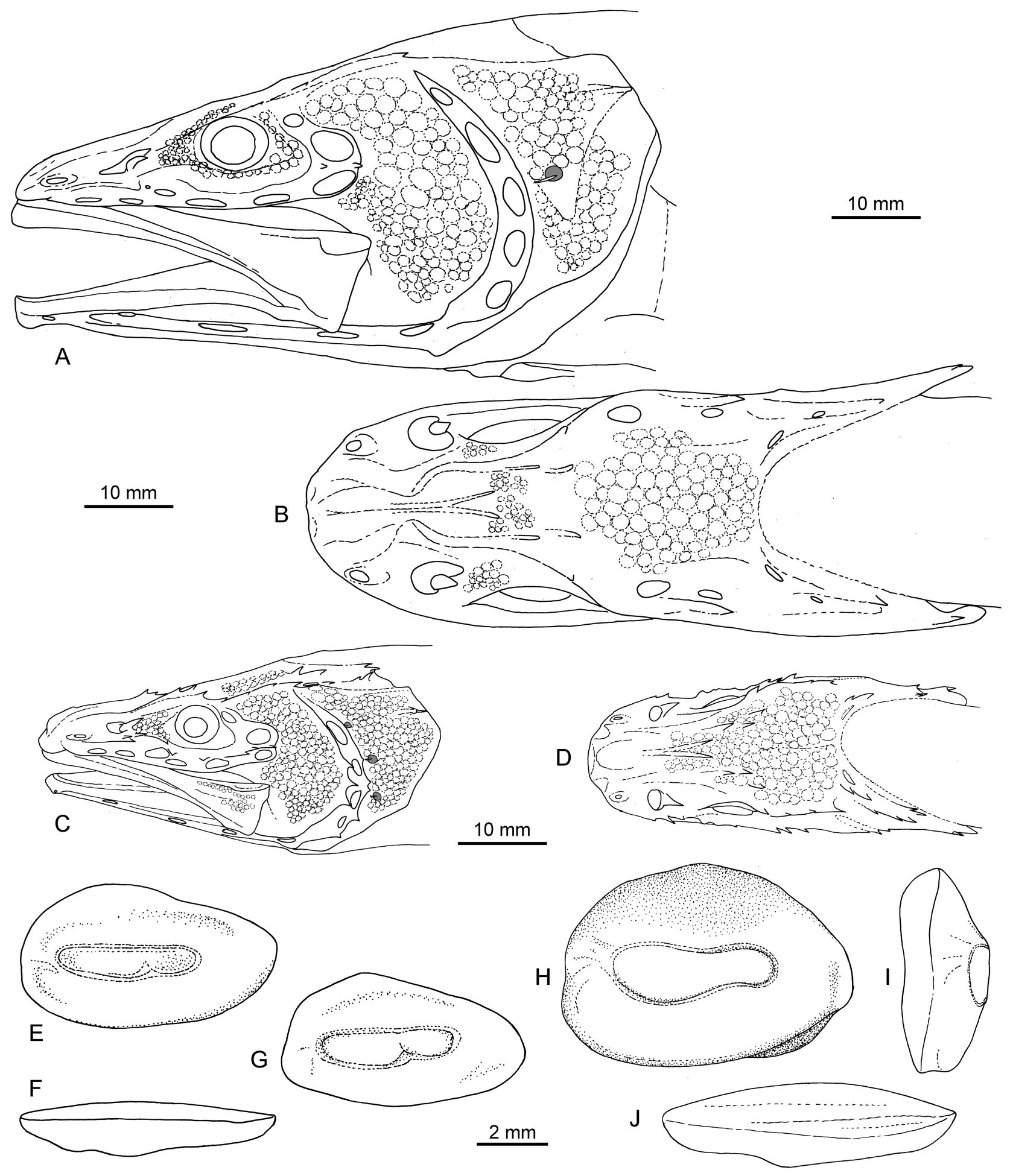

FIGURE 14. Porogadus longiceps Garman, 1899; 14A-B, MCZ 28660, lectotype, $405 \mathrm{~mm}$ SL, 045ㅇN, $80^{\circ} 52^{\prime} \mathrm{W}, 3240$ $\mathrm{m}$, head drawing; 14C-D, MCZ 28661, paralectotype, $258 \mathrm{~mm} \mathrm{SL}, 07^{\circ} 15^{\prime} \mathrm{N}, 7^{\circ} 36^{\prime} \mathrm{W}, 1865 \mathrm{~m}$, head drawing; 14E-F, MCZ 28660, lectotype, $405 \mathrm{~mm} \mathrm{SL}, 04^{\circ} 56^{\prime} \mathrm{N}, 80^{\circ} 52^{\prime} \mathrm{W}, 3240 \mathrm{~m}$, otolith (E inner face, F ventral view); 14G, SIO 89-30, 476 mm SL, $10^{\circ} 20^{\prime} \mathrm{N}, 103^{\circ} 39^{\prime} \mathrm{W}, 2644 \mathrm{~m}$, otolith (inner face); 14H-J, MCZ 28659, tentatively assigned specimen (syntype), $465 \mathrm{~mm}$ SL $06^{\circ} 21^{\prime} \mathrm{N}, 80^{\circ} 41^{\prime} \mathrm{W}, 3279 \mathrm{~m}$, otolith (H inner face, I anterior view, J ventral view). 
and also appears to be increasing with size, but with a less clear trend. No comparable late ontogenetic changes have been observed in any of the other Porogadus species including the similarly large growing $P$. miles.

Discussion. MCZ 28660 was selected as lectotype on the basis that it is the best preserved of the large syntypes and that it likely represents the specimen figured by Garman (1899; plate F, Fig. 2). Porogadus longiceps is the largest growing species of all Porogadus species together with P. miles and is very similar to P. miles differing mainly in the lower number of long gill rakers (11-13 vs 14-18) and the reduced intensity of spines on the head in large specimens. It differs from all other species of the Porogadus miles Group except P. mendax n. sp. and $P$. miles in the higher number of lower lateral line pores until the beginning of the anal fin (22-24 vs 16-21) and, except $P$. turgidus in the distinction of ostium and cauda of the sulcus. From P. mendax it differs further in the small opercular flap without ridges (vs large with ridges) and from P. turgidus further in the predorsal length (17.7-19.4 vs 15.7) and the preanal length (33.0-37.0 vs 29.6-30.5). We assume that $P$. longiceps has derived from a stock of the widespread $P$. miles that became isolated in the tropical eastern Pacific at some time.

Distribution. Porogadus longiceps is geographically restricted to a relatively small area off the tropical eastern Pacific chiefly between $10^{\circ} \mathrm{N}$ and the equator, and ventures out for about $800 \mathrm{~km}$ from the continental break. It occurs at depth primarily between 1800 and $3300 \mathrm{~m}$ but two specimens are caught in very shallow water at $245 \mathrm{~m}$ or near the surface. No other species of Porogadus has been caught substantially shallower than $1000 \mathrm{~m}$. The reason for the unusual shallow catches of this otherwise deep dwelling species are not known.

\section{Porogadus mendax n. sp.}

Figs. 15-16, 44, 49, Tab. 1-7

Material examined ( 2 specimens): Holotype BMNH 1996.2.14.31, 290+ $\mathrm{mm}$ SL, $31^{\circ} 18^{\prime} \mathrm{N} 16^{\circ} 47^{\prime} \mathrm{W}, 4435-4457$ m, R.R.S. Discovery Cruise semi-balloon otter trawl, 07 October 1995, collected by N. Merrett; paratype BMNH 1995.11.22.4, $287 \mathrm{~mm} \mathrm{SL}, 20^{\circ} 55^{\prime} \mathrm{N} 31^{\circ} 11^{\prime} \mathrm{W}, 4500-4610$ m, R.R.S. Discovery Cruise semi-balloon otter trawl, 16 October 1993, collected by N. Merrett.

Diagnosis. Precaudal vertebrae 18; long gill rakers on first gill arch 13-14; HL:HD 1.89-1.92; all head spines strong, present on ethmoidal, lacrimal, prefrontal, interorbital, supraorbital, sphenotic, 5th infraorbital, supratemporal, inner and outer posttemporal, inner and outer preopercular rims; opercular spine sharp, strong, extruding; additional (3rd) postorbital pore, many cavities and/or pores on top of head; maxilla without scales; large opercular flap with ridges; lower lateral line pores until beginning of anal fin 22-23; vomer with broad dentition patch (5-7 rows of teeth); palatines with broad dentition patch (9 rows of teeth); otolith with single, uniform colliculum; OL: $\mathrm{OH}=1.85-2.05 ; \mathrm{OL}: \mathrm{TCL}=2.15-2.3$.

Description. Meristics: precaudal vertebrae 18 (18), 1 (1) last vertebrae without ribs; pectoral-fin rays 18 (18); $\mathrm{D} / \mathrm{V}=5$ (5); $\mathrm{D} / \mathrm{A}=24$ (24-25); $\mathrm{V} / \mathrm{A}=19$ (19); long gill rakers on first gill arch 13 (13-14). Gill rakers in Holotype on lower first gill arch with nine plate-shaped rakers, followed by a series of 13 long rakers. The lower seven of those intercepted by single plate shaped rakers. Upper gill raker with a series of two plate shaped and three slightly longer rakers intercepted, followed by two slightly longer rakers and two short rakers.

Morphometrics: in \% of SL: HL 15.5 (15.5-15.7); maximal HD 8.1 (8.1-8.3); HD through center of eye 5.1 (5.1-5.7); bony interorbital width 2.7 (2.7); snout length 4.7 (4.7-5.3); upper jaw length 8.6 (8.5-8.6); predorsal 17.8 (17.4-17.8); preanal 31.1 (30.6-31.1); prepelvic 12.5 (12.5-13.0); prepectoral 15.8 (15.8-16.3); pectoral length $10.2(10.1-10.2)$. Relations: HL:HD = $1.92(1.89-1.92)$; HL to snout length 3.29 (2.96-3.29); preanal to predorsal 1.75 (1.75-1.76); predorsal to prepectoral $1.13(1.06-1.13)$.

Slender fish with long tapering tail and long, pointed snout. Maximal size of fishes investigated 290+ mm SL. Head long and slender, with slightly concave dorsal profile, with strong spines as follows: ethmoidal (1), lacrimal (ridge with 1 spine or up to 4 individual spines), prefrontal (1), interorbital (3), supraorbital (1-2), sphenotic (2-3), 5th infraorbital (2), supratemporal (1-2), inner and outer posttemporal (3-4), inner preopercular rim (3-5), outer preopercular rim (1-3, variable in strength). Opercle with sharp, strong, extruding spine. Eye small located in strongly asymmetric orbit. Maxilla extending far beyond eye, strongly widened posteriorly and with distinct supramaxilla. Infra-/postorbital and mandibular-preopercular pores wide, postorbital with 3 pores, the 3rd uppermost one being small, head top with 3 pores on occiput along inner edges of temporal spines in front of nape and cavernous system extending between squamation of occiput and sphenotic and supraorbital spines and thin skin cover apparently eas- 
ily affected by fish recovery and then giving impression of open pores (Fig. 16D). Head squamation on opercle, cheeks, occiput, frontal, and in front of and above eyes, area behind eyes, snout and maxilla without scales. Opercle with two to three distinct large neuromasts behind preopercular edge; opercular flap very large, with radial ridges along lower margin. All three lateral line rows reasonably well visible. Upper lateral line row with 7-8 pores; lower lateral line row with 22-23 pores until beginning of anal fin; central lateral line row long, lower and central lateral line rows fading behind beginning of anal fin.
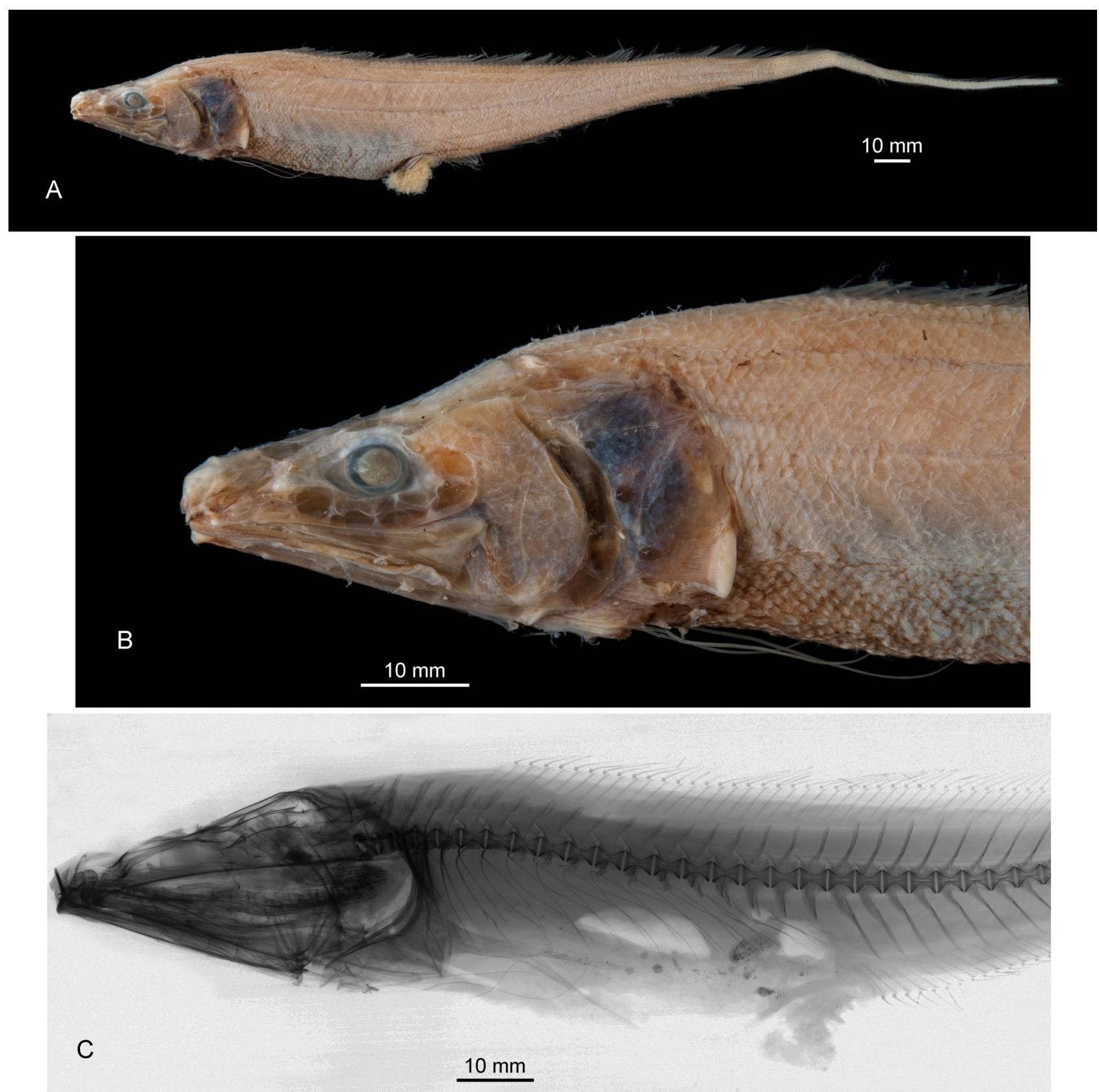

FIGURE 15. Porogadus mendax n. sp., BMNH 1996.2.14.31, holotype, 290+ mm SL, 31¹8’ N, 16²47’W, $4435-4457$ m.

Dentition. All teeth tiny and cone-shaped or flattened. Vomer with a broad dentition patch with 5-7 rows of teeth; palatines with wide dentition patches with nine rows of teeth. Premaxilla tooth patches, narrow, not fused anteriorly; ca. eight teeth rows anteriorly and very narrow with 1-2 rows posteriorly. Dentary tooth patches not fused anteriorly; ca. 5 teeth rows anteriorly and 1-2 rows posteriorly. Median basibranchial tooth patch short, anteriorly widened.

Otolith morphology $(n=2)$. Size up to $6.5 \mathrm{~mm}$ in length (holotype); $\mathrm{OL}: \mathrm{OH}=1.85-2.05 ; \mathrm{OH}: \mathrm{OT}=2.1-2.4$. Thin, elongate otolith, anteriorly and posteriorly rounded, posteriorly slightly expanded. Dorsal rim with broadly rounded predorsal lobe, ventral rim shallow, regularly curved. All rims smooth. Inner face slightly convex, smooth, 
with short, centrally positioned sulcus; OL:TCL $=2.15-2.3$. Sulcus with shallow, undivided, uniform, oval colliculum. Dorsal field with small, indistinct depression; ventral field with faint ventral furrow close to otolith rim in central portion, anteriorly and posteriorly turning upwards to near terminations of sulcus. Outer face smooth, relatively flat.

Coloration. Live coloration not known. Color of preserved specimens medium brown; head slightly darker than body, opercle distinctly darker.
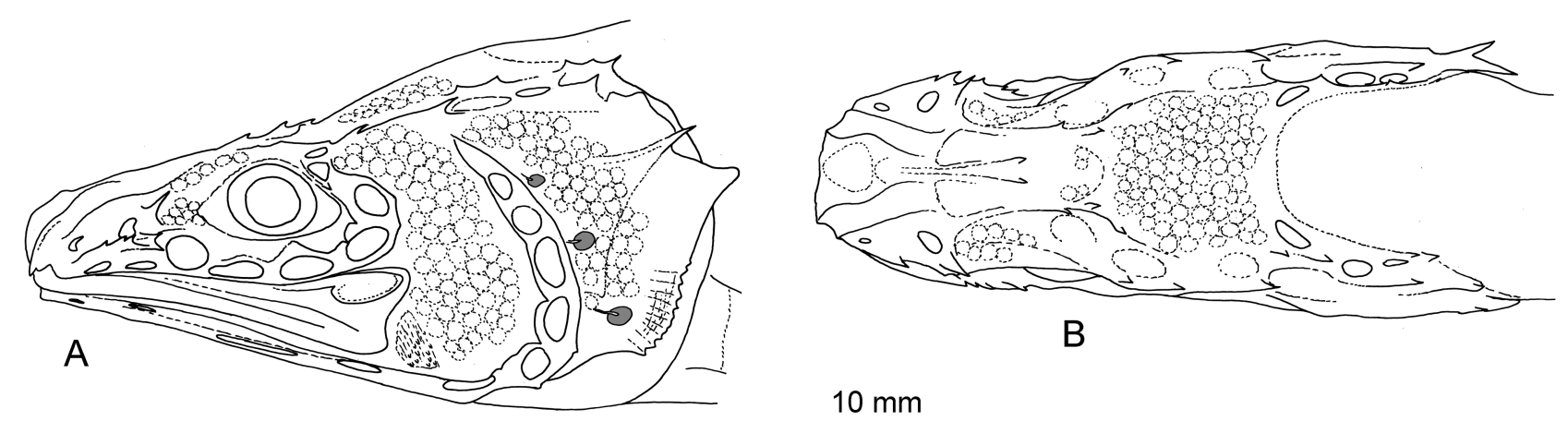

B

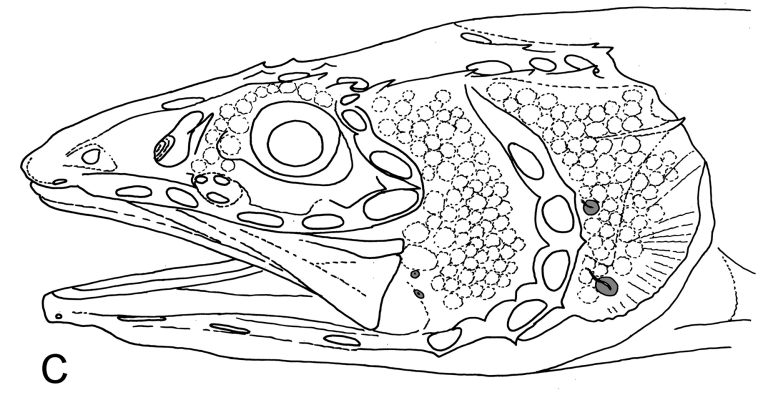

$10 \mathrm{~mm}$

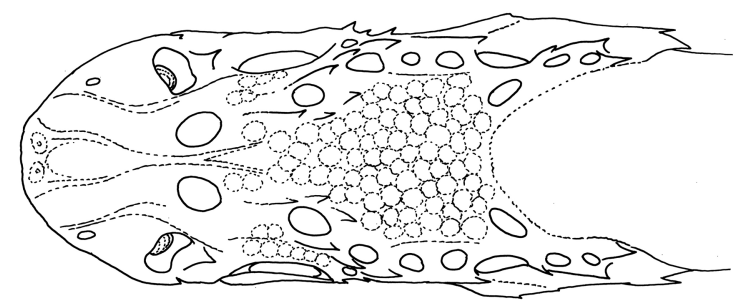

D
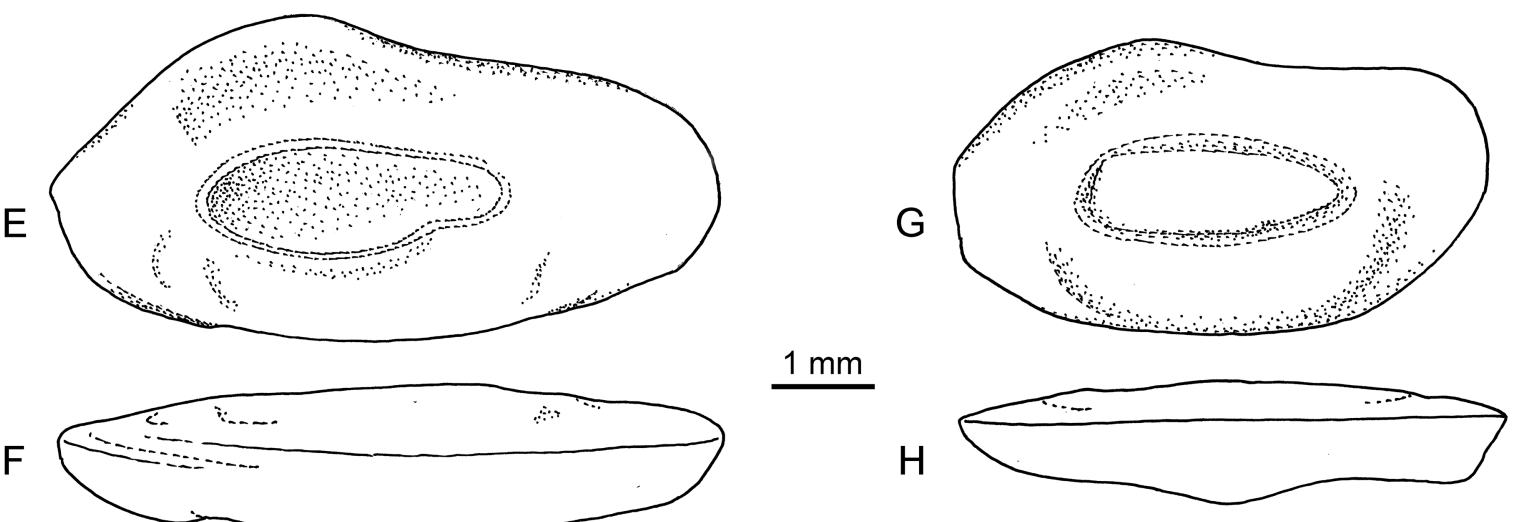

$\mathrm{F}$

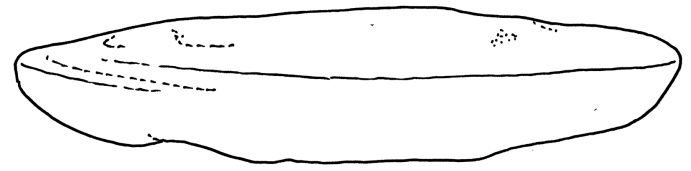

$\mathrm{H}$

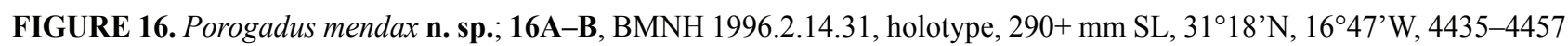
m, head drawing; 16C-D, BMNH 1995.11.22.4, paratype, 287 mm SL 2055'N, 31 ${ }^{\circ} 11^{\prime} \mathrm{W}, 4500-4610 \mathrm{~m}$, head drawing; 16E-F, BMNH 1996.2.14.31, holotype, 290+ mm SL, 31 ${ }^{\circ} 18^{\prime} \mathrm{N}, 16^{\circ} 47^{\prime} \mathrm{W}, 4435-4457 \mathrm{~m}$, otolith (E inner face, F ventral view); 16G-H, BMNH 1995.11.22.4, paratype, $287 \mathrm{~mm} \mathrm{SL}, 20^{\circ} 55^{\prime} \mathrm{N}, 31^{\circ} 11^{\prime} \mathrm{W}, 4500-4610 \mathrm{~m}$, otolith (G inner face, H ventral view).

Discussion. Porogadus mendax is similar to $P$. miles and the co-occurring $P$. caboverdensis and $P$. turgidus. The external differences to $P$. miles are subtle and depending on good preservation (see also to $P$. miles). Porogadus mendax has no scales on the maxilla (vs scales on the rear part of the maxilla), has 3 postorbital pores (vs 2), and an extensive cavernous system on the top of the head that $P$. miles does not show. The most reliable and secure character for distinction is the otolith, when preserved, which in P. mendax shows an undivided, relatively short colliculum (OL:TCL $=2.15-2.3$ ), while $P$. miles always shows clearly distinguished ostial and caudal colliculi and a relatively long sulcus (OL:TCL $=1.7-1.9)$. Porogadus mendax differs from $P$. caboverdensis and $P$. turgidus in the higher number of lower lateral line pores until the beginning of the anal fin (22-23 vs 16-20), the absence of scales on the maxilla, and the otolith, which in P. caboverdensis is considerably more compressed (OL:OH $=1.85-2.05$ in P. mendax vs 1.05-1.5 in P. caboverdensis) and in P. turgidus shows a clear separation of ostial and caudal colliculi. 
From $P$. caboverdensis it differs further in the broad vomer with 5-7 rows of teeth (vs narrow with 1-3, rarely 4 rows).

Distribution. Porogadus mendax is one of three deepwater species of the genus occurring in the Cape Verde and adjacent Canary Basins of the northeastern Atlantic (the other two being P. caboverdensis and P. turgidus). It has been caught at depths between 4435 and $4610 \mathrm{~m}$.

Etymology. From mendax $($ Latin $)=$ liar, narrator, referring to its close similarity to the common $P$. miles, which, however, does not seem to occur at depth exceeding $4000 \mathrm{~m}$.
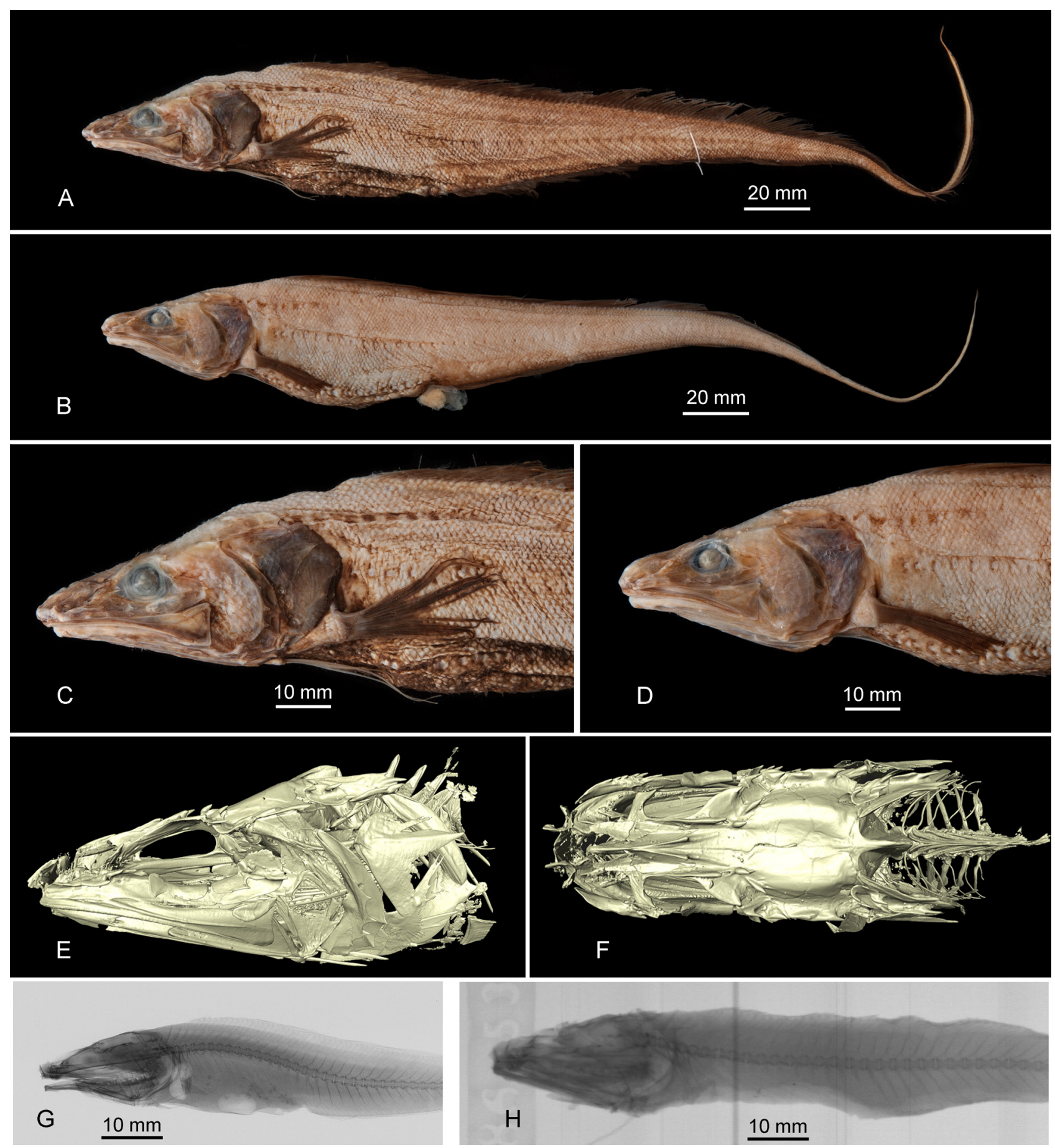

FIGURE 17. Porogadus miles Goode \& Bean, 1885; 17A,C, ZMUC P77588, $322 \mathrm{~mm}$ SL, $37^{\circ} 03^{\prime} \mathrm{N}, 7^{\circ} 07^{\prime} \mathrm{W}, 2150 \mathrm{~m}$; 17B,D,

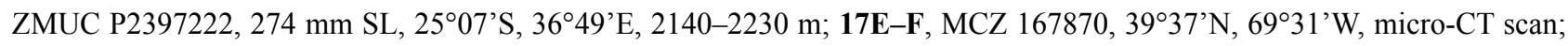
17G, x-ray photograph of USNM 35625, holotype, $145 \mathrm{~mm} \mathrm{SL}, 38^{\circ} 45^{\prime} \mathrm{N}, 73^{\circ} 03^{\prime} \mathrm{W}, 2136 \mathrm{~m}$; $1 \mathbf{1 7 H}$, x-ray photograph of MNHN 86-537, holotype of P. nudus, $198 \mathrm{~mm} \mathrm{SL}, 20^{\circ} 30^{\prime} \mathrm{N}, 16^{\circ} 32^{\prime} \mathrm{W}, 2321 \mathrm{~m}$. 


\section{Porogadus miles Goode \& Bean, 1885}

Figs. 1-2, 4, 6, 17-19, 44, 49, Tab. 1-7

Porogadus miles Goode \& Bean 1885: 602; Günther 1887: 113; Goode \& Bean 1895: 334, fig. 292; Jordan \& Evermann 1898: 2520; Grey 1956: 211 (see there for further citations); Grey 1958: 175; Shcherbachev 1980: 89, figs. 19-20; Nolf 1980: 91, pl. 11 fig. 7 (otolith); Schwarzhans 1981: 94, fig. 91 (otolith); Carter 1984: 2-183; Carter \& Sulak 1984: 376, fig. 6c; Machida \& Amaoka 1990: 64, fig. 2, 3(?); Nielsen et al. 1999: 86, fig. 83; Fahay 2007: 692, figs. p. 693 A-C; Mincarone et al. 2008: 55, fig. 3S; Shinohara et al. 2009: 707.

Porogadus nudus Vaillant 1888: 262, pl. 24, figs. 2-2b; Nybelin 1957: 291, textfig. 21; Machida \& Amaoka 1990: 67, Fig. 4; Nielsen et al. 1999: 86.

Porogadus sp.: Prokofiev 2005: 116, figs. 7-8.

?Porogadus sp. 2: Shcherbachev 1980: 88, fig. 18 (described here as Porogadus aff. miles).

Material examined (34 specimens): Holotype USNM 35625, $145 \mathrm{~mm}$ SL, 38 $45^{\circ} \mathrm{N} 73^{\circ} 03^{\prime} \mathrm{W}, 2136 \mathrm{~m}$, Albatross Expedition 1883-1900, Sta. D 2230, large beam trawl, 12 September 1884; holotype of P. nudus MNHN 86-537, 198 $\mathrm{mm}$ SL, $20^{\circ} 30^{\prime} \mathrm{N} 16^{\circ} 32^{\prime} \mathrm{W}, 2321 \mathrm{~m}$, R/V Talisman, 1883; paratype of $P$. nudus MNHN 86-536, $136 \mathrm{~mm}$ SL, $16^{\circ} \mathrm{N}$ $24^{\circ} \mathrm{W}, 3200 \mathrm{~m}, \mathrm{R} / \mathrm{V}$ Talisman, 1883; BMNH 2017.5.11.83, $272 \mathrm{~mm}$ SL, 1504’N 18³4’W, 2970-2990 m, R.R.S. Discovery Cruise semi-balloon otter trawl, collected by Institute of Oceanographic Sciences, 06 August 1983; BSKU 35715, 354 mm SL, 38²44-46’N 14311-12'E, 1950-1960 m, R/V Tansei-Maru, 3 m beam trawl, coll. Okamura, 25 July 1981; BSKU 98881, $167 \mathrm{~mm}$ SL, 01 ${ }^{\circ} 59^{\prime} \mathrm{S} 157^{\circ} 12^{\prime} \mathrm{E}, 1610 \mathrm{~m}$, R/V Hakuho-maru, $3 \mathrm{~m}$ beam trawl, 4 Jan. 1968; BSKU 116117-120 (1 of 5 specimens), 276 mm SL, 34 $52^{\prime} \mathrm{N}$ 139 $27-30^{\circ} \mathrm{E}, 1525-1685 \mathrm{~m}, \mathrm{R} / \mathrm{V}$ Tansei-maru, beam trawl, 17 Dec. 1982; BSKU 127724 (otolith only), 3847-48'N 14313-14'E, 2090-2120 m, R/V Hakuho-maru, beam trawl, 13 Aug. 1967; Dimitry Mendeleev (otolith only), 234 mm SL, St. 1542; FAKU 47604, 233 mm SL, $21^{\circ} 10^{\prime} \mathrm{N} 176^{\circ} 28^{\prime} \mathrm{E}, 1281 \mathrm{~m}$; MCZ 57618 (otolith only), 38 $58^{\prime} \mathrm{N} 69^{\circ} 50^{\prime} \mathrm{W}, 2903 \mathrm{~m}$, R/V Oceanus 093, 41' GMT, collected by Richard L. Haedrich, 31 March 1981; MCZ 59143, 340 mm SL, 3841'N 7049’W, 2960-2980 m, R/V Oceanus 043, 41' GMT, collected by Richard L. Haedrich, 15 April 1978; MCZ 146877, 275 mm SL, 39³5'N 70³2’W, 2290-2300 m, R/V Atlantis II 086, 41’ GMT, collected by Richard L. Haedrich, 18 March 1975; MCZ

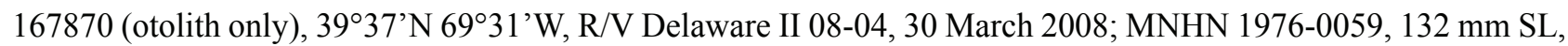
$00^{\circ} 45^{\prime} \mathrm{N} 08^{\circ} 27^{\prime} \mathrm{E}, 2231 \mathrm{~m}$, Walda Expedition, Sta. 32cy23, collected by J. Charcot, 02 August 1971; MNHN 20041327, 282 mm SL, 0549'S 0942'E, 3172-3193 m, R/V Atalante, Biozaire 3 Expedition, Sta. cp16, 28 December 2003; USNM 135626, $343 \mathrm{~mm}$ SL, Albatross, ND; USNM 316573 (otolith only), 38 ${ }^{\circ} 45^{\prime} \mathrm{N} 72^{\circ} 39^{\prime} \mathrm{W}, 2110-2160 \mathrm{~m}$, R/V Oceanus, Aslar Expedition, Cruise Ma-5, Sta. 4, 04 August 1985; ZMUC P2397222-223, R/V Vityaz 2639 (2 specimens), 257-274 mm SL, 2507'S 36²49'E, 2140-2230 m, 26 November 1988; ZMUC P2397224, R/V Vityaz sta. 2673, 265 mm SL, 32 ${ }^{\circ} 45^{\prime} \mathrm{S} 45^{\circ} 31^{\prime}$ 'E, 2100-2400 m, 9 December 1988; ZMUC P2397225, R/V Vityaz sta. 2772, 185 mm SL, 31 ${ }^{\circ} 59^{\prime} \mathrm{S} 45^{\circ} 11^{\prime} \mathrm{E}, 1950-2050 \mathrm{~m}, 25$ December 1988; ZMUC P2397226, R/V Vityaz 2779, $165 \mathrm{~mm}$ SL, 30³0'S 46 $53^{\circ}$ 'E, 2580-2680 m, 26 December 1988; ZMMGU 14411, 298 mm SL, R/V Zvezda Kryma, Cruse

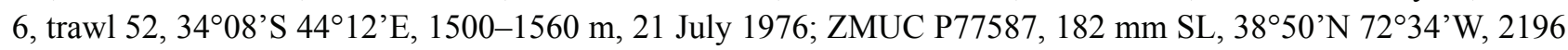

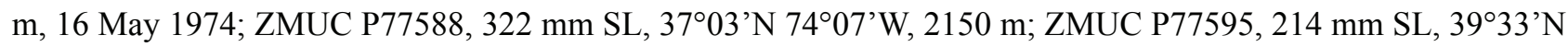
7043'W, 2379-2416 m, 10 July 1975; ZMUC P2397155, 229 mm SL, Galathea 2 expedition, sta.474, ST 300 - 3 m wide sledge trawl, , Sunda Trench, 0949’S 114¹3’E, 3810-3840 m, 11 September 1951; ZMUC P2397156-57, (2 specimens), 205+ and $259 \mathrm{~mm}$ SL, Galathea2 expedition, sta.299, herring otter trawl, Bay of Bengal, $17^{\circ} 10^{\prime} \mathrm{N}$ 84³0'E, 2820 m, herring otter trawl, 24 April 1951; Porogadus aff. miles: MNHN 1995-0948, 387 mm SL, 14²49'S $167^{\circ} 15^{\prime} \mathrm{E}, 1360 \mathrm{~m}$ R/V Alis, Musorstom 8 Expedition, Sta. cp1110, 08 October 1994; ZMMGU 15171 (otolith only), 312 mm SL, R/V Prof. Mesyatzev, Cruse 7, trawl 45,1655’'S 11453’E, 1600-1700 m, 24 April 1979.

Diagnosis. Precaudal vertebrae 17-19; long gill rakers on first gill arch 14-18; HL:HD 1.81-2.03; all head spines strong, present on ethmoidal, lacrimal, prefrontal, interorbital, supraorbital, sphenotic, 5th infraorbital, supratemporal, inner and outer posttemporal, inner and outer preopercular rims; opercular spine sharp, strong, extruding; maxilla with scales; small opercular flap with ridges; lower lateral line pores until beginning of anal fin 23-26; vomer with broad dentition patch (3-5 rows of teeth); palatines with broad dentition patch (4-9 rows of teeth); otolith with separate ostial and caudal colliculi; $\mathrm{OL}: \mathrm{OH}=1.55-1.9 ; \mathrm{OL}: \mathrm{TCL}=1.7-1.9$.

Description. Meristics: precaudal vertebrae $18(17-19), 1(0-2)$ last vertebrae without ribs; pectoral-fin rays 18 (17-21); D/V = 6 (5-7); D/A = 26 (24-30); V/A = 19 (18-21); long gill rakers on lower first gill arch 15 (14-18; 11 in Porogadus aff. miles, MNHN 1995-0948). Gill rakers in a typical specimen (MCZ 59143) on lower first gill arch with eight plate-shaped rakers, followed by a series of 17 long rakers. The lower 12 of those intercepted by single 
plate shaped rakers, broad and placed right between the long rakers. Upper gill arch with a serie of six plate shaped and three semi-long rakers intercepted.

Morphometrics: in \% of SL: HL 15.9 (15.6-17.6); maximal HD 8.1 (8.1-9.5); HD through center of eye (5.46.3); bony interorbital width (2.8-4.1); snout length 4.8 (4.8-6.4); upper jaw length 9.4 (9.4-10.2); predorsal 16.6 (16.6-20.3); preanal 29.9 (29.9-36.0); prepelvic (12.7-15.6); prepectoral (16.4-18.5); pectoral length (7.4-11.0). Relations: HL:HD = 1.95 (1.81-2.03); HL to snout length 3.29 (2.68-3.29); preanal to predorsal 1.81 (1.62-1.89); predorsal to prepectoral (0.99-1.16).

Slender fish with long tapering tail and long, pointed snout. Maximal size of fishes investigated $387 \mathrm{~mm}$ SL. Head long and slender, with flat dorsal profile, with strong spines as follows: ethmoidal (1), lacrimal (ridge or up to 3 individual spines), prefrontal (1), interorbital (3-4), supraorbital (2-3), sphenotic (2-4), 5th infraorbital (1-3), supratemporal (1-2), inner and outer posttemporal (2-4), inner preopercular rim (3-5), outer preopercular rim (1-3, variable in strength). Opercle with sharp, strong, extruding spine. Eye moderately sized located in strongly asymmetric orbit. Maxilla extending far beyond eye, strongly widened posteriorly and with distinct supramaxilla. Infra/postorbital and mandibular-preopercular pores wide, postorbital with 2 pores, head top with 1-2 pores on occiput along inner edges of temporal spines in front of nape. Head squamation on opercle, cheeks, occiput, frontal, snout, around eyes, and rear part of maxilla. However squamation on anterior part of head and on maxilla often indiscernible or lacking because of deciduous nature or preservation (see Figs. 18C-D, F). Opercle with two to three distinct large neuromasts behind preopercular edge; opercular flap small to mederately large, with radial ridges along lower margin. All three lateral line rows reasonably well visible. Upper lateral line row with 9-11 pores, sometimes expanded and then up to 16 pores; lower lateral line row with 23-26 pores until beginning of anal fin; central lateral line row long, lower and central lateral line rows fading behind beginning of anal fin.

Dentition. All teeth tiny and cone-shaped or flattened. Vomer with a narrow dentition patch in the entire length with 3-5 rows of teeth anteriorly; palatines with moderately broad to broad dentition patch with 4-9 rows of teeth in the middle part. Premaxilla tooth patches not fused anteriorly; 8-12 teeth rows anteriorly and 4-5 rows posteriorly. Dentary tooth patches not fused anteriorly; $4-7$ teeth rows anteriorly and 1-2 rows posteriorly. Median basibranchial tooth patch short to moderately long, wide.

Otolith morphology $(\mathrm{n}=18)$. Size up to $8.4 \mathrm{~mm}$ in length (in Porogadus aff. miles, MNHN 1995-0948); OL: $\mathrm{OH}=1.55-1.9 ; \mathrm{OH}: \mathrm{OT}=3.0-3.7$. Thin, elongate otolith, anteriorly with inferior rounded projection and posteriorly rounded and expanded. Dorsal rim with broadly rounded predorsal lobe, ventral rim shallow, regularly curved. All rims smooth or dorsal rim slightly undulating. Inner face slightly convex, smooth, with moderately long, centrally positioned sulcus; OL:TCL $=1.7-2.1$. Sulcus with shallow, distinctly separated ostial and caudal colliculi; length ostial to caudal colliculum very variable, ranging from 1.4 to 2.1. Dorsal field with indistinct depression; ventral field with faint ventral furrow close to otolith rim. Outer face smooth, relatively flat to slightly convex.

Coloration. Live coloration not known. Color of preserved specimens medium brown; snout slightly darker than body, opercle and pectoral fin distinctly darker.

Variability. Despite some remaining uncertainties in the delimitation of the species, the abundance of specimens and data of $P$. miles allows for a reasonable analysis of the intraspecific variability. Characters which are here considered useful for differentiation of species and showing a narrow range of variability are: precaudal vertebrae (17-18), pectoral-fin rays (18-21), HL in \% of SL (15.9-17.6), HL:HD (1.81-2.03), the number of lower lateral line pores until the beginning of the anal fin (23-26), the occurrence of most head spine patches and lateral head pores, and the status of the colliculi in the sulcus of the otolith. Characters with a moderate range of variability (not considering the two aff. specimens) are: long gill rakers (14-18), expression of head spines and exact numbers, width of vomer and palatine, snout (4.8-6.4 \% SL) and upper jaw lengths $(9.3-10.2 \% \mathrm{SL})$, predorsal (17.3-20.3 \% SL) and preanal lengths (29.9-36.0 \% SL), the ratio OL:OH (mostly 1.79-1.98 but with specific excursions, see below), and the ratio OL:TCL (1.7-2.1). These variability ranges may serve as bench marks for assessments of less common species in the Porogadus miles Group. Other useful characters such as head squamation, pectoral fin length, or number of pores on the top of the head require particularly good preservation of specimens. This restricts both its values for identification as well as recognition of variability ranges.

Comparison with previously published counts and measurements. Certain counts and measurements have been published, which we are not able to verify. Carter \& Sulak (1984) gave a range of 14 to 16 pectoral-fin rays (16 for the holotype) based on 18 specimens. Our recount of the pectoral-fin rays of the holotype was 18 and we counted a range of 17 to 21 pectoral-fin rays based on 20 specimens. This is in line with the counts published by 
Shcherbachev (1980; 19-20), Machida \& Amaoka (1990; 17-19), and Prokofiev (2005; as Porogadus sp.; 17-18), but not Grey $(1958 ; 16)$. The type specimens of $P$. nudus were counted with 20 and 21 pelvic-fin rays. Ranges of pectoral-fin rays given by Carter \& Sulak (1984) for syntypes of $P$. longiceps (19-20) and P. catena (15-17) are in line with our counts, but for syntypes of $P$. atripectus (16-18 vs 17-20), holotype of $P$. gracilis (14 vs 16) and holotype of $P$. abyssalis (18 vs 19 in Nybelin, 1957) are not and suggest a systematic difference in the method of counting. The preservation of the pectoral fins is often poor. We found high resolution x-rays to be of much help also for counting pectoral-fin rays.

The count of long gill rakers on the first gill arch is in line with counts given by Grey $(1958 ; 15)$, Shcherbachev (1980; 14-15), Carter \& Sulak (1984; 15), Machida \& Amaoka (1990; 13-17), and Prokofiev (2005; as Porogadus sp.; 16), but shows a larger variability than mostly recorded (14-18). The number of precaudal vertebrae (17-19) is in good agreement throughout literature.
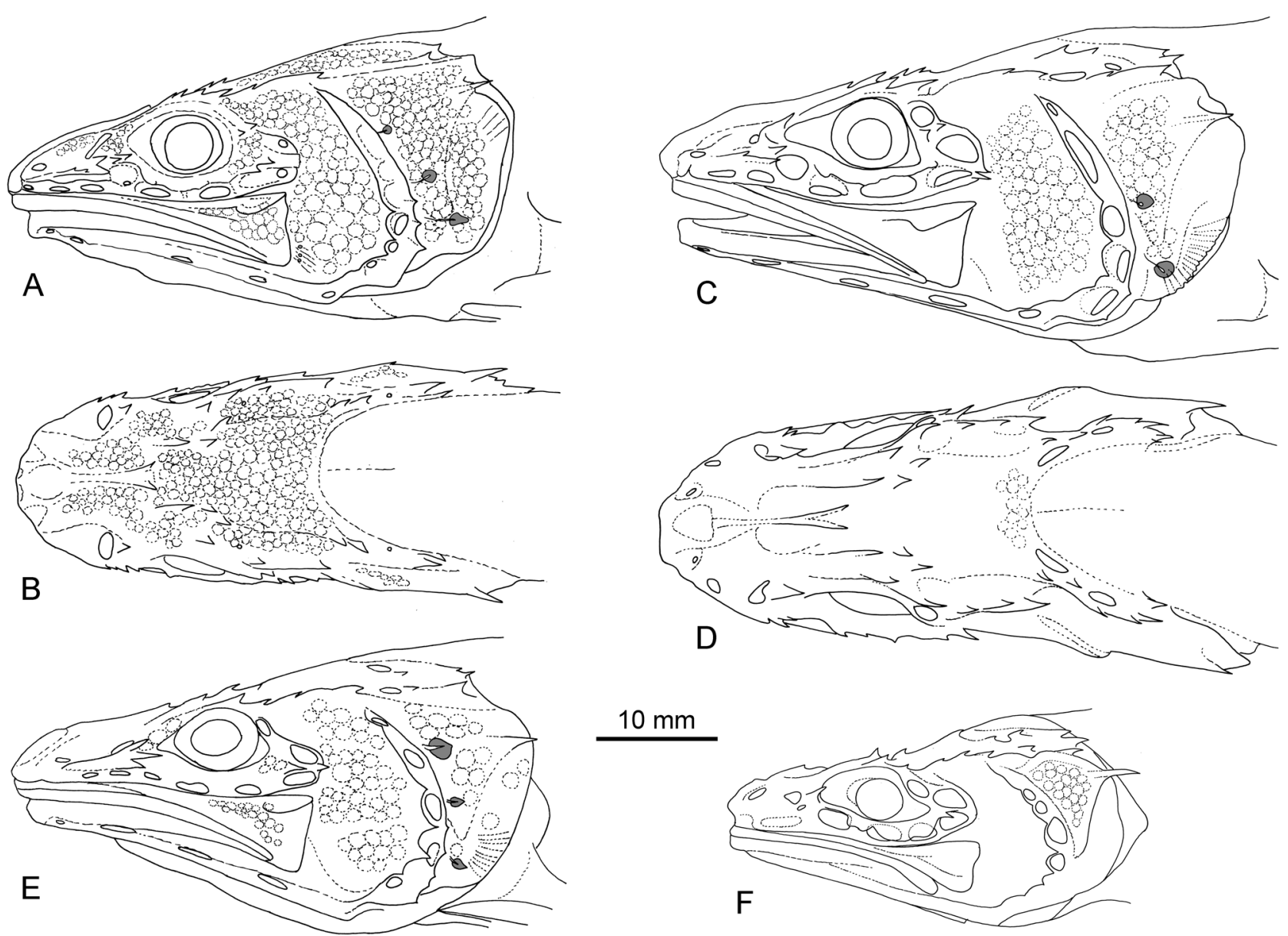

FIGURE 18. Porogadus miles Goode \& Bean, 1885, head drawings; 18A-B, MCZ 146877, $257 \mathrm{~mm} \mathrm{SL}, 39^{\circ} 35^{\prime} \mathrm{N}, 7^{\circ} 32^{\prime} \mathrm{W}$, 2290-2300 m; 18C-D, MNHN 2004-1327, 282 mm SL, 0549’'S, 0942’E, 3172-3193 m; 18E, ZMUC P2397222, 274 mm SL,

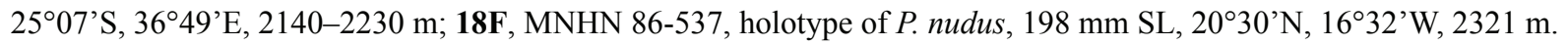

Measurements are given by Carter \& Sulak (1984) in \% of GPL, which we found less indicative than in \% of SL, even though this method somewhat restricts the number of usable measurements. Measurements given by Machida \& Amaoka (1990) for the type specimen of P. miles and one other specimen also studied here are well aligned. The same is apparently true for selected measurements given by Shcherbachev (1980) and Prokofiev (2005; for Porogadus sp.).

Discussion. Porogadus miles is the most commonly recorded and apparently most widely distributed species of the genus. It has been recorded throughout the tropical and subtropical Atlantic Ocean, from certain regions of the Indian Ocean and from the western Pacific off Japan and as far east as the Necker Ridge and the Emperor Seamounts west of Hawaii. The delimitation of $P$. miles however still remains somewhat uncertain. Porogadus miles was first described by Goode \& Bean (1885) based on a single, relatively small specimen (145 mm SL) from the northwestern Atlantic. Vaillant (1888) described P. nudus from the northeastern Atlantic based on two specimens 
(the holotype being $198 \mathrm{~mm} \mathrm{SL}$ and the paratype $136 \mathrm{~mm}$ ). Vaillant noted only a few differences. e.g., in the range of lateral pores, pectoral fin length and head length, which he regarded as not very important and easily affected by preservation of the specimens concerned. The key character in his assessment to distinguish $P$. nudus from $P$. miles was the distance of the pelvic fin base to the anus being one fourth longer than the head length (vs being of equal length in P. miles). We found that the ratio of the distance of the pelvic base to the beginning of the anal fin compared to the head length varies considerably within most well-defined species between just slightly under 1.0 to slightly over 1.3. We therefore consider this character to be of diagnostic value only in very few instances, i.e., in $P$. dracocephalus where it is the lowest measured and ranges from 0.72 to 0.98 . Grey (1958) commented that "P. nudus is closely related to $P$. miles and may prove to be the same species." She considered the complete absence of lateral lines in P. nudus as the principal difference, which we cannot confirm after having reviewed both type specimens. Discernibility of the lateral line on the body in the Porogadus miles Group is often a matter of preservation. Machida \& Amaoka (1990) reinvestigated the situation again and also studied the holotype of $P$. nudus. They concluded that the holotype of $P$. nudus does not show distinct lachrymal spines like the specimens of $P$. miles which they studied and considered this as the main distinctive character of the two species. Our study of several specimens of $P$. miles and $P$. nudus including the type series of both nominal species confirms that the holotype of $P$. nudus has a lachrymal ridge and no lachrymal spines (the paratype is too poorly preserved in that respect), while all other studied specimens indeed show 2 to 3 strong lachrymal spines. However, we also noted in several other species of the Porogadus miles Group that the status of the lachrymal may change from a ridge-like shape to a spinous appearance as part of an intraspecific variation and therefore do not regard this character as sufficient for distinguishing species on a stand-alone basis. Consequently, we propose here to regard $P$. nudus as junior synonymy of $P$. miles.

Porogadus miles generally shows a relatively large morphological diversity, which was also recognized by Machida \& Amaoka (1990) and which they considered as reflecting geographical variations of this widespread species. Shcherbachev (1980) described two large specimens (312 and $412 \mathrm{~mm} \mathrm{SL}$ ) from off Western Australia $\left(16^{\circ} 55^{\prime} \mathrm{S}, 114^{\circ} 53^{\prime} \mathrm{E}\right)$ as Porogadus sp. 2, which he considered different from P. miles because of the lower number of (developed) gill rakers (12-13 vs 14-18), the different form of the stomach and the different contour of the supramaxilla. His drawing shows a concave dorsal head profile, which is also not seen in $P$. miles. These specimens were not reinvestigated in detail for this study (except for a poorly preserved otolith with a high dorsal rim) and could indeed represent a different species. They seem to be similar to the large specimen from off Vanuatu (MNHN 1995-0948), which also has an unusually low gill raker count (11), a much longer extending upper lateral line row with 15-16 pores, a divergent otolith shape with a high dorsal rim and no distinct predorsal lobe, and a narrow sulcus (Fig. 19J-K). All three specimens are listed here as $P$. aff. miles.

Prokofiev (2005) described a large specimen of $364 \mathrm{~mm}$ SL from the Emperor Seamounts as Porogadus sp. concluding that it apparently represents an undescribed species. The morphometric measurements of this specimen all fall into the lower end of the variability here observed. Prokofiev considered the main differences to $P$. miles to be the count of the developed gill rakers (quote: 16 vs 14-15), the presence of a fundal projection of the stomach and the absence of pyloric caeca, 16 precaudal vertebrae (vs quote: 17-18), a wider tooth plate of the vomer and details in the head spines. We consider the number of gill rakers and the width of the vomer to fall well within the variations observed in P. miles while the number of precaudal vertebrae is indeed outside the variability observed by us. His description of the head spines does not give a proper indication of a specific difference. With only a single specimen being recorded by Prokofiev, the number of precaudal vertebrae being the only notable difference, and a specimen from the Necker Ridge (FAKU 47604) not differing significantly from other specimens of $P$. miles, we regard the specimen from the Emperor Seamounts also to represent $P$. miles.

We further observed that specimens from the southern Indian Ocean (ZMUC P2397224 and 2397226 from $30^{\circ}-32^{\circ} \mathrm{S}$ and $45^{\circ}-46^{\circ} \mathrm{E}$; Figs. $19 \mathrm{H}-\mathrm{I}$ ) and the southern eastern Atlantic (MNHN 2004-1327 from $05^{\circ} \mathrm{S}$ and $09^{\circ} \mathrm{E}$; Figs. 19L-M) show a relatively more compressed otolith than other specimens (OL:OH $=1.55-1.65$ vs $1.75-1.9)$, but further specimens from the southern Indian Ocean (ZMUC P2397222 at $25^{\circ} \mathrm{S}$ and $36^{\circ} \mathrm{E}$, Figs. $19 \mathrm{~F}-\mathrm{G}$, and ZMMGU 14411 from $34^{\circ} \mathrm{S}$ and $44^{\circ} \mathrm{E}$ ) exhibit the typical, more elongate otolith shape. The observed differences in otolith shape are not supported by other morphological features and therefore are considered to represent intraspecific variability or some specific environmental effect. However, the observed variability of the specimens of $P$. miles is so large that pertinent diagnostic characters for distinction from other species of the Porogadus miles Group are often rather subtle in nature (see above and below). 

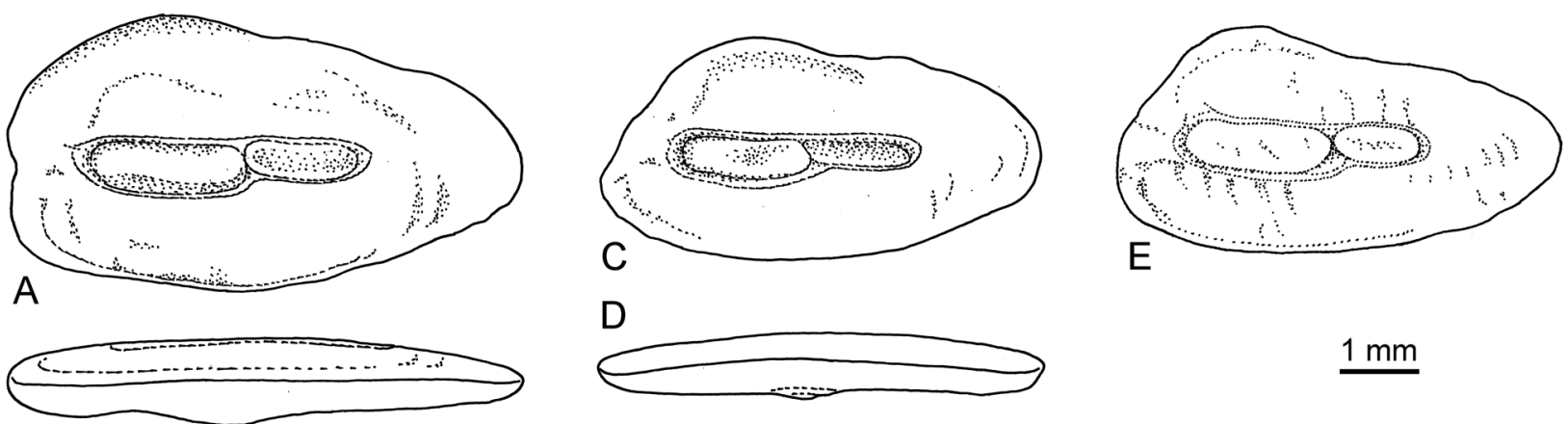

$\underline{1 \mathrm{~mm}}$

B
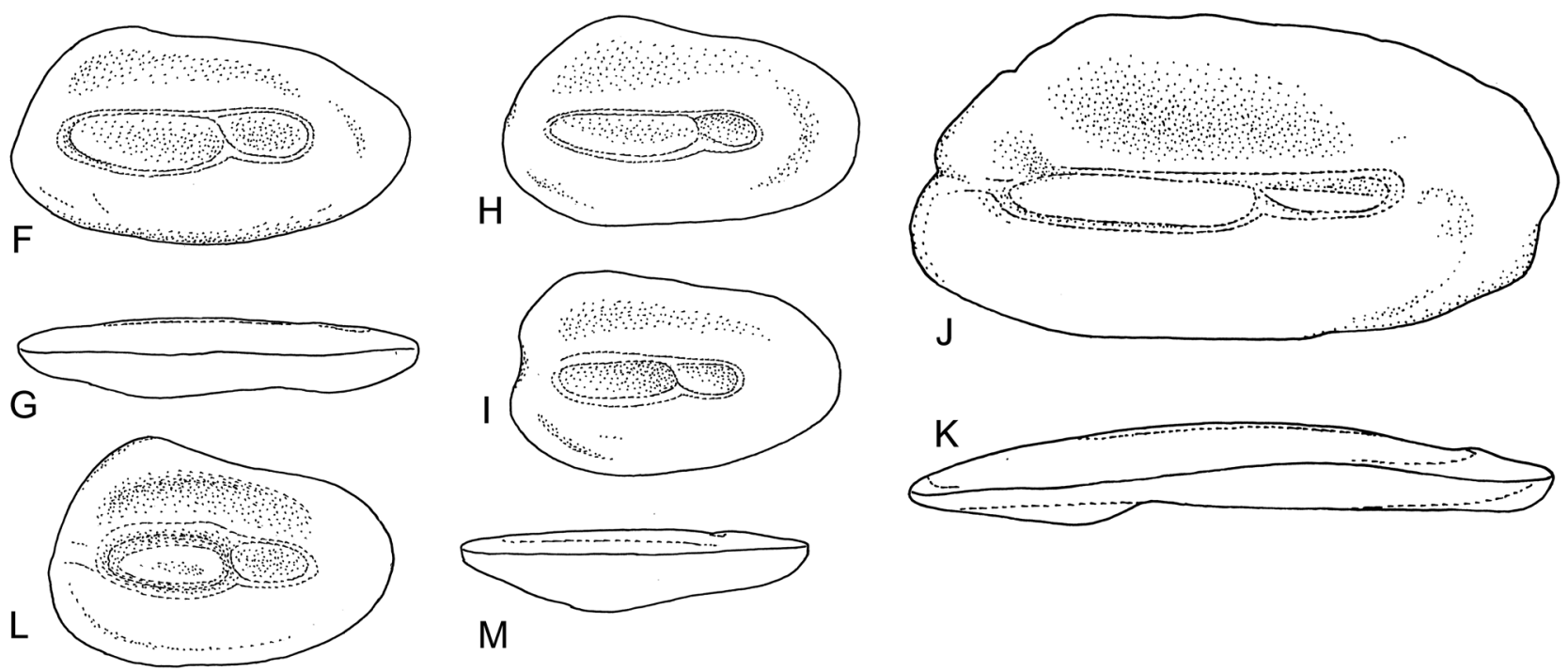

FIGURE 19. Porogadus miles Goode \& Bean, 1885, otoliths; 19A-B, BSKU 35715, 3844'N, 143'11'E, 1950-1960 m, 354 mm SL (A inner face, B ventral view); 19C-D, USNM 316573, 38 $45^{`} \mathrm{~N}, 72^{\circ} 39^{\prime} \mathrm{W}, 2110-2160 \mathrm{~m}$, (C inner face, D ventral

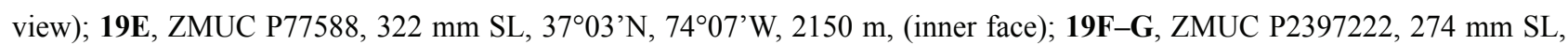

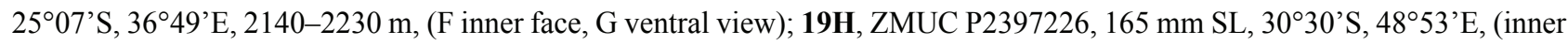

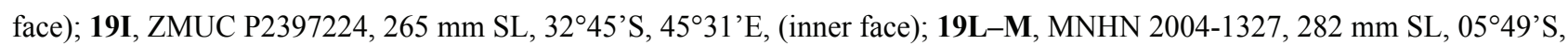
0943'E, 3172-3193 m, (L inner face, M ventral view). 19J-K, Porogadus aff. miles, MNHN 1995-948, 387 mm SL, 14²9'S, $167^{\circ} 15^{\prime} \mathrm{E}, 1360 \mathrm{~m}$, (J inner face, $\mathrm{K}$ ventral view).

Porogadus miles differs from all other species of the Porogadus miles Group except $P$. longiceps and $P$. mendax in the higher number of lower lateral line pores until the beginning of the anal fin (23-26 vs 16-21), and except for $P$. longiceps and P. turgidus in separated ostial and caudal colliculi of the sulcus of the otolith. From P. longiceps it differs additionally in the higher number of long gill rakers (14-18 vs 11-13) and from P. mendax in the presence of scales on the maxilla (vs absent) and 2 postorbital pores (vs 3). From P. turgidus it differs additionally in the lower index OL:TCL of 1.7-2.1 (vs 2.4-2.9).

\section{Porogadus turgidus n. sp.}

Figs. 20, 44, 49, Tab. 1-7

Material examined (2 specimens): Holotype BMNH 1995.11.22.6, $295 \mathrm{~mm} \mathrm{SL}, 20^{\circ} 55^{\prime} \mathrm{N} 31^{\circ} 11^{\prime} \mathrm{W}, 4500-4610$ m, R.R.S. Discovery Cruise semi-balloon otter trawl, 16 October 1993, collected by N. Merrett; paratype BMNH 1995.11.22.5, $282 \mathrm{~mm} \mathrm{SL}, 20^{\circ} 55^{\prime} \mathrm{N} 31^{\circ} 11^{\prime} \mathrm{W}, 4500-4610 \mathrm{~m}$, R.R.S. Discovery Cruise semi-balloon otter trawl, 16 October 1993, collected by N. Merrett.

Diagnosis. Precaudal vertebrae 17-18; long gill rakers on first gill arch 11-15; HL:HD 1.82-1.85; all head spines strong, present on ethmoidal, lacrimal, prefrontal, interorbital, supraorbital, sphenotic, 5th infraorbital, supratemporal, inner and outer posttemporal, inner preopercular rim, absent along outer preopercular rim; opercular 
spine sharp, strong, extruding; additional (3rd) postorbital pore, pores on top of head in front of nape; large opercular flap without ridges; lower lateral line pores until beginning of anal fin 18-21; vomer with broad dentition patch (4-7 rows of teeth); palatines with broad dentition patch (6 rows of teeth); otolith with clearly separated ostial and caudal colliculi; $\mathrm{OL}: \mathrm{OH}=1.6 ; \mathrm{OL}: \mathrm{TCL}=2.45-2.85$.

Description. Meristics: precaudal vertebrae $17(17-18), 1(1-2)$ last vertebrae without ribs; pectoral-fin rays 16 (16-18); D/V = 4 (4-5); D/A = 26 (24-26); V/A = 18 (18). Gill rakers in holotype on lower first gill arch with nine plate-shaped rakers, followed by a series of 11 long rakers. The lower four of those intercept by single plate shaped rakers. Upper gill raker with a series of three plate shaped and three slightly longer rakers intercepted, followed by two plate shaped rakers; total long rakers $11(11-15)$.

Morphometrics: in \% of SL: HL 16.0 (15.3-16.0); maximal HD 9.0 (8.0-9.0); HD through center of eye 6.5 (5.2-6.5); bony interorbital width 2.6 (2.6-3.0); snout length 5.4 (5.0-5.4); upper jaw length 9.3 (9.2-9.3); predorsal 15.7 (15.7); preanal 30.5 (29.6-30.5); prepelvic 13.8 (13.0-13.8); prepectoral 16.6 (16.1-16.6); pectoral length 9.5 (9.5-9.7). Relations: HL:HD = $1.82(1.82-1.85)$; HL to snout length 2.95 (2.95-3.07); preanal to predorsal 1.95 (1.88-1.95); predorsal to prepectoral 0.94 (0.94-0.97).

Slender fish with long tapering tail and long, pointed snout. Maximal size of fishes investigated $295 \mathrm{~mm}$ SL. Head long and slender, with flat dorsal profile, with strong spines as follows: ethmoidal (1), lacrimal (2), prefrontal (1), interorbital (3), supraorbital (1), sphenotic (2-3), 5th infraorbital (1), supratemporal (1), inner and outer posttemporal (3-5), inner preopercular rim (3-4), no spines along outer preopercular rim. Opercle with sharp, strong, extruding spine. Eye small located in strongly asymmetric orbit. Maxilla extending far beyond eye, strongly widened posteriorly and with distinct supramaxilla. Infra-/postorbital and mandibular-preopercular pores wide, postorbital with 3 pores, the 3 rd uppermost one being small, head top with 3 pores on occiput in front of nape and cavernous system extending between squamation of occiput and sphenotic and supraorbital spines. Head squamation on opercle, cheeks, occiput, frontal, around eyes, and possibly on rear of maxilla (indications of scale-pockets). Opercle with three distinct large neuromasts behind preopercular edge; opercular flap large, without radial ridges. All three lateral line rows reasonably well visible. Upper lateral line row with 8-9 pores; lower lateral line row with 18-21 pores until beginning of anal fin; central lateral line row long, lower and central lateral line rows fading behind beginning of anal fin.

Dentition. All teeth tiny and cone-shaped. Vomer with a broad dentition patch with 4-7 rows of teeth anteriorly; palatines with broad dentition patch with 6 rows of teeth throughout. Premaxilla tooth patches not fused anteriorly; ca. 7 teeth rows anteriorly and 3-4 rows posteriorly. Dentary tooth patches fused anteriorly; ca. 6 teeth rows anteriorly and 2-3 rows posteriorly. Median basibranchial tooth patch short, sometimes anteriorly widened.

Otolith morphology $(\mathrm{n}=2)$. Size up to $4.9 \mathrm{~mm}$ in length (holotype); OL:OH =1.6; OH:OT $=2.2-2.6$. Moderately thick and moderately elongate otolith, anteriorly broadly rounded, posteriorly slightly expanded and somewhat tapering. Dorsal rim with marked, broadly rounded predorsal lobe, ventral rim regularly curved. All rims smooth. Inner face slightly convex, smooth, with very short, centrally positioned sulcus; OL:TCL $=2.45-2.85$. Sulcus with shallow, clearly separated ostial and caudal colliculi; ostial colliculum nearly twice as long and wide as caudal colliculum; OCL:CCL $=1.85-1.90$. Dorsal field with indistinct depression; ventral field smooth, without ventral furrow. Outer face smooth, with mild umbo opposite to ostium on inner face.

Coloration. Live coloration not known. Color of preserved specimens medium brown; belly and frontal part of head top slightly darker than body, opercle distinctly darker.

Discussion. Porogadus turgidus is similar to P. miles and the co-occurring P. caboverdensis and P. mendax. External differences are subtle and depending on good preservation (see also discussion to P. miles). Porogadus turgidus differs from $P$. miles and $P$. mendax in the lesser pores of the lower lateral line until the beginning of the anal fin of 18-21 (vs 22-27). Its predorsal length is the shortest in this group ( $<16 \%$ of SL vs $17-20 \%)$. From $P$. caboverdensis it differs in the broader vomer (4-7 rows of teeth vs 1-3, rarely 4). It shares with $P$. caboverdensis the lack of spines along the outer preopercular rim (vs present in $P$. mendax and P. miles). It may further differ from $P$. mendax in the presence of scales on the rear part of the maxilla (scale-pockets; vs no scales on the maxilla). Another useful character to distinguish these four species is the otolith, when preserved. The otoliths of $P$. turgidus share with those of $P$. caboverdensis the compressed shape (OL:OH $=1.05-1.6$ vs 1.8-2.05 for $P$. mendax). Also, most otoliths of $P$. miles are more elongate (OL:OH $=1.7-2.0$, rarely $1.55-1.65$, see above). With the otoliths of $P$. miles it shares the clearly separated colliculi (vs a single, joined colliculum in $P$. caboverdensis and $P$. mendax). The otoliths of $P$. turgidus differ from those of $P$. miles in the very short sulcus as expressed in the ration OL:TCL of 2.45-2.85 (vs 
Distribution. Porogadus turgidus is one of three deepwater species of the genus occurring in the Cape Verde Basin of the northeastern Atlantic (the other two being P. caboverdensis and P. mendax). It has been caught at depths between 4500 to $4610 \mathrm{~m}$.
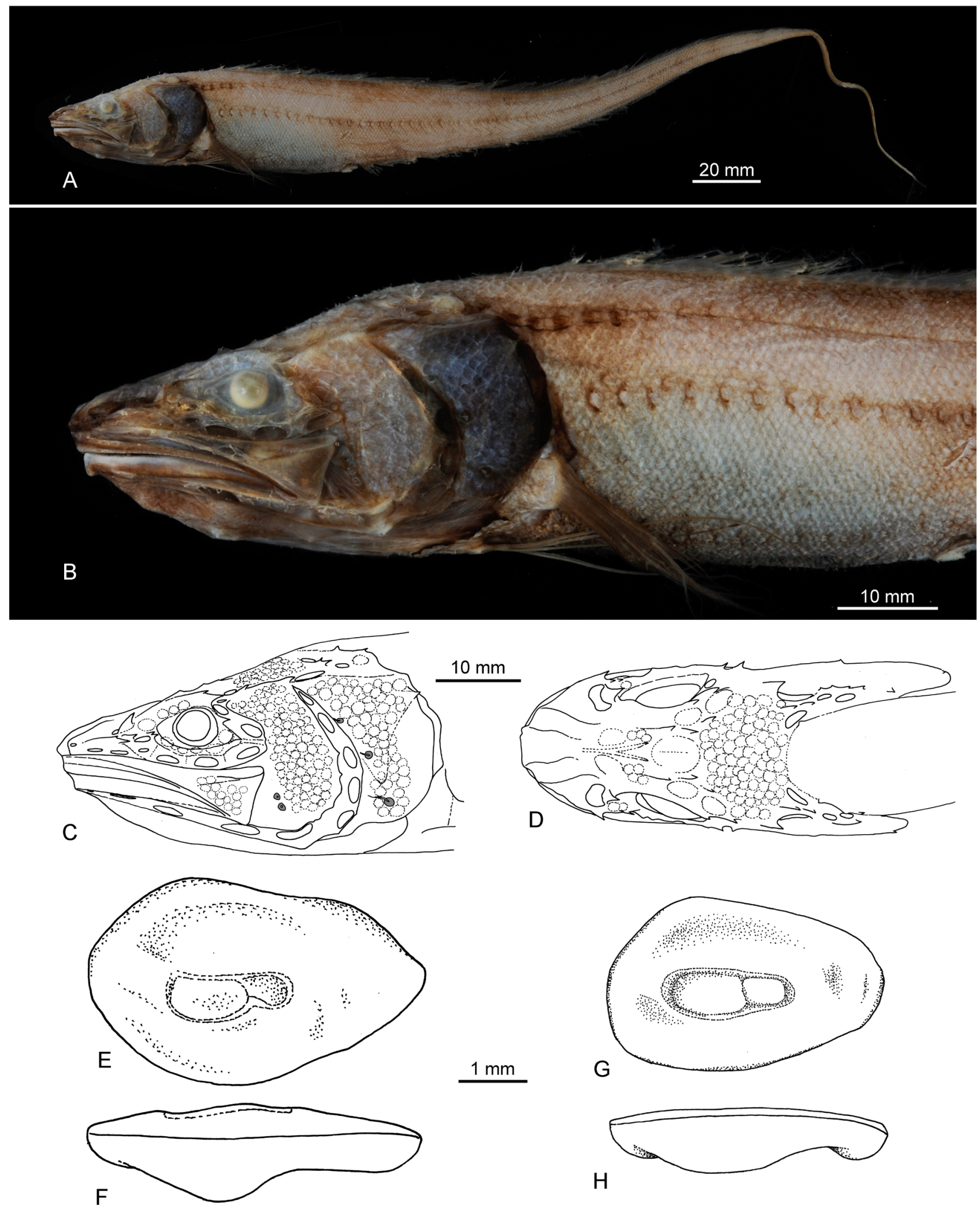

$1 \mathrm{~mm}$

G

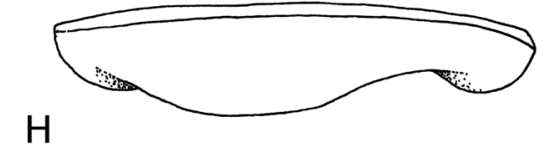

FIGURE 20. Porogadus turgidus n. sp.; 20A-F, BMNH 1995.11.22.6, holotype, 295 mm SL, 2055’N, 31¹1'W, 4500-4610 m, (A-B photographs, C-D head drawings, E otolith inner face, F otolith ventral view); 20G-H, BMNH 1995.11.22.5, paratype, $282 \mathrm{~mm} \mathrm{SL}, 20^{\circ} 55^{\prime} \mathrm{N}, 31^{\circ} 11^{\prime} \mathrm{W}, 4500-4610 \mathrm{~m}$, otolith (G inner face, H ventral view). 
Etymology. From turgidus (Latin) $=$ inflated, referring to the large otolith size compared to its small sulcus size.

\section{Porogadus trichiurus Group}

\section{Porogadus guentheri Jordan \& Fowler, 1902}

Figs. 21-22, 45, 50, Tab. 1-7

Porogadus guentheri Jordan \& Fowler 1902: 762, fig. 6; Machida 1982: 27; Machida in Masuda et al. 1984: 101, pl. 85J; Machida in Okamura \& Kitajima 1984: 261, 375; Nielsen et al. 1999: 86; Shinohara et al. 2005: 414.

Material examined (13 specimens): BSKU 43444, $257 \mathrm{~mm} \mathrm{SL}, 32^{\circ} 21^{\prime} \mathrm{N} 132^{\circ} 27^{\prime} \mathrm{E}$ to $32^{\circ} 23^{\prime} \mathrm{N} 132^{\circ} 28^{\prime} \mathrm{E}, 1642-$ $1651 \mathrm{~m}, \mathrm{R} / \mathrm{V}$ Tansei-maru, $3 \mathrm{~m}$ beam trawl, collcted by Okamura, 2 Nov. 1986; BSKU 47928 (otolith only), $32^{\circ} 26^{\prime} \mathrm{N}$ $133^{\circ} 50^{\prime} \mathrm{E}$ to $32^{\circ} 28^{\prime} \mathrm{N} 133^{\circ} 54^{\prime} \mathrm{E}, 1316-1542 \mathrm{~m}$, R/V Tansei-maru, $3 \mathrm{~m}$ beam trawl, 2 Sept. 1990; BSKU 86818, 251 $\mathrm{mm} \mathrm{SL}, 32^{\circ} 24^{\prime} \mathrm{N} 132^{\circ} 16^{\prime} \mathrm{E}$ to $32^{\circ} 25^{\prime} \mathrm{N} 132^{\circ} 17 \mathrm{E}, 1501-1561 \mathrm{~m}$, R/V Tansei-maru, $3 \mathrm{~m}$ beam trawl, coll. Endo and Nagatomo, 16 Dec. 1999; BSKU 86819, 86832 (2 specimens), 248-255 mm SL, 1678-1690 m, 32¹8'N 132²1'E to $32^{\circ} 17^{\prime} \mathrm{N} 132^{\circ} 20^{\prime} \mathrm{E}, \mathrm{R} / \mathrm{V}$ Tansei-maru, $3 \mathrm{~m}$ beam trawl, coll. Endo and Nagatomo, 16 Dec. 1999; CAS SU 7124, paratypes, 137-210 mm SL, 34 $97^{\prime} 90 \mathrm{~N}, 1^{\prime 3} 9^{\circ} 61^{\prime} 46 \mathrm{~S}$, Sagami Sea, Japan no depth information, year 1900 (date unknown); NSMT P.66377 (2 specimens), 170-199 mm SL, 961 m, 26²14’N 12516'E; NSMT 101668 (2 specimens), 110-120 mm SL, 1276-1319 m, 2759’N 127³4'E; SIO 53-366 (2 specimens), 226-235 mm SL, R/V Spencer F Baird, sta. 8, dredge, collected by T.J. Walker, Honshu Island, Kii Strait, S of Kobe, 3321'N 13454'E, 1298 m, 23 October 1953.

Diagnosis. Precaudal vertebrae 16-17; long gill rakers on first gill arch 18-21, broad, bladed; HL:HD 1.711.79; most head spines strong: on ethmoidal, prefrontal, interorbital, supraorbital, sphenotic, supratemporal, inner and outer posttemporal, inner preopercular rim, lacrimal with ridge, weak on outer preopercular rim, absent on 5th infraorbital; opercular spine sharp, extruding; maxilla with single row of scales along upper margin in front of supramaxilla; large opercular flap with ridges; lower lateral line pores until beginning of anal fin 16; vomer with narrow dentition patch with few or 1-2 (rarely 3 ) rows of teeth; palatines with moderately broad dentition patch (3-6 rows of teeth); otolith with single colliculum but indentation at ventral margin and rarely separate colliculi; OL:OH $=1.45-1.64 ; \mathrm{OL}: \mathrm{TCL}=1.87-2.52$.

Description (based on non-types). Meristics: precaudal vertebrae 16-17, 1-2 last vertebrae without ribs; pectoral-fin rays 15-17; $\mathrm{D} / \mathrm{V}=4-5 ; \mathrm{D} / \mathrm{A}=23-27 ; \mathrm{V} / \mathrm{A}=18$; long gill rakers on lower gill arch 18-21, broad, bladed. Gill rakers in a typical specimen (BSKU 86819) on lower first gill arch with six short rakers, followed by a series of 21 long rakers. The lower 11 of those intercept by plate shaped rakers. These are smaller than in most species an placed mostly on the inner part of the gill arch. The long rakers are blade shaped, broader than in most other species and armed with spinules. Upper gill arch with two plate shaped rakers, followed by a series of three semi-long rakers and two plate-like rakers intercepted, followed again by two plate shaped rakers.

Morphometrics: in \% of SL: HL 13.9-15.0; maximal HD 7.9-8.6; HD through center of eye 5.7-6.6; bony interorbital width 3.4-4.1; snout length 4.7-5.5; upper jaw length 8.2-9.4; predorsal 13.7-14.7; preanal 26.8-29.3; prepelvic 11.2-12.5; prepectoral 14.6-15.9; pectoral length 8.1-9.8. Relations: HL:HD =1.71-1.79; HL to snout length 2.66-3.04; preanal to predorsal 1.86-2.05; predorsal to prepectoral 0.90-1.00.

Slender fish with long tapering tail and moderately long snout. Maximal size of fishes investigated $257 \mathrm{~mm}$ SL. Head moderately long and moderately slender, with slightly convex dorsal profile, with strong spines and ridges as follows: ethmoidal (1), lacrimal (1 ridge), prefrontal (1), interorbital (3), supraorbital (1-2), sphenotic (2-4), supratemporal (2), inner and outer posttemporal (3-4), inner preopercular rim (5-6), outer preopercular rim (2-3 short and weak), no spines on 5th infraorbital. Opercle with sharp, extruding spine. Eye moderately large, located in strongly asymmetric orbit. Maxilla extending far beyond eye, strongly widened posteriorly and with distinct supramaxilla. Infra-/postorbital and mandibular-preopercular pores wide, head top with cavernous system extending between occiput and sphenotic and supraorbital spines and on occiput in front of nape, sometimes opening in up to 7 bilateral symmetrical openings (pores or damaged thin skin cover?). Head squamation on opercle, cheeks, and single row along upper margin of maxilla in front of supramaxilla, absent on occiput, frontal, and around eyes. Opercle with three distinct large neuromasts behind preopercular edge; opercular flap large, with radial ridges. Lateral line 
rows rarely well visible and therefore number of pores countable only in rare instances. Lower lateral line row with 16 pores until beginning of anal fin in one specimen.

Dentition. All teeth tiny and cone-shaped. Vomer narrow, anteriorly naked or with short dentition patch with 1-2 (rarely 3) rows of teeth anteriorly, naked posteriorly; palatines with a short and narrow dentition patch with 3-6 rows of teeth in middle part. Premaxilla tooth patches not fused anteriorly; ca. 6 teeth rows anteriorly and 2-3 rows posteriorly. Dentary tooth patches not fused anteriorly; ca. 6 teeth rows anteriorly and 2 rows posteriorly. Median basibranchial tooth patch short.
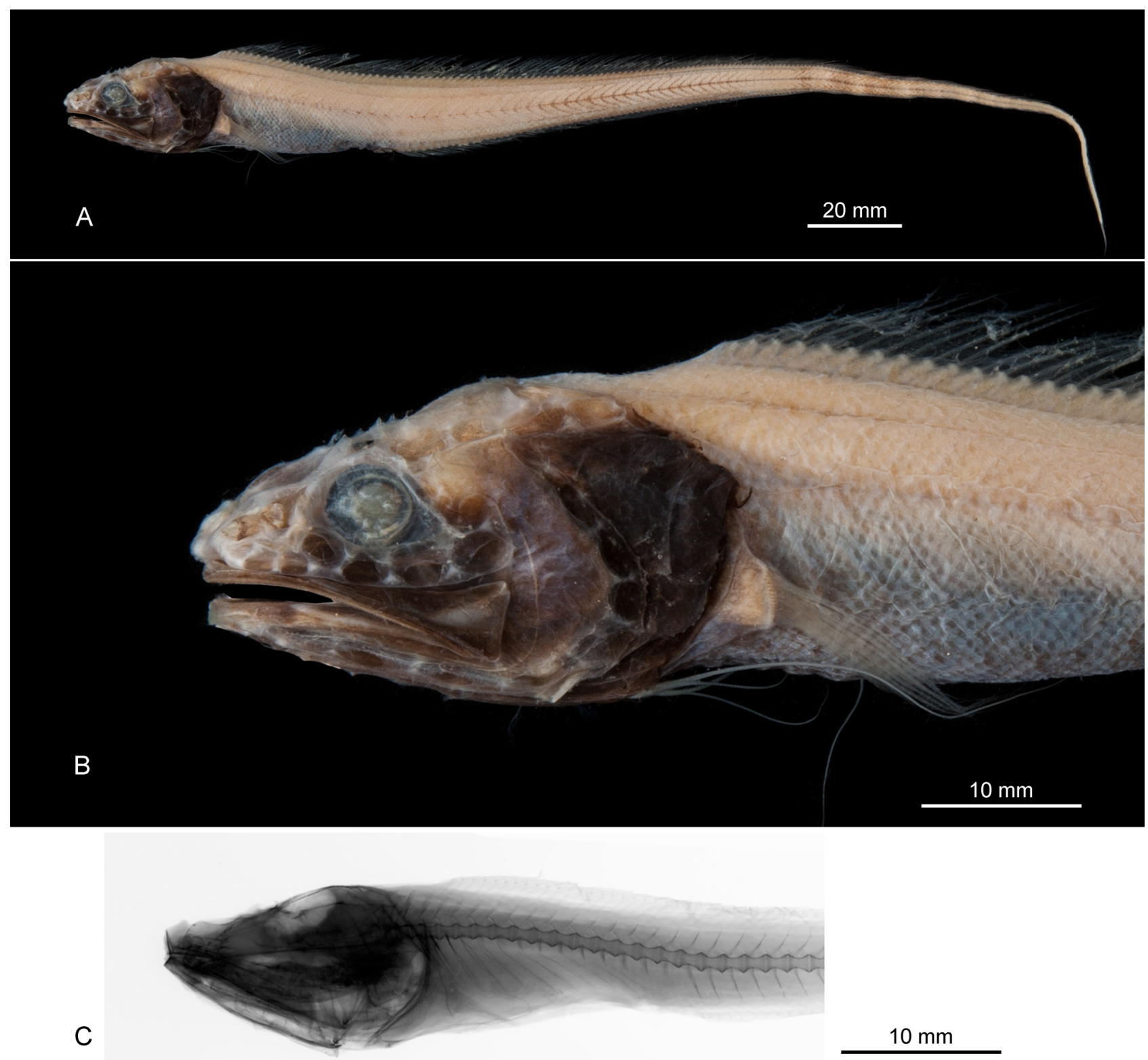

FIGURE 21. Porogadus guentheri Jordan \& Fowler, 1902; 21A-B, BSKU 86819, 248 mm SL, 32¹8'N, 132²1'E, 16781690 m; 21C, NSMT P.101668, 110 mm SL, 2759’'N, 127³4’'E, 1276-1319 m.

Otolith morphology $(\mathrm{n}=5)$. Size up to $4.1 \mathrm{~mm}$ in length; $\mathrm{OL}: \mathrm{OH}=1.45-1.64 ; \mathrm{OH}: \mathrm{OT}=2.4-2.9$. Relatively thin and moderately elongate otoliths, anteriorly broadly rounded, posteriorly slightly expanded, somewhat less rounded than anterior tip. Dorsal rim with broad, rounded pre- to mediodorsal lobe, ventral rim regularly curved. All rims smooth. Inner face nearly flat, smooth, with short, centrally positioned sulcus; OL:TCL $=1.87-2.52$. Sulcus with shallow, usually undivided sulcus, but with indentation of ventral margin at junction (collum) between ostium and cauda, rarely with indistinctly separated colliculi; OCL:CCL $=3.5$ in the event of distinctive colliculi (Fig. 22C). Dorsal field with large indistinct depression; ventral field smooth, without ventral furrow. Outer face smooth, with mild, anteriorly positioned umbo. 

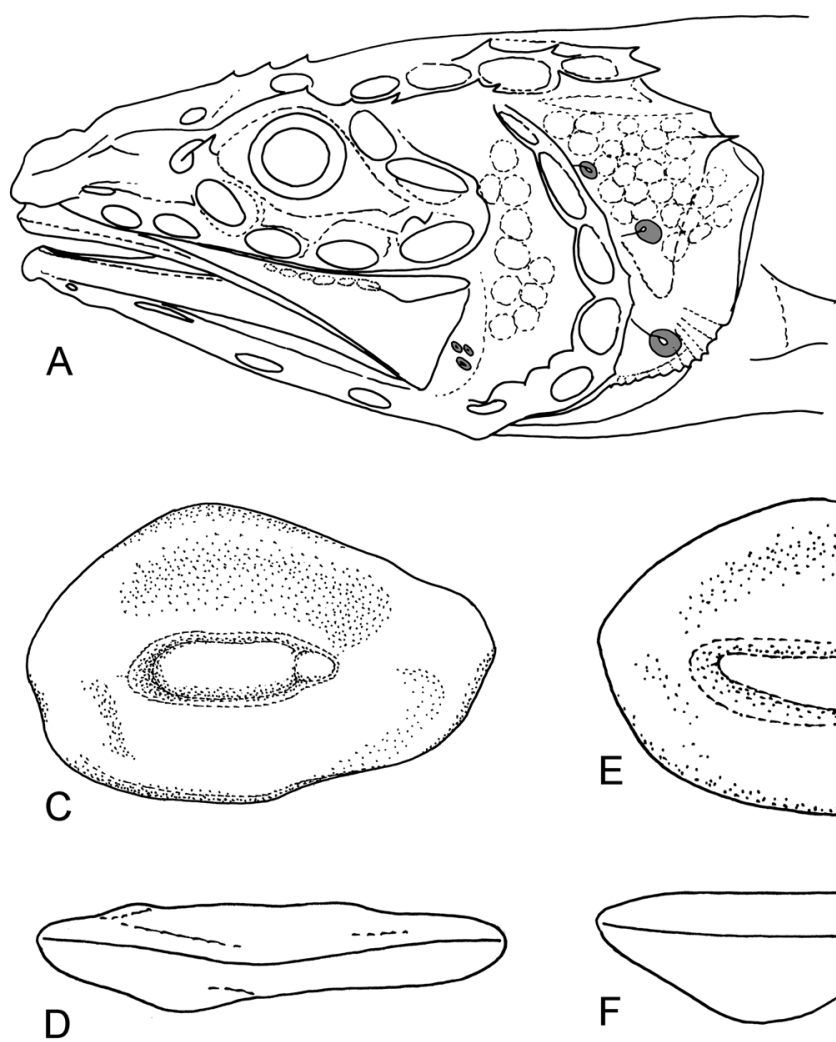
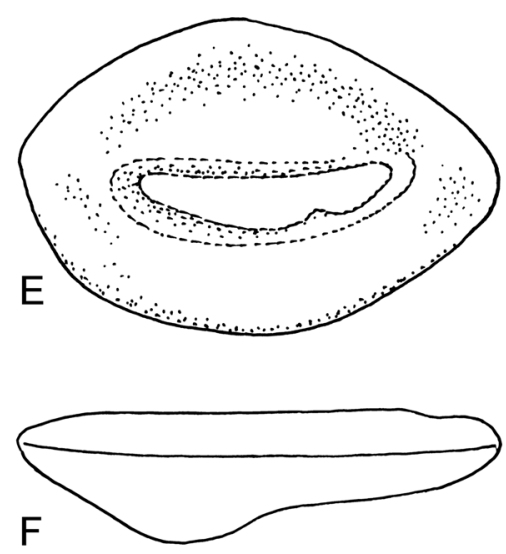

$1 \mathrm{~mm}$

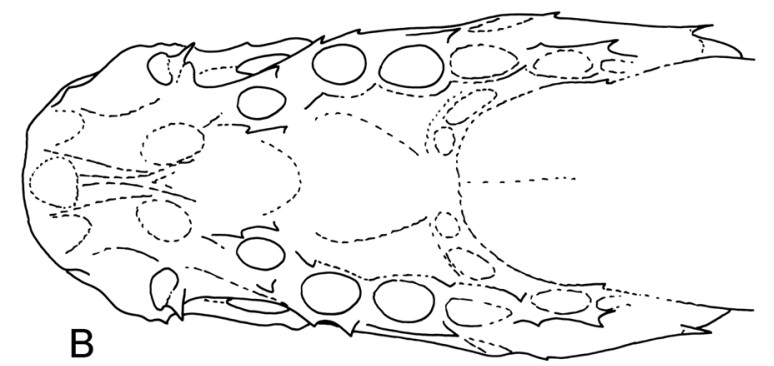

$10 \mathrm{~mm}$

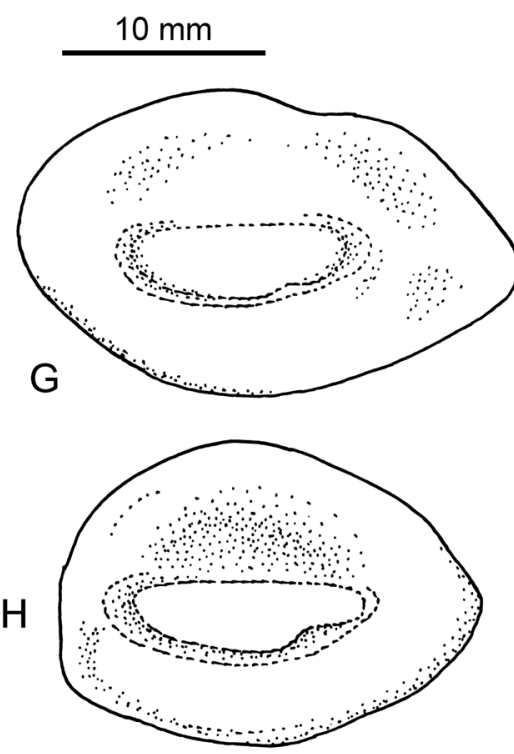

FIGURE 22. Porogadus guentheri Jordan \& Fowler, 1902; 22A-B, BSKU 86832, 255 mm SL, 32॰ 18 ’N, 132 $211^{\prime}$ E, 1678-1690

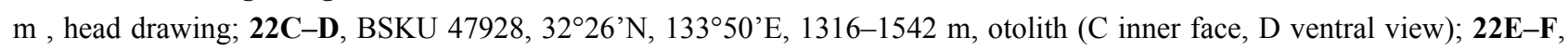
BSKU 86818, $251 \mathrm{~mm} \mathrm{SL}, 32^{\circ} 24^{\prime} \mathrm{N}, 132^{\circ} 16^{\prime} \mathrm{E}, 1501-1516 \mathrm{~m}$, otolith (E inner face, F ventral view); 22G, BSKU 86819, 248 $\mathrm{mm} \mathrm{SL}, 32^{\circ} 18^{\prime} \mathrm{N}, 132^{\circ} 21^{\prime} \mathrm{E}, 1678-1690 \mathrm{~m}$, otolith (inner face); 22H, BSKU 43444, $257 \mathrm{~mm} \mathrm{SL}, 32^{\circ} 21^{\prime} \mathrm{N}, 132^{\circ} 27^{\prime} \mathrm{E}, 1642-1651$ $\mathrm{m}$, otolith (Inner face).

Coloration. Live coloration not known. Color of preserved specimens light brown on body; belly darker and head distinctly darker than body, opercle black.

Discussion. Within the Porogadus trichiurus group, P. guentheri is characterized by an unusual short predorsal length (13.7-14.7 vs 14.5-18.2). It shares with P. trichiurus the bladed nature of the long gill rakers but has many intermittent plates (vs none or very few). It further differs from P. trichiurus in the presence of a sharp and free opercular spine (vs flat and weak), lesser teeth on the vomer, which is often partially naked, the lack of scales on the occiput and around the eye (vs present) and the presence of scales on the maxilla (vs absent), and a much more elongate otolith (OL:OH $=1.45-1.64$ vs $1.04-1.27)$. It differs from $P$. solomonensis additionally to the predorsal length in the number of long gill rakers (18-20 vs 16-17), the head length ( $\mathrm{HL}=13.6-15.0$ vs $15.3-16.2)$, the feeble dentition on vomer (naked up to 1-2 rows of teeth vs 4 and more rows of teeth), the absence of paired basibranchial tooth patches (vs present), and stronger head spines, particularly along the inner rim of the preopercle. Porogadus guentheri shares the sharp and extruding spine with P. lacrimatus but differs additionally to the predorsal length in the ratio HL:HD (1.71-1.79 vs 1.52-1.59), and the bladed gill rakers (vs not bladed). Porogadus guentheri is remarkable for a rather large variability in its otolith morphology, which is greater than in other species of the genus, particularly in respect to the degree of separation (or fusion) of ostium and cauda and the range in relative sulcus length (OL:TCL $=1.87-2.52)$.

Distribution. Porogadus guentheri appears to be endemic to the southern shores of Japan from the Sagami Bay southwards and along the back arc of the Ryukyu Island Chain at moderate depth (900-1700 m) and not venturing away from the shelf break for more than $100 \mathrm{~km}$. Prokofiev (2005) described a single specimen from the Emperor Seamount as Porogadus sp. cf. guentheri and noted that it differed (among others) in the lower number of long gill rakers on the first arch (16 vs 19 in the holotype of $P$. guentheri). We have not studied this specimen, but judging 
from the range observed in Japanese specimens in respect to gill raker counts we would indeed assume, that the specimen from the Emperor Seamount might represent a different species.

\section{Porogadus lacrimatus n. sp.}

Figs. 23-24, 45, 50, Tab. 1-7

Material examined (3 specimens): Holotype ZMUC P77845, $204 \mathrm{~mm}$ SL, BIOCAL exp. Sta. 05, off New Caledonia, 21 $1^{\circ} 16^{\prime} \mathrm{S} 166^{\circ} 43^{\prime} \mathrm{E}, 2340 \mathrm{~m}, 11$ August 1985; paratypes BSKU 82357, $194 \mathrm{~mm}$ SL and BSKU 82358, $161 \mathrm{~mm}$ SL, 0159'S 157²'ㄹ, 1610 m, R/V Hakuho-maru, 3 m beam trawl, 9 Feb. 1990.

Diagnosis. Precaudal vertebrae 16; long gill rakers on first gill arch 18-20; HL:HD 1.52-1.59; moderately strong head spines: on ethmoidal, prefrontal, interorbital, supraorbital, sphenotic, supratemporal, inner and outer posttemporal, weak along inner preopercular rim, on lacrimal with ridge, absent on outer preopercular rim and 5th infraorbital; opercular spine sharp, extruding; maxilla without scales; small opercular flap; lower lateral line pores until beginning of anal fin 18; vomer with narrow dentition patch with few teeth; palatines with moderately broad dentition patch (3-4 rows of teeth); otolith with single colliculum; OL:OH $=1.44 ; \mathrm{OL}: \mathrm{TCL}=2.37$.

Description. Meristics: precaudal vertebrae 16, 2 (1-2) last vertebrae without ribs; pectoral-fin rays 16 (1617); $\mathrm{D} / \mathrm{V}=5(5-6) ; \mathrm{D} / \mathrm{A}=21$ (21-24); V/A = 16 (16-17); long gill rakers 19-20 (18-20). Gill rakers in holotype on lower first gill arch with four short rakers, followed by a series of 20 long rakers. The lower seven of those intercept by short rakers. These are smaller than in most species and placed on the inner part of the gill arch. Upper gill arch with a series of six very short rakers and four semi long rakers intercepted.

Morphometrics: in \% of SL: HL 14.9 (13.7-14.0); maximal HD 9.3 (8.7-9.6); HD through center of eye 6.7 (6.4-6.7); bony interorbital width 3.8 (3.1-3.8); snout length 4.6 (4.4-4.6); upper jaw length 9.3 (8.6-9.3); predorsal 16.3 (15.4-16.3); preanal 28.7 (26.7-28.7); prepelvic 12.2 (11.3-12.2); prepectoral 15.5 (14.1-15.2); pectoral length no measurable. Relations: HL:HD = 1.59 (1.52-1.59); HL to snout length 3.26 (3.03-3.34); preanal to predorsal 1.76 (1.73-1.76); predorsal to prepectoral $1.05(1.05-1.10)$.

Slender fish with long tapering tail and short, rounded snout. Maximal size of fishes investigated $204 \mathrm{~mm}$ SL. Head relatively short and compact, with flat to slightly convex dorsal profile, with strong spines and ridges as follows: ethmoidal (1), prefrontal (1), interorbital (2-3), supraorbital (1-2), sphenotic (2), supratemporal (2), inner and outer posttemporal (2-3); weak spines as follows: inner preopercular rim (2-4), lacrimal (1 short ridge); no spines along outer preopercular rim and on 5th infraorbital. Opercle with sharp, extruding spine. Eye moderately large, located in strongly asymmetric orbit. Maxilla extending far beyond eye, strongly widened posteriorly and with distinct supramaxilla. Infra-/postorbital and mandibular-preopercular pores wide, head top with cavernous system extending between occiput and sphenotic and supraorbital spines, sometimes opening in up to 4 bilateral symmetrical openings (pores or damaged thin skin cover?). Head squamation on opercle, and cheeks, absent on maxilla, occiput, frontal, and around eyes. Opercle with two moderately sized neuromasts behind preopercular edge; opercular flap small. Lateral line rows rarely well visible and therefore number of pores countable only in rare instances. Lower lateral line row with 18 pores until beginning of anal fin in one specimen.

Dentition. All teeth tiny and cone-shaped. Vomer without or with only few teeth anteriorly and with a single row posteriorly; palatines with a short and narrow dentition patch with 3-4 rows of teeth in middle part. Premaxilla tooth patches narrow, not fused anteriorly; ca. 3 teeth rows anteriorly and 1-2 rows posteriorly. Dentary tooth patches not fused anteriorly; ca. 5 teeth rows anteriorly and 2 rows posteriorly. Median basibranchial tooth patch short.

Otolith morphology $(\mathrm{n}=1$; holotype). Size $3.6 \mathrm{~mm}$ in length; $\mathrm{OL}: \mathrm{OH}=1.44 ; \mathrm{OH}: \mathrm{OT}=2.8$. Relatively thin and moderately elongate otoliths with tear-drop shape, anteriorly broadly rounded, posteriorly slightly expanded and pointed. Dorsal rim with broad, rounded predorsal lobe, ventral rim regularly curved. All rims smooth. Inner face nearly flat, smooth, with short, centrally positioned sulcus; OL:TCL $=2.37$. Sulcus shallow, undivided, with broad and shallow colliculum. Dorsal field with indistinct depression; ventral field smooth, with faint ventral furrow anteriorly joining ventral rim of otolith below anterior part of sulcus. Outer face smooth, with mild, anteriorly positioned umbo.

Coloration. Live coloration not known. Color of preserved specimens light to medium brown throughout except for dark opercle. 

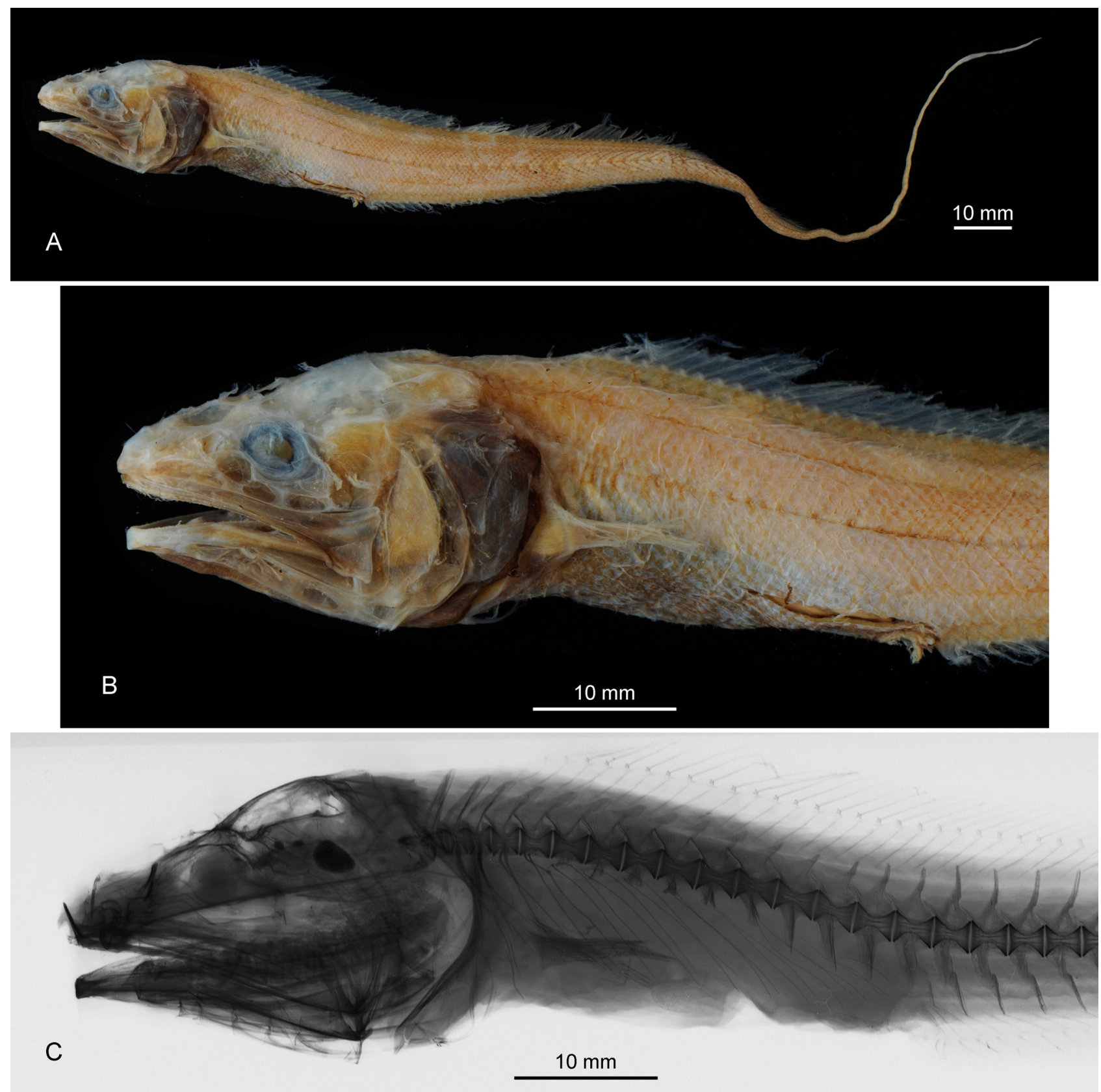

FIGURE 23. Porogadus lacrimatus n. sp., ZMUC P77845, holotype, $204 \mathrm{~mm} \mathrm{SL}, 21^{\circ} 16^{\prime} \mathrm{S}, 166^{\circ} 43^{\prime} \mathrm{E}, 2340 \mathrm{~m}$, (A-B photography, C x-ray photograph).

Discussion. Porogadus lacrimatus differs from other members of the Porogadus trichiurus group in the short and compact head (HL:HD = 1.52-1.59 vs 1.71-1.81) and the head being more light colored (in preserved specimens) than in the other species.

Distribution. Porogadus lacrimatus is known from few specimens from the tropical West-Pacific from the Solomon and New Hebrides seas, where it occurs at moderate depth between 1600 and 2340 m and apparently can venture out from the shelf break for a considerable distance to about $500 \mathrm{~km}$.

Etymology. From lacrima (Latin) = tear, referring to the tear-drop shape of the otolith. 

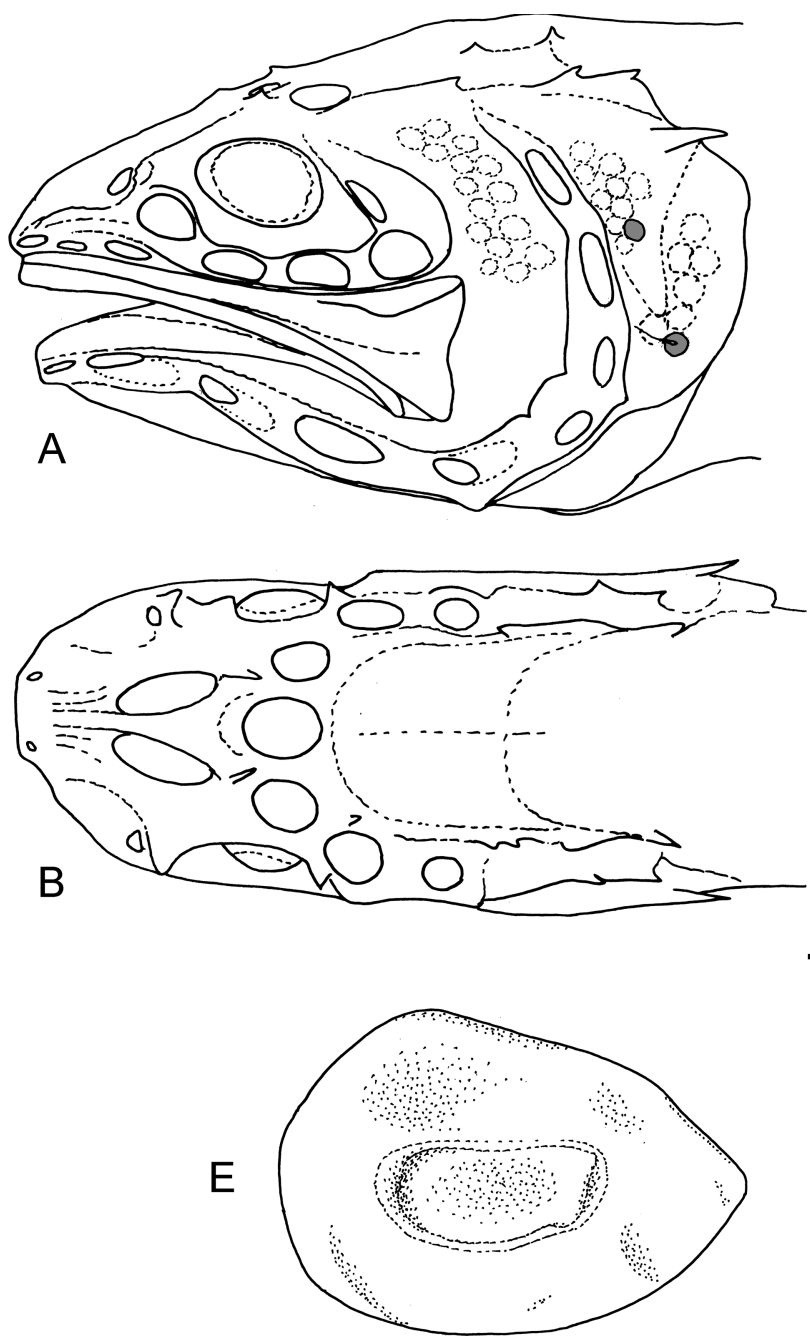
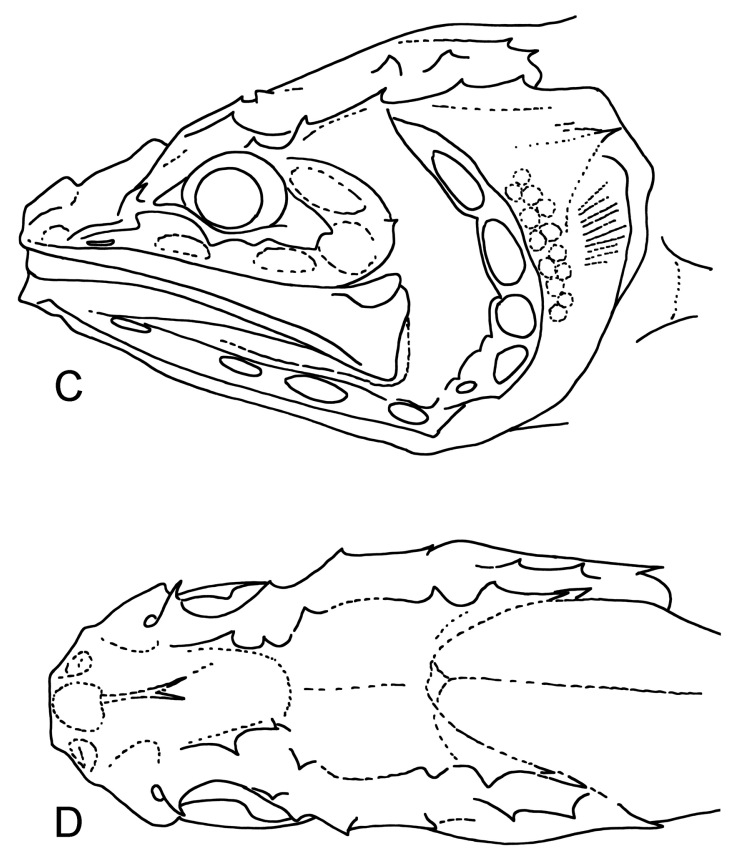

$10 \mathrm{~mm}$

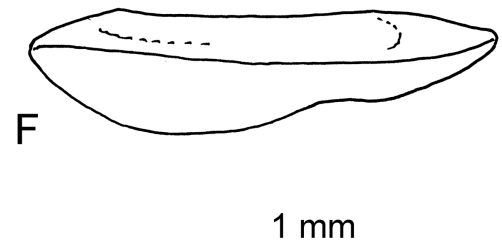

FIGURE 24. Porogadus lacrimatus n. sp.; 24A-B, ZMUC P77845, holotype, $204 \mathrm{~mm} \mathrm{SL}, 21^{\circ} 16^{\prime} \mathrm{S}, 166^{\circ} 43^{\prime} \mathrm{E}, 2340 \mathrm{~m}$, head drawing; 24C-D, BSKU 82358, paratype, 161 mm SL, 01 ${ }^{\circ} 59^{\prime}$ S, $157^{\circ} 12^{\prime}$ E, 1610 m; 24E-F, ZMUC P77845, holotype, $204 \mathrm{~mm}$ SL, $21^{\circ} 16^{\prime} \mathrm{S}, 166^{\circ} 43^{\prime} \mathrm{E}, 2340 \mathrm{~m}$, otolith (E inner face, F ventral view).

\section{Porogadus solomonensis n. sp.}

Figs. 4, 25-26, 45, 50, Tab. 1-7

Porogadus sp: Nielsen \& Møller 2007: 33, fig. 18.

Material examined (3 specimens): Holotype ZMUC P771579, 175+ mm SL, Galathea 3 expedition, R/V Vaedderen, sta. 061219-05, collected by Jørgen G. Nielsen and Tammes Menne, Solomon Sea, 1345' S 156 ${ }^{\circ} 41^{\prime} \mathrm{E}, 2255-$ 2283 m, 19 Dec. 2006; paratypes ZMUC P771578, 173+ mm SL and ZMUC P771581, 175 mm SL, same data as holotype.

Diagnosis. Precaudal vertebrae 17-18; long gill rakers on first gill arch 16-17; HL:HD 1.71-1.79; relatively few and moderately strong head spines: on ethmoidal, interorbital, supraorbital, sphenotic, supratemporal, inner and outer posttemporal; weak lacrimal ridge; absent on prefrontal, along inner and outer preopercular rim and 5th infraorbital; opercular spine weak, flat; maxilla without scales; small opercular flap; lower lateral line pores until beginning of anal fin 19; basibranchial tooth patches consisting of single median and pair of small lateral patches; vomer with broad dentition patch with 4 rows of teeth; palatines with broad dentition patch (5-7 rows of teeth); otolith with single colliculum; OL:OH =1.42-1.60; OL:TCL=2.24-2.34.

Description. Meristics: precaudal vertebrae 17 (17-18), 2 (1-2) last vertebrae without ribs; pectoral-fin rays 18 (17-18); D/V = 7 (6-7); D/A = 23 (23-27); V/A = 18 (18-19); long gill rakers on lower first gill arch 17 (16-17). 
Gill rakers in the holotype on lower first gill arch with seven short rakers, followed by a series of 17 long rakers. The lower seven of those intercept by small plate shaped rakers. The long rakers are blade shaped and armed with spinules on the inner rim. Upper gill arch with a series of five semi long rakers and five plate like rakers intercepted.

Morphometrics: in \% of SL: HL 16.2 (15.3-16.2); maximal HD 9.0 (8.9-9.1); HD through center of eye 6.3 (5.9-6.3); bony interorbital width 3.6 (3.1-3.6); snout length 5.0 (4.7-5.4); upper jaw length 9.8 (9.0-9.8); predorsal 18.2 (17.2-18.2); preanal 30.0 (29.6-30.0); prepelvic 13.5 (12.3-13.5); prepectoral 16.6 (15.6-16.6); pectoral length no measurable. Relations: HL:HD $=1.79(1.71-1.79)$; HL to snout length $3.21(2.81-3.33)$; preanal to predorsal 1.65 (1.65-1.72); predorsal to prepectoral $1.09(1.09-1.13)$.

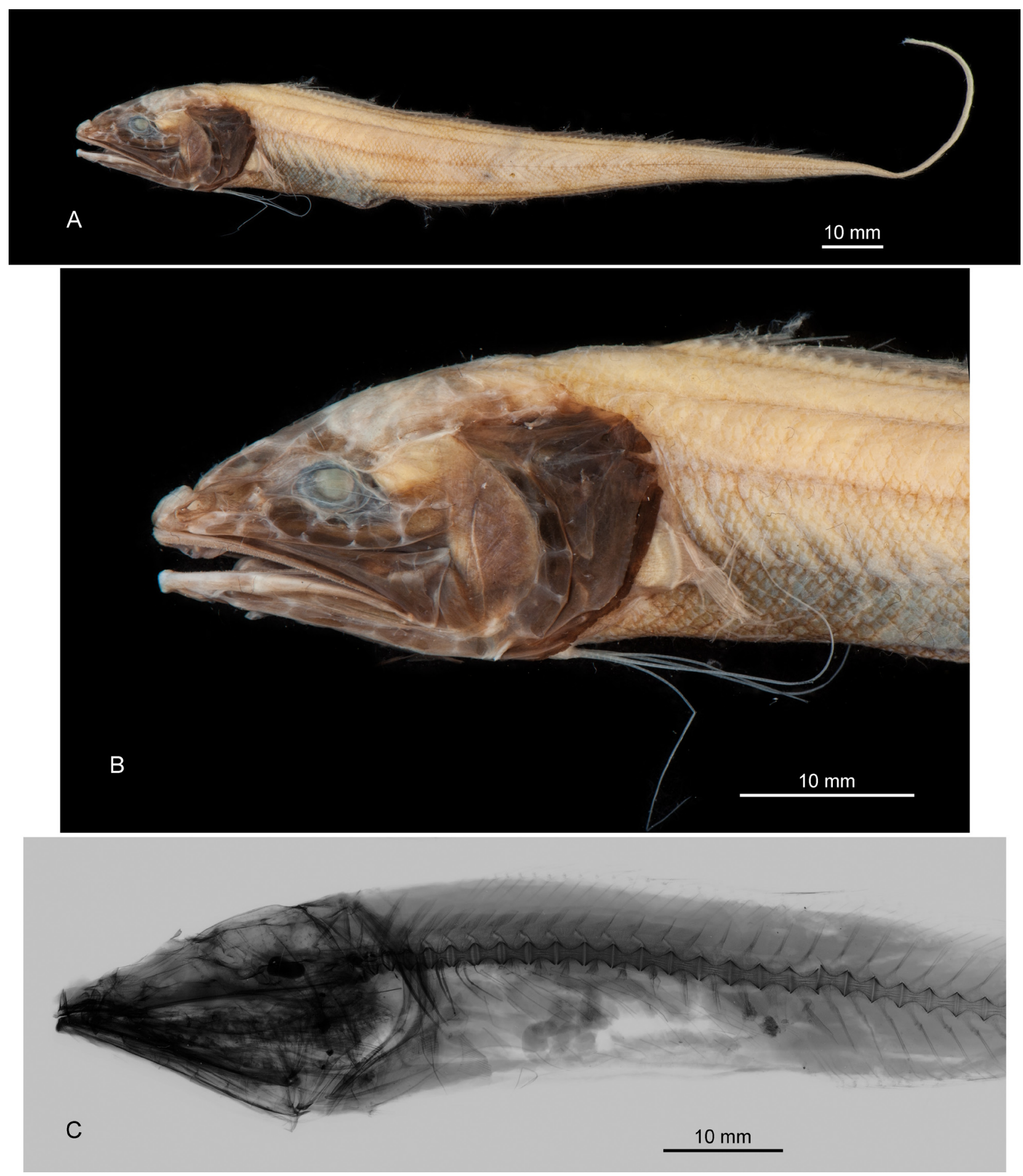

FIGURE 25. Porogadus solomonensis n. sp.; 25A-B, ZMUC P771579, holotype, $175+\mathrm{mm}$ SL, $13^{\circ} 45^{\prime} \mathrm{S}, 156^{\circ} 41^{\prime} \mathrm{E}, 2^{2255-}$ 2283 m; 25C, ZMUC P771578, paratype, 173+ mm SL, 134'ㅅ, 15641’E, 2255-2283 m. 
Slender fish with long tapering tail and moderately long snout. Maximal size of fishes investigated $175 \mathrm{~mm}$ SL. Head moderately long and moderately slender, with flat dorsal profile, with few strong spines and ridges as follows: ethmoidal (1), interorbital (1), supraorbital (1), sphenotic (2), supratemporal (2), inner and outer posttemporal (2-3); weak lacrimal ridge; no spines on prefrontal, along inner and outer preopercular rims and on 5th infraorbital. Opercle with weak, flat spine. Eye small, located in strongly asymmetric orbit. Maxilla extending far beyond eye, strongly widened posteriorly and with distinct supramaxilla. Infra-/postorbital and mandibular-preopercular pores wide, head top with cavernous system extending from prefrontal to between occiput and sphenotic and supraorbital spines and on occiput in front of nape with up to 5 bilateral symmetrical openings (pores or damaged thin skin cover?). Head squamation on opercle, and cheeks, absent on maxilla, occiput, frontal, and around eyes. Opercle with three moderately sized neuromasts behind preopercular edge; opercular flap small. Lateral line rows rarely well visible and therefore number of pores countable only in rare instances. Lower lateral line row with 19 pores until beginning of anal fin in one specimen.

Dentition. All teeth tiny and cone-shaped. Vomer with a short dentition patch with 4 rows of teeth anteriorly, naked or with few teeth posteriorly; palatines with a broad dentition patch with 5-7 rows of teeth in middle part. Premaxilla tooth patches not fused anteriorly; ca. 7 teeth rows anteriorly and 1-2 rows posteriorly. Dentary tooth patches narrow, not fused anteriorly; ca. 4 teeth rows anteriorly and a single row posteriorly. Basibranchial tooth patches consisting of single, long median and pair of small lateral patches

Otolith morphology $(\mathrm{n}=3$ ). Size up to $3.3 \mathrm{~mm}$ in length (holotype $2.8 \mathrm{~mm}) ; \mathrm{OL}: \mathrm{OH}=1.42-1.60 ; \mathrm{OH}: \mathrm{OT}=$ 2.7-2.9. Relatively thin and moderately elongate otoliths with irregular, subtriangular shape, anteriorly and posteriorly inferiorly rounded, posteriorly slightly expanded. Dorsal rim with broad, rounded pre- to mediodorsal angle, ventral rim shallow, nearly flat. All rims smooth, somewhat irregular. Inner face nearly flat, smooth, with short, centrally positioned sulcus; $\mathrm{OL}: \mathrm{TCL}=2.24-2.34$. Sulcus shallow, undivided, with broad and shallow colliculum, but somewhat narrowed posteriorly. Dorsal field with large indistinct depression; ventral field smooth, with faint ventral furrow anteriorly joining ventral rim of otolith below anterior part of sulcus. Outer face smooth, with mild, anteriorly positioned umbo.
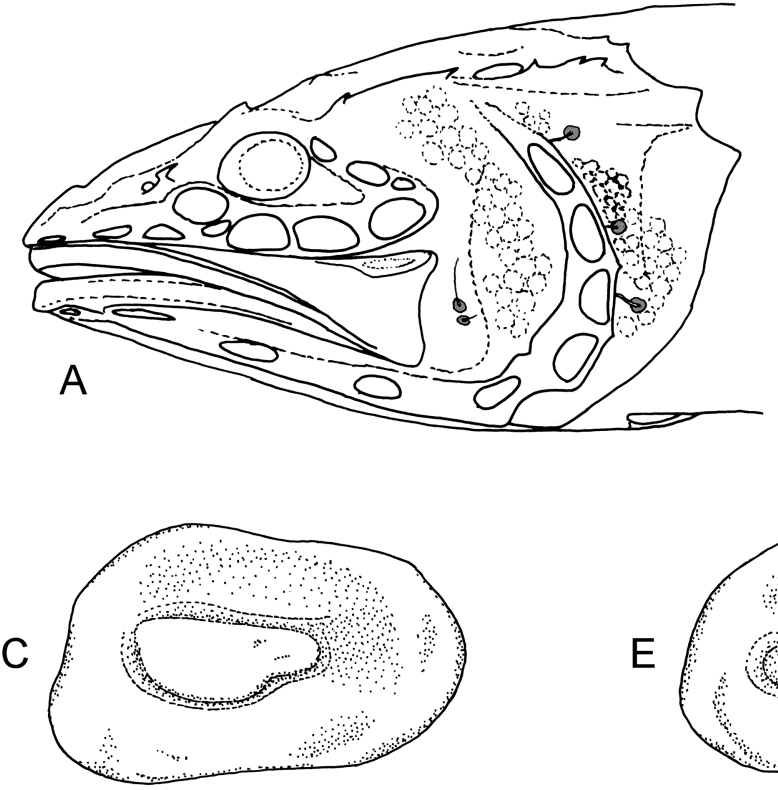

D

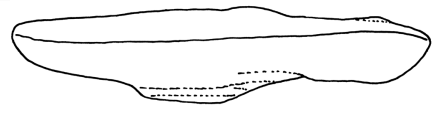

$\mathrm{F}$
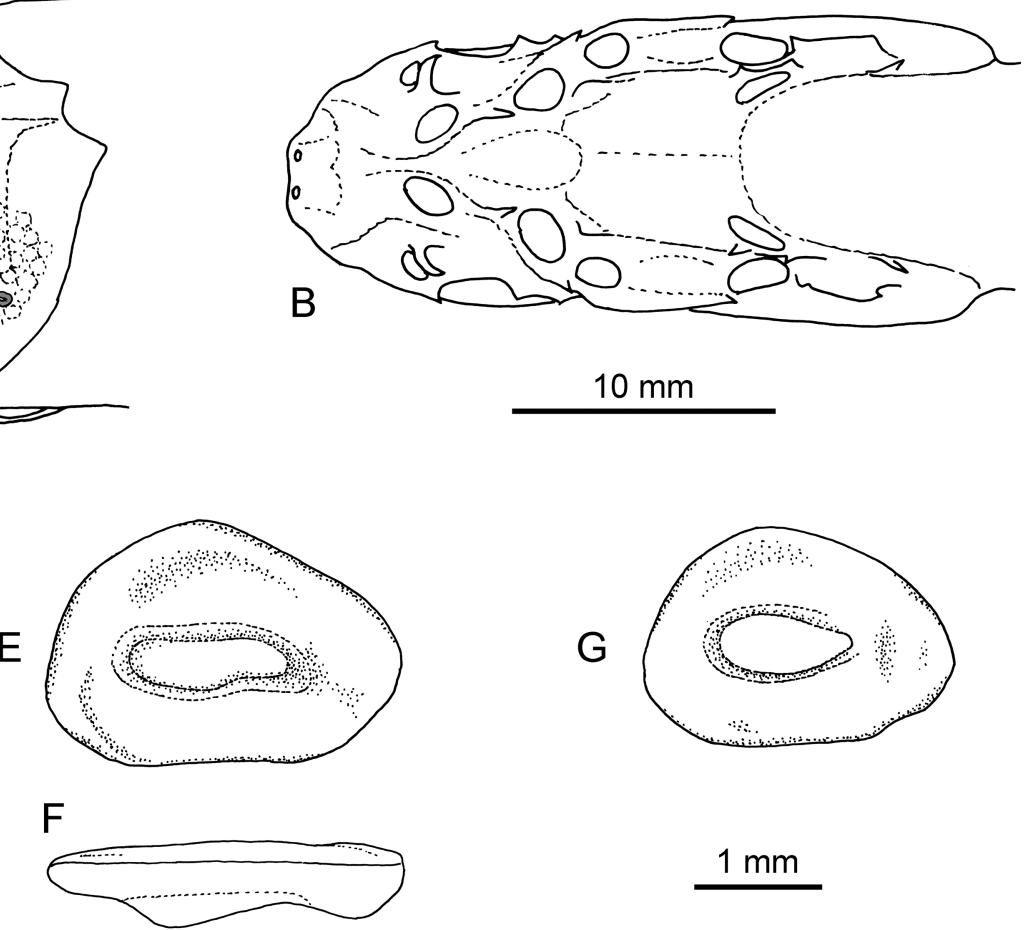

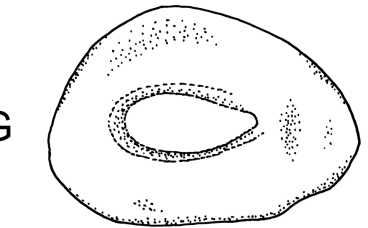

$1 \mathrm{~mm}$

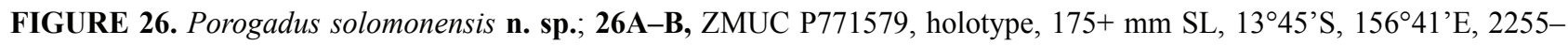
2283 m, head drawings; 26C-D, ZMUC P771578, paratype, 173+ mm SL, 1345'S, 156 41 'E, 2255-2283 m, otolith (C inner

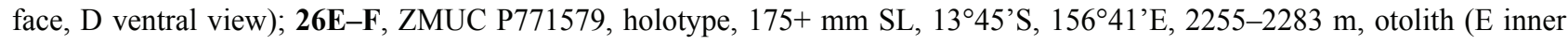
face, F ventral view); 26G, ZMUC P771581, $175 \mathrm{~mm} \mathrm{SL}$, paratype, 1345'S, 156 $41^{\prime}$ 'E, 2255-2283 m, otolith (inner face). 
Coloration. Fresh dead color with light brown body and dark, almost black head and opercle, but head top lighter; belly dusty grey. Color of preserved specimens similar, but darkness of head and opercle somewhat faded.

Discussion. Porogadus solomonensis is the only species with a regularly occurring pair of basibranchial tooth patches in addition to the long central patch. It differs from other members of the Porogadus trichiurus group also in the low number of long gill rakers on the first gill arch (16-17 vs 18-21), the high predorsal length (17.2-18.2 vs 13.7-16.3, rarely 17.0), and the broad tooth patches on vomer and palatines.

Distribution. Porogadus solomonensis is only known from the type locality in the Solomon Sea, where it occurs at moderate depth between 2255-2283 m and about $350 \mathrm{~km}$ off the shelf break.

Etymology. Named after the type location, the Solomon Sea.

\section{Porogadus trichiurus (Alcock, 1890)}

Figs. 27-28, 45, 50, Tab. 1-7

Dermatorus trichiurus Alcock 1890: 298; Alcock 1892: pl. 1, fig. 1.

Porogadus trichiurus: Nielsen et al. 1999: 86.

Porogadus (Dermatorus) trichiurus: Nolf 1980: 91: pl. 11 fig. 10 (otolith).

Material examined (9 specimens): AMS I.36456-009 (2 specimens), 162 and $172 \mathrm{~mm}$ SL, Philippines, Lagonoy Gulf, $13^{\circ} 21^{\prime} 19^{\prime \prime} \mathrm{N} 124^{\circ} 12^{\prime} \mathrm{E}, 1037-1100 \mathrm{~m}, 30 \mathrm{~m}$ otter trawl, collected by Dr. J. Paxton, 24. September 1995; CAS 83066 (2 specimens), 230 and 144 mm SL, (probably same location as AMS I.36456-009); MNHN 1994-0760 (4 specimens), 95-160 mm SL, $22^{\circ} 06^{\prime}$ S $166^{\circ} 27^{\prime} \mathrm{E}, 1850 \mathrm{~m}$, Biocal Expedition, Sta. cp27, collected by J. Charcot, 28 August 1985; SIO 03-157, $158 \mathrm{~mm}$ SL, $23^{\circ} 01^{\prime} \mathrm{N} 66^{\circ} 01^{\prime} \mathrm{E}$, Indian Ocean, off Karachi, trawl, 1677-1713 m, 14 Oc-

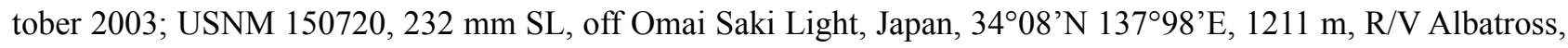
sta. D5082, 20 December 1906.

Diagnosis. Precaudal vertebrae 15-17; long gill rakers on first gill arch 18-21, with very few intermittent patches; HL:HD 1.73-1.81; strong head spines: on ethmoidal, lacrimal, prefrontal, interorbital, supraorbital, sphenotic, supratemporal, inner and outer posttemporal, inner and outer preopercular rims, and 5th infraorbital; opercular spine weak, flat; maxilla without scales; small opercular flap with ridges on lower part; lower lateral line pores until beginning of anal fin 15; vomer with moderately broad dentition patch with 1-3 rows of teeth; palatines with moderately broad dentition patch $2-4$ rows of teeth; otolith with single colliculum; $\mathrm{OL}: \mathrm{OH}=1.04-1.27 ; \mathrm{OL}: \mathrm{TCL}=$ $1.50-2.14$.

Description (based on non-types). Meristics: precaudal vertebrae 15-17, 0-1 last vertebrae without ribs; pectoral-fin rays 16-18; $\mathrm{D} / \mathrm{V}=4-6 ; \mathrm{D} / \mathrm{A}=22-26 ; \mathrm{V} / \mathrm{A}=17-19 ;$ long gill rakers on lower first gill arch 18-21. Gill rakers in a typical specimen (USNM 150720) from off Japan, on lower first gill arch with five short rakers, followed by a series of 19 long rakers. The lower 9 of those intercept by plate shaped rakers. These are placed on the inner part of the gill arch and not directly between the long rakers. The long rakers are blade shaped, and armed with spinules. Upper gill arch with two plate shaped rakers, followed by a semi-long raker, a plate like raker, two semi-long rakers and two plate shaped rakers.

Morphometrics: in \% of SL: HL 14.5-16.8; maximal HD 8.1-9.4; HD through center of eye 5.5-6.8; bony interorbital width 3.5-3.9; snout length 4.9-6.0; upper jaw length 8.9-10.6; predorsal 15.3-17.0; preanal 27.5-29.6; prepelvic 11.6-12.3; prepectoral 15.2-17.5; pectoral length 9.4 (single specimen). Relations: HL:HD = 1.73-1.81; HL to snout length 2.60-2.98; preanal to predorsal 1.71.187; predorsal to prepectoral 0.97-1.09.

Slender fish with long tapering tail and moderately long snout. Maximal size of fishes investigated $172 \mathrm{~mm}$ SL. Head moderately long and moderately slender, with flat to slightly convex dorsal profile, with few strong spines and ridges as follows: ethmoidal (1), lacrimal (ridge and 1 spine), prefrontal (1 weak), interorbital (1-3), supraorbital (2-3), sphenotic (2), supratemporal (1-2), inner and outer posttemporal (2-3), inner preopercular rim (4-5), outer preopercular rim (2-3 weak), and on 5th infraorbital (1-3). Opercle with short, weak spine and flat base. Eye relatively large, located in strongly asymmetric orbit. Maxilla extending far beyond eye, strongly widened posteriorly and with distinct supramaxilla. Infra-/postorbital and mandibular-preopercular pores wide, head top with cavernous system between occiput and sphenotic and supraorbital spines and on occiput in front of nape, the latter with 1 or 2 bilateral symmetrical openings (pores or damaged thin skin cover?). Head squamation on opercle, cheeks, and occiput, few scales around eye, scales absent on maxilla and frontal. Opercle with two to three moderately sized neu- 
romasts behind preopercular edge; opercular flap small, with radial ridges on lower third. Lateral line rows rarely well visible and therefore number of pores countable only in rare instances. Upper lateral apparently very long with 22 pores, and lower lateral line row with 15 pores until beginning of anal fin in one specimen.
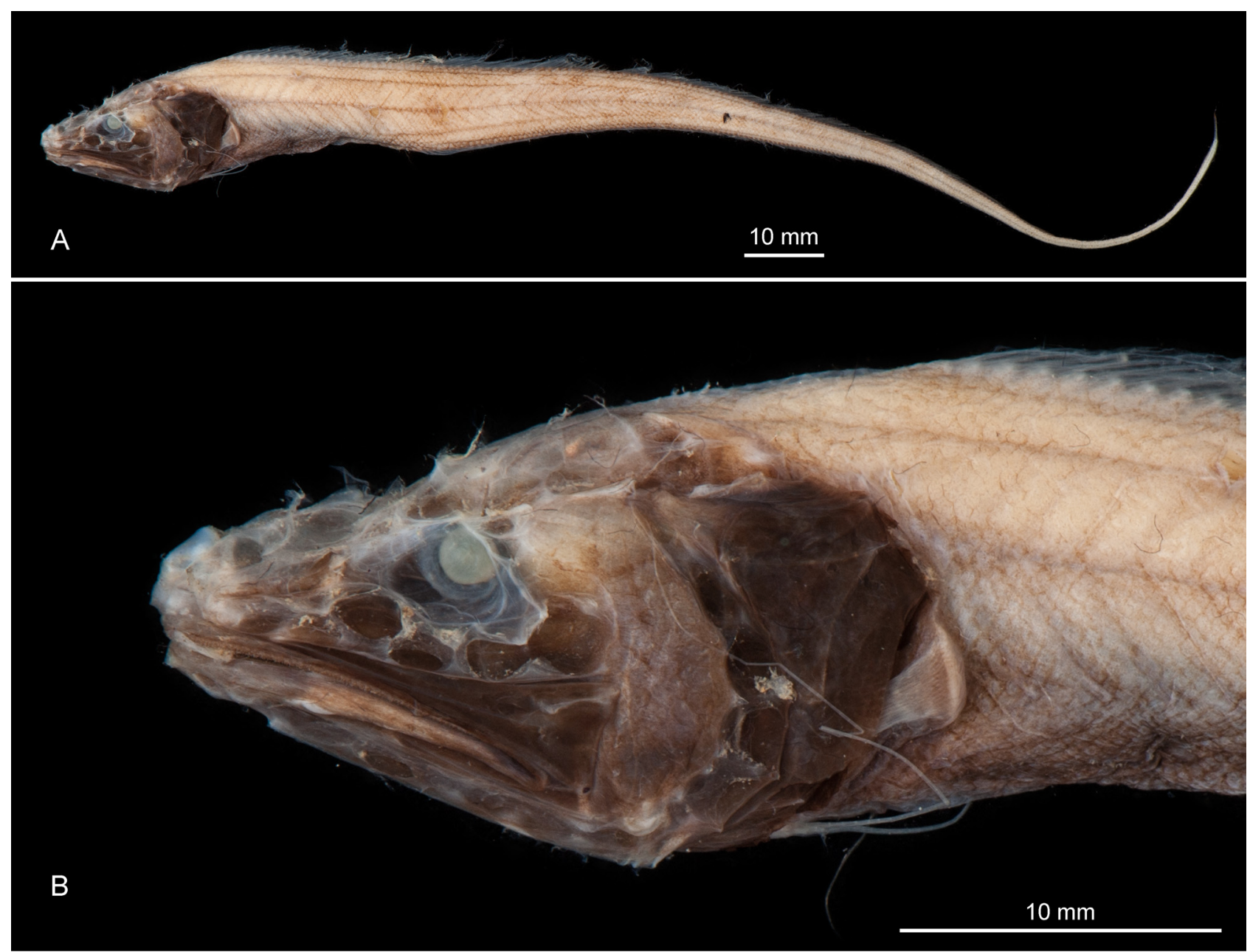

C

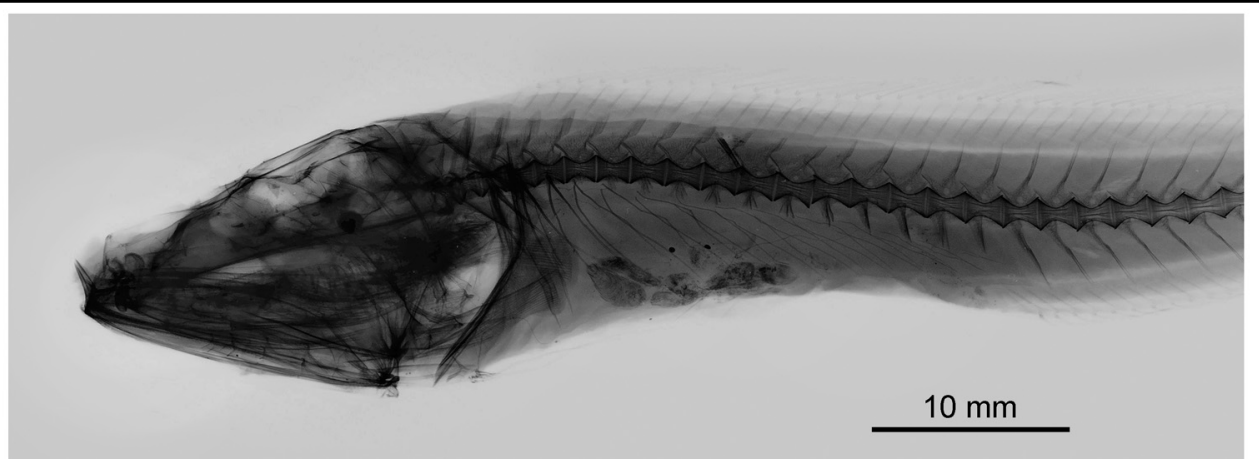

FIGURE 27. Porogadus trichiurus (Alcock, 1890), AMS I.36456-009, $162 \mathrm{~mm}$ SL, $13^{\circ} 21^{\prime} \mathrm{N}, 124^{\circ} 12^{\prime} \mathrm{E}, 1037-1100 \mathrm{~m}$, (A-B photographs, C x-ray photograph).

Dentition. All teeth tiny and cone-shaped. Vomer with a narrow and short dentition patch with 1-3 rows of teeth anteriorly, naked posteriorly; palatines with a short and narrow dentition patch with 2-4 rows of teeth in middle part. Premaxilla tooth patches not fused anteriorly; ca. 5 teeth rows anteriorly and 2-3 rows posteriorly. Dentary tooth patches not fused anteriorly; 3-4 teeth rows anteriorly and a single row posteriorly. Median basibranchial tooth patch short.

Otolith morphology $(\mathrm{n}=6)$. Size up to $2.5 \mathrm{~mm}$ in length; $\mathrm{OL}: \mathrm{OH}=1.04-1.27$; OH:OT $=2.2-3.5$. Variably thick and relatively compressed otoliths with roundish to oval outline. Anterior and posterior rims blunt, rounded. Dorsal rim high, rounded, ventral rim moderately deep, somewhat irregularly rounded. All rims smooth. Inner face 
nearly flat, smooth, with long, centrally positioned sulcus reaching relatively close to anterior and posterior rims of otolith; OL:TCL $=1.50-2.14$. Sulcus shallow, undivided, with broad and shallow colliculum. Dorsal field with large indistinct depression; ventral field smooth, sometimes with faint ventral furrow close to ventral rim of otolith. Outer face smooth, with mild, anteriorly positioned umbo.

Coloration. Live coloration not known. Color of preserved specimens with light brown body and dark brown head, and opercle particularly dark.
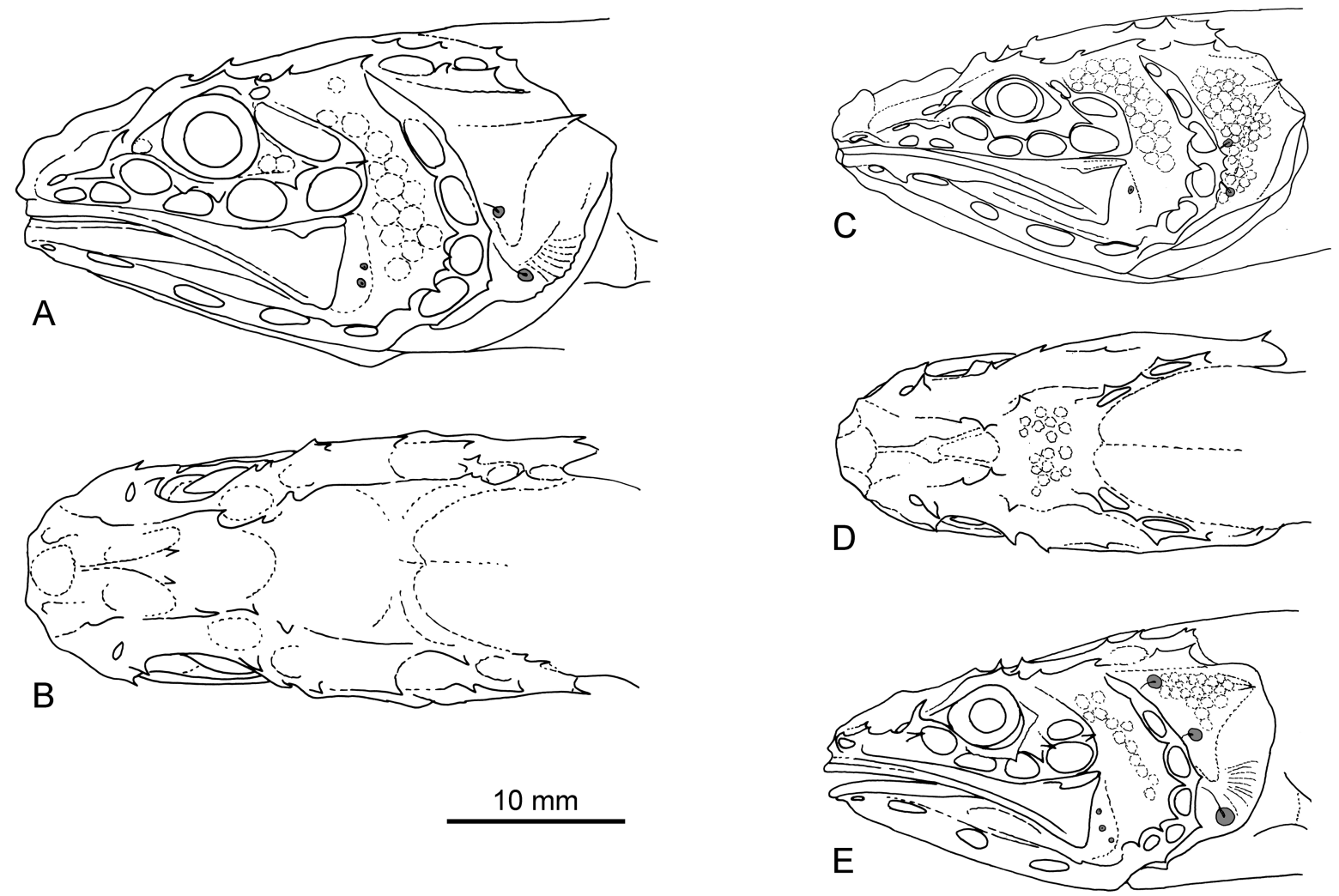

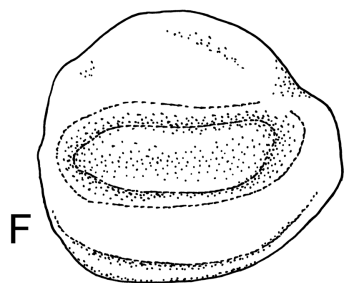

G

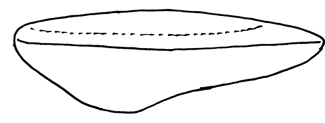

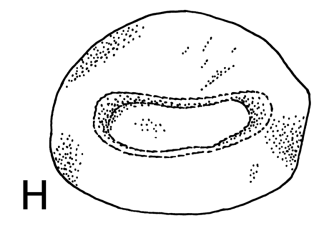

I

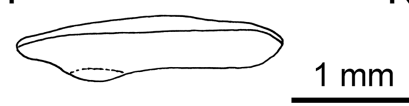

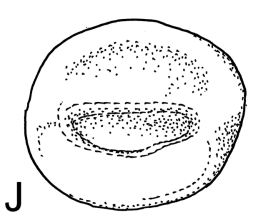

$\mathrm{L}$

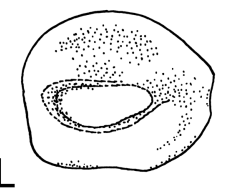

$\mathrm{M}$

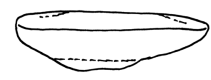

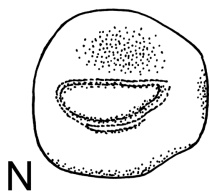

$\mathrm{O}$

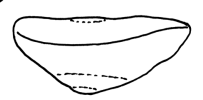

FIGURE 28. Porogadus trichiurus (Alcock, 1890); 28A-B, CAS 83066, 230 mm SL, Philippines, Lagonoy Gulf, 1037-1100 m, head drawing; 28C-D, AMS I.36456-009, 162 mm SL, $13^{\circ} 21^{\prime} \mathrm{N}, 1^{\circ} 4^{\circ} 12^{\prime} \mathrm{E}$, 1037-1100 m, head drawing; 28E, SIO 03-157, $158 \mathrm{~mm} \mathrm{SL}, 23^{\circ} 01^{\prime} \mathrm{N}, 66^{\circ} 01^{\prime} \mathrm{E}, 1677-1713 \mathrm{~m}$, head drawing; 28F-G, CAS 83066, $230 \mathrm{~mm}$ SL, Philippines, Lagonoy Gulf,

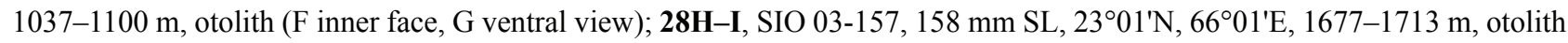
(H inner face, I ventral view); 28L-M, AMS I.36456-009, 162 mm SL, 132 $21^{\prime} \mathrm{N}, 1^{\circ} 4^{\circ} 12^{\prime} \mathrm{E}, 1037-1100 \mathrm{~m}$, otolith (L inner face, M ventral view); 28N-O, MNHN 1994-0760, 160 mm SL, 2206'S, 166²7’ E, 1850 m, otolith (N inner face, O ventral view).

Discussion. Alcock (1890) described Porogadus trichiurus based on a unique type housed at ZSI which was not available for review. His description is not very detailed, but the long gill raker count (20), pectoral fin count (16) and proportion of the head deduced from his detailed drawing (Alcock 1892) of a ratio of HL:HD of about 1.7 support the observations made with the specimens here described as P. trichiurus. Specimens described by Norman (1939) from the northeastern Indian Ocean as P. trichiurus have fewer long gill rakers (15) and a more slender head (HL:HD of nearly 2.0) and are here placed in Porogadus dracocephalus (see above). 
Within the Porogadus trichiurus group, P. trichiurus shares with P. guentheri the relatively intense and many spines on the head and the head proportions, but differs in the larger predorsal length (15.3-17.0 vs 13.7-14.7), the presence of scales on occiput and around the eye and lack of scales on maxilla, and the distinctly more compressed otolith $(\mathrm{OL}: \mathrm{OH}=1.04-1.27$ vs $1.45-1.64)$. It differs from most other Porogadus species by the position of the intermittent plates between the long gill rakers close to the inner side and not directly between the long rakers. This organization is probably a common trait for the Porogadus trichiurus group except for P. solomonensis.

Distribution. Porogadus trichiurus apparently is widely distributed in the western Pacific and has here been identified from southern Japan, eastern Philippines and off New Caledonia. The type specimen and one specimen described here stem from the northern Indian Ocean off the western coast of India. It occurs in moderate depth between 1037 and $1850 \mathrm{~m}$ and seems to stay close to the shelf break, i.e., not further away than $100 \mathrm{~km}$.

\section{Porogadus gracilis Group}

\section{Porogadus abyssalis Nybelin, 1957}

Figs. 29, 46, 49, Tab. 1-7

Porogadus abyssalis Nybelin, 1957: 288, figs. 19-20, pl.6 figs. 2-4; Nielsen et al. 1999: 86.

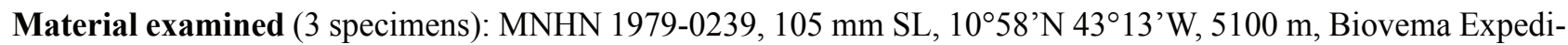
tion, Sta. a6/cp01, collected by J. Charcot, 13 November 1977; MNHN 1979-0240, 160 mm SL, 1058'N 43¹3'W, 5100 m, Biovema Expedition, Sta. a6/cp01, collected by J. Charcot, 13 November 1977; MNHN 1992-1231, 158 mm SL, $10^{\circ} 24^{\prime} \mathrm{N} 46^{\circ} 43^{\prime} \mathrm{W}, 4830$ m, Demeraby Expedition, Sta. cp14, collected by J. Charcot, 28 September 1980.

Diagnosis. Precaudal vertebrae 18-19; long gill rakers on lower part of first gill arch 13-14; pectoral-fin rays 19-23; HL:HD 1.85-2.09; most head spines moderately strong or weak, present on ethmoidal, prefrontal, interorbital, supraorbital, sphenotic, inner preopercular rim; absent on lacrimal, 5th infraorbital, supratemporal, inner and outer posttemporal, outer preopercular rim; opercular spine sharp, extruding; opercular flap small; lower lateral line pores until beginning of anal fin 23; vomer with moderately broad dentition patch with 2-3 rows of teeth; palatines with moderately broad dentition patch $2-4$ rows of teeth; otolith with single colliculum; $\mathrm{OL}: \mathrm{OH}=1.17$; OL:TCL $=$ 2.3 .

Description (based on non-types and holotype data from Nybelin 1957). Meristics: precaudal vertebrae 18-19, 1 last vertebrae without ribs; pectoral-fin rays 19 (19-23); $\mathrm{D} / \mathrm{V}=6$; $\mathrm{D} / \mathrm{A}=24-27 ; \mathrm{V} / \mathrm{A}=19-21$; long gill rakers on lower gill arch 14 (13-14). Gill rakers in a typical specimen (MNHN 1979-0240) on lower first gill arch with six short rakers, followed by a series of 16 long rakers. The lower 8 of those intercept by narrow plate shaped rakers. These are smaller than in most species. Upper gill raker with a series of three semi long rakers and three plate like rakers intercepted, followed by two very short rakers.

Morphometrics: in \% of SL: HL 16.5 (16.5-17.0); maximal HD 8.2-9.0; HD through center of eye 5.2-6.1; bony interorbital width 3.4-3.6; snout length 6.1; upper jaw length 9.7-10.1; predorsal 17.4-18.4; preanal 33.9 (29.3-33.9); prepelvic 12.2-13.4; prepectoral 16.6-17.4; pectoral length 10.4. Relations: HL:HD = 1.85-2.09; HL to snout length 2.72-2.77; preanal to predorsal 1.68-1.69; predorsal to prepectoral 1.05-1.06.

Slender fish with long tapering tail and long, pointed snout. Maximal size of fishes investigated $209 \mathrm{~mm}$ SL (holotype). Head long and very slender, with flat dorsal profile, with moderate to weak spines as follows: ethmoidal (1), prefrontal (1 weak), interorbital (3), supraorbital (2 weak), sphenotic (2-3), inner preopercular rim (3-4); no spines on lacrimal, 5th infraorbital, supratemporal, inner and outer posttemporal, outer preopercular rim. Opercle with sharp, short spine. Eye small located in strongly asymmetric orbit. Maxilla extending far beyond eye, strongly widened posteriorly and with distinct supramaxilla. Infra-/postorbital and mandibular-preopercular pores wide, 1 pore on occiput in front of nape. Head squamation on opercle, cheeks and occiput; absent on frontal, around eyes, and on maxilla. Opercle with two distinct large neuromasts behind preopercular edge; opercular flap small, with few radial ridges along lower margin. Lateral line rows rarely well visible and therefore number of pores countable only in rare instances. Lower lateral line row with 23 pores until beginning of anal fin in one specimen.

Dentition. All teeth tiny and needle like. Vomer with a narrow dentition patch with 2-3 rows of teeth anteriorly; palatines with a narrow dentition patch with $2-4$ rows of teeth in middle part. Premaxilla tooth patches not fused 
anteriorly; ca. 4 teeth rows anteriorly and 2-3 rows posteriorly. Dentary tooth patches not fused anteriorly; ca. 4 teeth rows anteriorly and a single row posteriorly. Median basibranchial tooth patch very short.

Otolith morphology $(\mathrm{n}=1)$. Size $1.8 \mathrm{~mm}$ in length (MNHN 1979-0240); OL:OH = 1.17; OH:OT 2.8. Thin, small, compressed, roundish otolith. All rims regularly rounded and smooth. Inner face flat, smooth, with short, centrally positioned sulcus; OL:TCL $=2.3$. Sulcus with shallow, undivided, uniform, oval, wide colliculum. Dorsal field with indistinct depression; ventral field with faint ventral furrow. Outer face smooth, without umbo.

Coloration. Color of preserved specimens light brown; belly slightly darker, opercle distinctly darker. Live coloration somewhat darker according to Nybelin (1957).
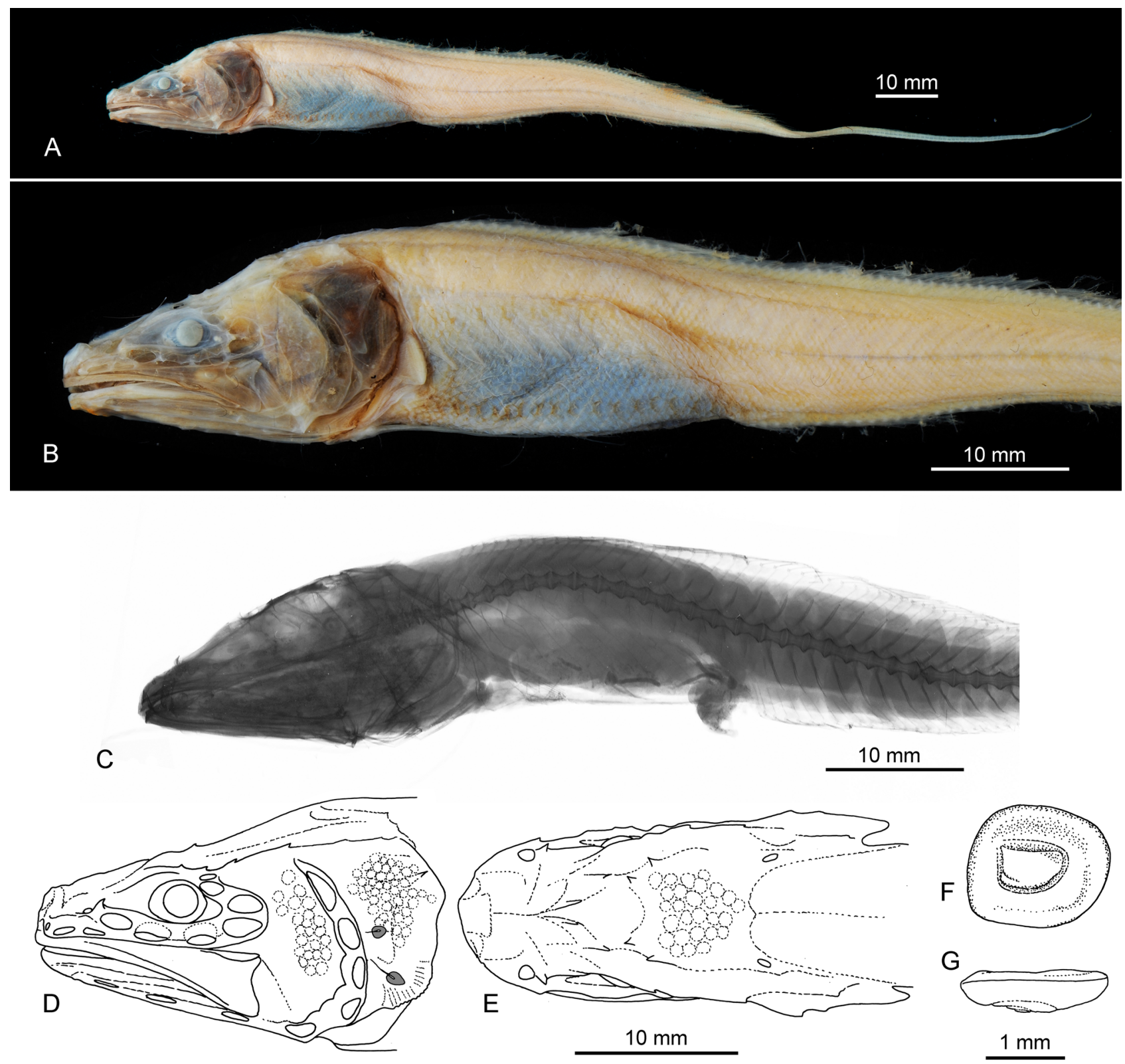

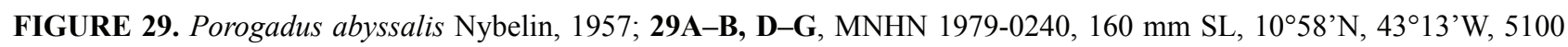
m, (A-B photographs, D-E head drawings, F otolith inner face, G otolith ventral view); 29C, MNHN 1992-1231, 158 mm SL, $10^{\circ} 24^{\prime} \mathrm{N}, 46^{\circ} 43^{\prime} \mathrm{W}, 4830 \mathrm{~m}$.

Discussion. Porogadus abyssalis was described based on a unique holotype by Nybelin (1957) caught at 5250$5300 \mathrm{~m}$ in the central Atlantic, which then was the deepest catch of any Porogadus specimen which hitherto were caught shallower than $3300 \mathrm{~m}$. The weak head ossification and armature and the small, morphologically simple otolith may reflect adaptation to a deep sea habitat below the CCD. Within the Porogadus gracilis group, Porogadus abyssalis is best recognized by its unusual high number of pectoral-fin rays (19-23 vs 15-18) and some relatively 
strong spines on the head. With its slender and elongate head and the high number of lower lateral line pores until the beginning of the anal fin P. abyssalis resembles several species of the Porogadus miles group, but differs in the generally much weaker head armature, weaker head ossification and the very small and compressed otoliths.

Distribution. The specimens described here are the only other specimens beside the unique holotype described by Nybelin (1957). They confirm the deep sea dwelling of the species in the tropical Atlantic and far away from any shelf break (700-1000 km, Fig. 49) on the abyssal plane near to the middle Atlantic ridge.

\section{Porogadus gracilis (Günther, 1878)}

Figs. 30-31, 46, 49, Tab. 1-7

Bathynectes gracilis Günther, 1878: 21; Günther 1887: 112, pl. 16 fig. B.

Porogadus gracilis: Nybelin 1957: 288, pl. 6 figs. 5-6; Nielsen et al. 1999: 86; Fricke et al. 2014: 33.

Material examined (5 specimens): Holotype BMNH 1887.12.7.52, $185+\mathrm{mm}$ SL, $12^{\circ} 08^{\prime} \mathrm{S} 145^{\circ} 10^{\prime} \mathrm{E}, 2560 \mathrm{~m}$, H.M.S. Challenger Expedition, trawl, 29 August 1874; ZMUC P2397227, 147 mm SL, R/V Vityaz 2615, 1507’'S 42 ${ }^{\circ} 10^{\prime} \mathrm{E}, 3000-3130 \mathrm{~m}, 17$ November 1988; ZMUC P2397158, $165 \mathrm{~mm}$ SL, Galathea 2 expedition, St. 575, $30 \mathrm{~m}$ wide shrimp otter trawl, Tasman Sea, $40^{\circ} 11^{\prime} \mathrm{S} 163^{\circ} 35^{\prime} \mathrm{E}, 3710 \mathrm{~m}, 19$ December 1951; tentatively assigned specimens: ZMUC P2397159-60, 181 and 195 mm SL, Galathea 2 expedition, Sta. 235 (2 specimens), $32 \mathrm{~m}$ wide herring

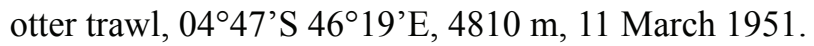

Diagnosis. Precaudal vertebrae 16-18; long gill rakers on first gill arch 13-17; pectoral-fin rays 16-18; HL:HD 1.73-2.01; most head spines weak, present on ethmoidal, lacrimal (ridge), prefrontal, interorbital, sphenotic, outer posttemporal, inner preopercular rim; absent on supraorbital, 5th infraorbital, supratemporal, inner posttemporal, outer preopercular rim; opercular spine sharp, extruding; opercular flap small; lower lateral line pores until beginning of anal fin 23 ; vomer with moderately broad dentition patch with $2-5$ rows of teeth; palatines with moderately broad dentition patch 3-5 rows of teeth; otolith with single colliculum; $\mathrm{OL}: \mathrm{OH}=1.3 ; \mathrm{OL}: \mathrm{TCL}=2.45$.

Description. Meristics: precaudal vertebrae 16 (16-18), 1 (1) last vertebrae without ribs; pectoral-fin rays 16 (16-18); D/V = 5 (5-6); D/A = 27 (26-27); V/A = 18 (18-19); long gill rakers on lower gill arch 17 (13-17). Gill rakers in holotype on lower first gill arch with seven plate-shaped rakers, followed by a serie of 17 long rakers. The lower seven of those intercept by single plate shaped rakers. Upper gill arch with three short rakers intercepted by four plate shaped rakers.

Morphometrics: in \% of SL: HL 15.0 (15.0-16.6); maximal HD 8.7 (7.8-9.0); HD through center of eye 5.6 (5.3-6.6); bony interorbital width 2.7 (2.2-3.4); snout length 4.7 (4.7-5.6); upper jaw length 9.0 (8.4-9.8); predorsal 18.2 (17.0-18.3); preanal 30.4 (28.2-30.4); prepelvic 11.8 (11.8-14.2); prepectoral 15.1 (15.1-17.3); pectoral length 9.8-10.8. Relations: HL:HD $=1.73(1.73-2.01)$; HL to snout length 3.14 (2.93-3.14); preanal to predorsal 1.67 (1.64-1.78); predorsal to prepectoral $1.21(0.99-1.21)$.

Slender fish with long tapering tail and moderately long snout. Maximal size of fishes investigated $195 \mathrm{~mm}$ SL (holotype $185+\mathrm{mm}$ ). Head long and slender, with flat dorsal profile, with weak spines as follows: ethmoidal (1), lacrimal (ridge), prefrontal (1), interorbital (1), sphenotic (2), supratemporal (1), outer posttemporal (1-3), inner preopercular rim (3-4); no spines on supraorbital, 5th infraorbital, inner posttemporal, outer preopercular rim. Opercle with sharp, extruding spine. Eye moderately small located in strongly asymmetric orbit. Maxilla extending far beyond eye, strongly widened posteriorly and with distinct supramaxilla. Infra-/postorbital and mandibular-preopercular pores wide, 1 pore on occiput in front of nape. Head squamation on opercle, cheeks and occiput; absent on frontal, around eyes, and on maxilla. Opercle with one or two distinct large neuromasts behind preopercular edge; opercular flap small, without ridges. Lateral line rows rarely well visible and therefore number of pores countable only in rare instances. Lower lateral line row with 23 pores until beginning of anal fin in one specimen.

Dentition. All teeth tiny and cone-shaped. Vomer with a moderately broad dentition patch with 2-5 rows of teeth anteriorly; palatines with a narrow dentition patch with 3-5 rows of teeth in the middle part, tapering to one row posteriorly and three rows anteriorly. Premaxilla tooth patches not fused anteriorly; ca. 10 rows of very tiny teeth in middle part. Dentary tooth patches fused anteriorly; ca. 5 rows anteriorly and 3 rows posteriorly. Median basibranchial tooth patch long.

Otolith morphology $(\mathrm{n}=1)$ ). Size $2.0 \mathrm{~mm}$ in length (ZMUC P2397227, ); OL:OH = 1.3; OH:OT 2.8. Thin, small, compressed, roundish otolith. All rims regularly rounded and smooth. Inner face flat, smooth, with short, 
centrally positioned sulcus; OL:TCL $=2.45$. Sulcus with shallow, undivided, uniform, oval, relatively narrow colliculum. Dorsal field with indistinct small depression; ventral field smooth. Outer face smooth, with low relief central umbo.

Coloration. Live coloration not known. Color of preserved specimens light brown throughout; opercle somewhat darker.
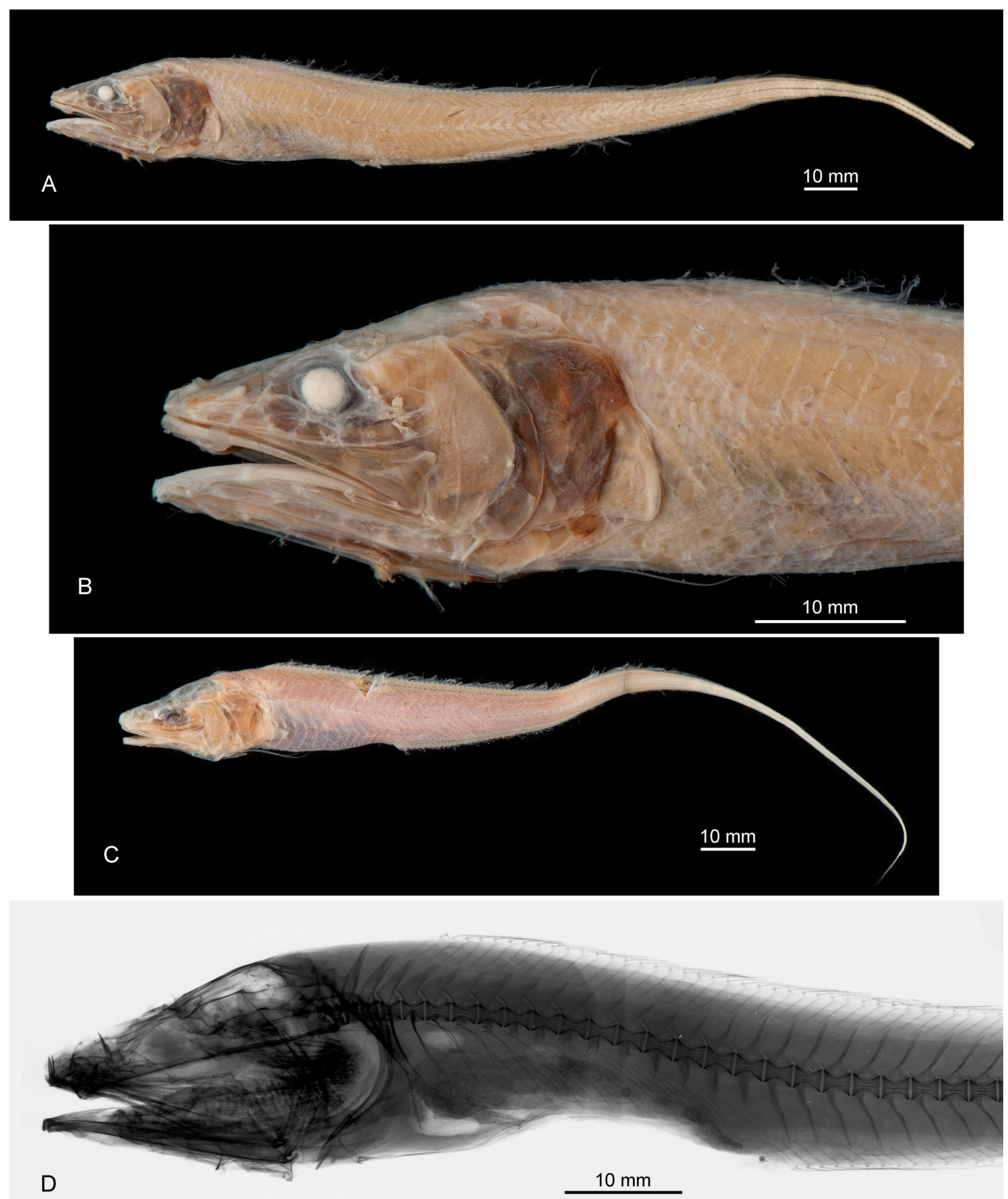

FIGURE 30. Porogadus gracilis (Günther, 1878); 30A-B, BMNH 1887.12.7-52, holotype, 185+ mm SL, 12 $08^{\prime} \mathrm{S}, 1^{\circ} 5^{\circ} 10^{\prime} \mathrm{E}$, 2560 m; 30C-D, ZMUC P2397158, 165 mm SL, 40¹1'S, 16335'E, 3710 m. 


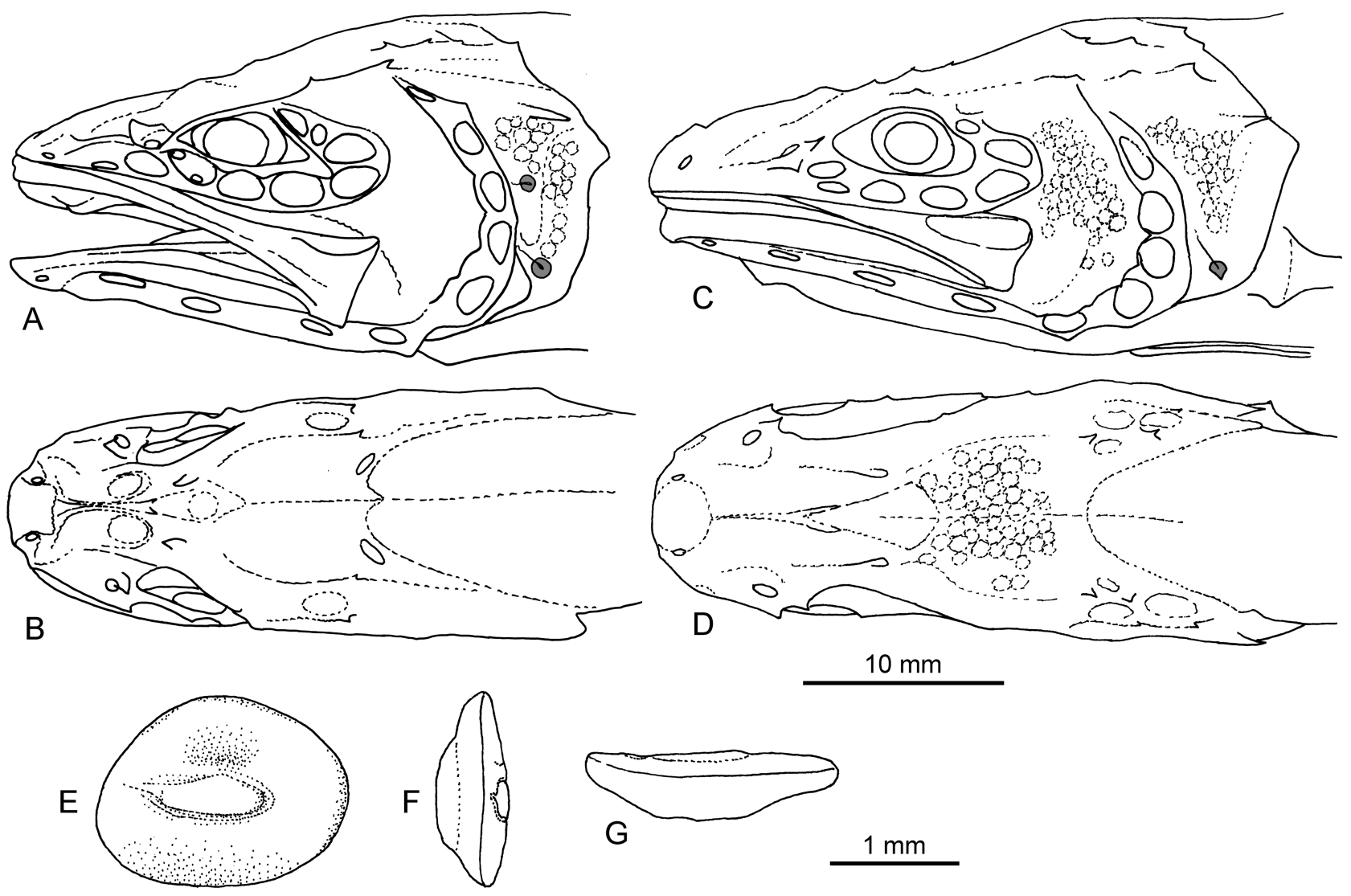

FIGURE 31. Porogadus gracilis (Günther, 1878); 31A-B, BMNH 1887.12.7-52, holotype, $185+\mathrm{mm} \mathrm{SL}, 1^{\circ} 08^{\prime} \mathrm{S}, 145^{\circ} 10^{\prime} \mathrm{E}$, $2560 \mathrm{~m}$, head drawings; 31C-D, tentatively assigned, ZMUC P2397160, $281 \mathrm{~mm} \mathrm{SL}, 04^{\circ} 47^{\prime} \mathrm{S}, 4^{\circ} 6^{\circ} 9^{\prime} \mathrm{E}$, $4810 \mathrm{~m}$, head drawing; 31E-G, ZMUC P2397227, 147 mm SL, 1507'S, 42 $10^{\circ}$ 'E, 3000-3130 m, otolith (E inner face, F anterior view, G ventral view).

Discussion. Two of the five specimens studied of $P$. gracilis are only tentatively allocated because of the relatively low number of long gill rakers (13-14 vs 15-17). Porogadus gracilis closely resembles $P$. abyssalis in the slender head and the weak head armature, but differs in the lower number of pectoral-fin rays (16-18 vs 19-23), the lower number of precaudal vertebrae (16-17, possibly 18 vs 18-19), and the even lesser and weaker head spines. Porogadus gracilis and $P$. abyssalis likely represent an vicariant species pair.

Distribution. Porogadus gracilis was originally described based on a single specimen from the deep water of the Coral Sea, off Raine Island, Queensland, Australia. A second specimen from off Madang, Papua New Guinea, has been listed in Fricke et al. (2014) but was not reviewed here. We have now also identified $P$. gracilis from the Tasman Sea and from off East Africa indicating that it is a widely distributed species in the southern Indian and West-Pacific oceans at depth of 2560 to $4810 \mathrm{~m}$. It is found offshore at about 100 to $700 \mathrm{~km}$ off the shelf break.

\section{Porogadus melanocephalus (Alcock, 1891)}

Figs. 32-33, 46, 49, Tab. 1-7

Dermatorus melanocephalus Alcock, 1891: 32; Alcock 1898: pl. 21 fig. 4.

Porogadus melanocephalus: Nielsen et al. 1999: 86.

Material examined (48 specimens): Syntype BMNH 1896.9.11.6, 183 mm SL, 11 ${ }^{\circ} 58^{\prime} \mathrm{N} 88^{\circ} 52^{\prime} \mathrm{E}, 3197 \mathrm{~m}$; BSKU $65559,175 \mathrm{~mm} \mathrm{SL}, 1^{\circ} 05^{\prime} \mathrm{N} 90^{\circ} 39^{\prime} \mathrm{E}$ to $13^{\circ} 03^{\prime} \mathrm{N}$ 90³7' E, 2967-2978 m, R/V Hakuho-maru, $3 \mathrm{~m}$ beam trawl, 9 Feb. 1990; ZMUC P2397161, 161 mm SL, Galathea 2 expedition, Sta. 282, $32 \mathrm{~m}$ wide herring otter trawl, $05^{\circ} 32^{\prime} \mathrm{N}$ 7841'E, 4040 m, 11 April 1951; ZMUC P2397162-206, (45 specimens), 86-172 mm SL, Galathea 2 expedition, Sta. 299, 32 m wide herring otter trawl, Bay of Bengal, 17²10’ $84^{\circ} 30^{\prime} \mathrm{E}, 2820 \mathrm{~m}, 24$ April 1951. 
Diagnosis. Precaudal vertebrae 16-17; long gill rakers on first gill arch 12-15; pectoral-fin rays 15-18; HL: HD 1.71-1.88; most head spines weak, present on ethmoidal, prefrontal, interorbital, sphenotic, outer posttemporal; absent on lacrimal, supraorbital, 5th infraorbital, supratemporal, inner posttemporal, inner and outer preopercular rim; opercular spine weak, flat; opercular flap small; lower lateral line pores until beginning of anal fin 17; vomer with narrow dentition patch with 1-2 rows of teeth; palatines with broad dentition patch with 5-8 rows of teeth; otolith with single colliculum; $\mathrm{OL}: \mathrm{OH}=1.15 ; \mathrm{OL}: \mathrm{TCL}=3.25$.
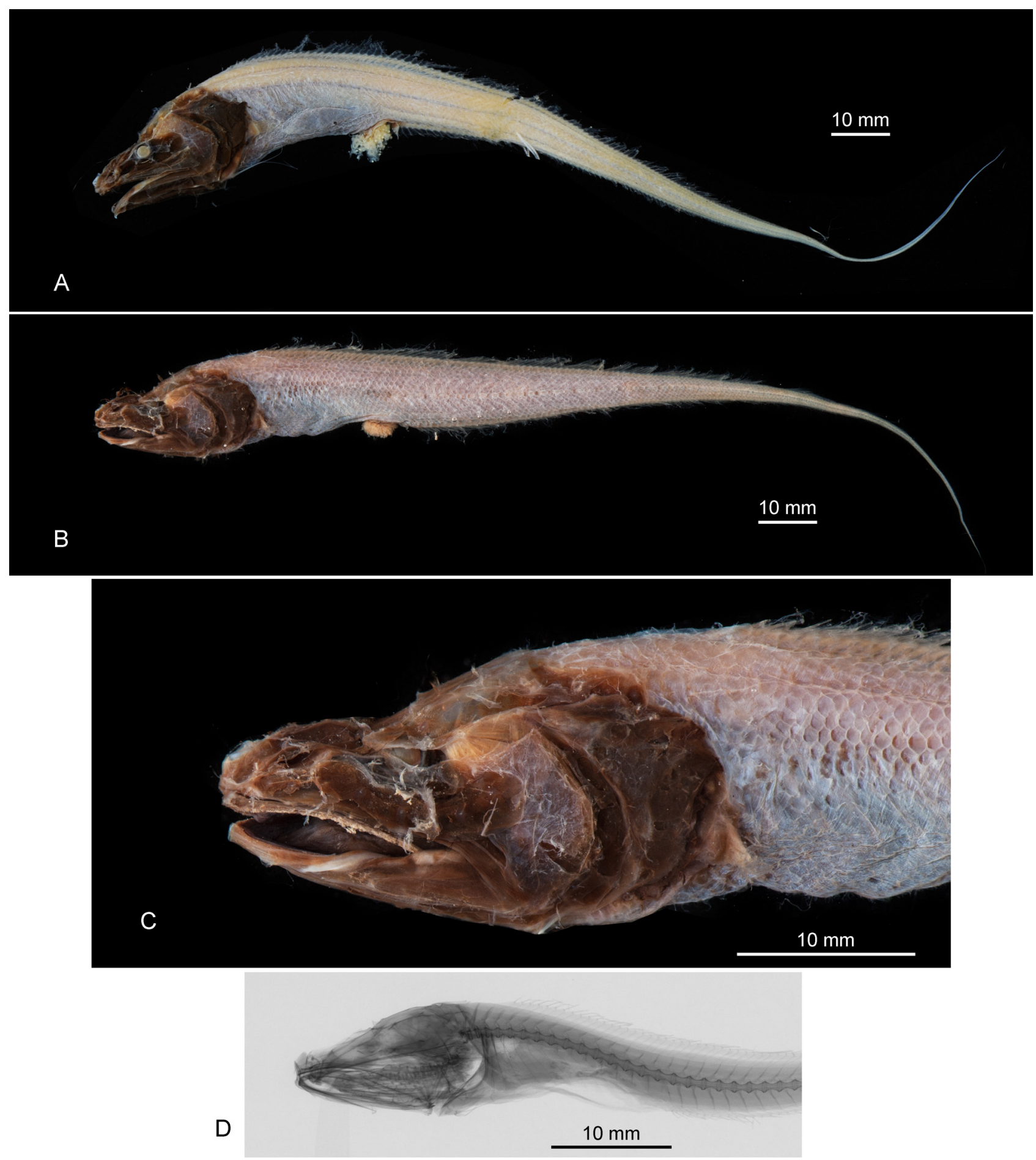

FIGURE 32. Porogadus melanocephalus (Alcock, 1891); 33A, BSKU 65559, $175 \mathrm{~mm} \mathrm{SL}, 1^{\circ} 05^{\prime} \mathrm{N}, 90^{\circ} 39^{\prime} \mathrm{E}, 2967-2978 \mathrm{~m}$;

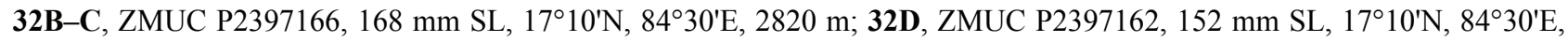
$2820 \mathrm{~m}$. 
Description (based on non-types and syntype with dissected head top). Meristics: precaudal vertebrae 16 (1617), 1 (1-2) last vertebrae without ribs; pectoral-fin rays 18 (15-18); $\mathrm{D} / \mathrm{V}=5$ (4-6); $\mathrm{D} / \mathrm{A}=24$ (23-26); $\mathrm{V} / \mathrm{A}=17$ (17-18); long gill rakers on first lower gill arch 12 (12-15), blade like. Gill rakers in a syntype (BMNH 1896.9.11.6) on lower first gill arch with seven short rakers, followed by a series of 12 long rakers. The lower four of those intercept by narrow plate shaped rakers. These are smaller than in most species and placed toward the inner margin. Upper gill raker with a serie of three semi long rakers and three plate like rakers intercepted, followed by two very short rakers.

Morphometrics: in \% of SL: HL 17.3 (15.4-17.3); maximal HD 8.3-9.8; HD through center of eye 5.4-6.5; bony interorbital width 2.4-3.1; snout length 5.1-6.1; upper jaw length 10.5 (9.1-10.6); predorsal 17.2-18.5; preanal 33.2 (29.9-33.2); prepelvic 13.8 (12.9-13.9); prepectoral 16.0-17.7; pectoral length 9.9-11.4. Relations: HL: $\mathrm{HD}=1.70-1.84$; HL to snout length 2.76 (2.64-3.07); preanal to predorsal 1.74 (1.72-1.87); predorsal to prepectoral $1.01(0.99-1.07)$.

Slender fish with long tapering tail and moderately long snout. Maximal size of fishes investigated $183 \mathrm{~mm}$ SL (syntype). Head moderately long and slender, with flat to slightly concave dorsal profile, with weak spines as follows: ethmoidal (1 broad), prefrontal (1), interorbital (1-2), sphenotic (2-3), supratemporal (2), outer posttemporal (1-2); no spines on lacrimal, supraorbital, 5th infraorbital, inner posttemporal, inner and outer preopercular rim. Opercle with weak, flat spine. Eye moderately small located in strongly asymmetric orbit. Maxilla extending far beyond eye, strongly widened posteriorly and with distinct supramaxilla. Infra-/postorbital and mandibular-preopercular pores wide. Head squamation only discernable on opercle on any of the specimens. Opercle with one moderately sized neuromast behind preopercular edge; opercular flap small. Lateral line rows rarely well visible and therefore number of pores countable only in rare instances. Upper lateral line row with 8 pores and lower lateral line row with 17 pores until beginning of anal fin in one specimen.
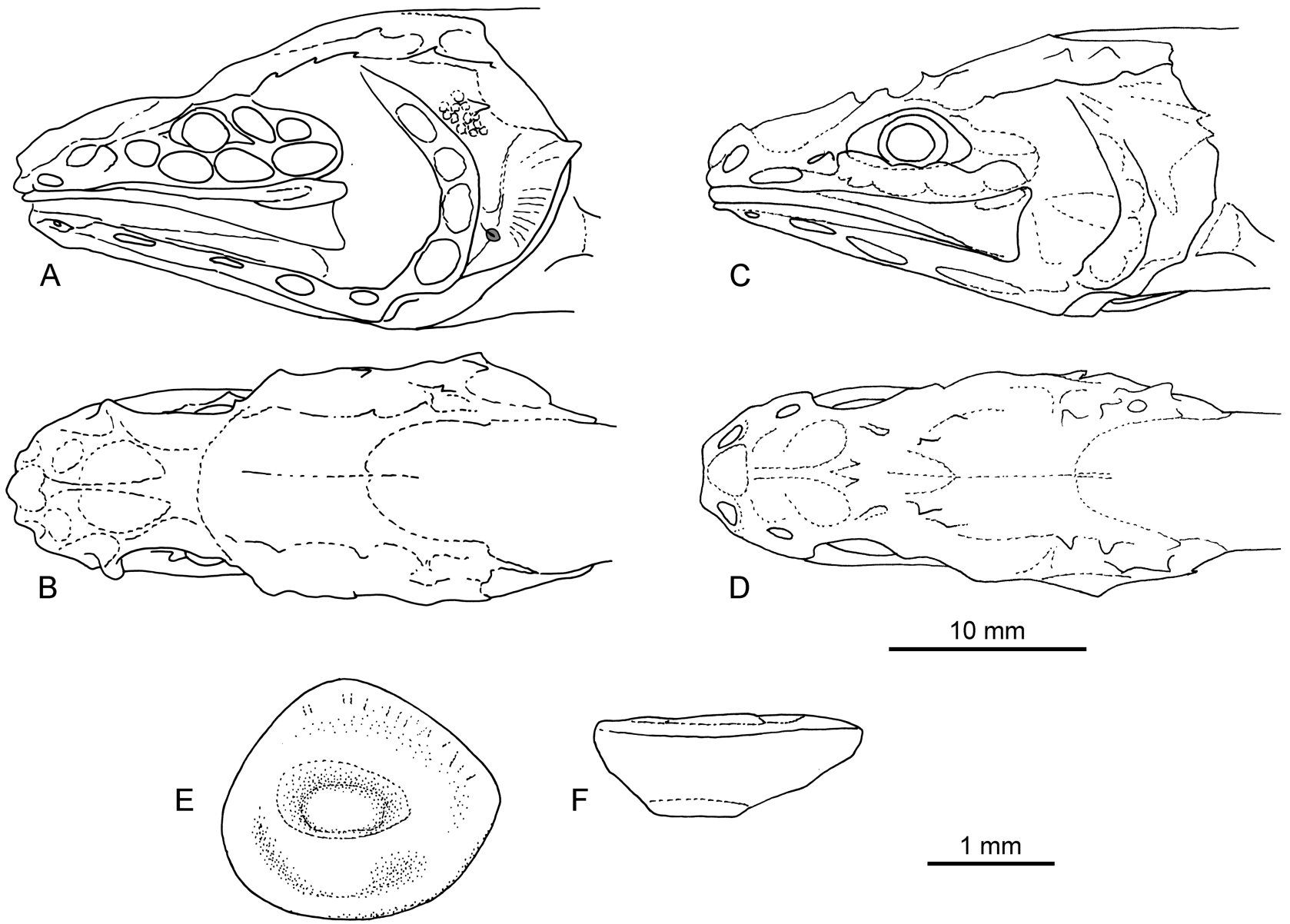

FIGURE 33. Porogadus melanocephalus (Alcock, 1891); 33A-B, BSKU 65559, 175 mm SL, 1305'N, 90³9'E, 2967-2978 $\mathrm{m}$, head drawing; 33C-D, ZMUC P2397174, $166 \mathrm{~mm} \mathrm{SL}, 17^{\circ} 10^{\prime} \mathrm{N}, 84^{\circ} 30^{\prime} \mathrm{E}, 2820 \mathrm{~m}$, head drawing; 33E-F, BSKU 65559,175 mm SL, $13^{\circ} 05^{\prime} \mathrm{N}, 90^{\circ} 39^{\prime} \mathrm{E}, 2967-2978 \mathrm{~m}$, otolith (E inner face, F ventral view). 
Dentition All teeth tiny and cone-shaped. Vomer dentition almost absent, with 1-2 rows of tiny teeth anteriorly; palatines with very broad dentition patch with 5-8 rows of teeth in the middle part. Premaxilla tooth patches very narrow and not fused anteriorly; ca. 1-2 rows of very tiny teeth in middle part. Dentary tooth patches not fused anteriorly; ca. 4 rows anteriorly and 3 rows posteriorly. Median basibranchial tooth patch short, moderately wide.

Otolith morphology $(\mathrm{n}=1)$. Size $2.2 \mathrm{~mm}$ in length (BSKU 65559); OL:OH $=1.15 ; \mathrm{OH}: \mathrm{OT}=2.35$. Moderately thick, small, compressed, roundish otolith. All rims regularly rounded and smooth; dorsal rim somewhat expanded middorsally. Inner face flat, smooth, with short, centrally positioned sulcus; OL:TCL $=3.25$. Sulcus with shallow, undivided, uniform, very small, oval colliculum. Dorsal field with indistinct depression; ventral field with broad, indistinct ventral furrow. Outer face smooth, with central umbo.

Coloration. Live coloration not known. Color of preserved specimens light to pinkish brown; entire head distinctly darker, almost black.

Discussion. Porogadus melanocephalus differs from the other two species in the Porogadus gracilis group in the weak nature of all head spines, the very dark, nearly black head (which however may fade in old specimens), the broad palatines with 5-8 teeth rows (vs 2-4 rows of teeth), the weak, flat opercular spine (vs sharp and pointed), and the very small colliculum in the sulcus of the otolith $(\mathrm{OL}: \mathrm{TCL}=3.25$ vs $2.3-2.5)$.

Distribution. Porogadus melanocephalus belongs to the relatively deep living species of the genus having been caught between 2820-4040 m. It appears to be endemic to the Bay of Bengal in the northeastern Indian Ocean. Alcock (1891) based his description of the species on two syntypes, one kept at BMNH and unfortunately not suitable as holotype and one at ZSI, which was not studied. A trawl in the Bay of Bengal during the Galatea 2 expedition (station $299,17^{\circ} 10^{\prime} \mathrm{N} 84^{\circ} 30^{\prime} \mathrm{E}, 2820 \mathrm{~m}$ ) has yielded 45 specimens of $P$. melanocephalus, which represents the single largest catch of Porogadus specimens and indicates that P. melanocephalus (and possible other species) may not be as rare as could be perceived from the relatively few specimens in institutional collections.

\section{Porogadus catena Group}

\section{Porogadus catena (Goode \& Bean, 1885)}

Figs. 34-35, 47, 50, Tab. 1-7

Bathyonus catena Goode \& Bean, 1885: 603, pl. 11 fig. A.

Bassozetus catena: Goode \& Bean 1896: 323, fig. 286; Jordan \& Evermann 1898: 2509; Jordan \& Evermann 1900: pl. 356, figs. $876,876 \mathrm{a}$.

Porogadus catena: Norman 1939: 87; Carter 1984: 2-183; Carter \& Sulak 1984: 374, fig. 6b; Nielsen et al. 1999: 86; Mincarone et al 2007: 55, fig. 3R.

Porogadus subarmatus Vaillant, 1888: 265, pl. 24 figs. 3-3c; Nybelin 1957: 288, textfig. 20, pl. 6 fig. 7; Nielsen et al. 1999 : 86.

Celema subarmata: Goode \& Bean 1896: 330.

Porogadus (Dermatorus) subarmatus: Nolf 1980: 91, pl. 11 fig. 9 (otolith).

Material examined (39 specimens): Specimens labeled as P. catena: Lectotype and paralectotype USNM 37341, 214 and $220 \mathrm{~mm} \mathrm{SL}, 28^{\circ} 00^{\prime} \mathrm{N} 87^{\circ} 70^{\prime} \mathrm{W}, 2683 \mathrm{~m}$, Albatross Expedition 1883-1900, Sta. D 2379, large beam trawl, 2 March 1885; NMP 1873 (4 specimens), 152-170 mm SL, NMP 1874, 130+ mm SL, NMP 1871, 133 mm SL, NMP 1878 (4 specimens), 138-170 mm SL, Portiguar, Brazil, 2000m; USNM 405732, 140+ mm SL, 28 23' $\mathrm{N} 88^{\circ} 21^{\prime} \mathrm{W}$, 1829 m, R/V Oregon, Cruise 68, Sta. 2820, 15 Jul 1960; ZMMGU 16653 (4 of 9 specimens), 152-170 mm SL, R/V

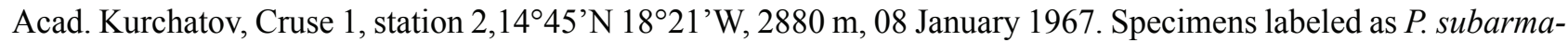
tus: Holotype MNHN 86-530, off Cape Verde Islands, 3200 m, R/V Talisman, 1883; paratype BMNH 1939.2.20.1, off Cape Verde Islands 3200 m; BMNH 2013.8.1.38-43, 103-193 mm SL, 2052’ N 18¹7'W (Cape Verde Plateau), 2010-2180 m, R.R.S. Discovery Cruise, collected by the Institute of Oceanographic Sciences, 06 July 1987; MNHN 2004-1330, 136 mm SL, 0546’S 0942’E, 3113-3159 m, R/V Atalante, Biozaire 3 Expedition, Sta. cp22, 03 January 2004; MNHN 2004-1333 (2 specimens) 140-174 mm SL, 0555'S 09³9’E, $3230 \mathrm{~m}$, R/V Atalante, Biozaire 3 Expedition, Sta. cp24, 04 January 2004; MNHN 2004-1348, 204 mm SL, 0548'S 09² '’'E, 3142-3163 m, R/V Atalante, Biozaire 3 Expedition, Sta. cp18, 30 December 2003; MNHN 2004-1349 (2 specimens), 188 mm SL, 0548'S 09²'', 3156-3172 m, R/V Atalante, Biozaire 3 Expedition, Sta. cp17, 30 December 2003; MNHN 2004-1350, $162 \mathrm{~mm} \mathrm{SL}, 05^{\circ} 47^{\prime} \mathrm{S} 09^{\circ} 42^{\prime} \mathrm{E}, 3113-3159 \mathrm{~m}$, R/V Atalante, Biozaire 3 Expedition, Sta. cp20, 02 January 2004; MNHN 2004-1352, 165 mm SL, 0549'S 09²'’'S, 3172-3193 m, R/V Atalante, Biozaire 3 Expedition, 
Sta. cp16, 28 December 2003; ZMUC P771459, 180 mm SL, 0548’'S 0943'E, 3156 m; ZMUC P2397207-208,

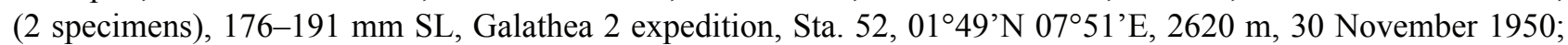
ZMUC P2397209-210, (2 specimens), 137 and 195+ mm SL, Galathea 2 expedition, Sta. 65, off Gabon, 02 ${ }^{\circ} 17^{\prime} \mathrm{S}$ 0810’E, 2840 m, 4 December 1950; ZMUC P2397211, 183 mm SL, collected by Mr. Frank, off Rabat, Morocco, 16 September 1897, $2000 \mathrm{~m}$.

Diagnosis. Precaudal vertebrae 16-17; long gill rakers on first gill arch 15-18; pectoral-fin rays 15-18; HL:HD 1.49-1.73; few and mostly weak head spines, present on ethmoidal, supraorbital, sphenotic, supratemporal, outer posttemporal, inner preopercular rim; absent on lacrimal, prefrontal, interorbital, 5th infraorbital, inner posttemporal, outer preopercular rim; opercular spine weak, flat; opercular flap small; lower lateral line pores until beginning of anal fin 15-17; vomer with narrow dentition patch with 1-2 rows of teeth; palatines with moderately broad dentition patch with 3-4 rows of teeth; otolith with single colliculum; $\mathrm{OL}: \mathrm{OH}=1.0-1.2 ; \mathrm{OL}: \mathrm{TCL}=1.8-2.2$.

Description (holotype values refer to $P$. catena). Meristics: precaudal vertebrae $17(16-17), 1(0-2)$ last vertebrae without ribs; pectoral-fin rays 16 (15-18); $\mathrm{D} / \mathrm{V}=6$ (5-7); $\mathrm{D} / \mathrm{A}=25$ (21-26); V/A $=18$ (17-18); long gill rakers on lower gill arch 16 (15-18). Gill rakers in a non-type (ZMUC P771459) on lower first gill arch with nine short rakers, followed by a series of 17 long rakers. The lower eight of those intercept by narrow plate shaped rakers, placed toward the inner margin. Upper gill raker with a series of two plate-like rakers followed by four semi-long and plate-like rakers intercepted, followed by two very short rakers.

Morphometrics: in \% of SL: HL 14.5-16.4; maximal HD 8.5-10.7; HD through center of eye 5.8-7.5; bony interorbital width 2.8-3.5; snout length 4.0-5.3; upper jaw length 8.7-10.4; predorsal 15.8-19.6; preanal 28.0-33.3; prepelvic 11.7-13.4; prepectoral 15.0-17.6; pectoral length 7.5-9.5. Relations: HL:HD = 1.59 (1.49-1.73); HL to snout length 2.77-3.28; preanal to predorsal 1.64-1.88; predorsal to prepectoral 1.0-1.13.

Slender fish with long tapering tail and relatively short head and snout. Maximal size of fishes investigated $220 \mathrm{~mm}$ SL (paralectotype). Head relatively short and compressed, with mostly flat dorsal profile, and mostly weak spines as follows: ethmoidal (1 sharp), supraorbital (1 weak), sphenotic (1-2 weak), supratemporal (1-2 weak), outer posttemporal (1-2 weak), inner preopercular rim (1-3); no spines on lacrimal, prefrontal, interorbital, 5th infraorbital, inner posttemporal, outer preopercular rim. Opercle with weak, flat spine. Eye moderately small located in strongly asymmetric orbit. Maxilla extending far beyond eye, strongly widened posteriorly and with distinct supramaxilla. Infra-/postorbital and mandibular-preopercular pores wide; extensive cavernous system on head top in front of occiput and nape, sometimes open (pores or damaged thin skin?). Head squamation only discernable on opercle and cheeks on few specimens. Opercle with two or three moderately sized neuromast behind preopercular edge; opercular flap small. Lateral line rows rarely well visible and therefore number of pores countable only in rare instances. Lower lateral line row with 15-17 pores until beginning of anal.

Dentition. All teeth small and cone-shaped. Vomer V-shaped usually with 3 rows of teeth anteriorly and one row posteriorly; palatines with a moderately broad dentition patch with 3-5 rows of teeth; premaxilla tooth patches narrow and not fused anteriorly; 5-8 rows of teeth anteriorly and 1-3 posteriorly; dentary tooth patches not fused anteriorly; ca. 4-7 rows anteriorly and 1-4 rows posteriorly. Median basibranchial tooth patch long and narrow

Otolith morphology $(\mathrm{n}=12)$. Size $2.0 \mathrm{~mm}$ in length; $\mathrm{OL}: \mathrm{OH}=1.02-1.21 ; \mathrm{OH}: \mathrm{OT}=2.0-2.7$. Moderately thick, small, compressed, roundish otolith. All rims rounded and smooth. Inner face flat, with short, deepened, centrally positioned sulcus; OL:TCL $=1.83-2.24$. Sulcus with undivided, uniform, sometimes deepened, oval colliculum. Dorsal field with indistinct depression; ventral field smooth. Outer face smooth, with prominent central umbo.

Coloration. Live coloration not known. Color of preserved specimens light to medium brown; entire head darker, opercle distinctly darker, almost black.

Discussion. Porogadus catena belongs to the Porogadus catena group further containing P. promelas and as a group is characterized by weak head spines and a compressed, relatively short head. Porogadus catena was originally described from the western Atlantic and has been considered as senior synonym of $P$. breviceps and $P$. promelas from the eastern Pacific by Carter \& Sulak (1984). However, we found certain consistent differences between Atlantic and East-Pacific specimens with the Atlantic ones (P. catena) showing weak supratemporal and inner preopercular spines (vs absent), scales on cheeks and opercle equally large (vs scales on cheeks larger than on opercle), narrower palatines (with 3-4 rows of teeth vs 4-9 rows), and a distinctly more compressed otolith (OL: $\mathrm{OH}=1.02-1.21$ vs $1.25-1.51$ ), indicating that two vicariant species exist in the respective seas. We therefore regard both $P$. catena and $P$. promelas (the latter with $P$. breviceps as junior synonym) as valid. In contrast we were unable to find consistent differences between the specimens from the West-Atlantic commonly placed in P. catena and from the East-Atlantic usually identified as $P$. subarmatus and therefore place the latter as junior synonym of the former. 

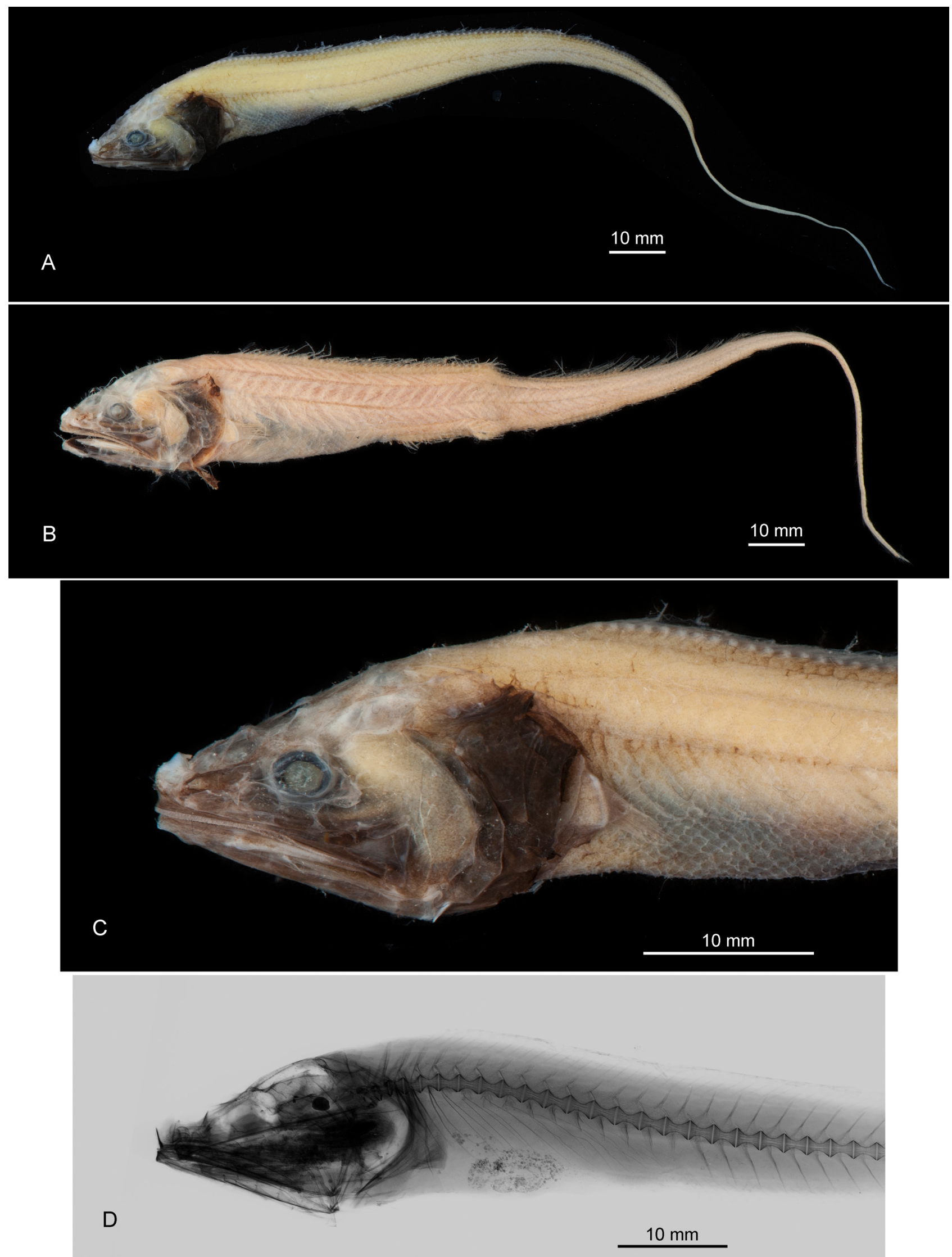

FIGURE 34. Porogadus catena (Goode \& Bean, 1885); 34A,C, NPM 1878, 170 mm SL, off Portiguar, Brazil, 2000 m; 34B, ZMUC P771459, 180 mm SL, 0548'S, 09²3'E, 3156 m; 34D, NPM 1878, 145 mm SL, off Portiguar, Brazil, 2000 m. 

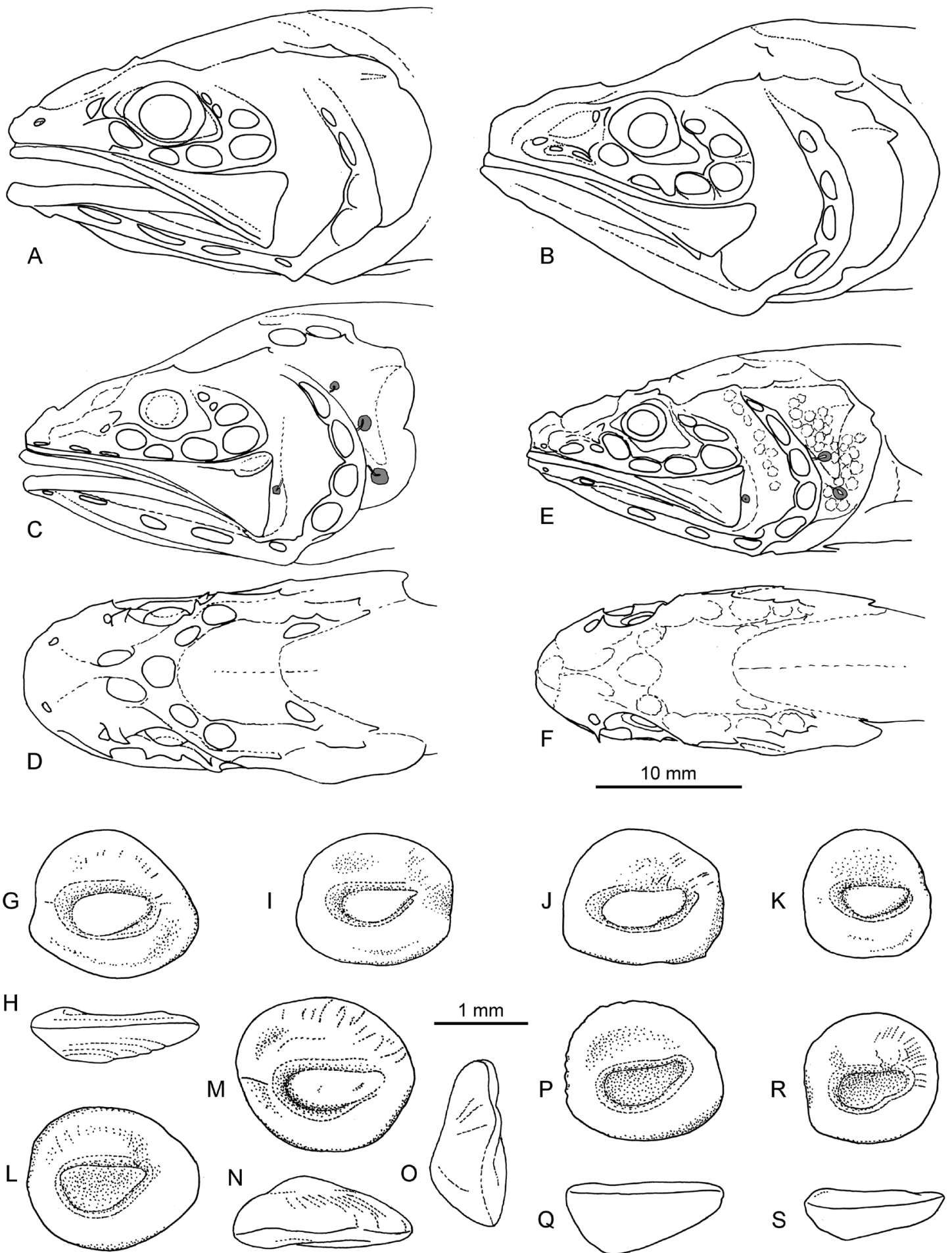

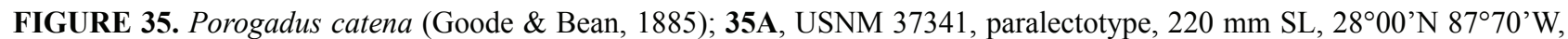
2683 m, head drawing; 35B, MNHN 86-530, holotype of Porogadus subarmatus, Cape Verde Islands, $3200 \mathrm{~m}$, head drawing; 35C-D, ZMUC P771459, 180 mm SL, 0548'S, 0943'E, 3156 m, head drawings; 35E-F, NPM 1878, 170 mm SL, off Portiguar, Brazil, 2000 m, head drawings; 35G-H, NPM 1873-0021994, 150+ mm SL off Portiguar, Brazil; otolith (G inner face, H ventral view); 35I, NPM 1878, 170 mm SL, off Portiguar, Brazil, 2000 m, otolith (inner face); 35J, NPM 1874, NPM 1878, 170 mm SL, 130+ mm SL, off Portiguar, Brazil, 2000 m, otolith (inner face); 35K, NPM 1873-0021919, 142 mm SL, off Portiguar, Brazil; otolith (inner face); 35L,P,Q, MNHN 2004-1349, (2 specimens), 188 mm SL, 05²48'S, 0943'E, 3156 m, otoliths (L,P inner faces, Q ventral view); 35M-O, BMNH 1939.2.20.1, Cape Verde Islands, 3200 m, otolith (M inner face, N dorsal view, O anterior view); 35R-S, MNHN 2004-1352, 165 mm SL, 0549'S, 0942'E, $3172-3193 \mathrm{~m}$, otolith (R inner face, S ventral view). 
Distribution. Porogadus catena is relatively common on both sides of the tropical to subtropical Atlantic from about $30^{\circ} \mathrm{N}$ to $12^{\circ} \mathrm{S}$ in the West-Atlantic and about $35^{\circ} \mathrm{N}$ to $10^{\circ} \mathrm{S}$ in the East-Atlantic. It has been caught at depths mostly between 1800 and $3200 \mathrm{~m}$ and one specimen between 4500 and $4600 \mathrm{~m}$ from the East-Atlantic where it appears to be residing somewhat deeper than the West-Atlantic. Also, it appears to be staying relatively close to the continental slope and has not been caught further away from the shelf break than $700 \mathrm{~km}$.

\section{Porogadus promelas Gilbert, 1892}

Figs. 36-37, 47, 50, Tab. 1-7

Porogadus promelas Gilbert, 1892: 546; Hanke et al. 2015: 74, fig. 6.

Porogadus breviceps Garman, 1899: 155.

Porogadus catena (not Goode \& Bean, 1885): Carter \& Sulak 1984: 374 (part).

Porogadus (Moebia) promelas: Nolf 1980: 91, pl. 11, fig. 11 (otolith).

Porogadus (Moebia) sp.: Schwarzhans 1981: 94, fig. 92 (otolith).

Material examined (14 specimens): Specimens labeled as P. promelas: Lectotype and paralectotype USNM 48265, 237 and $125 \mathrm{~mm} \mathrm{SL}, 2^{\circ} 39^{\prime} \mathrm{N} 111^{\circ} 42^{\prime} \mathrm{W}, 1838 \mathrm{~m}$, Albatross Expedition 1883-1900, Sta. D 3010, large beam trawl,

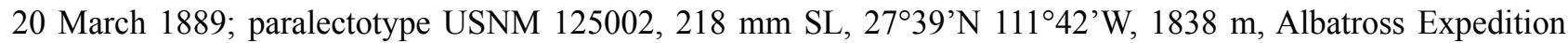
1883-1900, Sta. D 3010, large beam trawl, 20 March 1889; ZMUC P2397228, R/V Ak. Kurtshatov 239A, 205

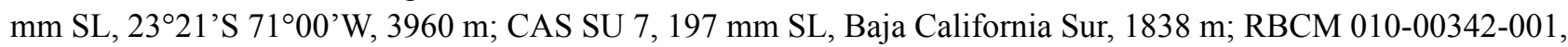
$280 \mathrm{~mm} \mathrm{SL}, 51^{\circ} 25^{\prime} \mathrm{N} 130^{\circ} 40-41^{\prime} \mathrm{W}, 1967 \mathrm{~m}$; ZMUC P2397212-213, 154 and $243 \mathrm{~mm}$ SL, Galathea 2 expedition,

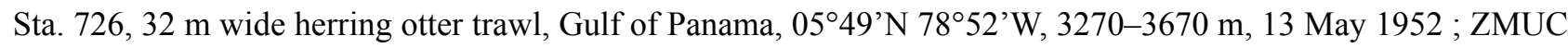
P2397214-218 (5 specimens), 110+ to $160 \mathrm{~mm} \mathrm{SL}$, Galathea 2 expedition, Sta. 716, $32 \mathrm{~m}$ wide herring otter trawl, off Acapulco, Panama, $09^{\circ} 23^{\prime} \mathrm{N} 89^{\circ} 32^{\prime} \mathrm{W}, 3570 \mathrm{~m}, 6$ May 1952. Specimens labeled as $P$. breviceps: Lectotype MCZ 28654, $245 \mathrm{~mm}$ SL, Gulf of California, $26^{\circ} 48^{\prime} \mathrm{N} 110^{\circ} 45^{\prime} \mathrm{W}, 1571 \mathrm{~m}, \mathrm{R} / \mathrm{V}$ Albatross, small beam trawl, 22 April 1891.

Diagnosis. Precaudal vertebrae 16-17; long gill rakers on first gill arch 15-18; pectoral-fin rays 17-18; HL: HD 1.50-1.72; few and mostly weak head spines, present on ethmoidal, interorbital, supraorbital, sphenotic, outer posttemporal; absent on lacrimal, prefrontal, 5th infraorbital, supratemporal, inner posttemporal, inner and outer preopercular rim; opercular spine weak, flat; opercular flap small; lower lateral line pores until beginning of anal fin 16-18; vomer with narrow dentition patch with 2-4 rows of teeth; palatines with moderately broad dentition patch with 4-9 rows of teeth; otolith with single colliculum; $\mathrm{OL}: \mathrm{OH}=1.25-1.5$; OL:TCL $=2.0-2.1$.

Description (holotype values refer to $P$. promelas). Meristics: precaudal vertebrae 16-17, 0-1 last vertebrae without ribs; pectoral-fin rays $18(17-18) ; \mathrm{D} / \mathrm{V}=5-6 ; \mathrm{D} / \mathrm{A}=24-29 ; \mathrm{V} / \mathrm{A}=18-19 ;$ long gill rakers on first gill arch 18 (15-18). Gill rakers in paralectotype (USNM 125002) on lower first gill arch with five plate like rakers, followed by a series of 15 long rakers. The lower 10 of those intercept by broad plate shaped rakers, placed between the long rakers. Upper gill raker with a series of four semi long rakers and five plate like rakers intercepted.

Morphometrics: in \% of SL: HL 15.1 (14.4-16.6); maximal HD 9.9 (8.8-11.5); HD through center of eye 6.1-7.8; bony interorbital width 2.4-3.5; snout length 4.8 (4.5-5.8); upper jaw length 9.0 (8.7-10.5); predorsal 16.8 (15.6-19.1); preanal 31.7 (29.0-32.0); prepelvic 11.7-13.2; prepectoral 15.1-16.9; pectoral length 8.3-9.8. Relations: HL:HD = 1.53 (1.50-1.72); HL to snout length 3.18 (2.81-3.18); preanal to predorsal 1.88 (1.67-2.05); predorsal to prepectoral $0.96-1.13$.

Slender fish with long tapering tail and relatively short head and snout. Maximal size of fishes investigated 280 mm SL (RBCM 010-00342-001). Head relatively short and compressed, with mostly flat dorsal profile, and mostly weak spines as follows: ethmoidal (1 small), interorbital (1-2 weak), supraorbital (1 weak), sphenotic (2-3 weak), outer posttemporal (1-2 weak); no spines on lacrimal, prefrontal, 5th infraorbital, supratemporal, inner posttemporal, inner and outer preopercular rim (rare up to 2 denticles on inner preopercular rim). Opercle with weak, flat spine. Eye moderately small located in strongly asymmetric orbit. Maxilla extending far beyond eye, strongly widened posteriorly and with distinct supramaxilla. Infra-/postorbital and mandibular-preopercular pores wide; extensive cavernous system on head top in front and lateral of occiput. Head squamation only discernable on opercle, cheeks and occiput; those on cheeks larger than those on opercle or occiput. Opercle with two moderately sized neuromast behind preopercular edge; opercular flap small. Lateral line rows rarely well visible and therefore number of pores countable only in rare instances. Lower lateral line row with 16-18 pores until beginning of anal. 


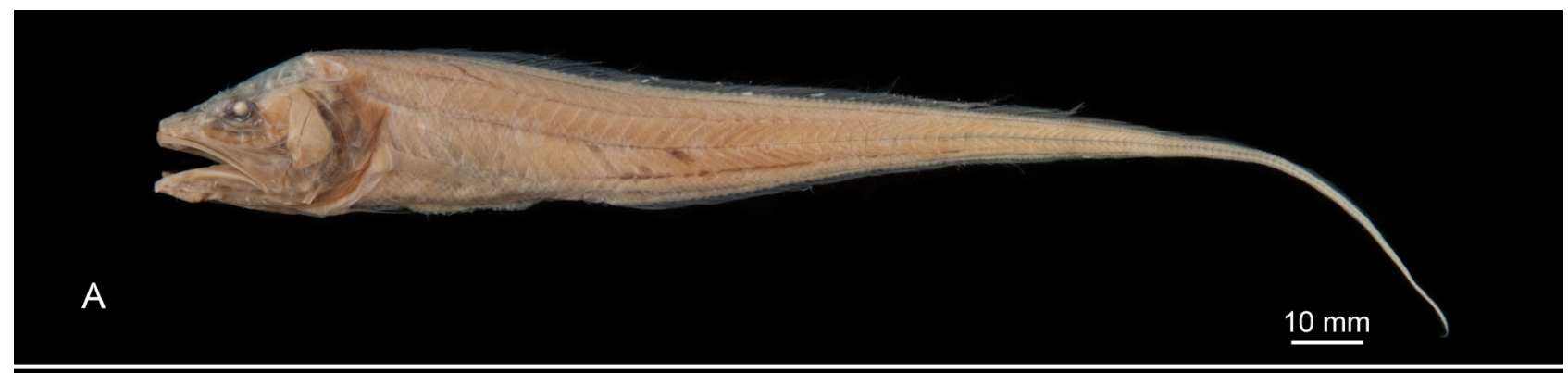

B
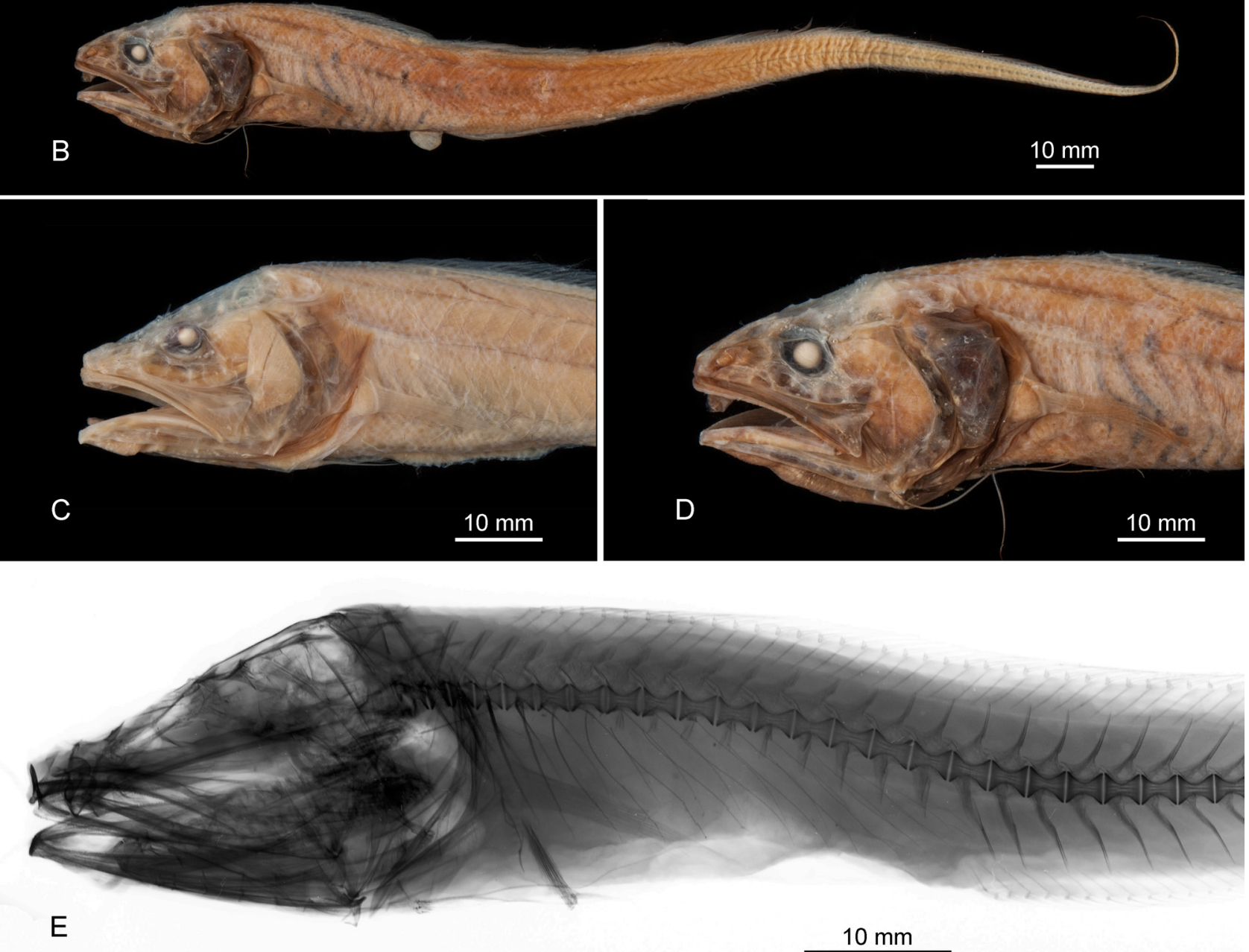

$E$

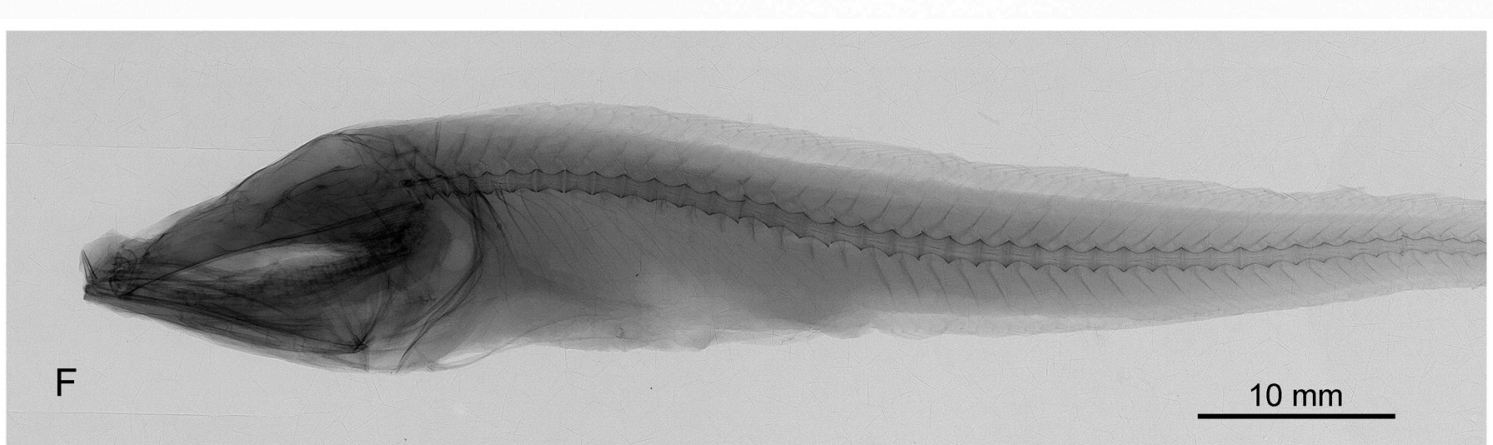

FIGURE 36. Porogadus promelas Gilbert, 1892; 36A,C,E, CAS SU 7, 197 mm SL, Baja California Sur, 1838 m; 36B,D, MCZ 28654, lectotype of Porogadus breviceps, $245 \mathrm{~mm}$ SL, $26^{\circ} 48^{\prime} \mathrm{N}, 110^{\circ} 45 \mathrm{~W}, 1571 \mathrm{~m} ; \mathbf{3 6 E}$, USNM 48265, paralectotype, $125 \mathrm{~mm}$ $\mathrm{SL}, 27^{\circ} 39^{\prime} \mathrm{N}, 111^{\circ} 42^{\prime} \mathrm{W}, 1838 \mathrm{~m}$. 

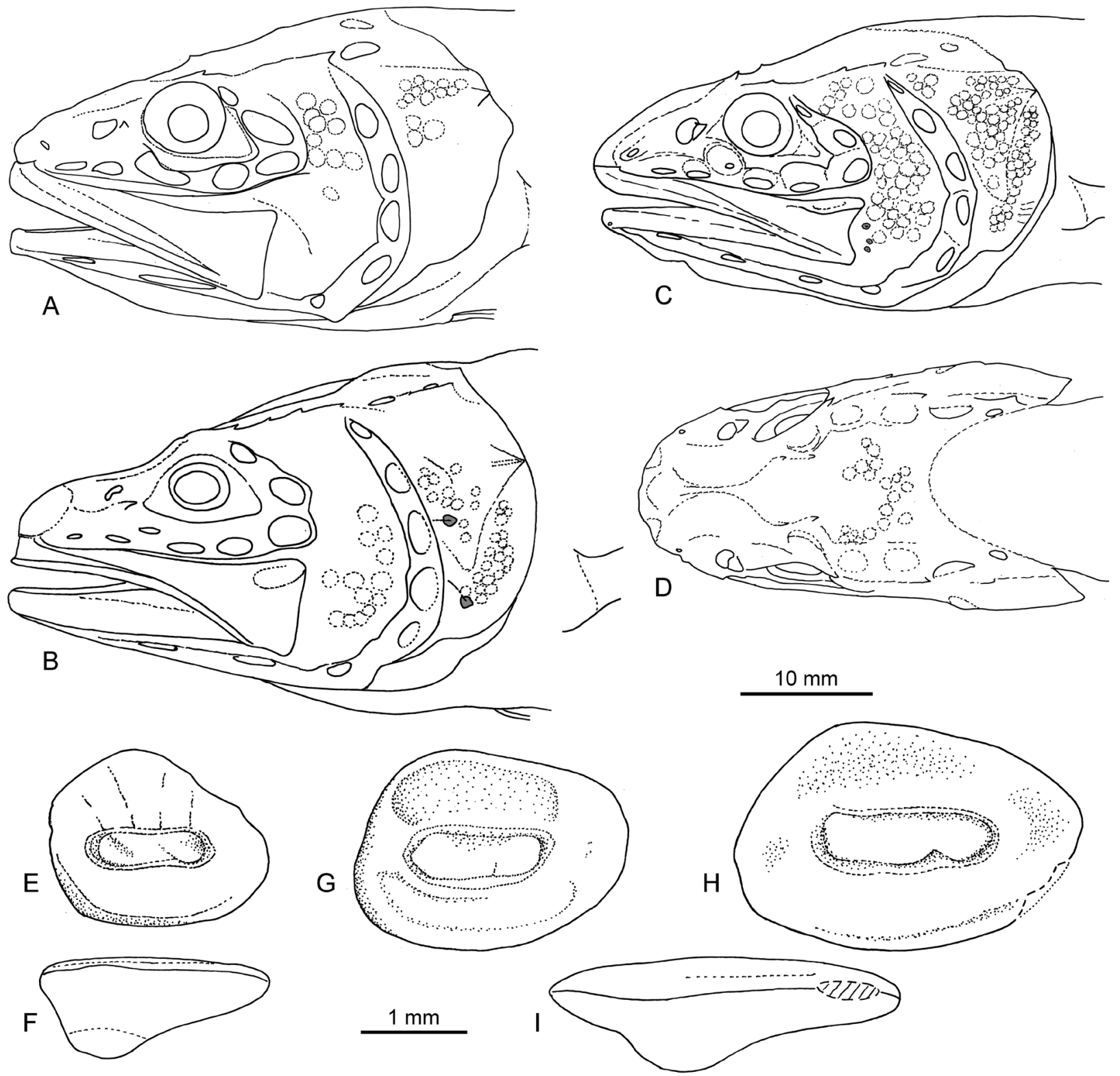

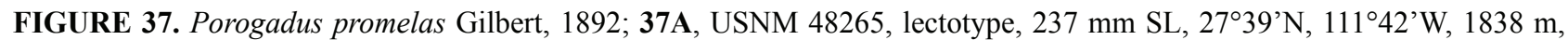
head drawing; 37B, RBCM 010-00342-001, 280 mm SL, 51 ${ }^{\circ} 25^{\prime} \mathrm{N}, 130^{\circ} 40-41^{\prime} \mathrm{W}, 1967 \mathrm{~m}$, head drawing; 37C-D, MCZ 28654, lectotype of Porogadus breviceps, $245 \mathrm{~mm} \mathrm{SL}, 26^{\circ} 48^{\prime} \mathrm{N}, 110^{\circ} 45 \mathrm{~W}, 1571 \mathrm{~m}$, head drawing; 37E-F, USNM 125002, paralectotype, $218 \mathrm{~mm} \mathrm{SL}, 27^{\circ} 39^{\prime} \mathrm{N}, 111^{\circ} 42^{\prime} \mathrm{W}, 1838 \mathrm{~m}$, otolith (E inner face, F ventral view); 37G, PZMUC P2397228, $205 \mathrm{~mm}$ SL, $23^{\circ} 21^{\prime} \mathrm{S}, 71^{\circ} 00^{\prime} \mathrm{W}, 3960 \mathrm{~m}$, otolith (inner face); 37H-I, MCZ 28654, lectotype of Porogadus breviceps, $245 \mathrm{~mm} \mathrm{SL,} 26^{\circ} 48^{\prime} \mathrm{N}$, $110^{\circ} 45 \mathrm{~W}, 1571 \mathrm{~m}$, otolith (H inner face, I ventral view).

Dentition. All teeth tiny and cone-shaped. Vomer with shout dentition patches with 2-4 rows of tiny teeth anteriorly and 1-2 rows posteriorly; palatines with a broad dentition patch with 4-9 rows of teeth in the middle part. Premaxilla tooth patches broad and not fused anteriorly; ca. 10 rows of teeth in middle part. Dentary tooth patches fused anteriorly; ca. 6 rows in the middle part. Basibranchial tooth patches consisting of long, narrow median patch sometimes accompanied by small single lateral patch and in case of one syntype of P. breviceps (MCZ 28654) with pair of lateral patches.

Otolith morphology $(\mathrm{n}=3)$. Size $2.6 \mathrm{~mm}$ in length; $\mathrm{OL}: \mathrm{OH}=1.25-1.51$; OH:OT $=1.75-2.5$. Moderately thick to thick, small, moderately compressed otolith. Dorsal rim with mostly prominent predorsal lobe or rounded predorsal angle; ventral rim shallower than dorsal rim. All rims smooth. Inner face flat, with short, centrally positioned sulcus; OL:TCL $=2.06-2.12$. Sulcus with undivided, uniform, sometimes deepened, oval, narrow colliculum. Dor- 
sal field with broad, sometimes distinct depression; ventral field with faint ventral furrow close to ventral rim of otolith. Outer face smooth, with prominent umbo in front of center.

Coloration. Live coloration not known. Color of preserved specimens light to medium brown; only opercle distinctly darker.

Discussion. Porogadus promelas was considered a synonym of $P$. catena from the West-Atlantic by Carter \& Sulak (1984), but we found a number of mostly subtle differences, with the otolith being the most obvious one, to distinguish both species (see above).

Distribution. Porogadus promelas is widely distributed along the deep continental slopes of the central EastPacific from about $51^{\circ} \mathrm{N}$ to $23^{\circ} \mathrm{S}$ and has been caught between 1500 and nearly $4000 \mathrm{~m}$.

\section{Genus Tenuicephalus n. gen.}

Type species: Porogadus silus Carter \& Sulak, 1984

Diagnosis. A genus of the subfamily Neobythitinae characterized by the following combination of characters: Body long and slender; depth at anus more than 10 times in standard length, prominent mucous cavities and large pores along the infraorbital and mandibular-preopercular canal systems; spines on head very few and weak or absent; upper jaw ends well behind eye; head very weakly ossified and head bones very thin and flexible; 1 narrow median basibranchial tooth patch (except sometimes missing in T. silus), no lateral basibranchial tooth patches; lateral line not discernable; developed gill rakers 14 to 21 ; pectoral-fin rays 16 to 19 ; precaudal vertebrae 14 to 17 ; ratio HL: HD 1.35 to 1.6; vomer naked or with few singular teeth or with 1 to 2, rarely 3 rows small villiform teeth anteriorly; palatine narrow with 2 to 3 rows small villiform teeth. Body color uniformly black or purple-black, but may fade to medium brown after long term preservation.

Similarity. Tenuicephalus is most remarkable for its weakly ossified head bones and the short and stubby head and snout. It differs from Porogadus, where its species have been placed in the past, additionally in the absence of discernable lateral line systems on the trunk, no or very weak and few head spines and a much reduced dentition on vomer, palatines and basibranchial tooth patches. All these characters are considered derived in the group containing the genera Porogadus, Alcockia, Bathyonus and Penopus and might be related to a live above the ground and feeding on very small crustaceans, as suggested by Carter (1984). These characters are probably autapomorphic in the context of this group of genera and we therefore assume that Tenuicephalus may represent a clade as sistergroup to the other four genera of the lineage.

Ethymology. From tenuis $($ Latin $=$ thin, weak) and cephalus $($ Latin $=$ head), referring to the delicate and weak nature of the head ossification which results in often damaged specimens recovered from deep-water trawls.

Species. We consider four species in Tenuicephalus two of which are replaced from a former position in Porogadus and two are newly described here: Tenuicephalus melampeplus (Alcock, 1896) from the western Indian Ocean and the Solomon Sea, Tenuicephalus multitrabs n. sp. from the Indian Ocean and the West-Pacific, Tenuicephalus silus (Carter \& Sulak, 1984) from the Caribbean, and Tenuicephalus squamilabrus n. sp. known disjunctive from the southwestern Indian Ocean and the West-Pacific.

Remarks. Fishes of the genus Tenuicephalus are exceptionally fragile. We have found only very few specimens in the collections that are well enough preserved to allow for an assessment of characters other than meristics, basic morphometrics, and otoliths (when not eroded by formalin). Particularly squamation, head pore systems and head morphometrics are only rarely identifiable or measurable. Hence the following key, diagnoses and descriptions rely on few specimens for those characters.

\section{Key to the species of Tenuicephalus}

1 Long gill rakers $14-16$ (up to 18 in T. silus); HL in \% SL $16.4-17.6$; no head spines . . . . . . . . . . . . . . . . 2

Long gill rakers $17-21 ; \mathrm{HL}$ in $\%$ SL $14.4-16.2$; weak ethmoidal and interorbital spines . . . . . . . . . . . . . . 3 Loin vertebrae 3 ; opercular spine sharp; $\mathrm{OL}: \mathrm{OH}<1.0 \ldots \ldots \ldots \ldots \ldots \ldots \ldots \ldots \ldots \ldots \ldots \ldots \ldots \ldots \ldots$ Tenuicephalus melampeplus Loin vertebrae $8-10$; opercular spine flat; otolith not known $\ldots \ldots \ldots \ldots \ldots \ldots \ldots \ldots \ldots \ldots \ldots$ Tenuicephalus silus Head squamation on occiput, cheeks, opercle and maxilla (but rarely preserved); maximal HD:HD through eye 1.75-1.90; OL in $\%$ HL $5.0-6.5$; OL:TCL $1.94-2.30 \ldots \ldots \ldots \ldots \ldots \ldots \ldots \ldots \ldots \ldots \ldots \ldots \ldots \ldots \ldots$ Tenuicephalus squamilabrus $\mathbf{n} . \mathbf{s p}$. 


\section{Tenuicephalus melampeplus (Alcock, 1896)}

Figs. 38, 48, 51, Tab. 1-7

Dermatorus melampeplus Alcock, 1896: 65; Alcock 1897: pl. 17 fig. 3.

Porogadus melampeplus: Nielsen et al. 1999: 86; non Shcherbachev 1980: 92.

Porogadus sp.: Nielsen \& Møller 2007: 33 (pars, not figured).

Material examined (2 specimens and photograph and selected data of holotype): Holotype ZSI F60/1, $218 \mathrm{~mm}$ SL (calculated from photograph), $1^{\circ} 11^{\prime} \mathrm{N} 72^{\circ} 28^{\prime} \mathrm{E}, 1702 \mathrm{~m}$; ZMMGU 15103, 177+ mm SL, R/V Fiolent, Cruse 9,

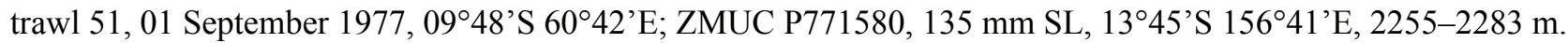

Diagnosis. Precaudal vertebrae 14-16, 3 loin vertebrae (last precaudal vertebrae without ribs); long gill rakers on first gill arch 14-16; pectoral-fin rays 16-17; HL:HD 1.40-1.48; no head spines; opercular spine sharp, extruding; opercular flap small; vomer narrow, naked or with few teeth; palatines narrow with $2-3$ rows of teeth; basibranchial tooth patch very small with $1-2$ rows of teeth; otolith with single colliculum; $\mathrm{OL}: \mathrm{OH}=0.95 ; \mathrm{OL}$ :TCL $=$ 1.87 .

Description. Meristics: precaudal vertebrae 14-16, 3 last vertebrae without ribs; pectoral-fin rays 16 (16-17); $\mathrm{D} / \mathrm{V}$ not discernable; $\mathrm{D} / \mathrm{A}$ not discernable; $\mathrm{V} / \mathrm{A}=15$; long gill rakers on lower gill arch 16 (14-16). Gill rakers in a non-type (ZMMGU 15103) on lower first gill arch with nine short rakers, followed by a series of 15 long rakers. The lower nine of those intercepted by short spiny rakers directed inwards. Upper gill arch with five semi-long rakers intercepted by five short rakers.

Morphometrics: in \% of SL (values for holotype calculated from photograph): HL 16.4 (16.4-17.2); maximal HD 11.6 (11.6-12.1); HD through center of eye 7.4; bony interorbital width not measurable; snout length 4.6 (4.6-5.8); upper jaw length 9.8 (9.8-11.9); predorsal 16.3 (16.0-16.3); preanal 32.2 (30.0-32.6); prepelvic and prepectoral not measurable; pectoral length not measurable. Relations: HL:HD = $1.42(1.40-1.48)$; maximal HD: HD through center of eye 1.50-1.63; HL to snout length 3,58 (2.95-3.58); preanal to predorsal 1.97 (1.97-2.04); predorsal to prepectoral not measurable.

Overall slender fish with long tapering tail, relatively stout head and moderately long snout. Maximal size of fishes investigated $218 \mathrm{~mm}$ SL (holotype, calculated from photograph). Head with flat or slightly concave dorsal profile, without spines except opercle with small but sharp, extruding spine. Eye moderately small located in strongly asymmetric orbit. Maxilla extending far beyond eye, strongly widened posteriorly; supramaxilla not discernable. Infra-/postorbital and mandibular-preopercular pores wide. No head squamation discernable. Opercular flap small, without ridges. Lateral line not discernable.

Dentition. All teeth tiny and cone-shaped. Vomer naked or with few sharp teeth posteriorly (in ZMUC P771580, Fig. 38D); palatines with a narrow dentition patch with 1-3 rows of teeth only anteriorly. Premaxilla tooth patches not fused anteriorly; 5 rows of teeth in middle part. Dentary tooth patches not fused anteriorly; ca. 8 rows anteriorly and 2 rows posteriorly. Median basibranchial tooth patch very small and narrow with 1-2 rows of teeth.

Otolith morphology $(n=1)$. Size $2.65 \mathrm{~mm}$ in length (ZMMGU 15103); OL:OH = 0.95; OH:OT = 2.9. Otolith distinctly higher than long, moderately thick. All rims regularly curved and smooth, preventral and postdorsal regions expanded. Inner face more or less flat, with short, distinctly inframedian sulcus; OL:TCL $=1.85$. Sulcus with shallow, undivided, uniform, oval, moderately narrow colliculum. Dorsal field very wide, without distinct depression; ventral field smooth. Outer face smooth, with low relief inferior umbo.

Coloration. Live coloration not known. Color of preserved holotype medium brown throughout (from photograph) but described by Alcock (1896) as uniform purple-black. The color change may be due to the extended period of preservation. The two more recently caught specimens are indeed nearly black and thus supporting Alcock's description.

Discussion. Alcock (1896) described Dermatorus melampeplus based on a single specimen which he noted as too much damaged for description but noted that it would be "at once distinguished from Dermatorus trichiurus and melanocephalus (1) by the complete absence of teeth on the vomer, and (2) by its uniform purple-black color." His drawing (Alcock 1897) is consistent with the photograph thankfully provided by ZSI. The characters mentioned by 
Alcock as diagnostic for T. melampeplus, however, are now consider prime diagnostic features for the new genus Tenuicephalus.

Tenuicephalus melampeplus is recognized by a relatively large head ( $\mathrm{HL}$ in $\%$ of SL $=16.4-17.2)$ and a low number of long gill rakers (14-16), while the co-occurring species T. multitrabs $\mathbf{n}$. sp. and T. squamilabrus $\mathbf{n}$. sp. have smaller heads (HL in \% of SL $=14.4-1.6 .2)$ and more long gill rakers (17-21). Also, both species exhibit a few weak head spines. Tenuicephalus melampeplus shares the absence of head spines with $T$. silus from the Caribbean, and the head size and number of gill rakers overlap as well, but it differs in having 3 loin vertebrae (vs 8-10) and a sharp opercular spine (vs flat). Tenuicephalus melampeplus further is unique for its otoliths which is higher than long, a unique observation in the entire Porogadus lineage, but however otoliths are not known from T. silus.

We were not able to investigate the unique holotype, but thankfully received photographs from ZSI (Kolkata, see acknowledgements) and also certain counts such as long gill rakers and pectoral fin-rays. Most of the specimens of the records of Porogadus melampeplus by Shcherbachev (1980) from the Indian Ocean held at ZMMGU were investigated and except for one are now interpreted to represent $T$. multitrabs $\mathbf{n}$. sp. The two newly recognized specimens of $T$. melampeplus unfortunately are poorly preserved and therefore a number of deemed important characters could not be sufficiently investigated or verified.

Distribution. Tenuicephalus melampeplus is based on only three verified specimens, two of which, including the holotype, stem from the western Indian Ocean and one from the Solomon Sea in the western Pacific.
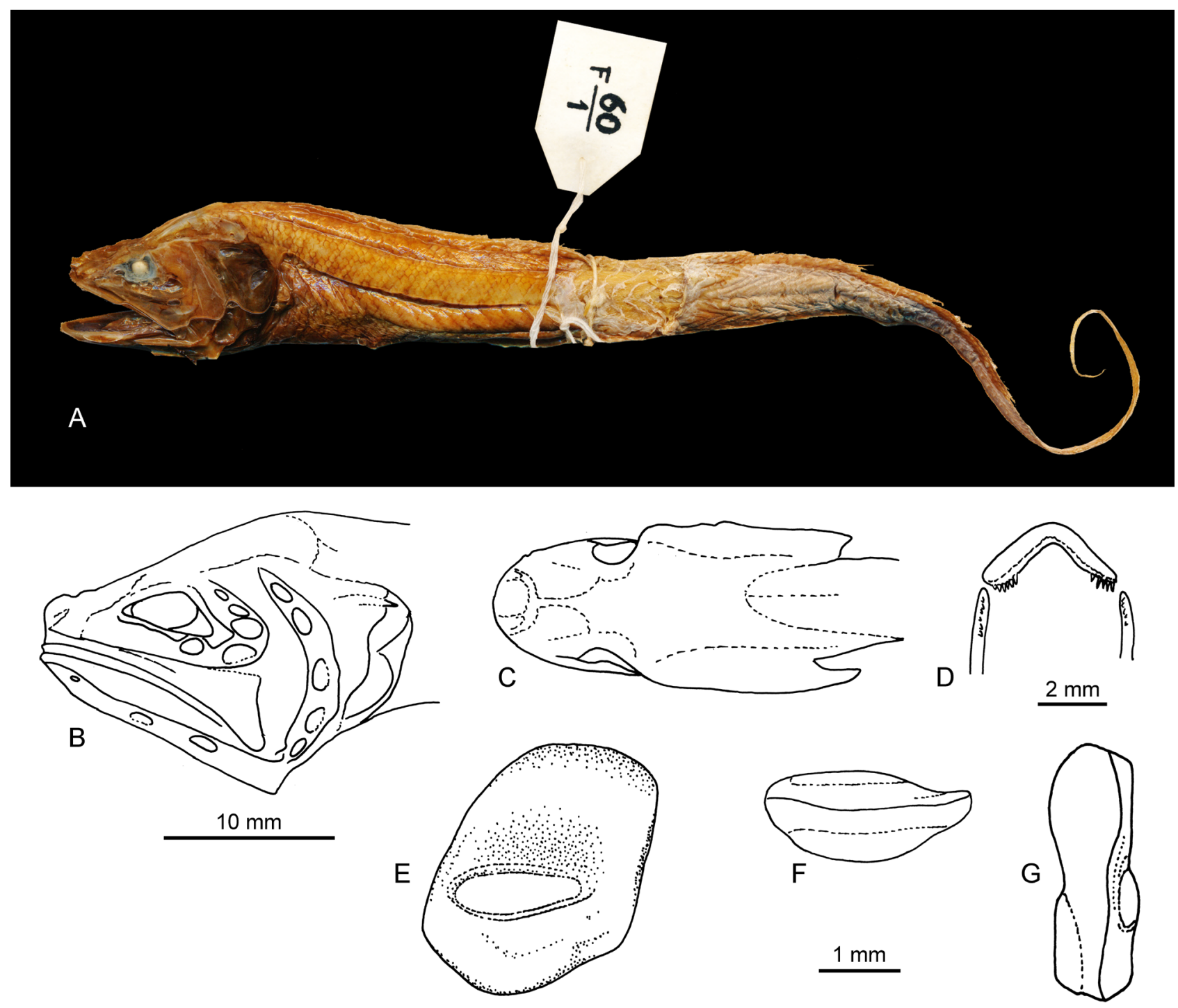

FIGURE 38. Tenuicephalus melampeplus (Alcock, 1896); 38A, ZSI F60/1, holotype, $218 \mathrm{~mm} \mathrm{SL,} 15^{\circ} 11^{\prime} \mathrm{N}, 7^{\circ} 28^{\prime} \mathrm{E}$, 1702 $\mathrm{m}$, (no scale given, calculated from photograph); 38B-D, ZMUC P771580, $135 \mathrm{~mm} \mathrm{SL}, 13^{\circ} 45^{\prime} \mathrm{S}, 1^{\circ} 6^{\circ} 41^{\prime} \mathrm{E}, 2255-2283 \mathrm{~m}$, B-C head drawings, D drawing of vomer and tooth bearing anterior part of palatines; 38E-G, ZMMGU 15103, 177+ mm SL, $09^{\circ} 48^{\prime} \mathrm{S}, 60^{\circ} 42^{\prime} \mathrm{E}$, otolith (E inner face, F ventral view, G anterior view). 


\section{Tenuicephalus multitrabs n. sp.}

Figs. 4, 39-40, 48, 51, Tab. 1-7

Porogadus sp: Shcherbachev 1980: 92.

Material examined (13 specimens): Holotype CAS 83066-3, 153+ mm SL, R/V Fishery Researcher 1, Philippines, Lagonoy Gulf, $13^{\circ} 20^{\prime} 30^{\prime}$ 'N , $124^{\circ} 16^{\prime} 30^{\prime}$ 'E, $30 \mathrm{~m}$ otter trawl, 1037-1100 m, collected by Tomio Iwamoto and party, 24 September 1995; paratypes: CAS 83066-2, $156 \mathrm{~mm} \mathrm{SL}$, same data as holotype; MNHN 1994-0761, $202 \mathrm{~mm}$ SL, 22 ${ }^{\circ} 06^{\prime}$ S $166^{\circ} 27^{\prime} \mathrm{E}, 1920-2040$ m, R/V Coriolis, Biogeocal Expedition, Sta. co273, 20 Apr 1987; MNHN 19970381, $133 \mathrm{~mm} \mathrm{SL}, 1^{\circ}{ }^{\circ} 2^{\prime} \mathrm{S} 167^{\circ} 18^{\prime} \mathrm{E}, 1550-1620 \mathrm{~m}, \mathrm{R} / \mathrm{V}$ Alis, Musorstom 8 Expedition, Sta. cp1109, 08 October

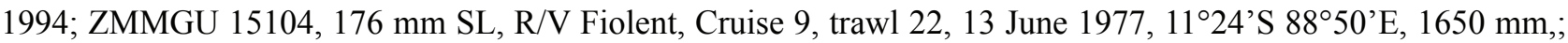

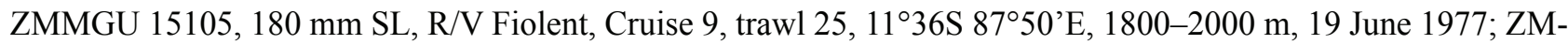

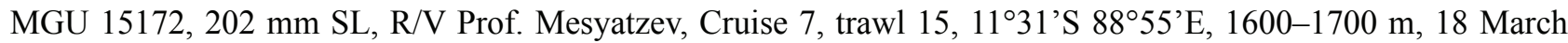

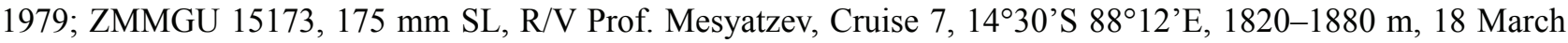
1979; ZMMGU 15174, 175-195 mm SL (3 specimens), R/V Prof. Mesyatzev, Cruise 7, trawl 11,1451S 86²9'E, 1760 m, 19 March 1979; ZMMGU 15175, 156-182 mm SL (3 specimens), R/V Prof. Mesyatzev, Cruise 7, trawl

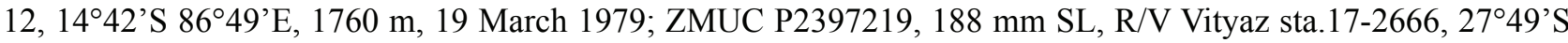
44ํํ'ㄹ, 1870-1880 m, 6 December 1988.

Diagnosis. Precaudal vertebrae 14-16, 3-5 loin vertebrae (last precaudal vertebrae without ribs); long gill rakers on first gill arch 18-21; pectoral-fin rays 16-18; HL:HD 1.38-1.63; maximal HD:HD through center of eye 1.35-1.70; weak head spines on ethmoidal, interorbital and 5th infraorbital; opercular spine sharp, extruding; opercular flap moderately large; vomer narrow, naked or with few teeth or one row of teeth; palatines narrow with 1-3 rows of teeth; basibranchial tooth patch small, narrow with 1-3 rows of teeth; otolith large, 11.5-14.5\% in HL, with single colliculum; $\mathrm{OL}: \mathrm{OH}=1.22-1.34 ; \mathrm{OL}: \mathrm{TCL}=2.46-2.92$.

Description. Meristics: precaudal vertebrae 14-16, last 3-5 vertebrae without ribs; pectoral-fin rays 18 (16$18) ; \mathrm{D} / \mathrm{V}=5(4-5) ; \mathrm{D} / \mathrm{A}=23(21-25) ; \mathrm{V} / \mathrm{A}=16$ (15-17); long gill rakers on lower gill arch 20 (18-21). Gill rakers in holotype on lower first gill arch with five short rakers, followed by a series of 20 long rakers. The lower nine of those intercepted by narrow plate shaped rakers with a single spine pointing inward. Upper gill arch with four short rakers intercepted by four semi long rakers.

Morphometrics: in \% of SL: HL 14.4-16.0; maximal HD 9.0-11.2; HD through center of eye 5.9-6.9; bony interorbital width 2.6-3.7; snout length 4.7-5.5; upper jaw length 9.5-10.7; predorsal 16.3-18.1; preanal 28.6-31.7; prepelvic 10.8-12.6; prepectoral 15.4-16.4; pectoral length not measurable. Relations: HL:HD = 1.38-1.63; maximal HD:HD through center of eye 1.35-1.70; HL to snout length 2.78-3.30; preanal to predorsal 1.68-1.94; predorsal to prepectoral 1.00-1.11.

Overall slender fish with long tapering tail, but stout head and moderately long snout. Maximal size of fishes investigated $202 \mathrm{~mm}$ SL (holotype 153+ mm). Head with flat or slightly concave dorsal profile, with few weak spines such as ethmoidal, interorbital and 5th infraorbital except; outer preopercular rim sometimes with few broad spines; opercle with small but sharp, extruding spine. Eye moderately small located in strongly asymmetric orbit. Maxilla extending far beyond eye, strongly widened posteriorly; supramaxilla very narrow. Infra-/postorbital and mandibular-preopercular pores very wide. Head with few scales on cheeks only. Opercular flap moderately large, sometimes with ridges. Lateral line not discernable.

Dentition. All teeth tiny and cone-shaped. Vomer v-shaped naked or with up to 3 teeth rows anteriorly; palatines with a narrow dentition patch with 1-3 rows of teeth. Premaxilla tooth patches not fused anteriorly; 5-6 rows. Dentary tooth patches not fused anteriorly; with 6-8 rows. Median basibranchial tooth patch small and narrow with 1-3 rows of teeth.

Otolith morphology $(\mathrm{n}=5$ ). Size up to $4.65 \mathrm{~mm}$ in length (MNHN 1994-0761) (holotype $2.9 \mathrm{~mm}$ ); OL in \% $\mathrm{HL}=11.5-14.5 ; \mathrm{OL}: \mathrm{OH}=1.22-1.34 ; \mathrm{OH}: \mathrm{OT}=2.45-2.75$. Otolith oval in shape with all rims regularly curved and smooth and without angles. Inner face flat, with very short sulcus positioned at center of inner face; OL:TCL = 2.46-2.92. Sulcus with shallow, undivided, uniform, oval, small colliculum. Dorsal field very wide, without distinct depression; ventral field smooth. Outer face smooth, convex, with low relief central umbo.

Coloration. Live coloration not known. Color of preserved uniformly black. 

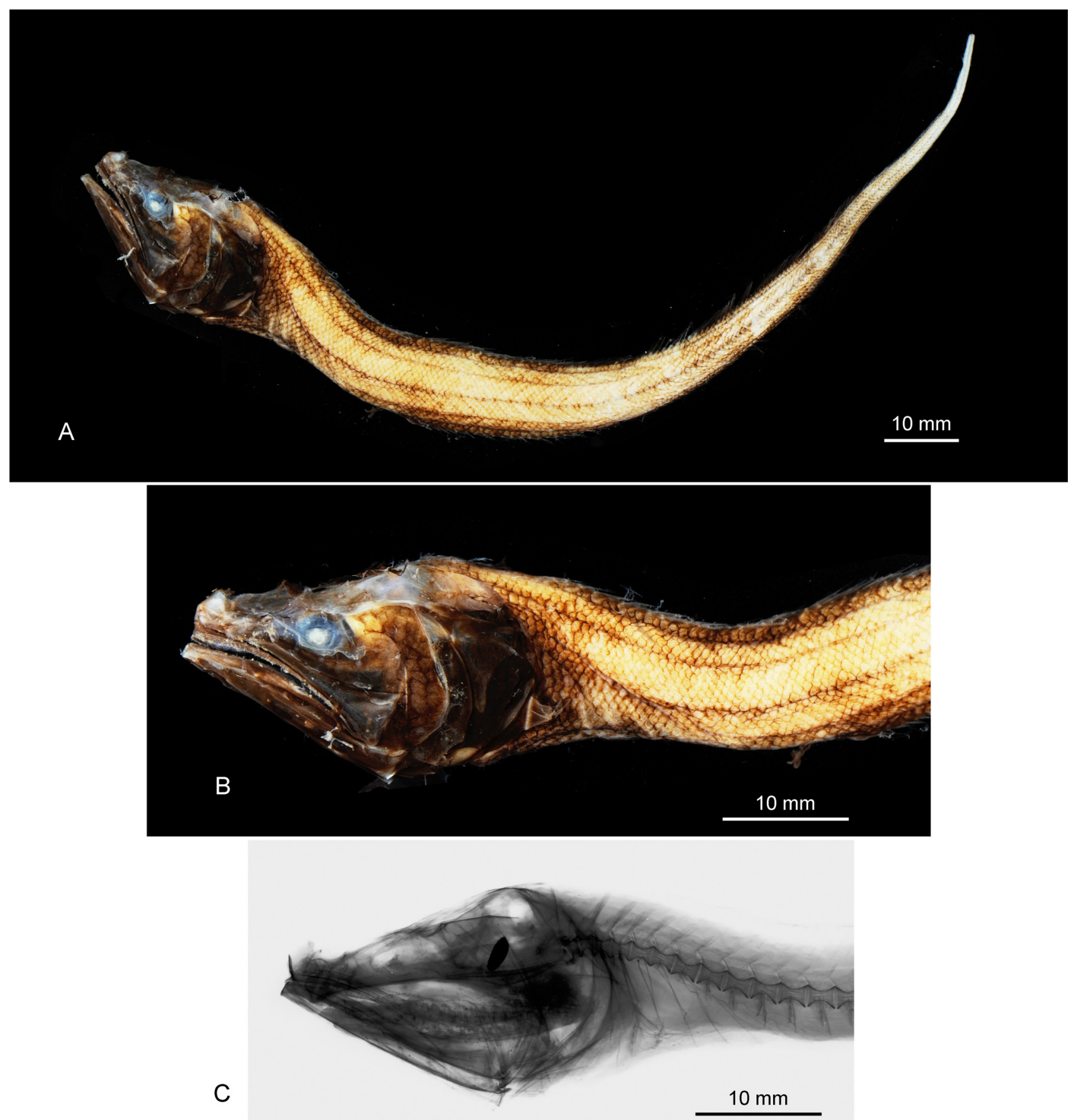

FIGURE 39. Tenuicephalus multitrabs n. sp., holotype, 153+ mm SL, CAS 83066, Laganoy Gulf, Philippines, $1037-1100$ m.

Discussion. Tenuicephalus multitrabs differs from T. melampeplus in the smaller head expressed in a lower ratio of HL in \% of 14.4-16.0 (vs 16.4-17.2), more long gill rakers (18-21 vs 14-16), presence of week ethmoidal, interorbital, 5th infraorbital and outer preopercular spines (vs no spines) and the large otolith (OL in \% HL $=11.5-$ 14.5 vs 8.5 ) with a small sulcus (OL:TCL $=2.46-2.92$ vs 1.87$)$. It differs from T. squamilabrus $\mathbf{n}$. sp. in the lack of scales on the occiput, opercle and maxilla (vs present), the ratio maximal HD:HD through center of eye of 1.35-1.70 (vs 1.75-1.90), the ratio OL in \% HL of 11.5-14.5 (vs 5.0-6.5) and the ratio OL:TCL of 2.46-2.92 (vs 1.94-2.30). Otolith sizes have been shown to vary with living depth and ocean basin (Wilson 1985), but here all three species share the same distribution and depth range and T. multitrabs and T. squamilabrus $\mathbf{n}$. sp. have even been collected in very close vicinity in the Lagonoy Gulf of the Philippines. Therefore we regard the relatively large size of the otoliths in T. multitrabs in comparison to the two other species as a valid morphological signal and in deed the most secure one to distinguish it from T. squamilabrus n. sp. (see below). 

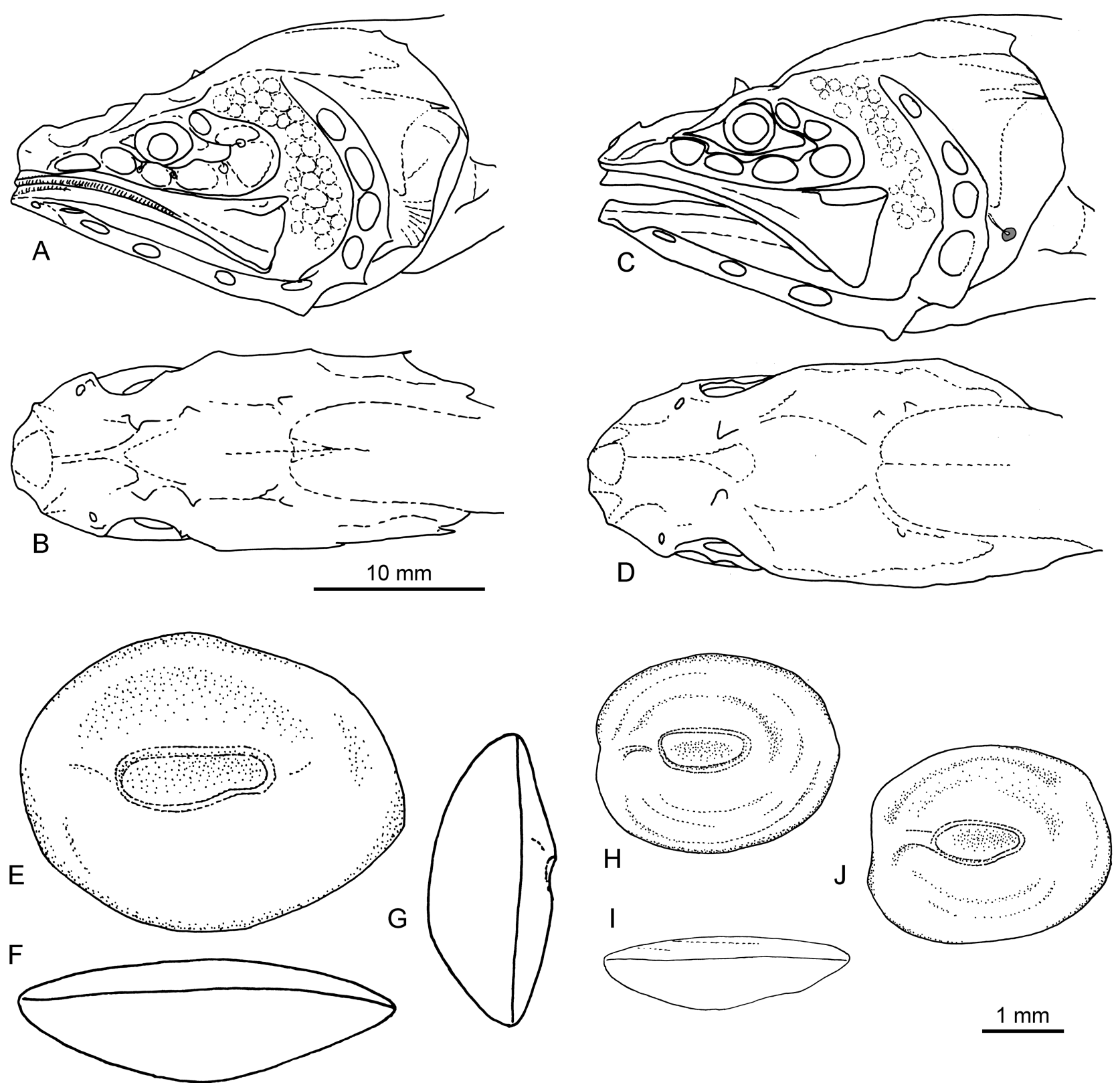

FIGURE 40. Tenuicephalus multitrabs n. sp.; 40A-B, holotype, 153+ mm SL, CAS 83066, Laganoy Gulf, Philippines, 1037-

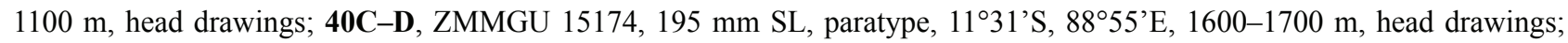
40E-G, MNHN 1994-0761, paratype, 202 mm SL, 2206’S, 166²7’E, 1920 -2040 m, otolith (E inner face, F ventral view, G anterior view); 40H-I, CAS 83066, paratype, 156 mm SL, Laganoy Gulf, Philippines, 1037-1100 m, otolith (H inner face, I ventral view); 40J, holotype, 153+ mm SL, CAS 83066, Laganoy Gulf, Philippines, 1037-1100 m, otolith (inner face).

Distribution. Tenuicephalus multitrabs is widely distributed in the Indian Ocean (except for its northern part) and the western Pacific. It occurs at depth between 1000 and $2000 \mathrm{~m}$ and has been caught at great distance from the nearest shelf areas in the central Indian Ocean (nearly $2000 \mathrm{~km}$, Fig. 51) above the Ninety-East Ridge. In fact the largest number of specimens have been caught over the Ninety-East Ridge, and well above the sea bottom indicating that these fishes might obtain a bathypelagic rather than a benthopelagic life style.

Etymology. From multi (Latin) = many, multi, and trabs (Latin) = club, spar, referring to the many long rakers in this species as compared to T. melampeplus. 


\section{Tenuicephalus silus (Carter \& Sulak, 1984)}

Figs. 41, 48, 51, Tab. 1-7

Porogadus silus Carter \& Sulak, 1984: 361, figs. 1-5, 6a, 7-8, 10-17; Nielsen et al. 1999: 86.

Material examined (5 specimens): Holotype USNM 238801, $139 \mathrm{~mm} \mathrm{SL}, 24^{\circ} 16^{\prime} \mathrm{N} 76^{\circ} 16^{\prime} \mathrm{W}, 1962 \mathrm{~m}$, R/V Columbus Iselin, Cruise 7511, Sta. 387, collected by Robins, Staiger and Sulak, 29 August 1975,; paratypes: USNM

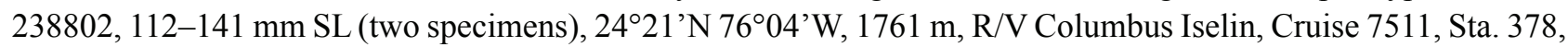
collected by Robins, Staiger and Sulak, 29 August 1975; ZMUC P77729-77730, 95-130 mm SL (two specimens), Same data as holotype.
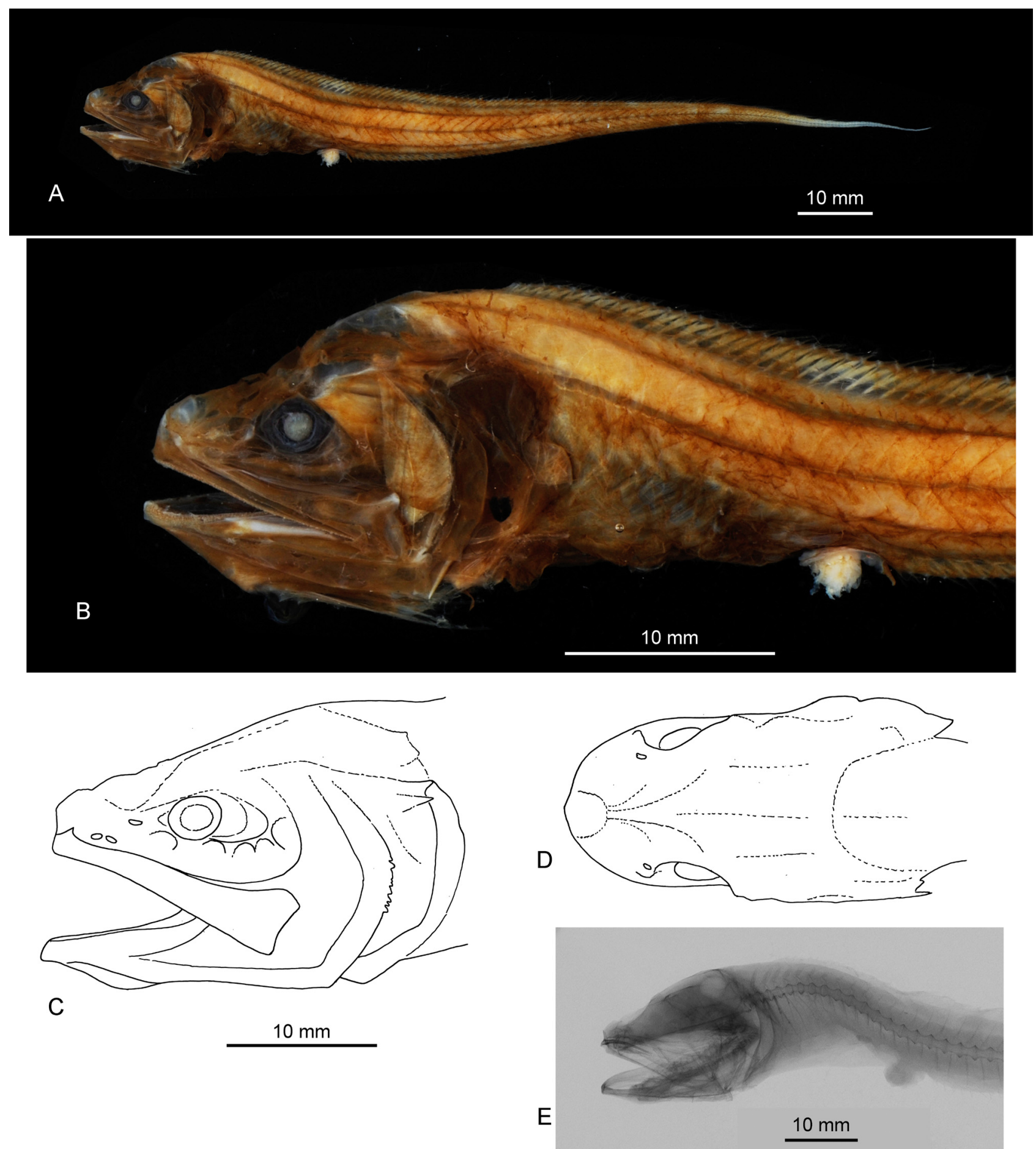

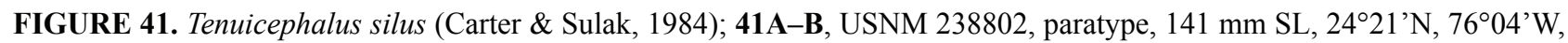

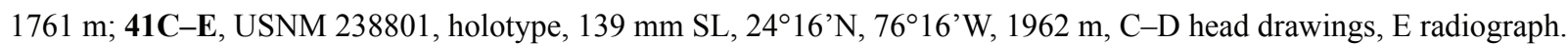


Diagnosis (new). Precaudal vertebrae 16-17, 8-10 loin vertebrae (last precaudal vertebrae without ribs); long gill rakers on first gill arch 15-18; pectoral-fin rays 17-19; HL:HD 1.35-1.45 (head depth 65-70\% of head length in Carter \& Sulak); no head spines; opercular spine flat, extruding; opercular flap small; vomer narrow, anteriorly naked, with few teeth posteriorly; palatines narrow with 1-2 rows of teeth; basibranchial tooth patch very small or absent. Addition from Carter \& Sulak: lateral line scales to level of vent 14-20; first dorsal fin pterygiophore originating between second and third neural spine.

Description. Meristics: precaudal vertebrae 16-17, last 8-10 vertebrae without ribs; pectoral-fin rays 18 (1719); $\mathrm{D} / \mathrm{V}=5$ (3-4); $\mathrm{D} / \mathrm{A}=23$ (22-25); V/A = 18 (17-19); long gill rakers on lower gill arch 17 (15-18). Gill rakers in a paratype (ZMUC P77730) on lower first gill arch with five relatively short rakers, followed by a series of 12 long rakers. The lower ten of those intercepted by narrow plate shaped rakers with a few spines pointing inward. Upper gill arch with five short rakers intercepted by three semi long rakers.

Morphometrics: in \% of SL: HL 14.8-17.6; maximal HD 10.3-12.8; HD through center of eye 7.4-8.6; bony interorbital width 3.5-3.7; snout length 4.6-5.6; upper jaw length 10.5-11.6; predorsal 16.0-17.1; preanal 28.332.3; prepelvic 11.8-12.0; prepectoral 16.1-17.7; pectoral length not measurable. Relations: HL:HD = 1.35-1.45; maximal HD:HD through center of eye 1.40-1.54; HL to snout length 2.88-3.30; preanal to predorsal 1.75-1.88; predorsal to prepectoral $0.93-1.04$.

Overall slender fish with long tapering tail, but stout head and snout. Maximal size of fishes investigated 141 $\mathrm{mm}$ SL (holotype $139 \mathrm{~mm}$ ). Head with flat or slightly concave dorsal profile, without head spines except opercle with small, flat, extruding spine. Eye moderately small located in strongly asymmetric orbit. Maxilla extending far beyond eye, strongly widened posteriorly; supramaxilla small. Infra-/postorbital and mandibular-preopercular pores wide, usually no single pores discernable. Scales on head absent or not discernable. Opercular flap small. Lateral line not discernable.

Dentition. All teeth tiny and cone-shaped. Vomer naked anteriorly and with 2-5 fang-like teeth posteriorly; palatines with a narrow dentition patch with 1-2 rows of teeth. Premaxilla tooth patches, broad, not fused anteriorly, 4-10 rows of teeth in middle part. Dentary tooth patches broad, not fused anteriorly, 5-10 rows in middle part. No basibranchial tooth patch or single very small median tooth patch.

Otoliths not known.

Coloration. Live coloration not known. Color of preserved dark brown to uniformly black.

Discussion. Tenuicephalus silus shows the probably most advanced morphology characterized by the complete absence of head spines except for a flat opercular spine, a short head (HL:HD $=1.35-1.45$ ), the last 8-10 precaudal vertebrae without ribs and a much reduced dentition on vomer, palatines and basibranchial, the latter often without tooth patch. Carter \& Sulak (1984) have undertaken a detailed osteological study of T. silus, the only one of its kind in the Porogadus lineage.

Distribution. Tenuicephalus silus is the only species of the genus occurring in the Atlantic Ocean, in a relatively restricted region within the Caribbean at depth of about 1750 to $2000 \mathrm{~m}$ and not venturing far from the shelf break.

\section{Tenuicephalus squamilabrus n. sp.}

Figs. 2, 42-43, 48, 51, Tab. 1-7

Material examined (11 specimens): Holotype: AMS I36456-007, $175 \mathrm{~mm} \mathrm{SL}, 13^{\circ} 21^{\prime} \mathrm{N} 124^{\circ} 12^{\prime} \mathrm{E}, 1037-1100 \mathrm{~m}$; paratypes: CAS 50160, 127-140 mm SL (2 specimens), R/V Anton Bruun, Cruise 8, 21 ${ }^{\circ} 18^{\prime} \mathrm{S} 36^{\circ} 18^{\prime} \mathrm{E}, 1510-1600$ m, 2 October 1964; MNHN uncat., 138-167 mm SL (3 specimens), Sta. CH 128, off Madagascar, $18^{\circ} 05^{\prime} \mathrm{S} 42^{\circ} 53^{\prime} \mathrm{E}$, 1930 m, collected by A. Crosnier, 16 January 1975; BSKU 82353-56, 106-173 mm SL (4 specimens), 01 $59^{\circ}$ 'S $157^{\circ} 12^{\prime} \mathrm{E}, 1610 \mathrm{~m}$ R/V Hakuho-maru, $3 \mathrm{~m}$ beam trawl, 04 January 1968; BSKU 98880, $174 \mathrm{~mm}$ SL, 0159’'S $157^{\circ} 12^{\prime} \mathrm{E}, 1610 \mathrm{~m}$, R/V Hakuho-maru, $3 \mathrm{~m}$ beam trawl, 4 January 1968.

Diagnosis. Precaudal vertebrae 15-16, 2-4 loin vertebrae (last precaudal vertebrae without ribs); long gill rakers on first gill arch 17-21; pectoral-fin rays 16-18; HL:HD 1.37-1.55; maximal HD:HD through center of eye 1.75-1.90; weak head spines on ethmoidal and interorbital; opercular spine sharp, extruding; opercular flap small; scales on occiput, cheeks, opercle and maxilla; vomer narrow, naked or with few teeth or one row of teeth; palatines narrow with 2-3 rows of teeth; basibranchial tooth patch small, narrow with 2 rows of teeth; otolith small, 5.0-6.5 $\%$ in HL, with single colliculum; $\mathrm{OL}: \mathrm{OH}=1.14-1.20 ; \mathrm{OL}: \mathrm{TCL}=1.94-2.30$. 
Description. Meristics: precaudal vertebrae 15-16, last 2-4 vertebrae without ribs; pectoral-fin rays 16 (16$18) ; \mathrm{D} / \mathrm{V}=5$ (5-6); $\mathrm{D} / \mathrm{A}=23$ (22-23); V/A = 15 (15-17); long gill rakers on lower gill arch 18 (17-21). Gill rakers in holotype on lower first gill arch with six short rakers, followed by a series of 18 long rakers. The lower ten of those intercepted by single plate shaped rakers. Upper gill arch with three short rakers intercepted by five plate shaped rakers.
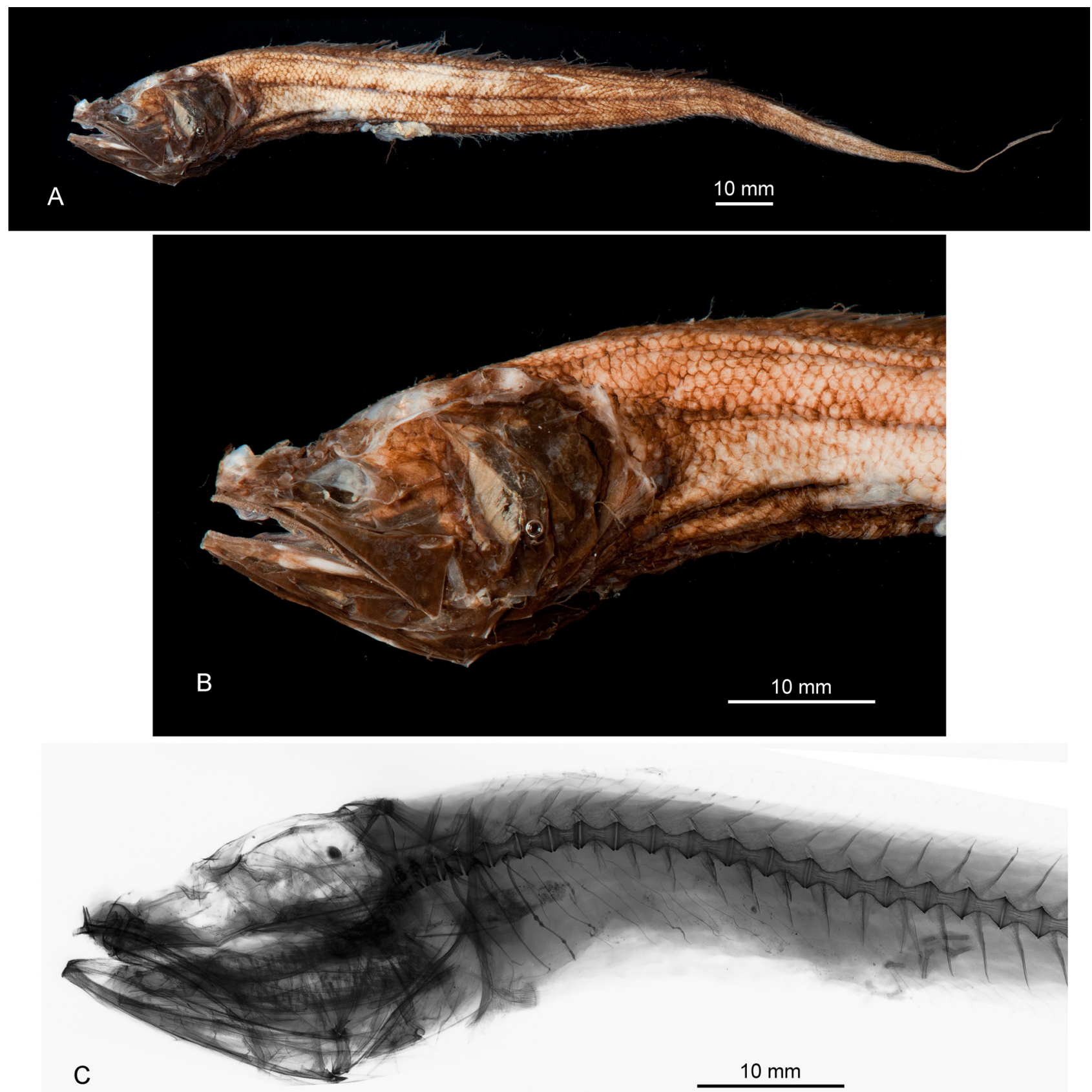

FIGURE 42. Tenuicephalus squamilabrus n. sp., holotype, AMS I.36456-007, 175 mm SL, 13²21'N, 124¹2’E, 1037-1100 m.

Morphometrics: in \% of SL: HL 14.7-16.2; maximal HD 9.5-11.7; HD through center of eye 5.0-6.4; bony interorbital width 2.3-3.7; snout length 4.9-5.5; upper jaw length 10.0-11.1; predorsal 16.5-17.4; preanal 28.930.8; prepelvic 12.2-13.3; prepectoral 15.8-17.7; pectoral length not measurable. Relations: HL:HD = 1.37-1.55; maximal HD:HD through center of eye 1.75-1.90; HL to snout length 2.64-3.28; preanal to predorsal 1.69-1.84; predorsal to prepectoral $0.95-1.08$.

Overall slender fish with long tapering tail, but stout, short head and moderately long snout. Maximal size of fishes investigated $175 \mathrm{~mm}$ SL (holotype). Head with distinctly concave dorsal profile, with few weak spines 
such as ethmoidal and interorbital; opercle with small but sharp, extruding spine. Eye moderately small located in strongly asymmetric orbit. Maxilla extending far beyond eye, strongly widened posteriorly; supramaxilla very narrow. Infra-/postorbital and mandibular-preopercular pores very wide. Head with many scales (preserved only in holotype) on cheeks and opercle, few scales on occiput, and many small scales on rear part of maxilla and very small scales on supramaxilla. Opercular flap moderately small. Lateral line not discernable.
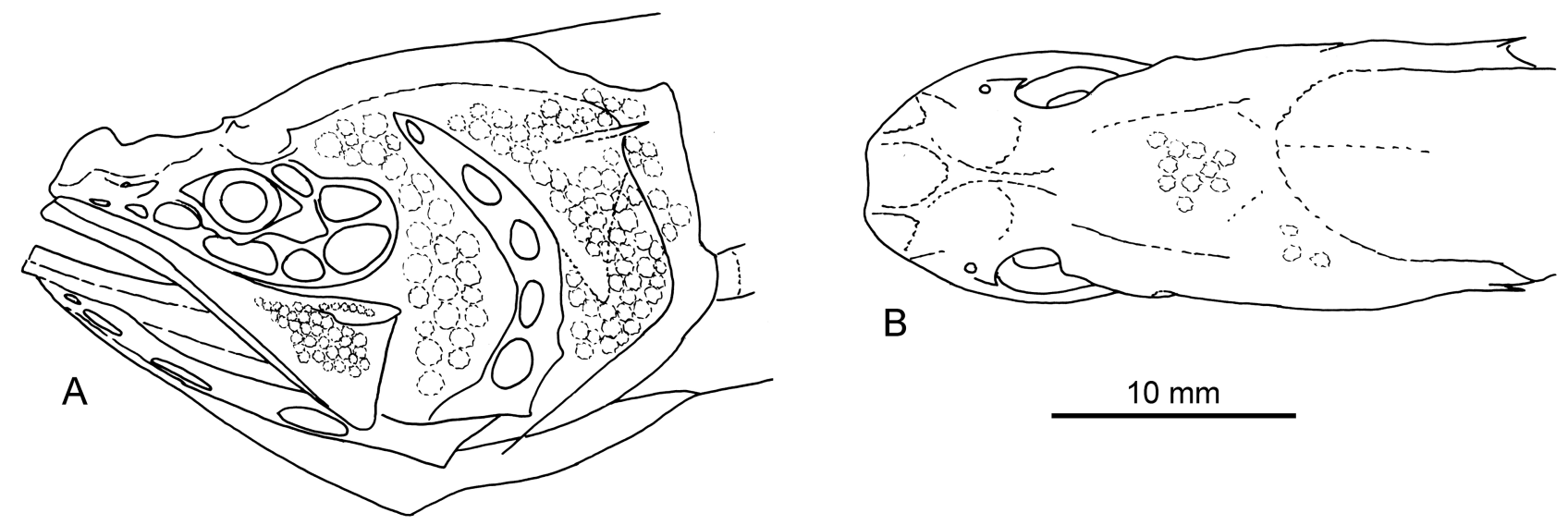

B
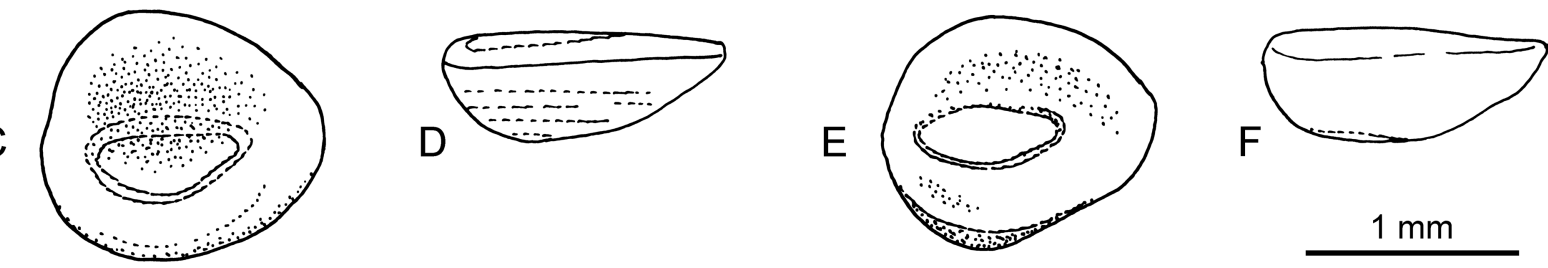

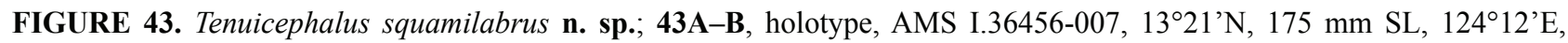
1037-1100 m, head drawings; 43C-D, CAS 50160, paratype, $140 \mathrm{~mm} \mathrm{SL}, 21^{\circ} 18^{\prime} \mathrm{S}, 36^{\circ} 18^{\prime} \mathrm{E}, 1510-1600$, otolith (C inner face, D ventral view); 43E-F, holotype, AMS I.36456-007, $175 \mathrm{~mm} \mathrm{SL}, 1^{\circ} 21^{\prime} \mathrm{N}, 124^{\circ} 12^{\prime} \mathrm{E}, 1037-1100 \mathrm{~m}$, otolith (E inner face, F ventral view).

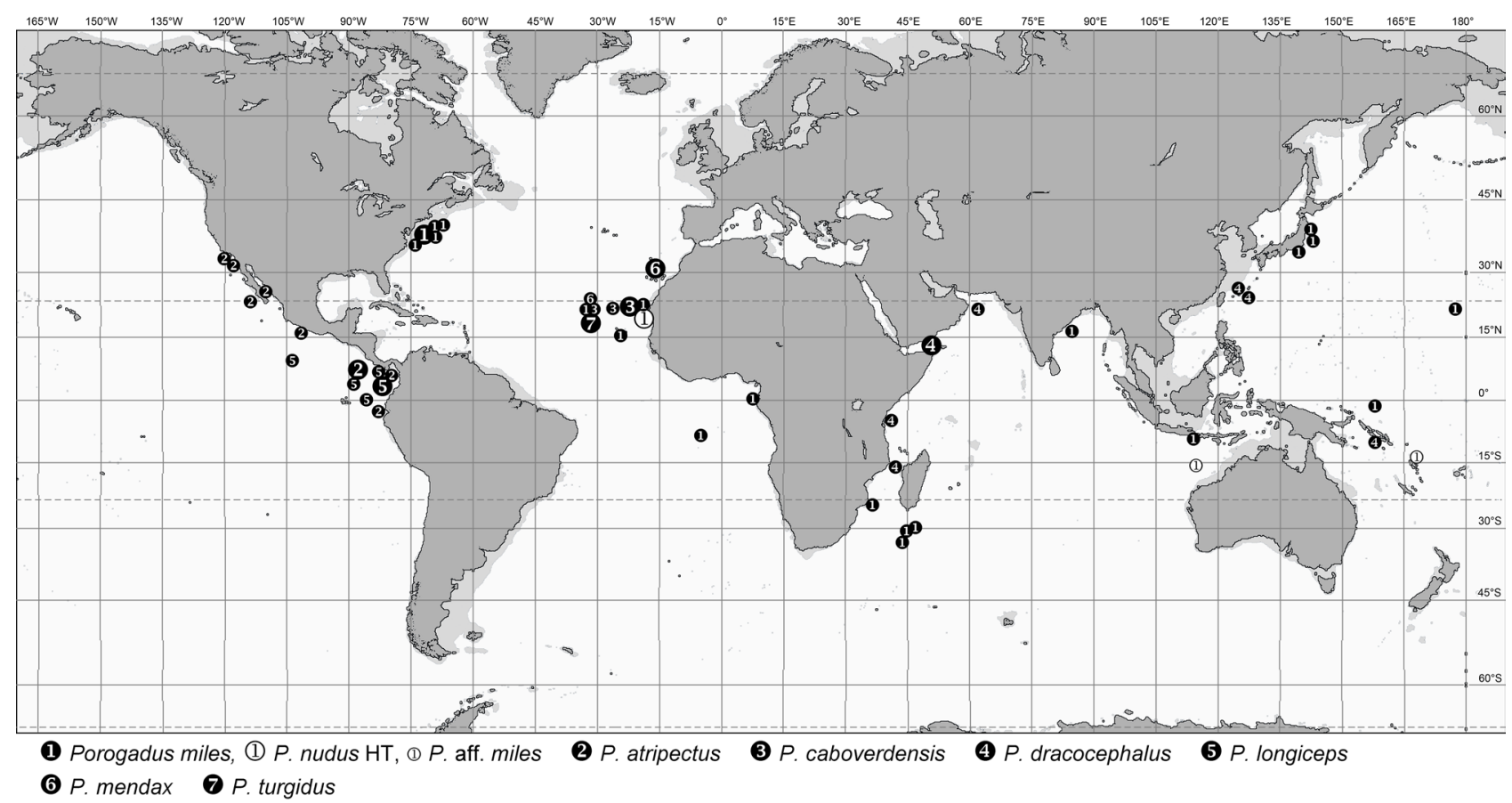

FIGURE 44. Geographic distribution of the species of the Porogadus miles group. 
Dentition. All teeth tiny and cone-shaped. Vomer naked or with a very narrow dentition patch with 1-2 rows of few teeth anteriorly, naked posteriorly; palatines with a narrow dentition patch with 2-3 rows of teeth. Premaxilla tooth patches not fused anteriorly; 5 rows of teeth in middle part. Dentary tooth patches fused anteriorly; ca. 5 rows anteriorly and 2 rows posteriorly. Median basibranchial tooth patch small and narrow with 2 rows of teeth.

Otolith morphology $(\mathrm{n}=4)$. Size up to $1.35 \mathrm{~mm}$ in length (CAS 83066) (holotype $1.35 \mathrm{~mm}$ ); OL in \% HL= $5.0-6.5 ; \mathrm{OL}: \mathrm{OH}=1.14-1.20 ; \mathrm{OH}: \mathrm{OT}=2.00-2.23$. Otolith nearly round in shape with all rims regularly curved and smooth and without angles. Inner face flat, with short sulcus positioned near center of inner face; OL:TCL = 1.94-2.30. Sulcus with shallow, undivided, uniform, oval, moderately wide colliculum. Dorsal field wide, without distinct depression; ventral field smooth. Outer face smooth, convex, with anteriorly shifted umbo.

Coloration. Live coloration not known. Color of preserved dark brown or uniformly black.

Discussion. Tenuicephalus squamilabrus is characterized by extensive head squamation including the maxilla and supramaxilla, which however is only reasonably preserved in the holotype, and the small otolith (OL in \% HL of 5.0-6.5), but otoliths are preserved only in about one-third of the specimens. In the absence of these two prime diagnostic features, the distinctly concave dorsal head profile and the resulting high ratio of the maximal HD to the HD through the center of the eye of $1.75-1.90$ (vs $1.35-1.65$, rarely 1.70) is the most distinctive character. For further differentiation see above discussion to T. melampeplus and T. multitrabs.

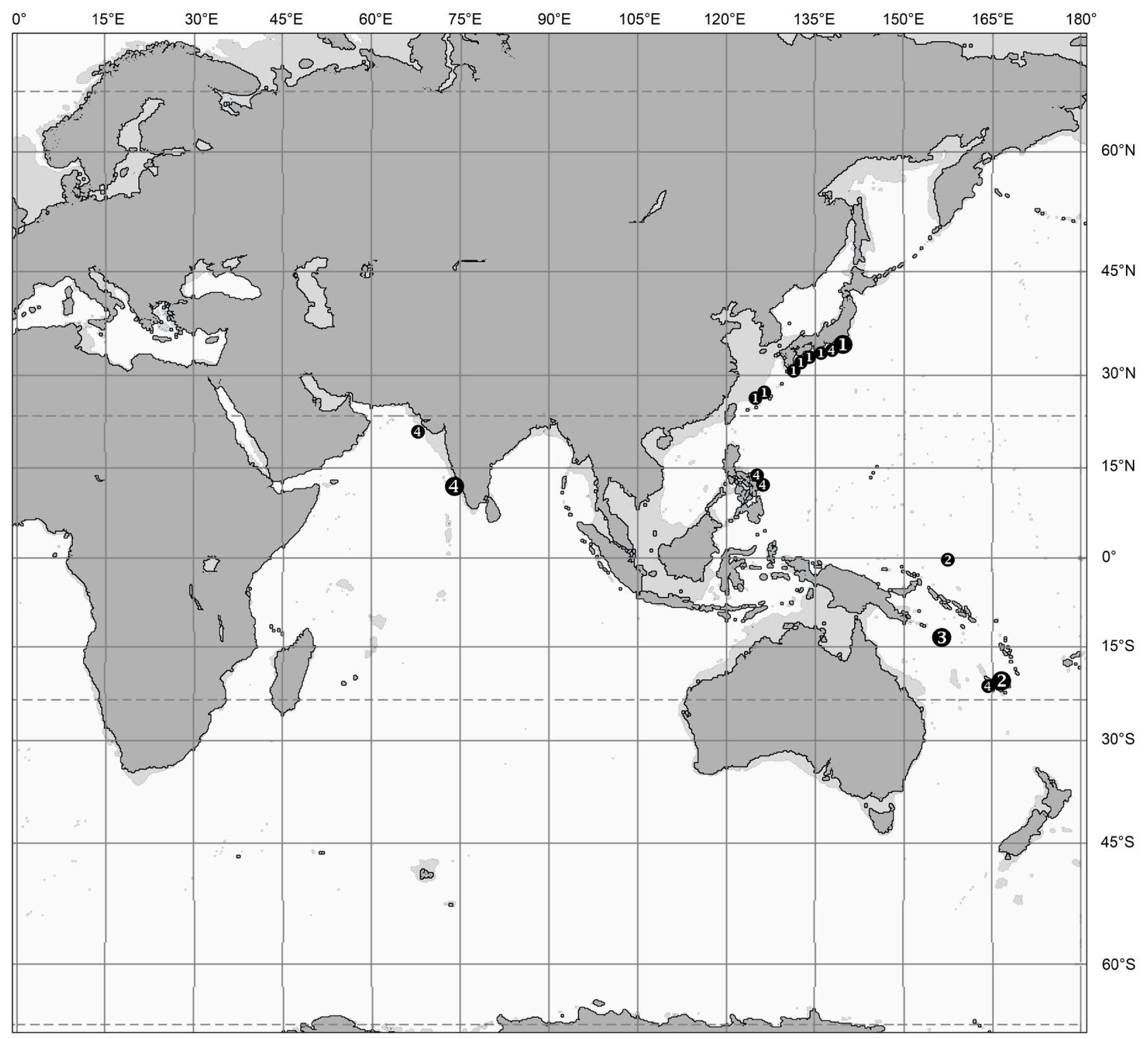

(1) Porogadus guentheri

(2) P. lacrimatus

3 $P$. solomonensis

P. trichiurus

FIGURE 45. Geographic distribution of the species of the Porogadus trichiurus group. 


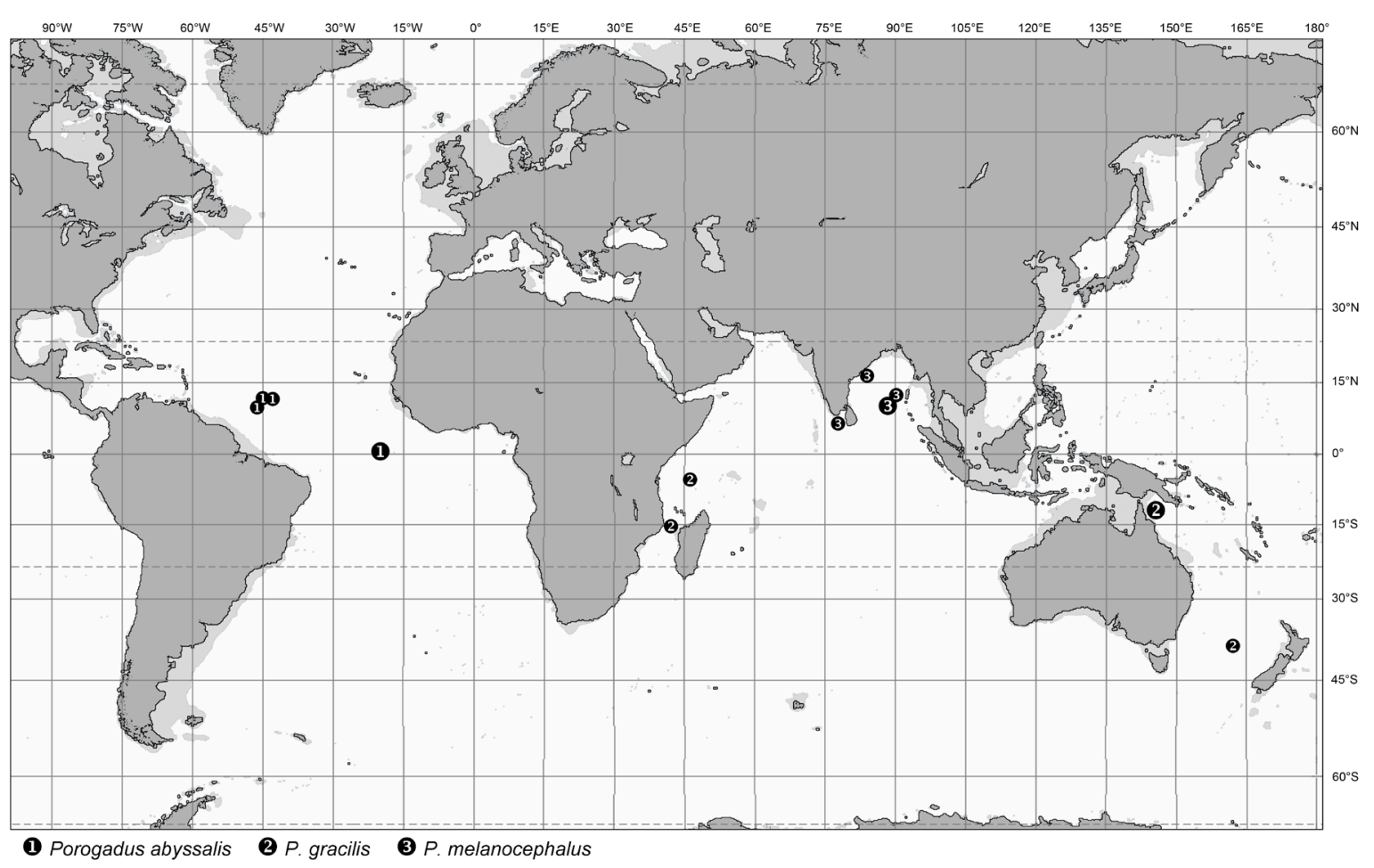

FIGURE 46. Geographic distribution of the species of the Porogadus gracilis group.

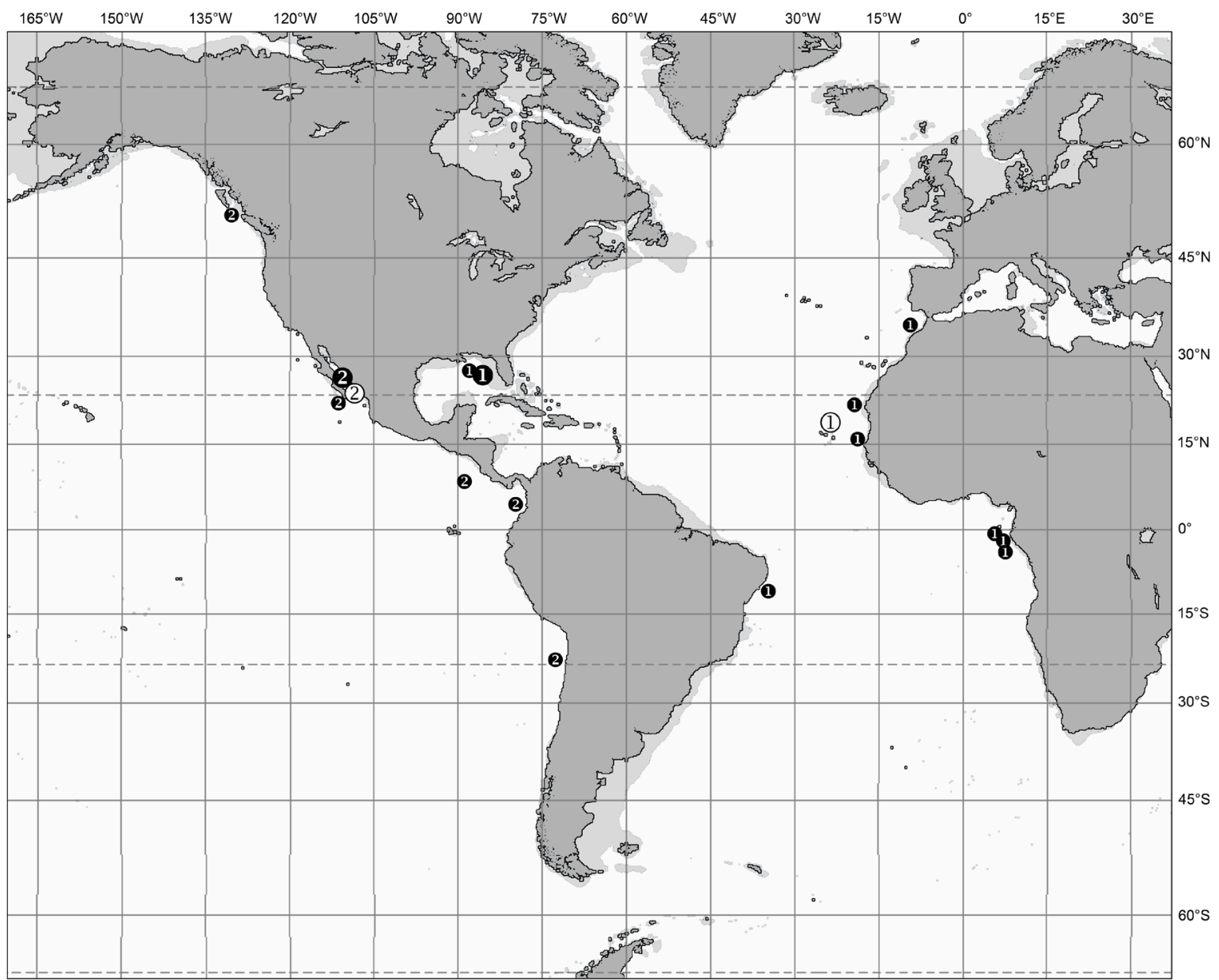

(1) Porogadus catena, (1) P. subarmatus HT 2 P. promelas, (2) P. breviceps $\mathrm{HT}$

FIGURE 47. Geographic distribution of the species of the Porogadus catena group. 


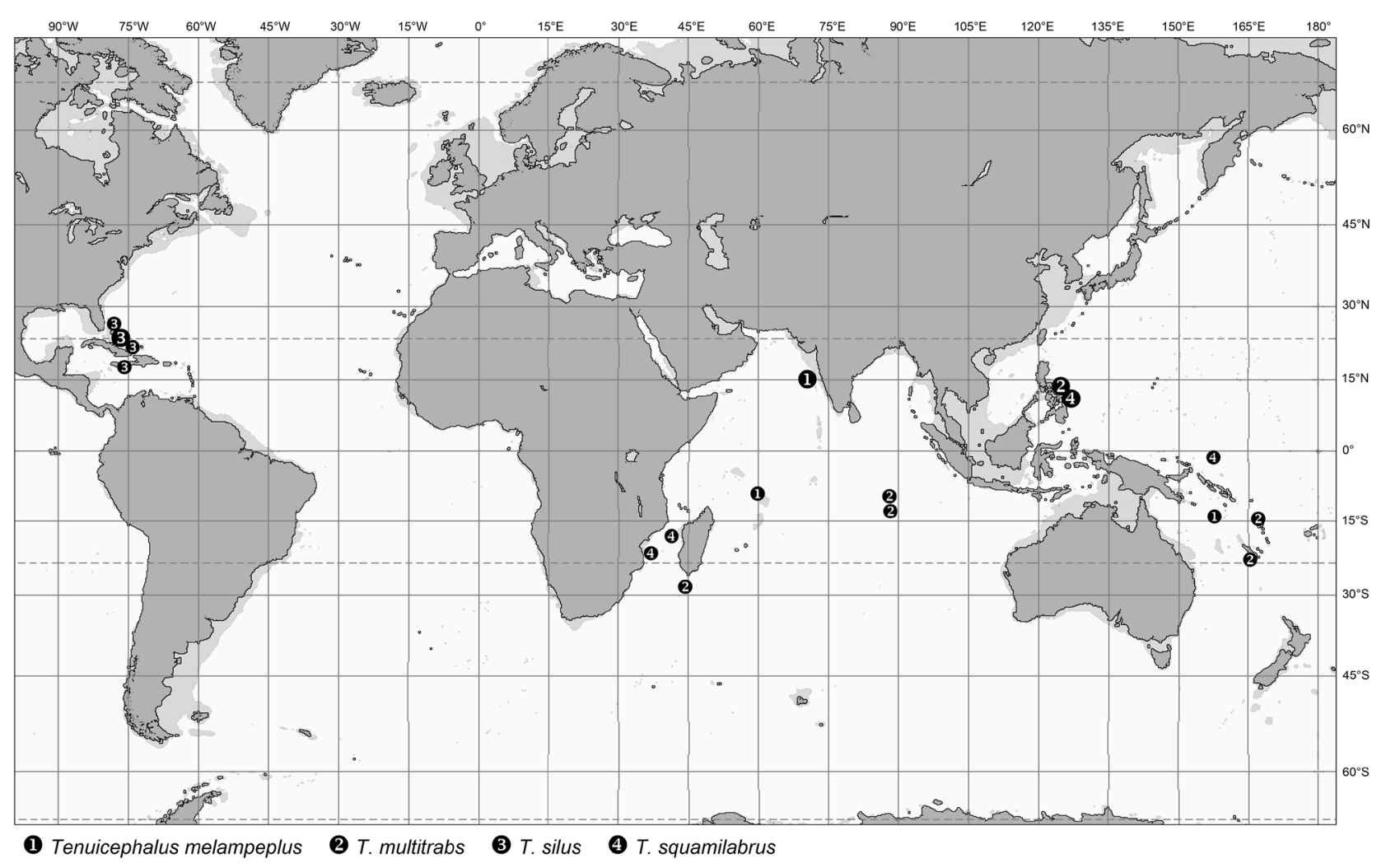

FIGURE 48. Geographic distribution of the species of the genus Tenuicephalus.

Distribution. The distribution of Tenuicephalus squamilabrus overlaps with that of T. multitrabs in the western Pacific and both species have been caught in close vicinity in the Lagonoy Gulf of the Philippines. Else, $T$. squamilabrus had been caught in the Madagascar Channel. Tenuicephalus squamilabrus does not seem to venture far away from the continental slopes and for instance has not been caught along the Ninety-East Ridge like $T$. multitrabs.

Etymology. From squama $($ Latin $)=$ scale and labrum $($ Latin $)=$ lip, referring to the many small scales on maxilla and supramaxilla.

\section{Ecology and biogeography}

Porogadus and Tenuicephalus are widely distributed beneath the oligotrophic tropical and subtropical seas of the world and in some regions reach into the temperate zone. Their live-style is benthopelagic below the oxygen minimum zone and to the best of our knowledge all catches were made by deep-sea bottom trawls. OTSB hauls (Otter Trawl Semi-Balloon) appear to have yielded the best results for catching larger benthopelagic fish at great depth. For instance many of the Porogadus specimens represented in the BMNH collection from off Cabo Verde Islands and Mauretania below $3000 \mathrm{~m}$ depth have been caught with this method (e.g., Merrett in Partridge 2000). While Porogadus specimens are generally few in individual hauls they can locally become quite abundant as exemplified by a Galathea II trawl in the Bay of Bengal that yielded 45 specimens of $P$. melanocephalus, as yet the highest record of a Porogadus species in any individual trawl.

The majority of Porogadus species and all species of Tenuicephalus occurs bathyal at depths between c. 1000 and $3500 \mathrm{~m}$ but there are specimens of primarily bathyal species that have occasionally been caught at depth greater than 3500 m, i.e., P. atripectus, P. dracocephalus, P. miles and P. promelas (Figs. 49-51). In addition there appears to be some depth segregation in the diversity within certain groups indicated by species having been caught regularly or exclusively at great depths. These are Porogadus gracilis and P. melanocephalus below $3000 \mathrm{~m} ; P$. caboverdensis, P. mendax and P. turgidus below $4000 \mathrm{~m}$; and P. abyssalis below $5000 \mathrm{~m}$. In addition there is a live photograph of a putative Porogadus specimen taken by a ROV of the NOAA ship Okeanos Explorer at $5856.8 \mathrm{~m}$ on 
the abyssal plain of the central Pacific near Phoenix Islands (Fig. 5) which would represent the deepest record for the genus. These species are amongst the deepest dwelling teleost fishes and they recruit only from the Porogadus miles and Porogadus gracilis groups, the latter being entirely restricted to below $3000 \mathrm{~m}$ water depth (Fig. 49). Interestingly, the three abyssal species of the Porogadus miles group so far have only been found in a relatively confined area on the abyssal plains off NW-Africa. This is an unusual diversity center but would be in line with observations made by Merrett \& Marshall (1981) that the species diversity off NW-Africa was considerably higher than off NE-America (for bathyal fish communities), but dominated by smaller species, which they related to the higher primary productivity related to the Mauretanian upwelling system even at considerable distance from shore. The reason, however, for the unusual diversity of Porogadus in the abyssal zone off NW-Africa remains elusive. Watling et al. (2013) do not show a specific abyssal bioprovince in the NE-Atlantic. We are uncertain whether this feature represents a genuine diversification event in the region, which we cannot readily explain or if it is a product of sampling bias in which case the same or other abyssal Porogadus species might be expected in other ocean basins. The abyssal regions of the world oceans are still severely undersampled, even though the use of deep-sea remotely operated vehicles (ROV) for scientific purposes have greatly increased our knowledge in recent years (Chave \& Mundy 1994; Linley et al. 2017; Mundy et al. 2018; Bell et al. 2012, 2016, 2107; Raineault et al. 2018, 2019, 2020) and abyssal biogeography of fishes therefore has remained largely elusive (Priede et al. 2020). The abyssal region discussed here off NW-Africa is located south of the warm, high salinity Mediterranean outflow zone that reaches down to about $2000 \mathrm{~m}$ (Potter \& Lozier 2004; Filipelli 2014) and far off from the coastal upwelling system in the Mauretanian Sea (Pelegrí et al. 2017). Seamounts in the vicinity have recently become known for large deep-sea sponge populations (Ramiro-Sánchez et al. 2019). Two of the three deep-water species of the Porogadus gracilis group occur in the Indian Ocean (P. gracilis and P. melanocephalus) and one of them in the southwestern Pacific Oceans (P. gracilis). This is a remarkable under-representation compared to the deep Atlantic and it is not entirely clear, if and how sampling bias may play a role in this discrepancy. The third abyssal species of the Porogadus gracilis group, $P$. abyssalis lives on the central Atlantic abyssal plains and represents the deepest dwelling species of the entire genus.

The Porogadus gracilis group is noticeable for a reduced ossification, reduced otolith size and low level head armature. We hypothesize that these features reflect an adaptation of the fishes for living at great (abyssal) depth generally below the carbonate compensation depth (CCD). In contrast to this group the three abyssal species of the Porogadus miles group, i.e. P. caboverdensis, P. mendax and P. turgidus do not show a reduced ossification or reduced otolith size or even reduced head armature. This in our view would indicate a less advanced adaptation to the abyssal zone compared to the species of the Porogadus gracilis group, which in turn might be a result from them having settled at great depth in more recent times.

Not surprisingly, the deep-water species mentioned above which live on the abyssal plains can occur far out from the continental breaks, but some of the bathyal species can also occur at great distance from the nearest continent (Figs. 49-51). Porogadus miles holds the record with over $2500 \mathrm{~km}$ away from the nearest continental mass on the Emperor Seamount Chain (Fig. 49). Tenuicephalus multitrabs also occurs off the continental breaks by 1000 to $2000 \mathrm{~km}$ on the Ninety East Ridge (Fig. 51). Other species have been found regionally restricted and on or close to continental slopes, which is a pattern found in all groups of both genera (Figs. 49-51).

A recent study by Agusti et al. (2015) revealed the ubiquitous presence of healthy photosynthetic cells, dominated by diatoms, down to $4,000 \mathrm{~m}$, which together with fecal pellets probably represent the basis for the deep-water food chain. Deep-sea fishes are the top predators in this short trophic sequence. Carter (1984) studied the feeding strategy and functional morphology of several deep-sea ophidiids at great detail including Porogadus miles, P. catena and T. silus. The species of both genera are remarkable for their tiny, uniform, cone-shaped teeth on dentary, premaxilla and vomer, which in the genus Porogadus are usually distributed on many rows with the outermost one(s) on the dentary sometimes bent outwards, whereas the number of teeth rows are reduced in Tenuicephalus. The many developed rakers on the first gill arch support filter function, sometimes additionally enhanced by their bladed structure (e.g. in P. guentheri). The mouth is terminal or slightly inferior with a wide gape. In Carter's (1984) assessment of the stomach content of the investigated ophidiids, substantial differences were observed in composition and diversity of the food as well as the content of sediment in the intestines the latter being indicative for infaunal feeding. The two Porogadus and the Tenuicephalus species studied showed no or negligible amounts of sediment inside and a high dependency on a prime food source. T. silus stomach content was mostly filled by calanoid copepods plus mysadaceans while in $P$. catena the diet contained primarily calanoid copepods 
plus substantial amounts of cumaceans. In P. miles the prime diet consisted of gammarideans. Carter (1984: 160) studied a total of twelve deep-sea ophidiids for their feeding strategy and grouped P. catena, P. miles, T. silus and Penopus macdonaldi in a group morphologically characterized by, among others: "a slender and highly attenuate body, narrow and short pectoral fins with low aspect ratios, moderate to large gape, slightly reduced upper jaw protrusibility, moderate to large eye, greater number of gill rakers on the anterior arch with high filtering capacity of the branchial sieve and similar configuration and shape of bony elements of the feeding apparatus" (Carter 1984: 82-83). Porogadus catena and Tenuicephalus species are further characterized by a short, terminal snout and a reduction of head ossification (moderate in P. catena, very strong in Tenuicephalus spp.). Carter (1984) concluded that these functional morphological traits combined with the selective pelagic copepod diet of $P$. catena and $T$. silus point to a "hovering, passive (not far) off-bottom foraging and facultative benthopelagic feeding strategy". The much more robust, anteriorly depressed head and subterminal mouth of $P$. miles and Penopus spp. would suggest bottom or near bottom feeding (Carter 1984). Other typical features observed in Porogadus and Tenuicephalus species is the often lacking or rejuvenated tip of the whip-like tail, which probably represents an escape mechanism against larger predators. The highly deciduous nature of the body scales may serve a similar purpose. The very strongly reduced head ossification in Tenuicephalus likely supports a live-style predominantly off the sea-bottom, while the heavily armored, spinous heads of the "dragon-head" Porogadus species may represent a defensive mechanism against food competitors or larger predators that may be foraging on or near the bottom.

Porogadus and Tenuicephalus species show varied geographic distribution patterns (Figs. 44-48). Some species are widely distributed beneath the tropical and subtropical oceans but there appears to be none with a circum-global distribution. Other species are rather restricted geographically. The most widespread species is $P$. miles known from the western and eastern Atlantic, throughout the Indian Ocean and the western Pacific as far east as the Emperor Seamounts but absent from the eastern Pacific (Fig. 45), where the closely related P. longiceps is represented. A number of species are known from the Indo-West Pacific but are missing from the Atlantic or eastern Pacific, e.g., $P$. dracocephalus, P. gracilis, P. trichiurus, T. multitrabs and T. squamilabrus (Figs. 44-48). Few species are seemingly restricted to the Atlantic, e.g., P. abyssalis and P. catena (Figs. 46-47). Finally, there are several species restricted to rather small geographic areas although in some instances their actual distribution pattern might be vague because of rather few catches. The more common regionally restricted species are $P$. atripectus, $P$. longiceps and P. promelas in the eastern Pacific, $P$. guentheri off southern Japan, P. lacrimatus and $P$. solomonensis chiefly in the Solomon Sea, P. melanocephalus in the Bay of Bengal, P. caboverdensis, P. mendax and P. turgidus off NW-Africa, and T. silus in the Caribbean. The most widely distributed species (P. miles and T. multitrabs) inhabit bathyal terrain and not surprisingly are also the ones capable of venturing furthest away from the continental masses. The abyssal species of the Porogadus gracilis group and the three deep NE-Atlantic species P. caboverdensis, P. mendax and P. turgidus show a rather restricted distribution pattern to few abyssal plain regions but in this case we are not certain about possible sampling biases. The narrow distribution areas of $P$. guentheri (off southern Japan), P. melanocephalus (Bay of Bengal) and T. silus (Caribbean) are based on many specimens caught in different cruises over some time and therefore appear to be genuine.

Another interesting aspect in the distribution pattern of Porogadus and Tenuicephalus species is the occurrence of morphologically similar and putatively closely related species pairs. One such pair is composed of $P$. miles (Atlantic to West Pacific) and P. longiceps (East Pacific), another of $P$. catena (Atlantic) and P. promelas (East Pacific). Both species pairs probably resulted from allopatric speciation that occurred after the rise of the Isthmus of Panama and the separation of the adjacent deep-sea of the tropical Atlantic and tropical East Pacific. Following current consensus, the final separation of the tropical West Atlantic from the East Pacific occurred between 4.7 to 3.0 Ma during the early to middle Pliocene, but shoaling and separation at bathyal depth may have occurred as early as 13 Ma during the Middle Miocene Climate Transition (MMCT) (e.g., Burton et al. 1997; Jackson \& O'Dea 2013). However, pelagic larval stages of bathyal fishes like in Porogadus may have facilitated exchange of populations for a considerable time into the gateway shoaling process. In the case of the separation of populations that may have given rise to $P$. miles and P. longiceps another barrier of exchange must have occurred in the Central Pacific. We speculate that the drivers for separation there may be related to the cool water regime established along the North Pacific rim latest with the initiation of the northern hemisphere glaciation that started at about 3.0-2.5 Ma (Anderson Dahl 2009), while the wide Central Pacific deep-water gap is a much older permanent feature. Warm pulses that could have facilitated some exchange of warm-water biota along the North Pacific rim could potentially have occurred as late as 5.0-3.5 Ma that culminated in the mid-Pliocene Climate Optimum 
Porogadus miles Group

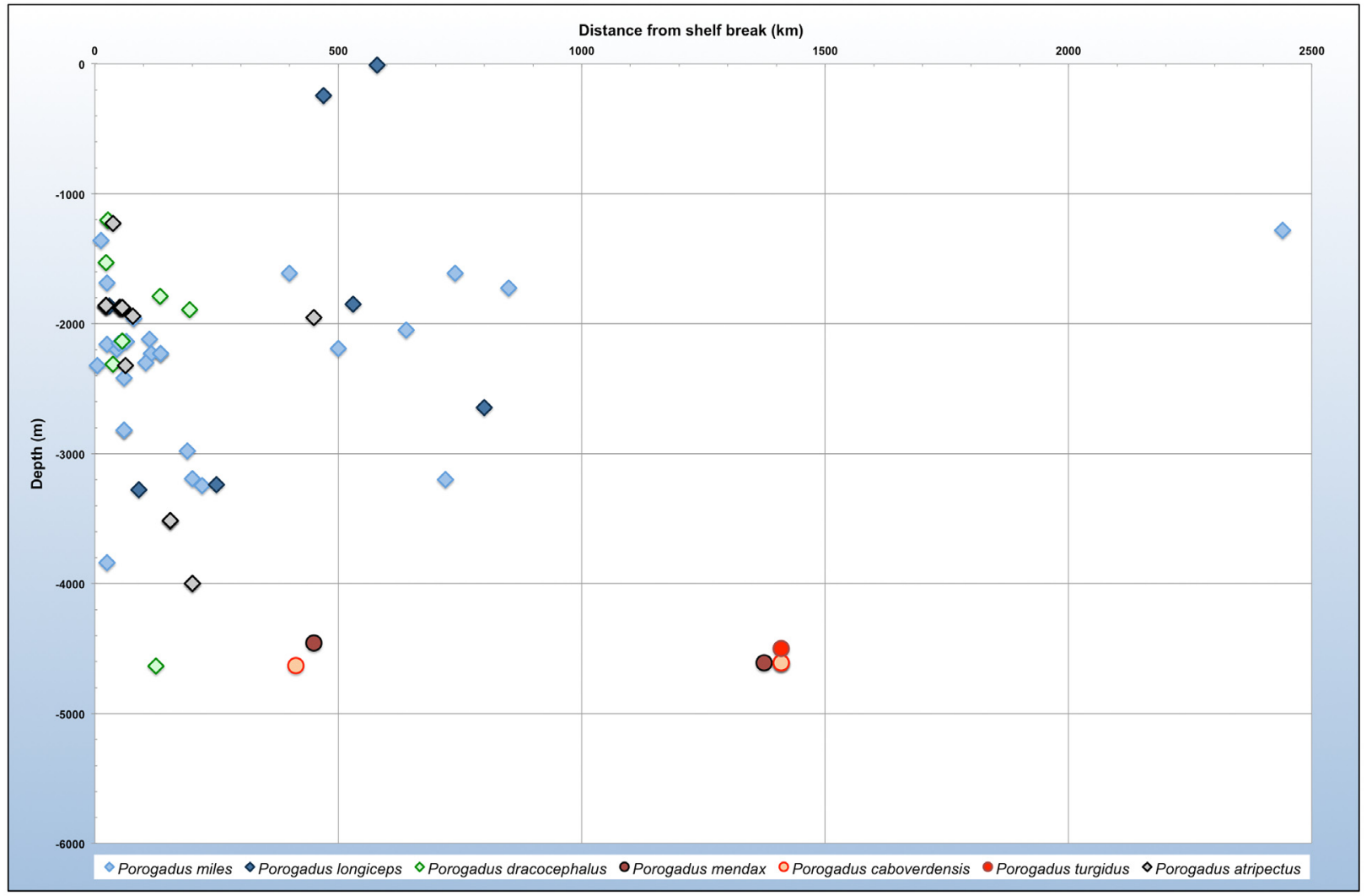

Porogadus gracilis Group

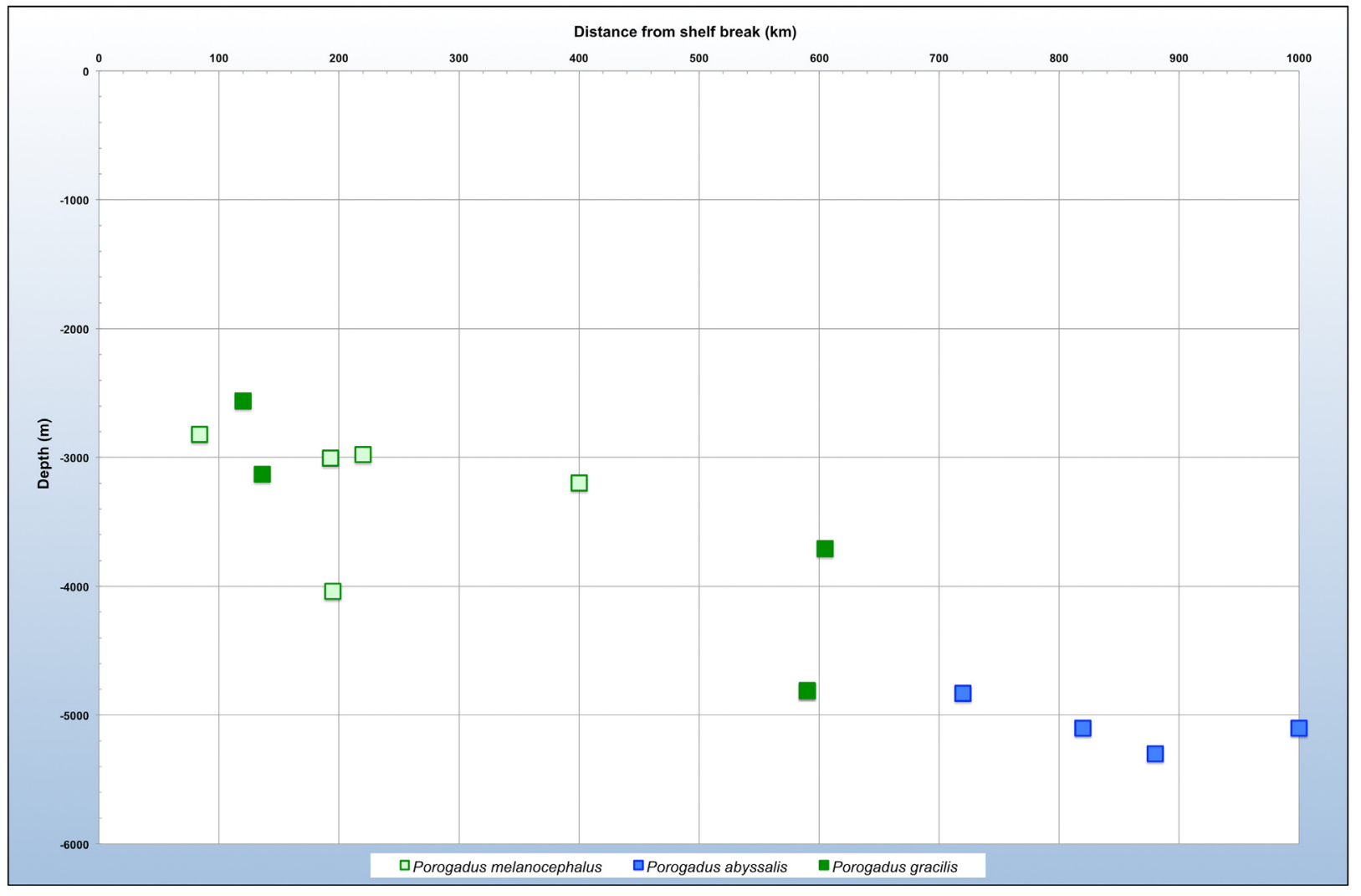

FIGURE 49. Depth versus distance from shelf plots for specimens of the Porogadus miles group (upper panel) and the Porogadus gracilis group (lower panel). 
Porogadus trichiurus Group

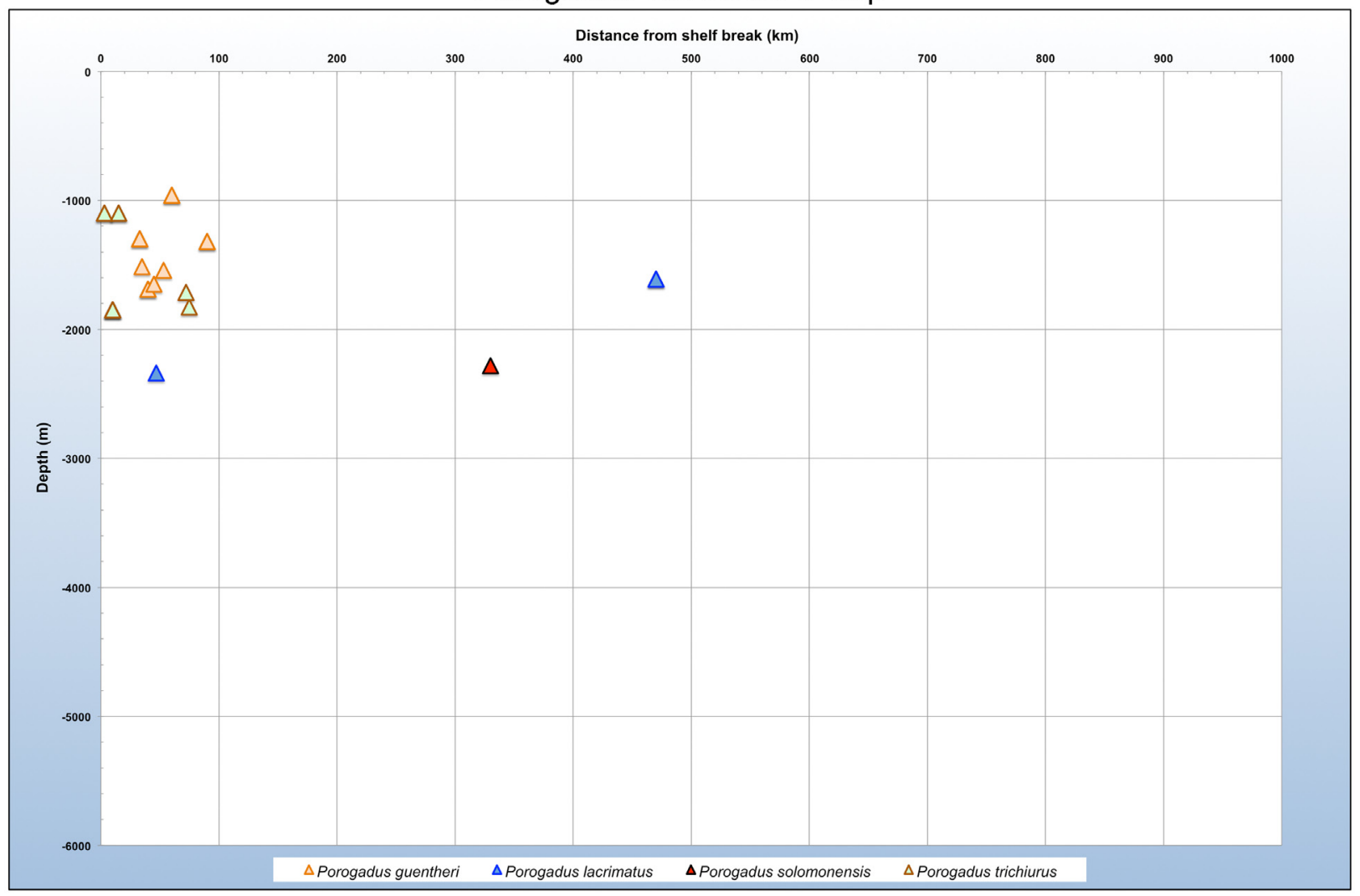

Porogadus catena Group

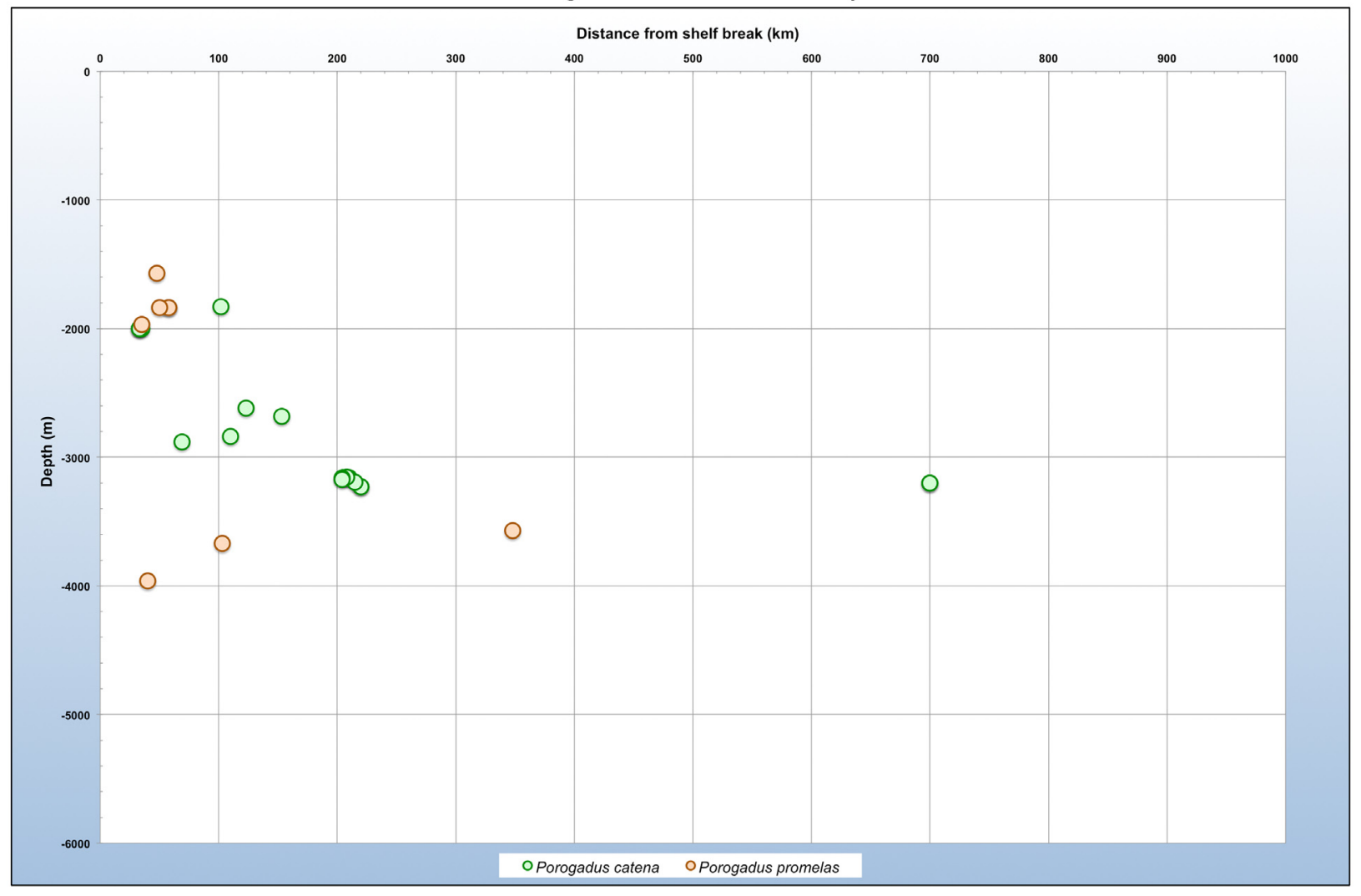

FIGURE 50. Depth versus distance from shelf plots for specimens of the Porogadus trichiurus group (upper panel) and the Porogadus catena group (lower panel). 
(e.g., Morley \& Dworetzky 1991; Gladenkov 1994; Tsuchi 2002). The closing process of the adjacent East Pacific and Caribbean basins apparently also led to an increase of the upwelling in the East Tropical Pacific that induced an expansion of the oxygen minimum zone in the intermediate ocean layer, i.e. the modern oceanographic conditions from about 4.2 Ma (Kamikuri et al. 2009). This is supported by the first occurrence of endemic East Pacific mesopelagic fishes in deep-sea sediments on the Pacific coast of Panama from about 2.5 Ma (Schwarzhans \& Aguilera 2013). While low oxygen zones will act as an effective barrier to most deep-water taxa, it has been observed that some ophidiids can tolerate remarkable low concentrations (Gallo et al. 2018). Whether this is the case for species of Porogadus (or Tenuicephalus) is unknown. In conclusion, a series of plate tectonic events and oceanographic and climatic changes during the time interval from about 4.5 to about $2.5 \mathrm{Ma}$ is thought to be responsible for an effective isolation of the tropical East Pacific deep-sea fish fauna both from the West Pacific as well as the West Atlantic. Consequently, we assume that phylogenetic divergence of the assumed species pairs mentioned above took place during this time interval.

\section{Tenuicephalus}

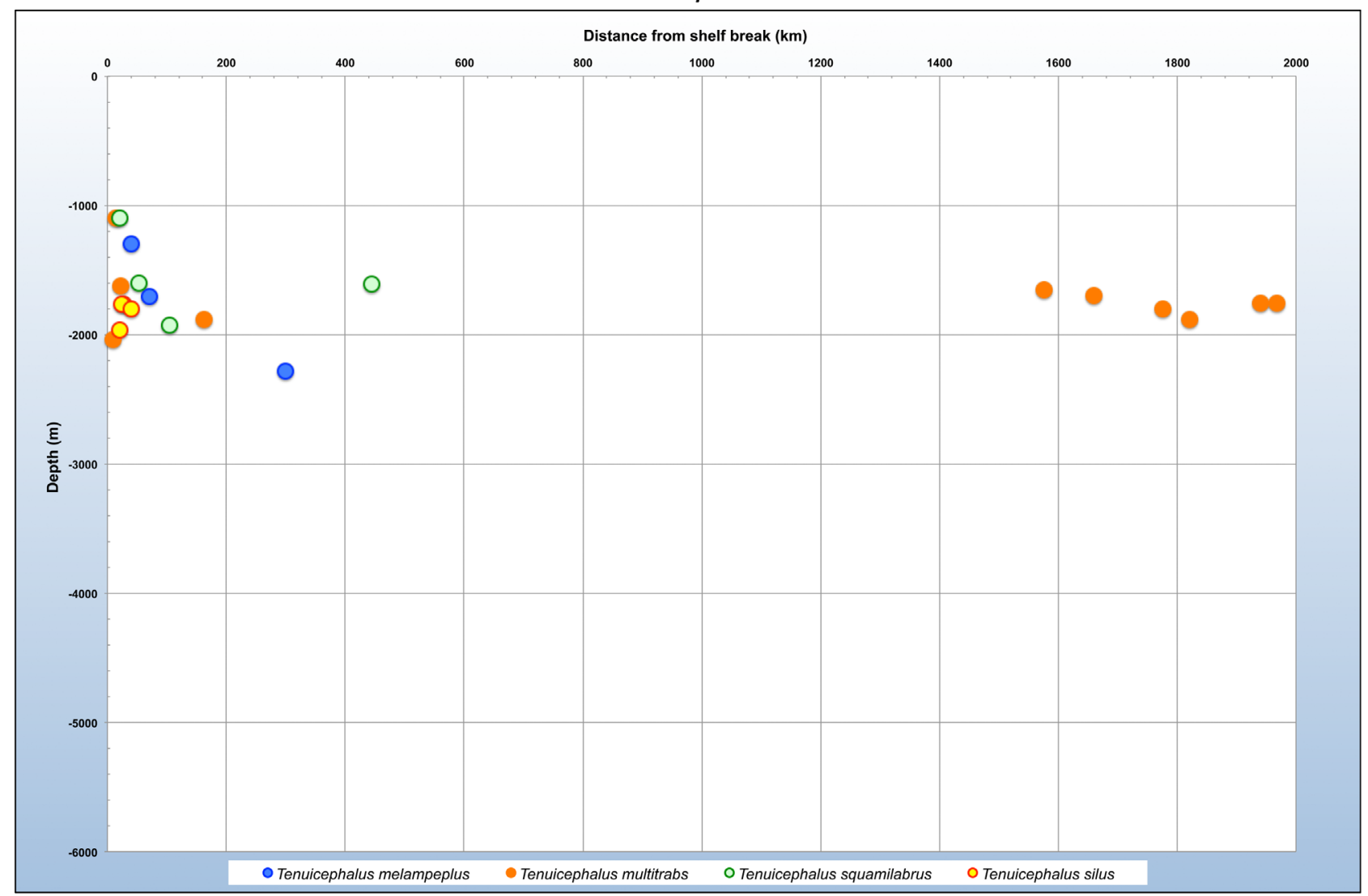

FIGURE 51. Depth versus distance from shelf plots for specimens of the genus Tenuicephalus.

Following our synonymization of $P$. nudus with $P$. miles, and $P$. subarmatus with $P$. catena we do not recognize an allopatric separation of species across the Atlantic. However, we postulate P. miles and P. mendax to form a species pair in the subtropical NE-Atlantic that has resulted from sympatric depth segregation. The interrelationships of two other abyssal species in the Cabo Verde and Canaries basins, P. caboverdensis and P. turgidus, within the Porogadus miles group are less clear. The isolating mechanism for the NE-Atlantic abyssal species is elusive (see above) and hence we are unable to identify potential causes and timing. Aspects that could potentially be linked to speciation events in the deep-sea of the region are the origination and development of the warm, high salinity, high-density Mediterranean outflow zone in intermediate depths of the adjacent NE-Atlantic (Potter \& Lozier 2004, Filipelli 2014) and the coastal upwelling system in the Mauretanian Sea (Pelegrí et al. 2017). The Mediterranean outflow zone was established sometime after the reconnection of the Mediterranean with the NE-Atlantic after the Messinian Salinity Crisis. Filipelli (2014) concluded that from 4.5 to 3.5 Ma the flow was weak and assumed its full extend only after 3.2 Ma. The timing of the formation of the coastal upwelling system in the Mauretanian Sea is still incompletely known. Diester-Haass \& Schrader (1979) found indications of coastal upwelling as early as 
early Miocene in the DSDP well 369A off the Canary Islands, which however diminished towards late Miocene. This is consistent with observations made by Schwarzhans (1993) who described early Pliocene sciaenid otoliths from northern Morocco of taxa that today are only found southwards of the Mauretanian upwelling zone in tropical West Africa. These findings indicate a weakening or intermission of the Mauretanian upwelling which would allow marine tropical West African fishes to expand northwards at the time. In any case, given the close morphological similarity of $P$. miles and P. mendax (see above) we would assume a young dichotomy, possibly younger than 5.0 to 4.5 Ma.

Other potential species pairs are the abyssal P. abyssalis in the Central Atlantic and P. gracilis in the Indo-West Pacific and the bathyal P. trichiurus on the continental rise in the Indo-West Pacific and P. guentheri off southern Japan. Timing and mechanism that led to the separation of the species in these two pairs is unknown to us, however in the case of $P$. guentheri it coincides with an abundance of endemic fish species offshore southern Japan and Taiwan in shallow and deep water (e.g., Masuda et al. 1984, Schwarzhans \& Møller 2008, Schwarzhans \& Prokofiev 2017). Porogadus guentheri and P. trichiurus are unique amongst Porogadus species in their specialization of the developed gill rakers on the first gill arch likely enhancing their filter function. In $P$. guentheri the elongate gill rakers are blade-like extended while in $P$. trichiurus they are very narrowly placed without many intermittent short plates. For the remainder of the Porogadus species and all of the Tenuicephalus species close interrelationships that could be interpreted as 'species pairs' are not obvious.

\section{Acknowledgements}

This review would have been impossible without the most generous support of many colleagues from many museums and research institutions providing specimens for investigation. We like to cordially thank Philippe Béarez (MNHN, Paris), David Catania (CAS, San Francisco), Hiromitsu Endo (BSKU, Kochi), Rick Feeney (LACM, Los Angeles), Karsten Hartel (MCZ, Cambridge, Massasuchetts), James Maclaine (GMNH, London), Mark McGrouther (AMS, Sydney), Nigel Merrett (Wormley, formerly BMNH, London), Michael Maia Mincarone (NMP, Macaé, Brazil), Peter Konstantinidis (OSU formerly RBCM, Corvallis, Oregon), Jeffrey Seigel (SIO, La Jolla), Gento Shinohara (NSMT, Tsukuba, Tokyo), David Smith (USNM, Washington D.C.), Christine Thacker (LACM, Los Angeles), Ekaterina Vasilieva (ZMMGU, Moscov), Jeffrey Williams (USNM, Washington D.C.) and Andrew Williston (MCZ, Cambridge, Massasuchetts). We are very thankful to Subhrendu Sekhar Mishra (ZSI, Kolkata) for providing photographs and fin ray and gill raker counts for the unique holotype of Tenuicephalus melampeplus. Andrew Williston (MCZ, Cambridge, Massasuchetts) kindly provided a micro-CT scan of a head of Porogadus miles. Zouhaira (Zora) Harakati Gabsi (MNHN, Paris) kindly provided x-ray photographs of certain type specimens of the collection of L. Vaillant. We thank the crew, officers, and scientists aboard the NOAA Office of Ocean Exploration and Research ship Okeanos Explorer 2015-2017 CAPSTONE expeditions in the Pacific Ocean, as well as the numerous scientists who participated in those expeditions by tele-presence and Bruce Mundy (Hawaii) for providing live photographs from deep-sea ROV's of presumable Porogadus specimens in their natural habitat. Jørgen Nielsen (ZMUC, Copenhagen) helped with much expert advice on ophidiiforms. Further useful information and advice was provided by Mackenzie Gerringer (Geneseo, New York), Bruce Mundy (Hawaii) and Nigel Merrett (Wormley). We thank Marcus Anders Krag (ZMUC, Copenhagen) for preparing photographs and handling of loan specimens together with Tammes Menne (ZMUC, Copenhagen). Finally, we want to thank hiromitsu endo (BSKU, Kochi) for his most helpful review of the manuscript and Peter Konstantinidis (OSU, Corvallis, Oregon) for the editing of our monograph.

\section{References}

Agusti, S., Gonzáles-Gordillo, J.I., Vaqué, D., Estrada, M., Cerezo, M.I., Saöazar, G., Gasol, J.M. \& Duarte, C.M. (2015) Ubiquitous healthy diatoms in the deep sea confirm deep carbon injection by the biological pump. Nature Communications, 6 , $7608,1-8$. https://doi.org/10.1038/ncomms 8608

Alcock, A.W. (1890) Natural history notes from H. M. Indian marine survey steamer 'Investigator,' Commander R. F. Hoskyn, R. N., commanding. - No. 18. On the bathybial fishes of the Arabian Sea, obtained during the season 1889-1890. Annals 
and Magazine of Natural History, (Series 6), 6 (34), 295-311.

https://doi.org/10.1080/00222939008694038

Alcock, A.W. (1891) Class Pisces. In: II.- Natural history notes from H. M. Indian marine survey steamer 'Investigator,' Commander R. F. Hoskyn, R. N., commanding. Series II., No. 1. On the results of deep-sea dredging during the season 1890-91. Annals and Magazine of Natural History, (Series 6), 8 (43/44), 16-34 and 119-138. https://doi.org/10.1080/00222939109460385

Alcock, A.W. (1892) Illustrations of the zoology of the Royal Indian marine surveying steamer Investigator, Fishes. Calcutta. Part 1, pls. 1-7.

Alcock, A.W. (1896) Natural history notes from H. M. Indian marine survey steamer 'Investigator,' Commander C. F. Oldham, R. N., commanding. Series II. No. 23. A supplementary list of the marine fishes of India, with descriptions of two new genera and eight new species. Journal of the Asiatic Society of Bengal, 65 (3), 301-338.

Alcock, A.W. (1897) Illustrations of the zoology of the Royal Indian marine surveying steamer Investigator, Fishes. Calcutta. Part 4, pl. 17.

Alcock, A.W. (1898) Illustrations of the zoology of the Royal Indian marine surveying steamer Investigator, Fishes. Calcutta. Part 5, ps. 18-24.

Anderson Dahl, C. (2009) Neogene Climates. In (Gornitz, V. ed.): Encyclopedia of Palaeoclimatology and Acient Environments. Springer Science+Business Media B.V., Dordrecht, 4 pp.

Bell, K.L.C., Elliott, K., Martinez, C. \& Fuller, S.A. eds. (2012) New Frontiers in Ocean Exploration: The E/V Nautilus and NOAA Ship Okeanos Explorer 2011 field season. Oceanography, 25 (1), supplement, 68 pp. https://doi.org/10.5670/oceanog.2011.supplement.01.

Bell, K.L.C., Brennan, M.L., Flanders, J., Raineault, N.A \& Wagner, K. eds. (2016) New frontiers in ocean exploration: The E/V Nautilus and NOAA Ship Okeanos Explorer 2015 field season. Oceanography, 29 (1), supplement, 84 pp. https://doi.org/10.5670/oceanog.2016.supplement.01.

Bell, K.L.C., Flanders, J., Bowman, A. \& Raineault, N.A. eds. (2017) New frontiers in ocean exploration: The E/V Nautilus, NOAA Ship Okeanos Explorer, and R/V Falkor 2016 field season. Oceanography, 30 (1), supplement, 94 pp. https://doi.org/10.5670/oceanog.2017.supplement.01.

Burton, K.W., Ling, H.-F. \& O’Nions, R.K. (1997) Closure of the Central American Isthmus and its effect on deep-water formation in the North Atlantic. Nature, 386, 27, 382-386. https://doi.org/10.1038/386382a0

Carter, H.C. (1984) Feeding strategies and functional morphology of demersal deep-sea ophidiid fishes. PhD dissertation, The Faculty of the School of Marine Science The College of William and Mary in Virginia, 236 pp.

Carter, H.C. \& Sulak, K.J. (1984) A new species and a review of the deep-sea fish genus Porogadus (Ophidiidae) from the western north Atlantic. Bulletin of Marine Science, 34 (3), 358-379.

Castellanos-Galindo, G.A., Rincon, E.A.R., Beltrán-Léon, B., Zapata, L.A. \& Baldwin, C.C. (2006) Check list of gadiform, ophidiiform and lophiiform fishes from Colombian waters of the tropical eastern Pacific. Biota Colombiana, 7 (2), $191-$ 209.

Chave, E.H. \& Mundy, B.C. (1994) Deep-sea benthic fish of the Hawaiian Archipelago, Cross Seamount, and Johnston Atoll. Pacific Science, 48 (4), 367-409.

Cohen, D.M. \& Nielsen, J.G. (1978) Guide to the identification of genera of the fish order Ophidiiformes with a tentative classification of the order. NOAA Technical Report NMFS, 417, 1-72. https://doi.org/10.5962/bhl.title.63242

Diester-Haass, L. \& Schrader, H.-J. (1979) Neogene coastal upweling history off northwest and southwest Africa. Marine Geology, 29, 39-53. https://doi.org/10.1016/0025-3227(79)90101-4

Fahay, M.P. (2007) Early stages of fishes in the western North Atlantic Ocean (Davis Strait, southern Greenland and Flemish Cap to Cape Hatteras). West Bath, Maine, 1696 pp.

Filipelli, G. (2014) A salty start to modern ocean circulation. Science, 344 (6189), 1228-1229. https://doi.org/10.1126/science. 1255553

Fricke, R. \& Eschmeyer, W. (2013) A Guide to Fish Collections in the Catalog of Fishes Database. In: Catalogue of Fishes. Internet publication, http://research.calacademy.org/research/Ichthyology/Catalog/collections.asp.

Fricke, R., Allen, G.R., Andréfouet, S., Chen, W.-J., Hamel, M.A., Laboute, P., Mana, R., Hui, T.H. \& Uyeno, D. (2014) Checklist of the marine and estuarine fishes of Madang District, Papua New Guinea, western Pacific Ocean, with 820 new records. Zootaxa, 3832, 1-247.

https://doi.org/10.11646/zootaxa.3832.1.1

Gallo, N.D., Levin, L.A., Beckwith, M. \& Barry, J.P. (2019) Home sweet suboxic home: remarkable hypoxia tolerance in two demersal fish species in the Gulf of California. Ecology, 100 (3), e02539, 1-5. https://doi.org/10.1002/ecy.2539

Garman, S. (1899) The Fishes. In: Reports on an exploration off the west coasts of Mexico, Central and South America, and off the Galapagos Islands, in charge of Alexander Agassiz, by the U. S. Fish Commission steamer "Albatross," during 1891, Lieut. Commander Z. I. Tanner, U. S. N. commanding. No. XXV, the fishes. Memoires of the Museum of Comparative Zoology, 24, 1-431. 
https://doi.org/10.5962/bhl.part.27494

Gerringer, M.E. (2019) On the success of hadal snailfishes. Integrative Organismal Biology, 1-18. https://doi.org/10.1093/iob/obz004

Gilbert, C.H. (1892) Descriptions of thirty-four new species of fishes collected in 1888 and 1889, principally among the Santa Barbara Islands and in the Gulf of California. In: Scientific results of explorations by the U. S. Fish Commission steamer Albatross. Proceedings of the United States National Museum, 14 (880), 539-566. https://doi.org/10.5479/si.00963801.14-880.539

Gladenkov, Y.B. (1994) Cenozoic paleogeography and climatic change in the North Pacific Ocean. Palaeogeography, Palaeoclimatology, Palaeoecology, 108, 311-318. https://doi.org/10.1016/0031-0182(94)90239-9

Goode, G.B. \& Bean, T.H. (1885) Descriptions of new fishes obtained by the United States Fish Commission mainly from deep water off the Atlantic and Gulf coasts. Proceedings of the United States National Museum, 8 (543), 589-605. https://doi.org/10.5479/si.00963801.8-543.589

Goode, G.B. \& Bean, T.H. (1896) Oceanic ichthyology, a treatise on the deep-sea and pelagic fishes of the world, based chiefly upon the collections made by the steamers Blake, Albatross, and Fish Hawk in the northwestern Atlantic, with an atlas containing 417 figures. Special Bulletin U. S. National Museum, 2, i-xxxv + 1-26 + 1-553.

Grey, M. (1956) The distribution of fishes found below a depth of 2000 m. Fieldiana Zollogy, 36 (2), 77-337. https://doi.org/10.5962/bhl.title.2788

Grey, M. (1958) Descriptions of abyssal benthic fishes from the Gulf of Mexico. Fieldiana Zoology, 39 (16), $149-183$. https://doi.org/10.5962/bhl.title.3323

Günther, A. (1878) Preliminary notices of deep-sea fishes collected during the voyage of H. M. S. 'Challenger'. Annals and Magazine of Natural History, (Series 5), 2 (7/8/9), 17-28, 179-187 + 248-251. https://doi.org/10.1080/00222937808682417

Günther, A. (1887) Report on the deep-sea fishes collected by H.M.S. Challenger duribg the years 1873-1876. Zoological Challenger Expedition, 5 (22), 1-335. https://doi.org/10.5962/bhl.title.15693

Hanke, G., Gillespie, G., Fong, K., Boutillier, J., Nielsen, J., Møller, P., Bedard, J. \& Riley, J. (2015) New records of seven cusk-eels (Ophidiidae) and brotulas (Bythitidae) in coastal waters of British Columbia, Canada. Northwestern Naturalist, 96, 71-80. https://doi.org/10.1898/NWN14-17.1

Hubbs, C.L. \& Lagler, K.F. (1958) Fishes of the Great Lakes region. Cranbrook Institute of Science Bulletin, $26,1-213$.

Jackson, J.B.C. \& O'Dea, A. (2013) Timing of the oceanographic and biological isolation of the Caribbean Sea from the tropical eastern Pacific Ocean. Bulletin of Marine Science, 89 (4), 779-800.

Jordan, D.S. \& Evermann, B.F. (1898) The fishes of North and Middle America. Bulletin of the U.S. national Museum, 47 (111), 2183-3136.

Jordan, D.S. \& Evermann, B.F. (1900) The fishes of North and Middle America: a descriptive catalogue of the species of fishlike vertebrates found in the waters of North America, north of the Isthmus of Panama. Part IV. Bulletin of the United States National Museum, 47, 3137-3313.

https://doi.org/10.5962/bhl.title.39720

Jordan, D.S. \& Fowler, H.W. (1902) A review of the ophidioid fishes of Japan. Proceedings of the United States National Museum, 25 (1303), 743-766. https://doi.org/10.5479/si.00963801.25-1303.743

Kamikuri, S.-i., Motoyama, I., Nishi, H. \& Iwai, M. (2009) Evolution of Eastern Pacific warm pool and upwelling process since the middle Miocene based on analysis of radiolarian assemblages: Response to Indonesian and Central American seaways. Palaeogeography, Palaeoclimatology, Palaeoecology, 280, 469-479.

https://doi.org/10.1016/j.palaeo.2009.06.034

Kennedy, B., Demopoulos, A. \& Auscavitch, S. (2017). Oceanographic data and information collected during the EX1703 Howland/Baker PRIMNM and PIPA (ROV/Mapping) expedition on NOAA Ship OKEANOS EXPLORER in the South Pacific Ocean from 2017-03-07 to 2017-03-29 (NCEI Accession 0162616). NOAA National Centers for Environmental Information. Available from: https://doi.org/10.7289/v5sj1hw0. (accessed 08 August 2020)

Kennedy, B., France, S. \& Gerringer, M. (2019). Oceanographic data and ROV dive-related multimedia and information collected during the EX1504L4 (Campaign to Address Pacific monument Science, Technology, and Ocean NEeds (CAPSTONE) Leg IV) expedition on NOAA Ship OKEANOS EXPLORER in the North Pacific Ocean from 2015-09-07 to 2015-09-30 (NCEI Accession 0131887). NOAA National Centers for Environmental Information. Dataset. Available from: https://doi. org/10.7289/v5gb223t (accessed 08 August 2020)

Linley, T.D., Stewart, A.L., McMillan, P.J., Clark, M.R., Gerringer, M.E., Drazen, J.C., Fujii, T. \& Jamieson, A.J. (2017) Bait attending fishes of the abyssal zone and hadal boundary: Community structure, functional groups and species distribution in the Kermadec, New Hebrides and Mariana trenches. Deep-Sea Research I, 121, 38-53. https://doi.org/10.1016/j.dsr.2016.12.009

Machida, Y. (1982) Rare ophidiid fish, Porogadus guentheri, from Japanese waters. Reports of the Usa Marine Biological Institute, Kochi University, 4, 27-33. 
Machida, Y. (1984) Order Ophidiiformes. In (Masuda, H., Amaoka, K., Araga, C., Uyeno, T. \& Yoshino, T. eds.) The fishes of the Japanese Archipelago. Tokyo (Tokai University Press), 99-101.

Machida, Y. (1984) Ophidiidae. In (Okamura, O. \& Kitajima, T. eds.) Fishes of the Okinawa Trough and the adjacent waters. Vol. I. The intensive research of unexploited fishery resources on continental slopes. Japan Fisheries Resource Conservation Association, Tokyo, 261, 375.

Machida, Y. \& Amaoka, K. (1990) Pacific records of the deep-sea fish Porogadus miles (Ophidiiformes, Ophidiidae). Japanese Journal of Ichthyology, 37 (1), 64-68.

Masuda, H., Amaoka, K., Araga, C., Uyeno, T. \& Yoshino, T. (1984) The fishes of the Japanese Archipelago. Tokai University Press, Tokyo, 437 pp.

Merrett, N.R. (2000) Fishes. In (Partridge, J.C. ed.) Sensory biology in the deep-sea: anatomy, physiology, and molecular biology. Cruise Report, RRS Discovery Cruise 243, $11^{\text {th }}$ October to $22^{\text {nd }}$ November 1999, 50.

Merrett, N.R. \& Marshall, N.B. (1981) Observations on the ecology of deep-sea bottom-living fishes collected off northwest Africa $\left(08^{\circ}-27^{\circ} \mathrm{N}\right)$. Progress Oceanography, 9, 185-244. https://doi.org/10.1016/0079-6611(80)90002-6

Mincarone, M.M., Nielsen, J.G. \& Costa, P.A.S. (2007) Deep-sea ophidiiform fishes collected on the Brazilian continental slope, between $11^{\circ}$ and $23^{\circ} \mathrm{S}$. Zootaxa, 1770 (1), 41-64. https://doi.org/10.11646/zootaxa.1770.1.2

Morley, J.J. \& Dworetzky, B.A. (1991) Evolving Pliocene-Pleistocene climate: a north Pacific perspective. Quaternary Science Reviews, 10, 225-237. https://doi.org/10.1016/0277-3791(91)90021-L

Mundy, B.C., Gerringer, M.E., Nielsen, J.G., Fryer, P. \& Leitner, A. (2018) First in situ observation of an aphyonid fish (Teleostei, Ophidiiformes, Bythitidae). Deep-Sea Research Part II, 150, 164-169. https://doi.org/10.1016/j.dsr2.2017.09.009

Nielsen, J. G. \& Machida, Y. (1988) Revision of the Indo-west Pacific bathyal fish genus Glyptophidium (Ophidiiformes, Ophidiidae). Japanese Journal of Ichthyology, 35 (3), 289-319. https://doi.org/10.1007/BF02938429

Nielsen, J.G., Cohen, D.M., Markle, D.F. \&vRobins, C.R. (1999) Ophidiiform fishes of the world (Order Ophidiiformes). FAO Fisheries Synopsis, 125, FAO Species Catalogue, 18, 1-178.

Nielsen, J.G. \& Møller, P.R. (2007) New and rare deep-sea ophidiiform fishes from the Solomon Sea caught by the Danish Galathea 3 Expedition. Steenstrupia, 30 (1), 21-46.

Nolf, D. (1980) Etude monographique des otolithes des Ophidiiformes actuels et révision des espèces fossiles (Pisces, Teleostei). Mededelingen van de Werkgroep voor Tertiaire en Kwartaire Geologie, 17 (2), 71-195.

Norman, J.R. (1939) Fishes. The John Murray Expedition 1933-1934 Scientific Reports, 7, 1-116.

Nybelin, O. (1957) Deep-sea bottom fishes. Reports of the Swedish Deep-Sea Expedition 1947-1948, 2, $247-345$.

Ocean Networks Canada, SeaTube Pro (2017) NOAA OER Howland/Baker Islands EX1703, Dive 16. Available from: https:// data.oceannetworks.ca/SeaTube (accessed 12 August 2020)

Pelegrí, J.L., Peña-Izquierdo, J., Machín, F., Meiners, C. \& Presas-Navarro, C. (2017) Oceanography of the Cape Verde Basin and Mauritanian Slope Waters. In: Ramos A., Ramil, F. \& Sanz, J. (Eds.), Deep-Sea Ecosystems Off Mauritania. Springer, Dordrecht, 119-153. https://doi.org/10.1007/978-94-024-1023-5_3

Potter, R.A. \& Lozier, M.S. (2004) On the warming and salinification of the Mediterranean outflow waters in the North Atlantic. Geophysical Research Letters, 31, L01202, 1-4. https://doi.org/10.1029/2003GL018161

Priede, I.G., Drazen, J.C., Bailey, D.M., Kuhnz, L.A. \& Fabian, D. (2019) Abyssal demersal fishes recorded at station M $\left(34^{\circ} 50^{\prime} \mathrm{N}, 123^{\circ} 00^{\prime} \mathrm{W}, 4100 \mathrm{~m}\right.$ depth) in the northeast Pacific Ocean: An annotated check list and synthesis. Deep-Sea esearch Part II, 173, 104648. https://doi.org/10.1016/j.dsr2.2019.104648

Prokofiev, A.M. (2005) On some rare ophidiiform fishes from the South Atlantic and Indo-West Pacific, with erection of a new genus, Megacataetyx gen. novum (Teleostei: Ophidiiformes). Estestvennye i technicheskie Nauki, 2, 111-128.

Raineault, N.A, Flanders, J. \& Bowman, A. eds. (2018) New frontiers in ocean exploration: The E/V Nautilus, NOAA Ship Okeanos Explorer, and R/V Falkor 2017 field season. Oceanography, 31 (1), supplement, 126 pp. https://doi.org/10.5670/oceanog.2018.supplement.01

Raineault, N.A. \& Flanders, J. eds. (2019) New frontiers in ocean exploration: The E/V Nautilus, NOAA Ship Okeanos Explorer, and R/V Falkor 2018 field season. Oceanography, 32(1), supplement, $150 \mathrm{pp}$. https://doi.org/10.5670/oceanog.2019.supplement.01

Raineault, N.A. \& Flanders, J. eds. (2020) New frontiers in ocean exploration: The E/V Nautilus, NOAA Ship Okeanos Explorer, and R/V Falkor 2019 field season. Oceanography, 33 (1), supplement, 122 pp. https://doi.org/10.5670/oceanog.2020.supplement.01

Ramiro-Sánchez, B., González-Irusta, J.M., Henry, L.-A., Cleland, J., Yeo, I., Xavier, J.R., Carreiro-Silva, M., Sampaio, I., Spearman, J., Victorero, L., Messing, C.G., Kazanidis, G., Roberts, J.M. \& Murton, B. (2019) Characterization and mapping of a deep-sea sponge ground on the Tropic Seamount (northeast tropical Atlantic): Implications for spatial manage- 
ment in the high sea. Frontiers in Marine Science, 6, 278, 1-19.

https://doi.org/10.3389/fmars.2019.00278

Schwarzhans, W. (1981) Vergleichende morphologische Untersuchungen an rezenten und fossilen Otolithen der Ordnung Ophidiiformes. Berliner Geowissenschaftliche Abhandlungen, A, 32, 63-122.

Schwarzhans, W. (1993) A comparative morphological treatise of recent and fossil otoliths of the family Sciaenidae. Piscium Catalogus, Otolithi Piscium, 1, 1-245.

Schwarzhans, W. (2010) Otolithen aus den Gerhartsreiter Schichten (Oberkreide: Maastricht) des Gerhartsreiter Grabens (Oberbayern). Palaeo Ichthyologica, 4, 1-100.

Schwarzhans, W. \& Aguilera, O. (2013) Otoliths of the Myctophidae from the Neogene of tropical America. Palaeo Ichthyologica, 13, 83-150.

Schwarzhans, W. \& Møller, P.R. (2008) Review of the Dinematichthyini (Teleostei: Bythitidae) of the Indo-West Pacific. Part III. Beaglichthys, Brosmolus, Monothrix and eight new genera with description of 20 new species. The Beagle, Records of the Museums and Art Galleries of the Northern Territory, 23, 29-110.

Schwarzhans, W.W. \& Prokofiev, A.M. (2017) Reappraisal of Synagrops Günther, 1887 with rehabilitation and revision of Parascombrops Alcock, 1889 including description of seven new species and two new genera Perciformes: Acropomatidae). Zootaxa, 4260 (1), 1-74. https://doi.org/10.11646/zootaxa.4260.1.1

Shcherbachev, Y.N. (1980) A preliminary review of deep-sea ophidiids (Ophidiidae, Ophidiiformes) of the Indian Ocean.Trudy Okeanography Institut, 110, 86-94.

Shinohara, G., Sato, T., Aonuma, Y., Horikawa, H., Matsuura, K., Nakabo, T. \& Sato, K. (2005) Annotated checklist of deep-sea fishes from the waters around the Ryukyu Islands, Japan. In (Hasegawa, K., Shinohara, G. \&Takeda, M., eds.) Deep-sea fauna and pollutants in the Nansei Islands. National Museum of Nature and Science Monographs, 29, 385-452.

Shinohara, G., Narimatsu, Y., Hattori, T., Ito, M., Takata, Y. \& Matsuura, K. (2009) Annotated checklist of deep-sea fishes from the Pacific coast off Tohoku District, Japan. In: Fujita, T. (Ed.), Deep-sea fauna and pollutants off Pacific coast of northern Japan. National Museum of Nature and Science Monographs, 39, 683-735.

Tsuchi, R. (2002) Neogene evolution of surface marine climate in the Pacific and notes on related events. Revista Mexicana de Ciencias Geológicas, 19 (3), 260-270.

Vaillant, L.L. (1888) Expéditions scientifiques du "Travailleur" et du "Talisman" pendant les années 1880, 1881, $1882,1883$. Poissons. Paris, 1-406. https://doi.org/10.5962/bhl.title.13677

Watling, L., Guinotte, J., Clark, M.R. \& Smith, C.R. (2013) A proposed biogeography of the deep ocean floor. Progress in Oceanography, 111, 91-112. https://doi.org/10.1016/j.pocean.2012.11.003

Wilson, R.R. (1985) Depth-related changes in sagitta morphology in six macrourid fishes of the Pacific and Atlantic oceans. Copeia, 1985 (4), 1011-1017. https://doi.org/10.2307/1445256 